\title{
Drown-proofing New Zealand: The Learn-to-Swim and Prevent Drowning Campaigns, 1936-1956
}

by

Jessica Maynard

A thesis submitted to the Victoria University of Wellington in fulfilment of the requirements for the degree of Master of Arts in History 


\begin{abstract}
This thesis examines the development of recreational amateur swimming in New Zealand between 1936 and 1956. During this period, swimming ability and drowning prevention became issues of national importance and extensive measures were introduced to encourage the expansion of amateur swimming culture. The growth of interest in swimming was partly a response to the perception that drowning deaths were too common. This thesis discusses the trends and characteristics of deaths by drowning. The extension of swimming was also largely thanks to the efforts of the Labour Government, elected in 1935, which instituted a new and active approach to enabling leisure. In 1936, just months after being elected, Labour made its first move towards extending New Zealanders' opportunities for aquatic recreation by offering greater support to voluntary swimming and lifesaving associations. In 1938, under the newly enacted Physical Welfare and Recreation Act, the Government launched the Learn-to-Swim campaign, followed by the Prevent Drowning campaign in 1949. These campaigns helped to establish 'proper' swimming as a valuable part of modern life, an increasingly popular leisure pursuit, and an expected skill, as well as advocating the necessity of 'water wisdom'. By 1956, the perceived need for government intervention into leisure had diminished and swimming and drowning prevention were once again viewed as private matters, the concern of the individual and not of the state. Consequently, the Government (now that of the National administration) withdrew its support from the campaigns. However, swimming was firmly established as an enjoyable, valuable, and important recreational pursuit. Thus, the Water Safety campaign was launched by voluntary swimming and lifesaving organisations to take the place of the Learn-to-Swim and Prevent Drowning campaigns. This thesis argues that the 1936-1956 period was one of significant growth in recreational swimming and the state was an important and active agent in this process of modernising New Zealand's swimming culture.
\end{abstract}




\section{Table of Contents}

Abstract

Table of Contents $\quad$ iii

Acknowledgements iv

List of Abbreviations $\mathrm{V}$

List of Figures and Graphs

Introduction 1

Chapter One

'Drowning is, in New Zealand, one of the most popular ways of dying

before your time': drowning deaths, 1935-1960

Chapter Two

'We have accepted a great responsibility and pledged our organisation to the Government to do the work': a new commitment to swimming education and drowning prevention

Chapter Three

The Learn-to-Swim and Prevent Drowning campaigns at work, 1936-1956

Conclusion

Appendices

Appendix A: Pākehā Drownings, 1858-1901 118

Appendix B: Pākehā Drownings, 1935-1960 121

Appendix C: Māori Drownings, 1935-1960 122

Appendix D: Pākehā Drowning Rate, 1935-1960 123

Appendix E: Māori Drowning Rate, 1935-1960 124

Appendix F: Drowning Rate (Total Population), 1935-1960 125

Appendix G: Pākehā Drownings by Sex, 1935-1960 126

Appendix H: Māori Drownings by Sex, 1935-1960 127

Appendix I: Pākehā Drownings by Age, 1935-1960 128

Appendix J: Māori Drownings by Age, 1935-1960 131

Bibliography 


\section{Acknowledgements}

Firstly, I would like to give my sincerest thanks to my supervisor, Charlotte Macdonald. Her unending patience, energy, and fervour for and knowledge of history have been an inspiration. I cannot thank Charlotte enough for the dedication, thought, and time she afforded me and this project. My initial supervisor, Ben Schrader, also provided me with much needed support, feedback, and coffee breaks for which I offer him my wholehearted gratitude.

I owe many, everlasting thanks to Brenda and Aporo Joyce who not only assisted me in my research, but also presented me with the Jack Pearce Scholarship. Without their generosity, this thesis would not have been possible. I will always admire their kindness and sincerity.

I am also indebted to the Faculty of Humanities and Social Sciences Research Committee of VUW for the grant which allowed me to consult source material in Auckland and Dunedin. To the VUW library staff and the team at Archives New Zealand, I thank you for your assistance and patience.

Furthermore, the help, support, and friendship offered to me by the staff and postgraduate students in the History Department at VUW made the process of completing this thesis much more endurable. In particular, I would like to thank Charlotte Bennett who was always willing to listen, lend a hand, and have a laugh. Her encouragement and understanding went a long way to getting me through to the end of this project.

I would also like to acknowledge those people who took the time to write to me and/or be interviewed as part of my research. John Mokomoko, Marie Terrie, and William Moore, your stories provided me with such helpful and important insight into New Zealand's past. I truly appreciate the interest you showed in my work. Thank you.

Finally, to Mum, Aaron, and Ben, who have supported me throughout my studies and my life, I hope that my achievements will make you as proud of me as I am of you. 


\section{List of Abbreviations}

AJHR Appendices to the Journal of the House of Representatives

$\begin{array}{ll}\text { ANZA } & \text { Archives New Zealand, Auckland } \\ \text { ANZW } & \text { Archives New Zealand, Wellington } \\ A S & \text { Auckland Star } \\ E G & \text { Ellesmere Guardian } \\ \text { EP } & \text { Evening Post } \\ \text { MP } & \text { Member of Parliament } \\ \text { NZJPE } & \text { New Zealand Journal of Physical Education } \\ \text { NZRM } & \text { New Zealand Railways Magazine } \\ \text { NZPD } & \text { New Zealand Parliamentary Debates } \\ \text { TT } & \text { The Times }\end{array}$




\section{List of Figures and Graphs}

1. Graph. Pākehā Drownings, 1858-1901. Statistics of New Zealand, 1858-1901

2. Graph. Number of Māori and Pākehā Accidental Drownings, 1935-60. Statistics of New Zealand, 1935-60

3. Graph. Rate of Māori and Pākehā Accidental Drownings, 1935-60. Statistics of New Zealand, 1935-60

4. Graph. Table of Rate of Drownings, 1927-1958. Appendix to the Journal of the House of Representatives, Vol. 3, 1959, H-22-67

5. Graph. Accidental Pākehā Drownings by Sex, 1935-60.

Statistics of New Zealand, 1935-60

6. Graph. Accidental Māori Drownings by Sex, 1935-60.

Statistics of New Zealand, 1935-60

7. Graph. Proportion of Female Accidental Drowning Victims, 1935-60. Statistics of New Zealand, 1935-60

8. Graph. Age at Drowning for Māori and Pākehā, 1935-60.

Statistics of New Zealand, 1935-60

9. Graph. Pākehā Child and Youth Accidental Drownings, 1935-1960. Statistics of New Zealand, 1935-60

10. Graph. Māori Child and Youth Accidental Drownings, 1935-1960. Statistics of New Zealand, 1935-60

11. Diagram of a Learners' Pool. E, 2, 698, 29/19/15, part 2, 1952/15b, Archives New Zealand Wellington (ANZW)

12. Learn-to-Swim window display. IA, 70, 3, 11, ANZW

13. Lifesaving is Something We Need to Know, Newspaper article - National Committee of Swimming and Life Saving. Auckland Star, IA 70 4, 12, ANZW

14. Swimming instruction, Newspaper article - National Committee of Swimming and Life Saving. Valerie Bloomfield, 'New Zealand is the Leading Swimming Nation - Not Australia', BCDQ, A739, 4614b, 28/9/2, Archives New Zealand Auckland (ANZA) 
15. Learning to Swim, Newspaper article - National Committee of Swimming and Life Saving. New Zealand Herald, 17 January 1939, IA 1, 2937, 139/19/2, part 3, ANZW

16. Instruction on breathing in the water, Newspaper article -

National Committee of Swimming and Life Saving. Evening Post (EP), 18 January 1940, p. 14

17. Learning to Crawl First, Newspaper article - National Water Safety Council. EP, 11 February 1957, IA, 70, 4, 12, ANZW

18. New Zealand Amateur Swimming Association Certificate.

BCDQ, A739, 4614b, 28/9/2, ANZA

19. Don't Just Learn to Swim, Learn to Swim Wisely, Advertisement - National Prevent Drowning Campaign Committee.

Challenge: Transport Workers' Magazine, 1 February, 1952,

IA, 70, 3, 11, ANZW

20. Prevent Drowning stickers. ABDU, W3570, 240, 7/16, ANZA

21. Who me?, Advertisement - National Prevent Drowning Campaign Committee. The New Zealand Herald, 12 March 1953, p. 5, IA, 1, 2934, 139/7/15, part 6, ANZW

22. Child drownings, Advertisement - National Prevent Drowning Campaign Committee. IA 70, 4, 12, ANZW

23. The Maori Drowning Rate is 4 Times as high as the Pakeha, Advertisement - National Prevent Drowning Campaign Committee. Te Ao Hou, no. 10, April, 1955, p. 66

24. 'Tiakina A Koutou Tamariki', Advertisement National Prevent Drowning Campaign Committee, Te Ao Hou, no. 12, September, 1955, p. 66.

25. Simple Methods of Drowning, Advertisement National Prevent Drowning Campaign Committee. IA, 70, 4, 12, ANZW

26. Enjoy the Water, but First Check Your Knowledge of Water Wisdom, Advertisement - National Prevent Drowning Campaign Committee. IA, 1, 2934, 139/7/15, part 6, ANZW

27. More Fun Swimming When You're Water-Wise, Advertisement - National Prevent Drowning Campaign Committee. 8 o'clock Sports Edition and Star, 15 March 1952, IA, Series 70, Box 3, Item 11, ANZW 


\section{Introduction}

“"Learn to swim"”, W. E (Bill) Parry, Minister of Internal Affairs (1935-1949), relentlessly urged New Zealanders throughout the late 1930s and 1940s, "“and the problem, how to be happy, healthy and useful, would seem to be solved". ${ }^{1}$ During the mid-twentieth century, swimming became a highly valued leisure pursuit in New Zealand and was swept up in the nation's modernising directions. This thesis examines the expansion of recreational amateur swimming and water safety activities, from 1936 to 1956, with particular emphasis on the Learn-to-Swim and Prevent Drowning campaigns.

Prior to the late 1930s, the idea that swimming ability was such an important skill that it could not be left to chance was not widely held; whether or not an individual learnt to swim was a private concern and responsibility. However, when the Labour Government came to power in 1935 and began to work towards its goal of improving conditions for workers and democratising the nation's resources, which included the wellbeing of its citizens, a new perception of swimming arose. In 1936, Parry made the first move towards improving the status and popularity of swimming by increasing government assistance to New Zealand's voluntary swimming and lifesaving associations. With the passage of the Physical Welfare and Recreation Act in 1937 that support was extended even further as the Physical Welfare Branch of the Department of Internal Affairs assumed an active role in carrying out the Learn-to-Swim and Prevent Drowning campaigns, run from 1936 and 1949 respectively, to 1956 . Shaped by concerns over the frequency of drowning deaths and widespread swimming inability, these campaigns existed within a framework of changing perceptions of leisure, health, and the role of the state in the mid-twentieth century.

This study considers why and how the Learn-to-Swim and Prevent Drowning campaigns came to be regarded as necessary and viable. Why, during this period, did swimming ability and drowning prevention become political issues? Examining the extent of the 'drowning problem' to which the campaigns responded is essential to understanding why the campaigns were introduced. The thesis considers how risky swimming was, why drownings were seen as more preventable

\footnotetext{
${ }^{1}$ William Parry, in Baxter O’Neill, New Zealand Amateur Swimming Association: Official Swimming Instructor (Auckland: New Zealand Amateur Swimming Association, [1940]), p. 3.
} 
in the mid-twentieth century than they had been before, and how contemporary views and patterns of mortality shaped responses to and perceptions of death by drowning. The 1930s and 1940s period is well known as a time marked by recovery from the Great Depression, an innovative Labour Government, an active state, and the building of a welfare state. ${ }^{2}$ But a less well known area of the 1935-1949 Labour Government's efforts is the initiatives taken with regard to swimming and drowning prevention. How did political, as well social, circumstances propel the instigation and design of the Learn-to-Swim and Prevent Drowning campaigns? This thesis also discusses how swimming culture was influenced by the campaigns.

The focus of this study rests primarily on the years 1936-1956. However, when investigating New Zealand's drowning statistics, the discussion extends beyond this period in an attempt to determine what, if any, impact the Learn-toSwim and Prevent Drowning campaigns had in terms of improving the drowning rate. The year 1936 marks the beginning of the period with which this thesis is concerned because it was in April of that year that Parry first met with the New Zealand Amateur Swimming Association, Royal Life Saving Society of New Zealand, and the New Zealand Surf Life Saving Association to discuss the potential to expand their work. The meeting is the first indication of the new priority given to swimming and water safety within public and political domains up until the late 1950s. 1956 is the end point of this study. It was at this time that the Government (now that of the National administration led by Sidney Holland) relinquished its role in the Learn-to-Swim and Prevent Drowning campaigns; the voluntary swimming and lifesaving associations resumed sole responsibility for offering recreational swimming and water safety education. This occasion signified the end of an era of government intervention in New Zealanders' water-based leisure and a reorientation of the country's commitment to the place of amateur swimming in New Zealand society.

The major primary sources consulted for this thesis were those generated by the government departments responsible for and/or involved in the swimming and drowning prevention campaigns. These records are held at Archives New Zealand.

\footnotetext{
${ }^{2}$ For examples see Philippa Mein Smith, A Concise History of New Zealand (Cambridge: Cambridge University Press, 2005); Keith Sinclair, A History of New Zealand (Auckland: Penguin, 1991); Michael King, The Penguin History of New Zealand (Auckland, Penguin, 2003); Michael Bassett and Michael King, Tomorrow Comes the Song: A Life of Peter Fraser (Auckland, Penguin, 2000); Barry Gustafson, From the Cradle to the Grave: A Biography of Michael Joseph Savage (Auckland: Penguin, 1988).
} 
The files pertaining to the Physical Welfare Branch and the campaigns provide an array of material, ranging from newspaper articles, campaign posters, and magazine advertisements, to drowning reports, scripts for radio talks and advertisements, financial records, copies of ministerial speeches, and letters from the voluntary swimming and lifesaving organisations, Physical Welfare Officers, and members of the public. These sources offer insight into the administrative and political levels of government that shaped the campaigns. Both of these government mechanisms are examined in this thesis.

Information was also sought from those voluntary organisations with which the Physical Welfare Branch worked on the Learn-to-Swim and Prevent Drowning campaigns. However, little material exists outside of the collections held at Archives New Zealand. Several preventative medicine dissertations from Otago University, particularly R. N. Akel's 'Public Health Survey of Baths of Wellington City and Environs and the Learn-to-Swim Campaign', provide some information about the campaigns, as well as swimming culture more generally. They are, furthermore, evidence in themselves of New Zealanders' growing interest in swimming in the mid-twentieth century. Newspaper articles made available through Papers Past were also a component part of the research for this thesis, as were oral history interviews, conducted for the specific purpose of this thesis with members of the general public who were children or young adults in the mid-twentieth century. The interviewees were respondents to a call for stories placed in an issue of the New Zealand Genealogy Magazine. The aim of these interviews was to better understand firsthand experiences of New Zealand swimming culture.

Swimming is a subject and pursuit which sits within the domain of sport and leisure. As such, histories of swimming need to be viewed within the wider framework of sport and leisure historiography. The array of sporting and recreational activities which New Zealanders have engaged in throughout the country's history has occupied a prominent place within New Zealand historiography. Frequently viewed in isolation from other activities, nations, and social processes though, these pursuits are often described as unique and 'uniquely suited to the particular characteristics of New Zealand and New Zealanders'. ${ }^{3}$ However, in the New Oxford History of New Zealand, Charlotte Macdonald has written a general, overarching

\footnotetext{
${ }^{3}$ Caroline Daley Leisure and Pleasure: Reshaping and Revealing the New Zealand Body 1900-1960 (Auckland: Auckland University Press, 2003), p. 4.
} 
history of sport and leisure, exposing the similarities between various sporting pastimes and how they were connected by and to broader social forces. Macdonald reveals that, from the 1840 s to 2007 , the sporting domain experienced five phases of change during which time the ways in which people identified with sporting activities, particular interests, and each other shifted. Between the 1840s and 1860s, sport was independent, unorganised, and limited, largely as a result of the indistinct demarcation of time. However, from the 1870s to 1914, working hours (in urban centres) became more structured and 'the informal nature of sports gave way ... to more organised activities' as sporting clubs and associations were established to meet the demands of a mechanised society. These clubs introduced 'codified games, with consistent rules, conditions of play and regular competition'. This period was followed by one of major expansion in recreation amidst concerns about the quality of New Zealanders' bodies, the launch of national fitness schemes, and the growth of railway networks and car ownership. From 1918-1945, Macdonald notes, 'with modernity driving a new emphasis on fit bodies and public health', recreation became a 'right' for every citizen, and as such it began 'to carry an imperative of duty, and state priority, as well as voluntary desire'. ${ }^{5}$ In the post-World War II era up to 1972, amateurism gained renewed importance and sports clubs saw 'an explosion of activity' as part of New Zealanders' desire to get " "back" to "normal life" after the disruptions of the war' and resume 'ordinary enjoyments' ${ }^{6}$ The last phase, from 1972-2007, marks a period when the wider divisions and conflicts in New Zealand society became undeniably apparent within sporting domains. It was during the 1918-1945 and 1945-1972 time periods that the Learn-to-Swim and Prevent Drowning campaigns were instituted.

In Strong, Beautiful, and Modern: National Fitness in Britain, New Zealand, Australia, and Canada, 1935-1960, Macdonald has also looked specifically at recreation in the mid-twentieth century, the shape that that recreation took, and the government's role in shaping it. This book examines the national fitness programmes that were introduced in Britain (Physical Training and Recreation Act), New Zealand (Physical Welfare and Recreation Act), Australia, and Canada

\footnotetext{
${ }^{4}$ Charlotte Macdonald, 'Ways of Belonging: Sporting Spaces in New Zealand History', in Giselle Byrnes (ed.), The New Oxford History of New Zealand (Melbourne: Oxford University Press, 2009), pp. 269, 274.

${ }^{5}$ Ibid., pp. 280, 281.

${ }^{6}$ Ibid., pp. 284, 285.
} 
(National Fitness Act) in the 1930s and 1940s. Macdonald considers how and why national fitness schemes came into being during this period, or more explicitly, why the state became actively involved in encouraging 'people to continue with sport or some form of physical exercise once they left school', and how the schemes progressed and eventually declined. ${ }^{7}$ This new, national approach to health and fitness, Macdonald argues, represents 'a convergence in the history of states, bodies, and modernity'. ${ }^{8}$ Part of the wider modern project, efforts to better regulate recreation were an expression of the sense of ambivalence that plagued modern, rapidly changing societies, but similarly embraced notions of the malleable, 'better body' which would pave the 'way to a better life'. ${ }^{9}$ Furthermore, Strong, Beautiful, and Modern suggests that the expansion of recreational opportunities that was facilitated through legislation also sat 'within the longer-term pattern of the expansion and subsequent retreat of the state' from the social lives of citizens throughout the twentieth century. ${ }^{10}$ Sport, recreation, and leisure were one area of life which politicians could not ignore 'because healthy adults citizens now demanded more of governments in the form of leisure time and health'. ${ }^{11}$ Importantly, Macdonald argues that the fact that the national fitness movements were short-lived is revealing not of their failure, but of their accurate representation of a particular age. ${ }^{12}$ Macdonald's Strong, Beautiful, and Modern, narrowing the focus from her chapter in the New Oxford History of New Zealand, examines the time period on which this thesis concentrates and also provides a history of the Physical Welfare and Recreation Act, through which the Learn-to-Swim and Prevent Drowning campaigns were instituted. This thesis examines how it was that swimming developed during that era and how it developed through the political mechanisms that the Government applied to New Zealanders' recreation.

In the past two decades, water-based recreation has emerged as a popular topic of historical examination in New Zealand. Swimming, however, has received relatively little attention within this field. Surfing, surf lifesaving, bathing costumes,

\footnotetext{
${ }^{7}$ Charlotte Macdonald, Strong, Beautiful, and Modern: National Fitness in Britain, New Zealand, Australia, and Canada, 1935-1960 (Wellington: Bridget Williams Books, 2011), p. 151.

${ }^{8}$ Ibid., p. 10.

${ }^{9}$ Ibid, pp.12, 271.

${ }^{10}$ Ibid., p. 24.

${ }^{11}$ Ibid., p. 26.

${ }^{12}$ Matthew Worley, Oswald Mosely and the New Party (Basingstoke: Palgrave Macmillan, 2010), p. 11, in Ibid., pp. 151-2.
} 
and the increasing popularity of the beach as a place for bathing have dominated histories of New Zealanders' recreational interactions with the water. Frequently 'linking beach-going to nationalism', these histories have chiefly been concerned with examining how, from around the $1880 \mathrm{~s}$, the beach was reframed from a site of work to one which afforded health, and then, in the early twentieth century, became a popular space for pleasure, freedom, and recreation. ${ }^{13}$ Within this framework, the body and the beach as sites of moral dispute and the effect of these contestations on the shape of beach culture have been a common theme; that is, beach histories largely consider how the 'old morality', which advocated modesty, reserve, and restraint, clashed and was reconciled with the 'new morality' and the 'cult of personal health' on New Zealand's beaches. ${ }^{14}$ Despite the fact that beach histories acknowledge that New Zealanders went to the beach and occupied its shores and waters, what people actually did in the water is overlooked. Swimming has been treated as a given, without any questions posed as to why and how people swam, and how they learnt, if they did so at all. Rather than the focus of investigations, swimming has generally been relegated to a lens through which to understand the expansion of beach-going.

Caroline Daley's Leisure and Pleasure: Reshaping and Revealing the New Zealand Body 1900-1960 provides the most comprehensive account of the place of swimming in New Zealanders' leisure culture. The main chapter dealing with swimming in the book discusses how the New Zealand body became modern, how it was reconstructed ' $[\mathrm{t}] \mathrm{o}$ fit the modern era', through its display on New Zealand's beaches. ${ }^{15}$ This process of modernisation was driven by the increasing popularity of bathing, sunbathing, and shrinking bathing costumes amid a new preoccupation with health and healthy bodies. Daley reveals that as bathing and swimming began to gain popularity around the turn of the century, thanks to the growing 'acceptance of the health benefits of swimming', local councils grew concerned about bathers, in their various degrees of undress, and the potential for licentious behaviour on unsupervised shores. ${ }^{16}$ In response, councils across the country passed bylaws to

\footnotetext{
${ }^{13}$ Emma Joyce, 'The Pursuit of Sun, Sand, and Surf: Beach-going in New Zealand, 1910-1970', MA thesis, University of Auckland, 2006, p. 3.

${ }^{14}$ Douglas Booth, 'Healthy, Economic, Disciplined Bodies: Surfbathing and Surf Lifesaving in Australia and New Zealand, 1890-1950', New Zealand Journal of History, Vol. 31, no. 1, 1998, p. 49.

${ }^{15}$ Daley, p. 5.

${ }^{16}$ Ibid., p. 119.
} 
restrict beach use and prohibit bathing. ${ }^{17}$ They also built public baths, in which bathers' behaviour could be monitored and controlled, in an attempt to encourage people to give up their morally (and physically) dangerous 'daily dip' in the sea. Although some people were happy to follow bathing regulations and enjoyed swimming in the confines of municipal pools, Daley notes that bathing by-laws were frequently flouted and with 'no entrance fee to pay, all-day access on Sundays and no restrictions on how long you were allowed in the water', the beach proved to have a strong pull for some bathers. ${ }^{18}$ Thus, by 1914 ,

[T] he freedoms of the beach were attracting more New Zealanders but municipal baths still had appeal ... But for those who did not want to be constrained, and who were as interested in pleasure as leisure, surf and sand seemed so much more inviting than pools and rules. ${ }^{19}$

Locating the bathing body within a leisure/pleasure framework, Daley argues that New Zealanders restrained their bathing bodies but also enjoyed them and embraced the freedoms and opportunities that modern society afforded. While some New Zealanders may have been reserved in their bathing practices and cautious when it came to revealing their bodies, others also criticised and contravened those restrictions which prevented them from bathing when and where they pleased, from sunbathing in the sand dunes, and from wearing fashionable bathing costumes. Leisure and pleasure both constituted New Zealanders' recreational experiences between 1900 and 1960. Therefore, Leisure and Pleasure challenges the perception that exists in New Zealand historiography and society more generally that the nation, during this period, was characterised by 'provincial puritanism', and contends that the paradoxical nature of the bathing body reveals that New Zealand was well and truly modern. ${ }^{20}$ Daley provides an important backdrop to the topic of this thesis as she sheds light on the bathing culture that existed prior to the 1930s. It also raises the question that if the beach and beach body became modern in the early twentieth century, if they were shaped by both restraint and enjoyment, was this modernity relayed in New Zealanders' interactions with the water?

\footnotetext{
${ }^{17}$ Ibid., pp. 120-1.

18 Ibid., p. 127.

${ }^{19}$ Ibid., p. 126.

${ }^{20}$ Macdonald, Strong, Beautiful, and Modern, p. 16.
} 
Moving away from the dominant focus of the beach as a site of leisurely bathing/swimming, two New Zealand histories bring swimming to the fore of their historical analysis. The first is Daley's article, 'Women Endurance Swimmers: Dissolving Grease Suits and Decentring New Zealand History', which provides insight into the professional/competitive/sporting side of swimming that existed (alongside New Zealanders' sporadic, casual, leisurely bathing) prior to the introduction of the Learn-to-Swim and Prevent Drowning campaigns. This article explores the 'brief moment [during the 1930s Depression era when] the swimming pools of Australasia became aquatic sideshows, peopled by almost-famous overseas "stars", freaks and struggling battlers'. ${ }^{21}$ During this period, Australasia was swept up in the global fervour for endurance swimming, a sporting spectacle whereby swimmers attempted great feats of fortitude, swimming long distances in open waters and/or spending hours in the water. Daley looks into the careers of three female "stunt" swimmers: Englishwoman Mercedes Gleitze, who introduced endurance swimming into New Zealand, and New Zealanders Katerina Nehua and Lily Copplestone. A subject of limited historical interest, Daley argues that female endurance swimmers 'have been written out of the national story because roles have not been created for them'; as women and as individuals rather than national representatives, these swimmers 'do not fit the standard, masculinity, national framework' within which sport histories often operate. ${ }^{22}$ Similar to Gary Osmond's examination of two Australian stunt swimmers, 'Women Endurance Swimmers' is, thus, not so much concerned with the place of swimming in New Zealand society as it is with 'the selective, present-centred dimensions of history making'. ${ }^{23}$ Nevertheless, Daley provides a valuable account of a period in swimming's history when the 'taint of professionalism' had not yet been supplanted by 'a fully amateur, modern sporting activity'. ${ }^{24}$ It is that rise of amateur swimming to the status of a popular leisure pursuit with which this thesis is concerned. ${ }^{25}$

\footnotetext{
${ }^{21}$ Caroline Daley, 'Women Endurance Swimmers: Dissolving Grease Suits and Decentring New Zealand History', Sporting Traditions, Vol. 21, no. 2, May 2005, p. 30. The topic of female endurance swimmers first came to light in 1991 with the publication of The Book of New Zealand Women, in which Katerina Nehua's story featured.

${ }^{22}$ Ibid., pp. 45, 46.

${ }^{23}$ Gary Osmond, 'Forgetting Charlie and Tums Cavill: Social Memory and Australian Swimming History', Journal of Australian Studies, Vol. 33, no. 1, 2009, p. 93.

${ }^{24}$ Ibid., p. 101.

${ }^{25}$ In nineteenth-century England, in order to distinguish themselves from professional swimmers (i.e. swimmers who swam or performed for money/strictly as a form of entertainment), middle-class
} 
In addition to Daley's history of swimming as a sport, Kevin Moran, a surf lifeguard and senior lecturer in Health and Physical Education at Auckland University, has recently written a history of swimming in schools. Based on his 1999 M.Ed thesis, The Shaping of Swimming and Water Safety Education in New Zealand examines the establishment of swimming within physical education programmes in schools. It investigates the way in which the purpose and practices of school swimming changed amid shifting concerns and intentions in the school curriculum between the late nineteenth century and 2010. Moran asserts that swimming first made its appearance in some secondary schools in the last two decades of the nineteenth century, thanks to teachers and principals who were themselves swimming enthusiasts. By the early twentieth century, swimming was included in teacher training courses and the government began to offer various subsidies to schools which sought to include swimming in their timetable as a means to prevent or correct 'physical deformities', as well as to raise levels of health, cleanliness, and lifesaving capabilities. In 1920, swimming was finally included in the Syllabus of Physical Training for primary schools, making it a legitimate, though not compulsory, school subject. Moran notes, however, that school swimming remained sporadic and irregular until the 1940s, when swimming was given much more attention by the Education Department. From the 1940s, school pool construction boomed, swimming became more common in secondary schools, and increasing attention was given to general water and survival skills as the diversity of New Zealanders' aquatic recreation grew in the 1960s. Swimming for fitness became the emphasis of the curriculum in the 1980s, and by the end of the twentieth century, most schools had a school pool, or access to one, and were teaching swimming as part of their physical education programmes. But, Moran reveals that surveys conducted in schools in the 2000s by Water Safety New Zealand seemed to suggest that swimming and water safety standards were slipping. Such results have led to

swimmers referred to themselves as amateur swimmers. These swimmers still participated in competitions and were skilled swimmers. However, theirs was a leisure pursuit, rather than a livelihood. While professional swimmers were common in Australia, they were a rarity in New Zealand. Thus, amateur swimmers largely filled this role in New Zealand and competition, speed, and distance, rather than skill, were the key features of amateur swimming in New Zealand. However, with the instigation of the Learn-to-Swim campaign, skilled amateur swimming, as opposed to swimming for sport/competition, increasingly became the goal. 
fears that, unless more is done to ensure children have better water skills, the number of drowning accidents is going to increase significantly. ${ }^{26}$

The Shaping of Swimming and Water Safety Education in New Zealand, Moran claims, dismisses the congratulatory nature of education reports which often emphasised the positive, and instead presents 'a history that is neither complimentary nor celebratory'. ${ }^{27}$ However, the stated intention of the book was to inform the teaching profession and private aquatic organisations "on "what was", meaning that they can better determine "what is" and "what ought to be". ${ }^{28}$ Such knowledge, Moran hoped, would encourage swimming teachers and coaches to ensure that swimming remains a key activity within physical education programmes in the face of the apparent decline of school swimming and increasing drowning numbers. Thus, Moran's is ultimately a 'proud history' of New Zealand's education system, a story of the successful growth of swimming and water safety education in New Zealand schools. ${ }^{29}$

Moran's history drew primarily on parliamentary debates, the Appendices to the Journals of the House of Representatives, and various reports and teaching materials printed by the Education Department. He does not draw on the details of archive files and thus presents limited information on the administrative and political factors that influenced the development of school swimming. Such material may have revealed a less polished state of affairs. The Shaping of Swimming and Water Safety Education in New Zealand, though, is the sole example of a history of swimming in New Zealand. Thus, it cannot be overlooked with regard to this thesis, and it does provide a basic outline of changes made to swimming in schools for the period under discussion in this study.

In historiography overseas, swimming has generally been given the same level of attention as has been the case in New Zealand; that is, swimming has primarily been an auxiliary subject within histories of the rise of the recreational beach/seaside resort, and in addition, of histories of municipal baths. However, in the last decade, swimming has gradually become a topic of scholarly historical interest in and of itself, particularly in England and Australia. These swimming

\footnotetext{
${ }^{26}$ Kevin Moran, The Shaping of Swimming and Water Safety Education in New Zealand (Auckland: Tradewinds, 2010), pp. 170-1.

${ }^{27}$ Ibid., p. iii.

${ }^{28}$ Ibid.

${ }^{29}$ Ibid., p. 173.
} 
histories focus their investigations on the approximate period of the mid-nineteenth century to the outbreak of World War I and tend to either examine the development of swimming as a sport or swimming's introduction into schools. Within these two branches, gender, class, amateur versus professional debates, and civic pride have been notable themes. In Australian histories, swimming has also often been examined within a nationalistic context. Richard Light and Tracy Rockwell, for instance, have noted that the "transformation of bathing as a leisure activity into the regulated and rationalised sport of competitive swimming during the mid-nineteenth century occurred as part of the development of a distinctive Australian sporting culture' ${ }^{30}$

Although separated by distance and time from the subject of this study, Alison Claire Parker's PhD thesis, 'An Urban Historical Perspective: Swimming a Recreational and Competitive Pursuit 1840 to 1914 ', is the most immediate history of modern swimming and thus illuminates elements of the type of swimming New Zealanders adopted in the mid-twentieth century. Placing swimming within the social and cultural setting of nineteenth-century Britain, Parker's thesis examines the realisation of swimming as a rational recreation, its rise as a competitive sport, the institutionalisation of swimming, swimming in schools, and swimming as 'the first modern urban sport for women'. ${ }^{31}$ Before industrialisation and urbanisation got underway in Britain in the nineteenth century, Parker notes that swimming was a spontaneous and unorganised pastime, pursued for pure enjoyment. However, the new social and physical environments produced by industrial expansion saw substantial changes develop in the structure and nature of swimming.

'An Urban Historical Perspective' explains that swimming and public bath construction became one way of alleviating middle-class concerns about public health and social order amid the growing incidence of poverty and disease in urban centres. Not only was swimming/bathing/washing seen as a means of cleansing the body and thereby preventing disease and illness, cleanliness was also believed 'to be an indicator of good social behaviour'. ${ }^{32}$ Thus, bathing would ensure the '[h]igher standards of behaviour, both in public and in private, [that] were now advocated by

\footnotetext{
${ }^{30}$ Richard Light and Tracy Rockwell, 'The Cultural Origins of Competitive Swimming in Australia', Sporting Traditions, Vol. 22, no. 1, November 2005, p. 21.

${ }^{31}$ Alison Claire Parker, 'An Urban Historical Perspective: Swimming a Recreational and Competitive Pursuit 1840 to 1914', PhD thesis, University of Sterling, 2003, p. 10.

${ }^{32}$ Ibid., p. 89.
} 
those in authority ${ }^{33}$ In response, private individuals and municipal authorities set about constructing public baths. These baths, Parker argues, afforded a major step towards transforming bathing, as an enjoyable, sociable activity, into a modern competitive sport as the indoor facilities, with their standardised and controlled environment, meant that a 'regulated, standardize[d], and controlled' sport could be developed. ${ }^{34}$ The initial association of public baths with the urban poor meant that bathing/swimming was largely regarded as an inappropriate pursuit for the middle class. However, in an attempt to achieve higher levels of health as an antidote to the negative side of urbanisation, some middle-class enthusiasts sought regular physical exertion in public baths. In order to extinguish urban bathing's reputation and legitimise their pastime, middle-class bathers adopted 'a sports creed' and formed swimming clubs. ${ }^{35}$ These clubs initiated the final stage in the modernisation of swimming by developing rules, holding competitions, instigating role differentiation (i.e. different levels of swimming skill/ability), producing public information, and collecting and recording statistics and achievements. In other words, swimming became an activity focused on technique, skill, and fitness, governed by conventions and codes which determined specific movements and activities within a defined space and time - a vastly different activity to the one that had been practiced before 1840. This structuring of swimming, that is, the 'transformation of swimming from a recreative activity, into an urban recreation and "modern" competitive sport' was, according to Parker, a 'response to the chaos of the urban transformation and a desire to bring order to all aspects of city life'. ${ }^{36}$ As such, Parker argues that swimming culture cannot be understood in isolation from the society in which it was developed and practiced. Although this thesis does not touch on these questions, Parker's thesis presents an opportunity to consider whether the pattern of development in Britain was similar to the rise of swimming as a modern competitive sport in New Zealand. Were differences in climates, population size or the age of the population, access to water and types of water, or leisure hours, a factor in transforming the way people swam?

Histories like Parker's examine swimming as a sporting pursuit, that is, the focus is on the development of amateur swimming. This marked a significant change

\footnotetext{
${ }^{33}$ Ibid., p. 52.

${ }^{34}$ Ibid. pp. 135, 329.

${ }^{35}$ Ibid., pp. 63, 116.

${ }^{36}$ Ibid., pp. i, 75.
} 
in the history of swimming, which has had resounding effects on leisure, sporting, and educational cultures right up to the twenty-first century. But, swimming histories generally end their investigation at the point at which swimming was introduced into schools in the early twentieth century, implying that after this event, there were no further developments in swimming. There is, consequently, a considerable gulf in understanding how amateur swimming spread and progressed. The consensus of these histories is that swimming was a modern development, a product of modern conditions. Thus, as those conditions changed, how did swimming change? How did New Zealand's swimming become modern? These are questions which this study will consider.

This thesis extends international historical understandings of swimming culture by examining post-World War I developments and adds to New Zealand's miniscule swimming historiography. But more than this, the study examines the state's role in swimming culture. Existing swimming histories are concerned with swimming that is either a specialised, regulated, and controlled sport, managed by voluntary associations, or an educational subject in schools. However, the Learn-toSwim and Prevent Drowning campaigns do not fit into either category. In New Zealand, from 1936-1956, amateur swimming became an increasingly ubiquitous pastime and it was considered, particularly in the early years of this period, to be 'the duty of every non-swimmer to learn to swim'. ${ }^{37}$ This occurrence was principally a result of the central government's active role in encouraging and providing opportunities for swimming as a general leisure pursuit. As such, the Learn-to-Swim and Prevent Drowning campaigns represent a very different type of swimming culture to what has previously been written about, and also to the nature of swimming prior to the mid-twentieth century, and indeed after 1956. Therefore, the campaigns provide additional evidence of the diverse meanings and purposes for which swimming has been pursued, promoted, and practiced. Drawing on wider sport and leisure historiography, this thesis reveals that the campaigns represented a new way of thinking within the domain of swimming, but this thinking was not unique within New Zealand's wider leisure culture in the mid-twentieth century.

The discussion is organised into three chapters, each one dealing with distinct (though related) aspects of the expansion of recreational amateur swimming

37 'Learn to Swim Campaign', Grey River Argus, 25 February, 1939, IA 1, 2937, 139/19/2, part 3, Archives New Zealand Wellington (ANZW). 
between 1936 and 1956. Chapter one examines the patterns and characteristics of drowning fatalities in New Zealand from 1935-1960. The Learn-to-Swim and Prevent Drowning campaigns were partly a response to these deaths, and thus the chapter assesses how the fatalities which occurred during this period justified the instigation of more concerted efforts to prevent deaths by drowning. Chapter two is focused on the response to those drowning patterns and other factors that prompted the launch of campaigns promoting swimming and drowning prevention. It examines the administrative and political structures that shaped the campaigns and reveals the extent to which the state acted as a modernising agent with regard to swimming culture. The Learn-to-Swim and Prevent Drowning campaigns themselves are the subject of the third chapter, which explores the nature, content and means the campaigns deployed in order to achieve a 'water wise' swimming nation. This chapter considers how the campaigns introduced New Zealanders to a new leisure culture from 1936-1956. 


\section{Chapter One}

'Drowning is, in New Zealand, one of the most popular ways of dying before your time': drowning deaths, $1935-1960^{1}$

Roughly seventy years after he fought for his life in the waters of Maraetai beach, New Zealand writer C. K. Stead could still vividly remember his immense relief at being rescued and 'the horror of that battle between the will to hold one's breath and the compulsion to suck in whatever element is out there'. ${ }^{2}$ Thousands of New Zealanders have shared in Stead's experience of near drowning; thousands more have not been so lucky as to escape with their life. By 1940, around the time when an eight-year-old Stead had this near-death experience, drowning had long since lost its haunting nineteenth-century status as the 'New Zealand Death'. This, however, did not make drowning accidents any less frightening or any less distressing.

Drowning and drowning prevention are topics which have received scarce historical attention. Histories of swimming generally state that the growth of swimming education and its extension into schools was in part a reaction to anxiety over increasing drowning deaths. However, little evidence is provided to support this claim. Claire Parker and Rachel Winterton, for example, have argued that the inclusion of swimming in the school curriculum in Victoria, Australia, in the early twentieth century was a means of addressing 'the high prevalence of drownings'. 3 Yet, the occurrence of drowning is not actually examined in their article. The absence of concerted investigations into patterns of and attitudes towards death by drowning in such histories has consequently resulted in much misunderstanding about the prevention of these deaths.

The Learn-to-Swim and Prevent Drowning campaigns, run between the 1930s and 1950s, were partly a response to the perception that New Zealand's drowning rate was 'appallingly high'. ${ }^{4}$ This chapter examines the trends and characteristics of drowning fatalities in New Zealand, focusing on the period 1935-

\footnotetext{
1 'Must People Drown?', The Hokitika Guardian, 10 December 1957, IA 70, 4, 13, Archives New Zealand, Wellington (ANZW).

${ }^{2}$ C. K. Stead, South-West of Eden: A Memoir, 1932-1956 (Auckland: Auckland University Press, 2010), p. 79.

${ }^{3}$ Claire Parker and Rachel Winterton, “'A Utilitarian Pursuit": Swimming Education in NineteenthCentury Australia and England', International Journal of the History of Sport, Vol. 26, no. 14, November 2009, p. 2125.

4 'Drowning Still New Zealand Death', The Northland Times, 31 January, 1959, IA 70, 4, 13, ANZW.
} 
1960, with the aim of answering one of the overarching questions of this thesis: why were the Learn-to-Swim and Prevent Drowning campaigns instituted during this period? Why did drowning deaths trigger this intensive, public response at this particular point in time?

Between the 1850s and the 1950s, the occurrence of death by drowning dropped dramatically in New Zealand. In the nineteenth century, drowning posed by far the greatest threat to settlers in terms of accidental deaths, for both males and female. ${ }^{5}$ In 1858, drownings accounted for seventy-six per cent of all violent/accidental deaths, and '[f]or the three years following $1864 \ldots 47$ per cent [of all sudden deaths] were drownings'. ${ }^{6}$ Over the 1858-1901 period, 6,204 Pākehā, of all ages and both sexes, were recorded to have died as a result of drowning (figure 1 ). ${ }^{7}$ This was a huge number of drowning deaths to occur in just over a forty-year period. Drowning's title as the 'New Zealand Death' was thus justified by the frequency of deaths. It was also vindicated by the perception of the scale of drowning deaths. As one traveller wrote, the regularity of drowning fatalities 'compared with death from disease made colonists describe death by drowning as a natural one'. 8

Not only was the actual and perceived incidence of drowning high in comparison to other accidental deaths in nineteenth-century New Zealand, it was also high in comparison to other countries. According to David Madle, in 1863, New Zealand's drowning rate per 100,000 population was eighty-six, while the

\footnotetext{
${ }^{5}$ David Victor Madle, 'Patterns of Death by Accident, Suicide and Homicide in New Zealand, 1860-1960: Interpretation and Comparisons', Ph.D. thesis, Victoria University of Wellington, 1996, p. 56. No official statistics exist regarding Māori drownings during the nineteenth century. However, this does not mean that Māori were spared such an unfortunate end. Newspaper articles, though providing few details, attest to the fact that drownings were frequent incidents in Māori communities.

${ }^{6}$ John Pascoe, 'The New Zealand Death', New Zealand's Heritage: the Making of a Nation, Vol. 20, no. 2, 1971, p. 559.

${ }^{7}$ The actual number of drowning deaths was likely to be significantly higher than the numbers recorded in the official statistics because these deaths were seriously underreported. If no body was found, which was not uncommon given the potential for drowning victims to be swept away by currents, then deaths went unrecorded. It was also not unusual for individuals to go missing without anyone noticing thanks to the transitory nature of colonial New Zealand society (Madle, p. 53). There does not appear to be any obvious explanation as to the massive spike in the number of drowning deaths recorded to have happened in 1895, unless the 121 deaths which resulted from the wrecking of the Wairarapa, which was the country's worst shipping disaster, at Great Barrier Island in October 1894 were not officially recorded until the following year ('Wairarapa', from $A n$ Encyclopaedia of New Zealand, edited by A. H. McLintock, originally published in 1966, Te Ara the Encyclopedia of New Zealand; http://www.TeAra.govt.nz/en/1966/disasters-and-mishapsshipwrecks/5 [accessed 20 June 2012]).

${ }^{8}$ A. S. Thomson, The Story of New Zealand: Past and Present - Savage and Civilised, Vol. 2 (London: John Murray, 1859), 2 volumes, p. 61.
} 
1856 rate of various regions in England and Wales was fourteen, making the drowning rate for New Zealand in the 1860s ... more than four times that in Britain'. ${ }^{9}$ Deaths by drowning occurred as a consequence of a variety of factors, but New Zealand's relatively elevated drowning rate can be attributed to the general issue of the 'rigours and occupational dangers of pioneering in a new land'; New Zealand's settlers were more exposed to bodies of water, and thus had greater chances of drowning, than their compatriots in Britain. ${ }^{10}$ The abundance of lakes, rivers, and coastline in New Zealand, the lack of bridges and roads, reliance on water-based transportation both to get to New Zealand and to journey through the country, the popularity of gold mining, the frequency of flash floods, as well as widespread swimming inability, were all factors which contributed to New Zealand's long list of, predominantly male, drowning victims. ${ }^{11}$

Water was unavoidable in colonial New Zealand. But, as the country became more urbanised, as railway lines and roads were built across the land, as bridges were erected over rivers, as lighthouses were positioned along the coastline, and as people took up jobs in factories, offices, and shops as opposed to on farms or in the bush, the prospects of drowning were significantly reduced. This change was reflected in the frequency of drowning fatalities. In 1858, New Zealand had a drowning rate of eighty-nine per 100,000 population. By 1896 , the drowning rate had more than halved, and it halved again by 1901. At the beginning of the twentieth century, New Zealand's drowning rate sat at nineteen drownings per 100,000 population, and death by drowning accounted for a mere two per cent of all deaths. The 1858-1901 period saw a steep and remarkable decline in the incidence of drowning in New Zealand.

\footnotetext{
${ }^{9}$ Madle, p. 39.

${ }^{10}$ W. D. Borrie, The European Peopling of Australasia: A Demographic History, 1788-1988 (Canberra: ANU Printing Services, 1994), p. 157.

${ }^{11}$ Drownings were mainly a result of unintentional submersion (i.e. not from swimming), and the most common reason for this submersion was the capsizing of boats. Other familiar ways of drowning included (drunkenly) falling off wharves or out of a boat, slipping off rocks while fishing, falling overboard, and attempting to rescue someone else from the water. Wells, sheep dips, and uncovered drains also posed a major threat to children in the colony. However, more often than not, there was no known cause of how drowning victims came to be in the water and in such cases the cause of death was simply recorded as 'found drowned'. Shipwrecks around New Zealand's coasts caused numerous deaths (1109 from 1866-1900) (Madle, p. 45), but it was rivers which proved to be the most dangerous. One official report on drownings from 1870 revealed that 1,115 people had drowned in rivers and streams alone since 1840 ('Return of Names of Persons Drowned in New Zealand from the $1^{\text {st }}$ of January 1840', Appendix to the Journal of the House of Representatives, Vol. $3,1870, \mathrm{D}-46)$.
} 
Figure 1

Pākehā Drownings, 1858-1901

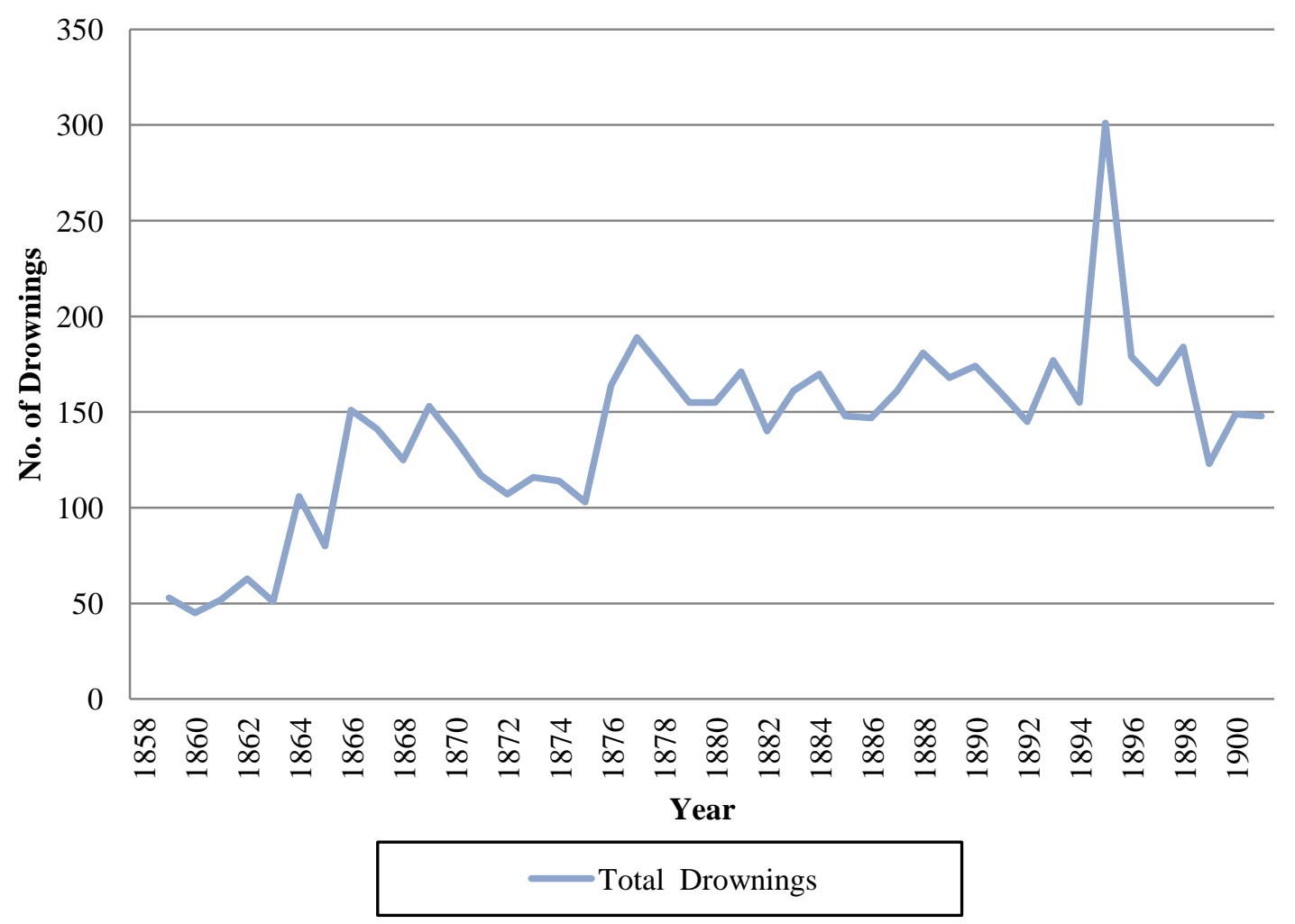

Statistics of New Zealand, 1858-1901

Drowning was the 'most common form of accidental death' in New Zealand until 1928 when it was surpassed by traffic accidents. ${ }^{12}$ However, the pattern of decline in the drowning rate throughout the nineteenth century continued into the twentieth century, though it was not as striking. In 1931, the Royal Life Saving Society of New Zealand noted that the drowning rate in Auckland per 100,000 population dropped from twenty-one in 1905-9 to eleven between 1926 and 1930, while the drowning rate for the entire country fell from eighteen to ten over the same period. ${ }^{13}$ This was not a trend that was exclusive to drowning deaths, though. It also echoed the decrease in the Pākehā death rate as a whole and was similarly consistent with declining rates of (accidental) deaths in other nations. ${ }^{14}$ By the 1920s, extensive infrastructure had been and was being built, boats and canoes were becoming less common forms of cross-country travel, considerable

\footnotetext{
${ }^{12}$ Keith Sinclair, A Destiny Apart: New Zealand's Search for National Identity (Wellington: Allen and Unwin, 1986), p. 61.

${ }^{13}$ Royal Life Saving Society of New Zealand, Special Souvenir Number, $21^{\text {st }}$ Annual Report for the Year Ended July 31, 1931 (Christchurch: Royal Life Saving Society of New Zealand, 1931), p. 15.

${ }^{14}$ Borrie, pp. 155-6.
} 
advancements in shipping technology and safety requirements (i.e. radio communications) had been made, urbanisation continued, and new developments, like connecting homes to town water supplies, made domestic wells redundant - all factors which reduced exposure to potential hazards and hence reduced the risk of drowning. ${ }^{15}$ Thus, in the early twentieth century, drowning was nowhere near the threat that it had been in the nineteenth century, and the threat that drowning did pose was no longer essentially through occupation and daily business. Instead, drowning became a recreational hazard.

In the mid-twentieth century, the occurrence of drowning deaths continued to decline, but some sectors of New Zealand society saw more improvement than others. 2,820 people drowned in New Zealand from 1935-1960, representing approximately 113 drownings per annum. The number of Pākehā drowning fatalities overall, though unevenly, declined during this period. ${ }^{16}$ The annual sum of Māori fatalities, on the other hand, remained relatively steady throughout the twenty-five year period (figure 2). Both Māori and Pākehā, however, experienced a significant drop in drowning rates (figure 3). In 1935, 134 Pākehā accidentally drowned, equal to a rate of nine deaths per 100,000 population. By 1960, this rate had fallen to three drowning deaths per 100,000 population. The accidental drowning rate for Māori in 1935 was close to three times that of the Pākehā rate, totalling twenty-four drownings per 100,000 population. This rate was almost halved by 1960 . However, the Māori drowning rate was now more than four times higher than the Pākehā rate. Examining the differences between Māori and Pākehā drownings from another perspective, accidental drownings accounted for nine per cent of all violent/accidental Pākehā deaths, but half a per cent of the total number of deaths from 1935-1960. For Māori, drowning represented seventeen per cent of violent/accidental deaths and just over one per cent of all Māori deaths. Thus, drowning was a significantly more common cause of accidental death among the Māori population than the Pākehā population. Māori were also notably overrepresented among New Zealand's drowning victims in that they comprised

\footnotetext{
15 Madle, p. 48; Gerard Hutching. 'Shipwrecks - 20th-century shipwrecks', Te Ara - the Encyclopedia of New Zealand; http://www.TeAra.govt.nz/en/shipwrecks/5 [accessed 20 June 2012]. 16 There was considerable variation in the number of Pākehā drownings which occurred from 19351960. However, it is almost impossible to explain the spikes and depressions from year to year. One explanation that was frequently given at the time was the length of New Zealand's summers/the variability of weather conditions and its influence in determining the frequency and type of recreational encounters with the water.
} 
approximately seventeen per cent of all accidental drownings from 1935-1960, and yet they constituted roughly seven per cent of New Zealand's population in 1960. Māori were, accordingly, markedly more vulnerable to drowning deaths than were Pākehā.

One explanation for the difference in drowning rates between Māori and Pākehā may be that Māori still largely lived in rural areas, and therefore were more exposed to (natural) bodies of water than were the predominantly urban-dwelling Pākehā. ${ }^{17}$ That is, in general, drowning remained a greater everyday hazard among Māori longer than it did for Pākehā. This, however, does not wholly explain the increasing disparity between Māori and Pākehā rates of drowning in this period. Mark Haimona and Nātana Takurua attribute differences between Māori and Pākehā drowning rates in the twenty-first century to the 'dissociation of many Maori from traditional beliefs and [water safety] practices that has accompanied colonization'. ${ }^{18}$ Although no Māori drowning statistics existed prior to colonisation or even in the nineteenth century, thereby allowing for an assessment as to whether Māori drowning rates increased with colonisation, Haimona and Tukurua's argument does not fully apply to 1935-1960 drowning patterns as the Māori drowning rate was declining. Still, such an explanation may have some relevance given that the Māori drowning rate was substantially higher than the Pākehā rate. Instead, the disproportionate provision of swimming facilities in favour of nonnative schools may have been an important, more plausible determining factor in the higher Māori drowning rate. ${ }^{19}$ Nonetheless, the Māori drowning rate did undergo considerable improvement, while the nation as a whole saw drowning deaths fall from ten per 100,000 population to four between 1935 and 1960. This was a pattern which was not only revealed in New Zealand's official statistics but was recognised by voluntary associations who were involved in drowning prevention efforts (figure 4).

\footnotetext{
${ }^{17}$ Only thirty-five per cent of Māori were living in urban centres by 1956 (Paul Meredith, 'Urban Māori - Urbanisation', TeAra - Encyclopedia of New Zealand; http://www.teara.govt.nz/en/urbanmaori/1 [accessed 20 July 2011]).

${ }^{18}$ Mark Haimona and Nātana Takurua, 'Kia Maanu, Kia Ora: Stay Afloat, Stay Alive Acknowledging the Significance of Tikanga Māori in Formulating and Communicating Water Safety Policies and Practices', Journal of Maori and Pacific Development, Vol. 8, no. 2, September 2007, p. 83.

${ }^{19}$ Kevin Moran, The Shaping of Swimming and Water Safety Education in New Zealand (Auckland: Tradewinds, 2010), pp. 129-32.
} 
Figure 2

Number of Māori and Pākehā Accidental Drownings, 1935-60

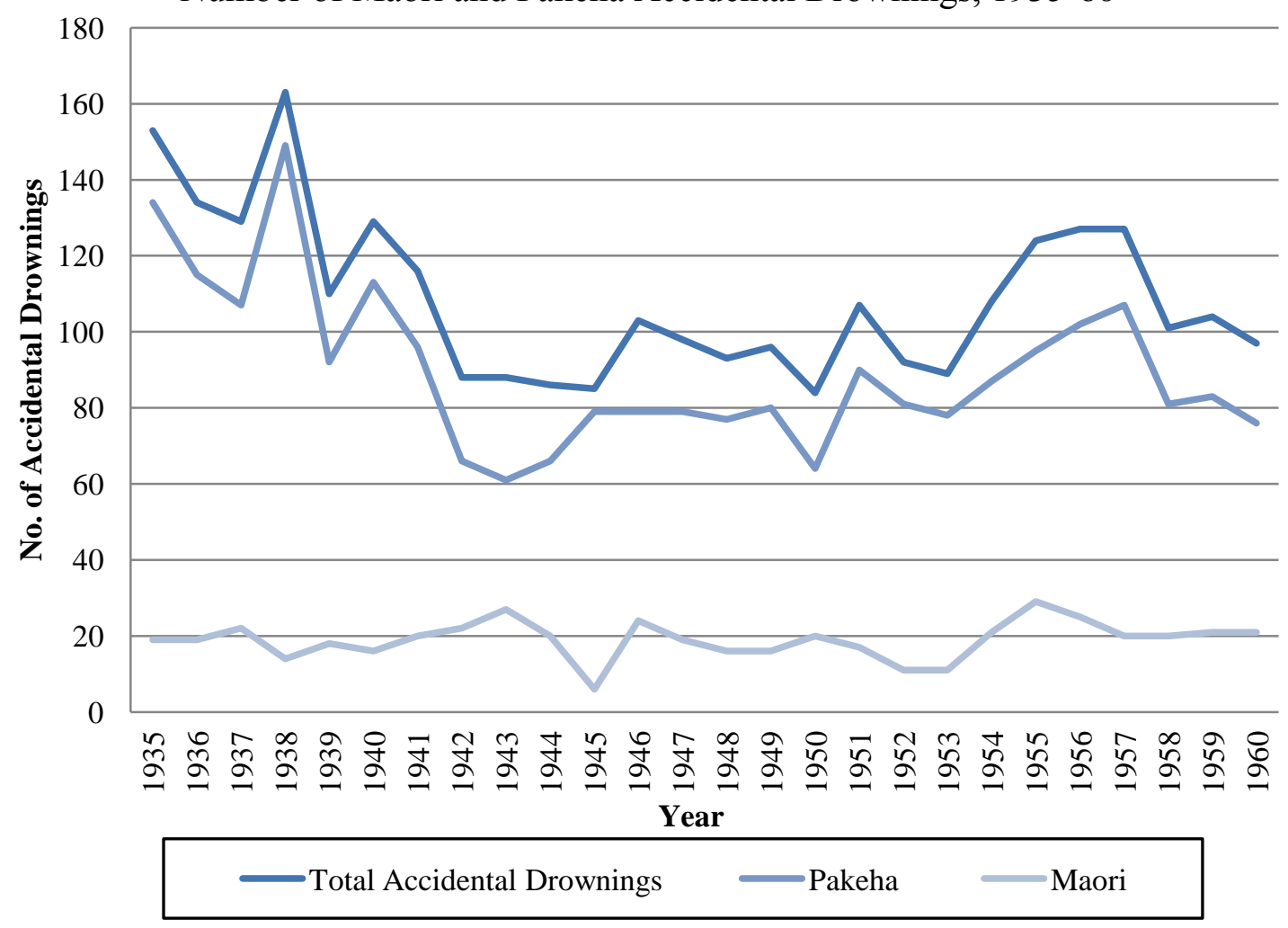

Statistic of New Zealand, 1935-1960.

Figure 3

Rate of Māori and Pākehā Accidental Drownings, 1935-60

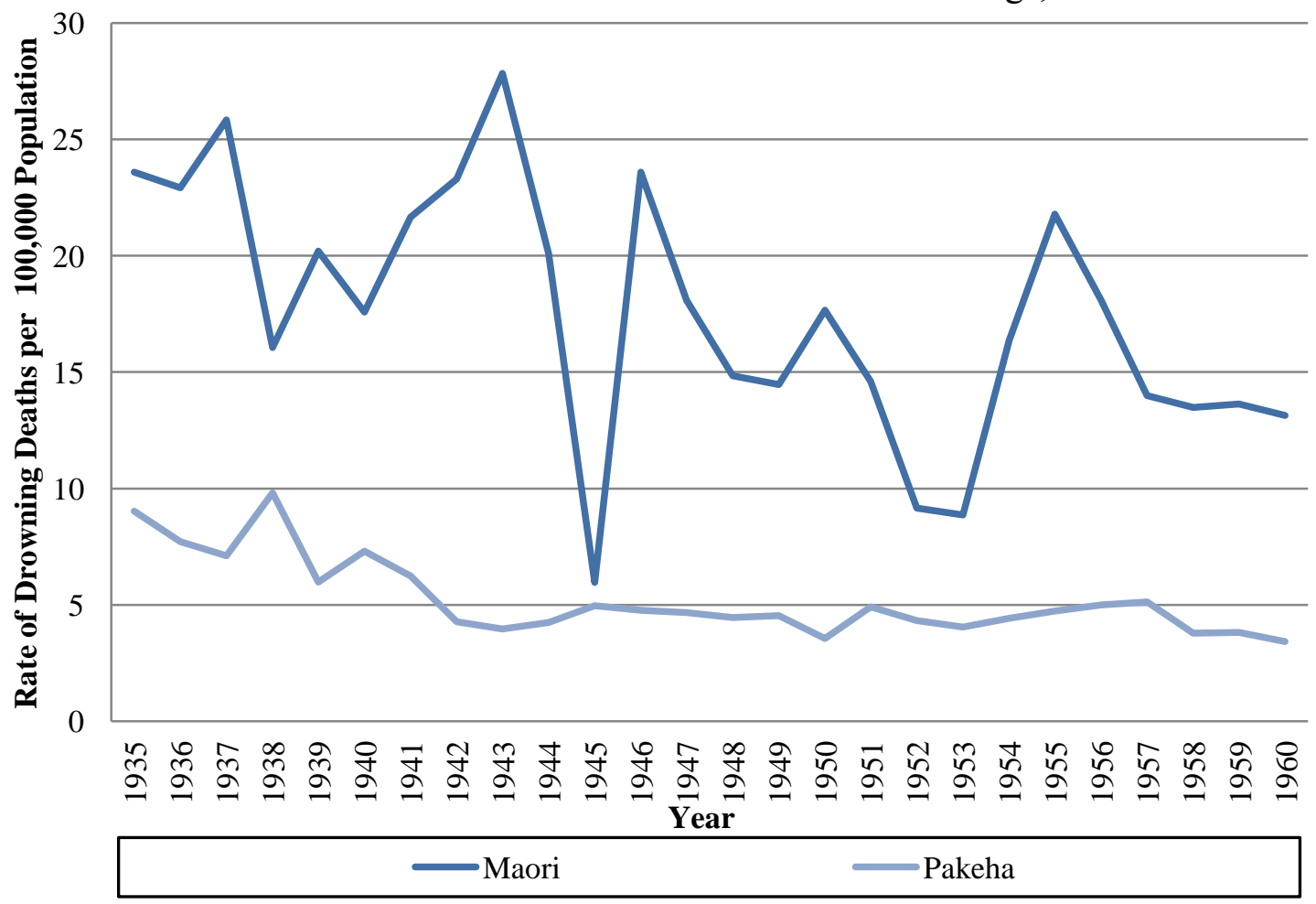

Statistics of New Zealand, 1935-1960. 
Figure 4

National Water Safety Council, Table of Rate of Drownings, 1927-1959

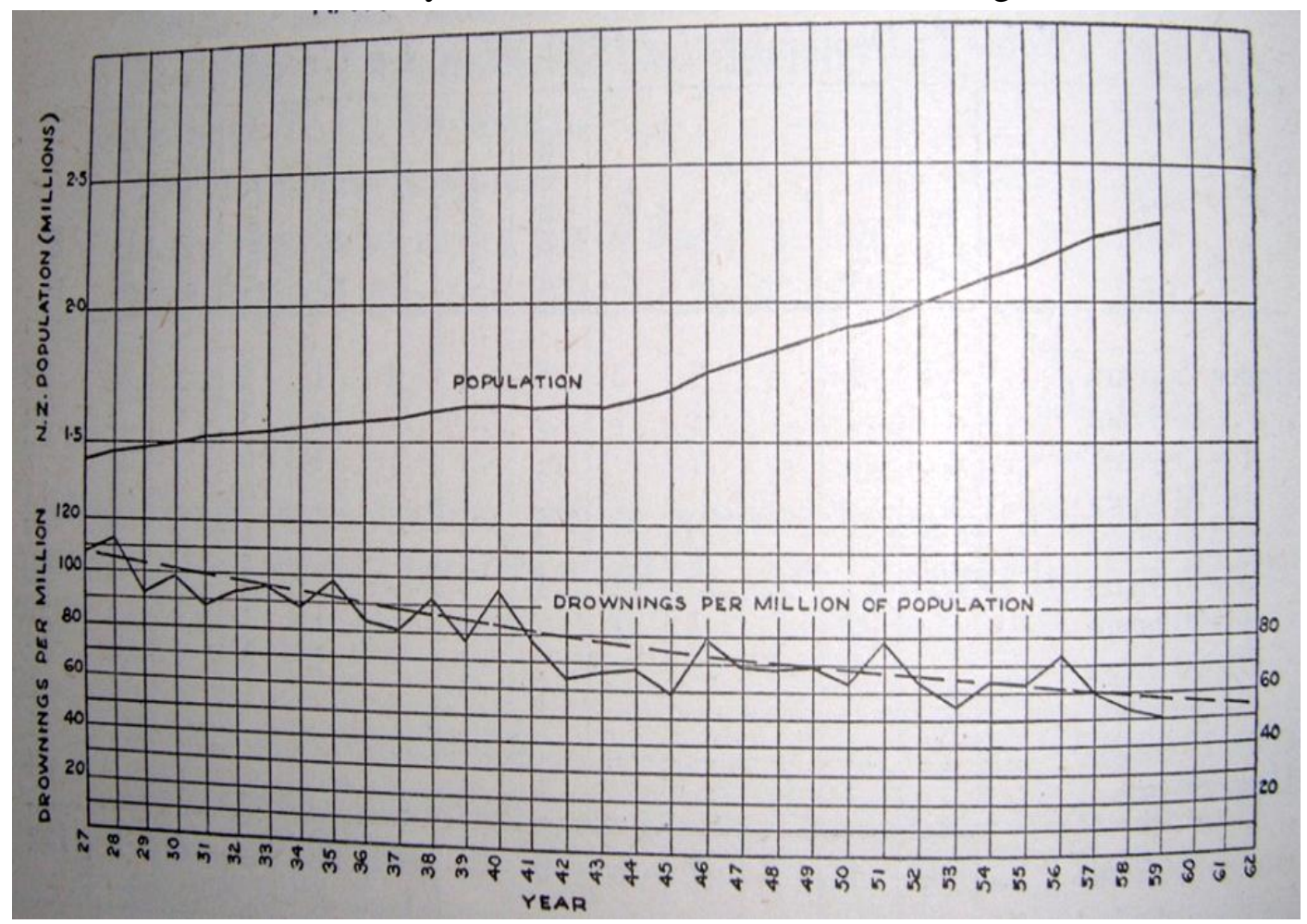

Appendix to the Journal of the House of Representatives, Vol. 3, 1959, H-22, p. 67.

From 1935-1960, not only was drowning more common among Māori than Pākehā, it was also more common among males than females. For the Pākehā population, females accounted for twenty per cent of all accidental drowning victims. The situation was similar among the Māori population, but the proportion of female deaths by drowning was slightly higher, with females representing twenty-four per cent of the total Māori drownings. Being male in New Zealand during the mid-twentieth century was obviously a risky business. The number of Pākehā males who drowned during the 1935-1960 period was, on the whole, declining (figure 5), and the steep reduction in numbers of male drowning victims occurred between 1938 and 1943 may be attributable to the Second World War and the exodus of a large segment of New Zealand's male population. In the post-war period, the number of Pākehā male drowning victims increased, but drowning figures remained significantly lower than in the pre-war years. 
Figure 5

Accidental Pākehā Drownings by Sex, 1935-60

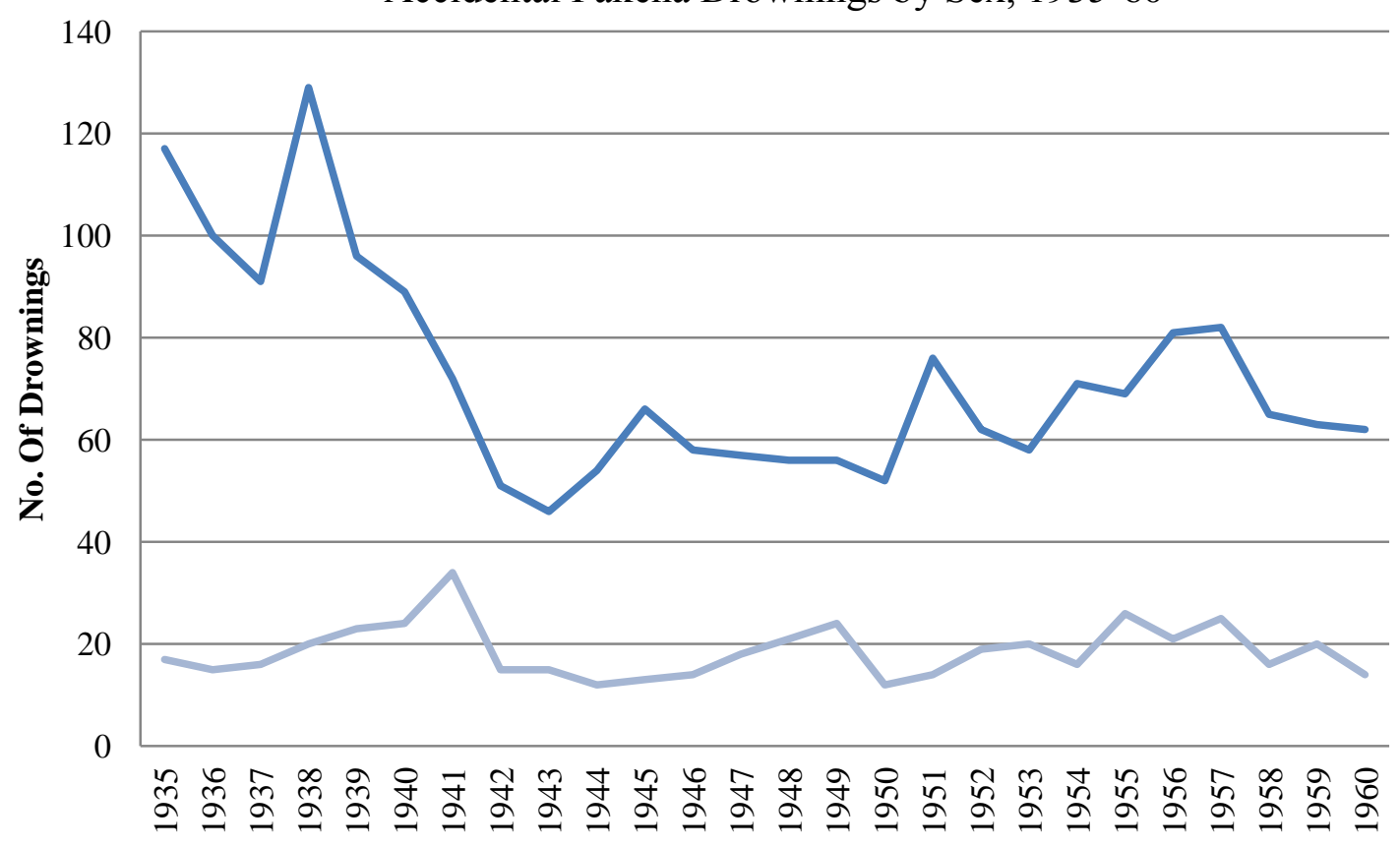
Year

Pakeha Males $\quad$ Pakeha Females

Statistics of New Zealand, 1935-1960.

Figure 6

Accidental Māori Drownings by Sex, 1935-60

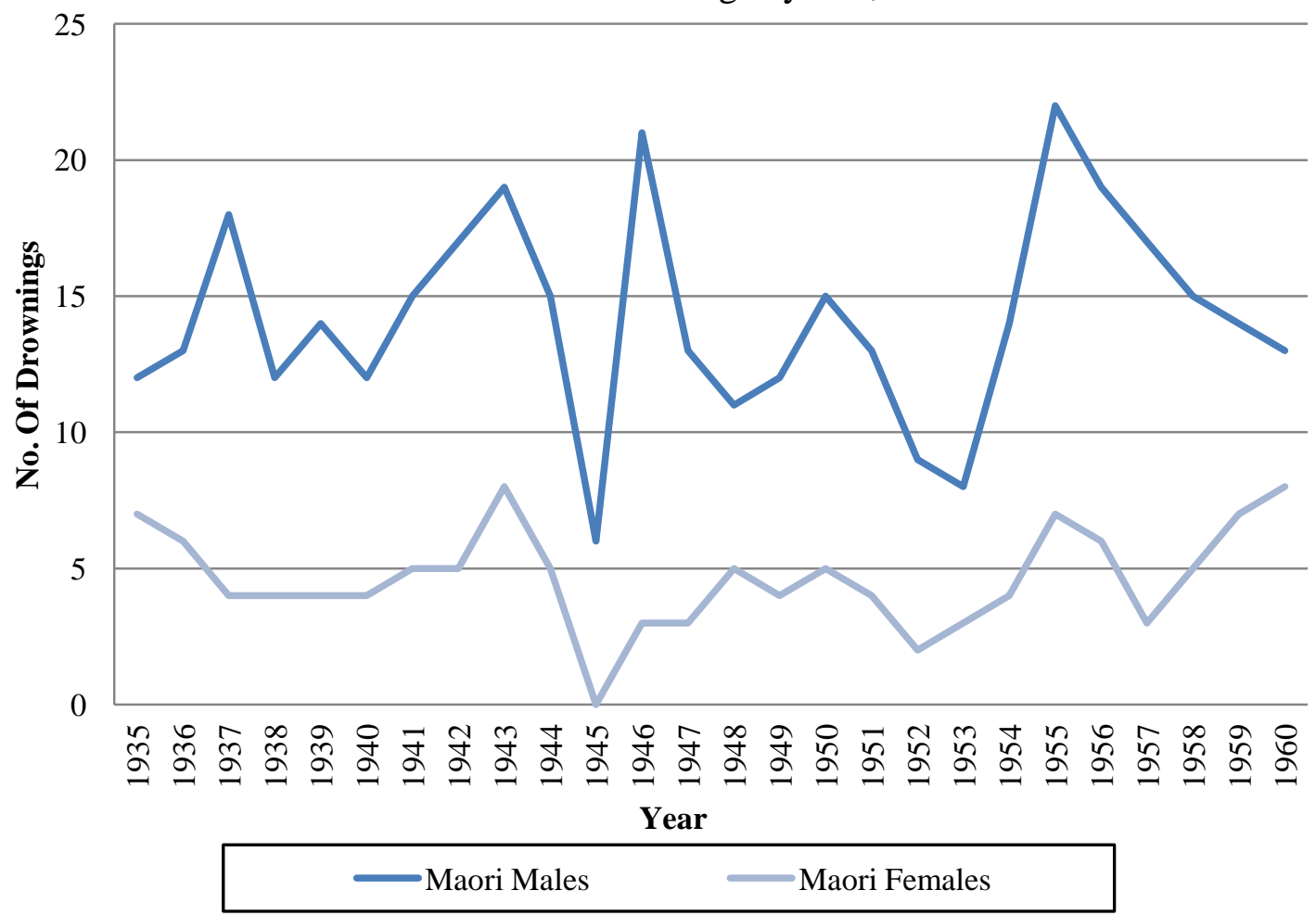

Statistics of New Zealand, 1935-1960. 
Figure 7

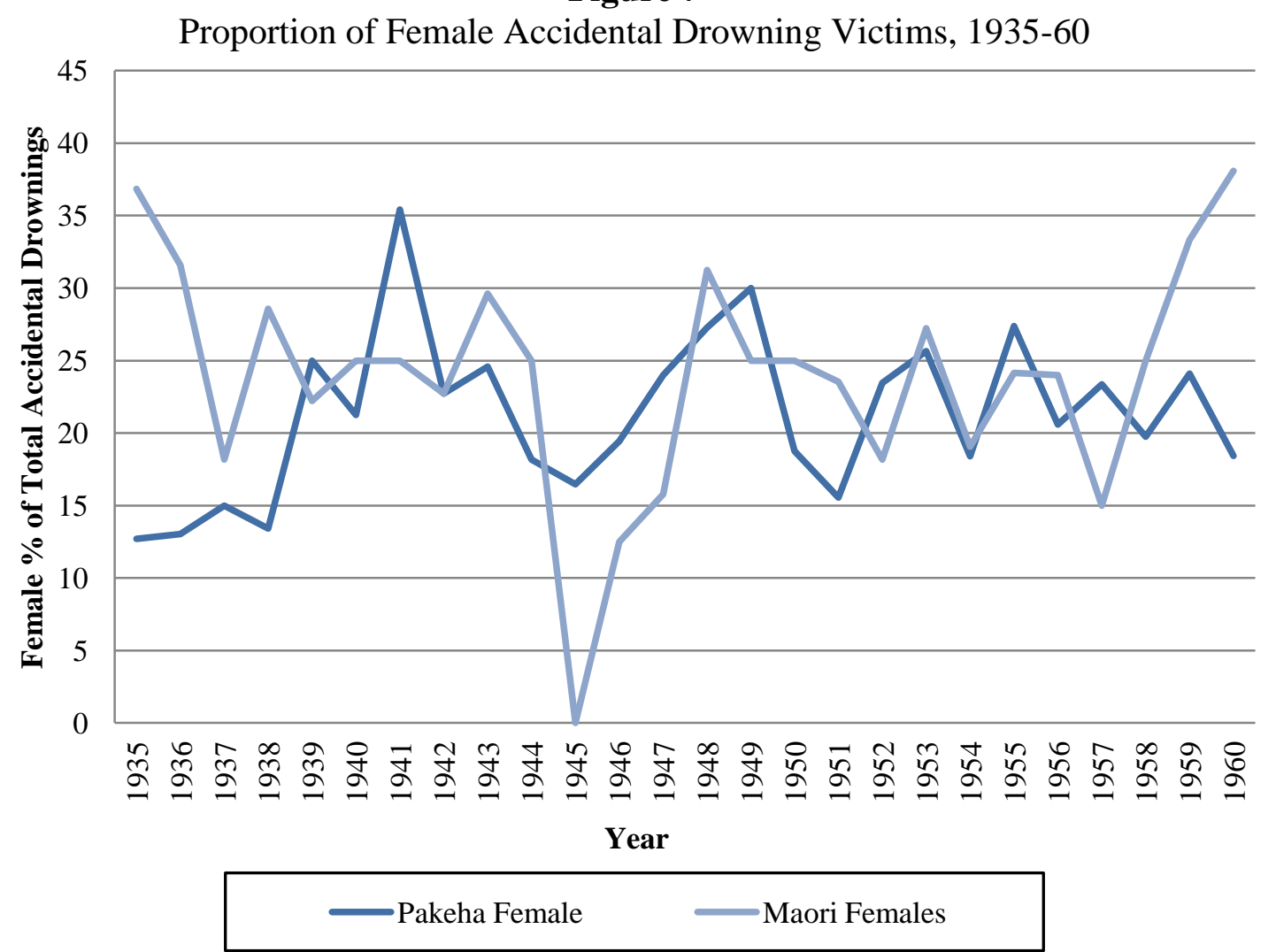

Statistics of New Zealand, 1935-60.

There are numerous reasons why Pākehā males drowned in fewer numbers in 1960 than in 1935. The long term social transformations New Zealand was undergoing in terms of work and workers, alongside changes to the country's rural and urban populations, may present the most immediate explanation. That is, as New Zealand continued its development from a largely agrarian society to a highly urbanised one, New Zealand's job market also changed and work in the traditionally male-dominated primary industries (i.e. mining, forestry, and agriculture) declined, reducing the opportunities to come into contact with bodies of water and thus to drown. In comparison, there was little change in the number of Pākehā females who drowned. However, the overall proportion of female drownings, which fluctuated between thirteen and twenty-seven per cent of all drownings, increased (figure 7). This situation suggests that the rise in the rate of female drowning victims was not a consequence of females' increased risk of drowning. Rather, because the number of male drowning victims declined, while the number of female drownings stayed relatively consistent, the ratio of female victims subsequently increased. 
The number of Māori male and female drownings which occurred between 1935 and 1956 fluctuated considerably, but there was a general rise in drowning numbers for both sexes (figure 6). This growth can possibly be explained as a proportionate increase corresponding to population growth. Although the number of Māori male drownings increased more than for females, the rising trend in the number of drownings among both sexes meant that there was little change in the proportion of female-to-male drownings among Māori (figure 7). As such, it could be argued that Māori did not undergo any shifts in gendered drowning risks during this period and thus perhaps did not experience any change in gender divisions with regard to interactions with the water in work and recreation in the mid-twentieth century.

Sadly, in the mid-twentieth century, children and youths (up to nineteen years of age) constituted a high proportion of New Zealand's drowning victims. During the 1935-1960 period, 968 Pākehā and 357 Māori children and youths drowned, accounting for forty-two and seventy-two per cent respectively of Pākehā and Māori deaths by drowning, or forty-eight per cent of the total accidental drownings. Children aged less than one year, and adults over the age of eighty, featured the least among New Zealand's drowning victims, which was possibly a consequence of their general lack of mobility, though this detail could and did result in drowning deaths among babies. The age group which was the most vulnerable to deaths by drowning was children aged one to four years (figures 8,9 , and 10). For both Māori and Pākehā, these children far outnumbered any other age group with regard to the frequency of deaths and comprised eighteen per cent of all drowning victims from 1935-1960. Overall, the risk of drowning decreased with age. However, there was a marked spike in drowning incidents among people aged fifteen to twenty-four. This trend among teenagers and young adults was well known in New Zealand at the time and was attributed to their apparent reckless, indomitable disposition which saw such individuals confidently swim 'out beyond the breakers or into a current, the strength of which he [sic] does not realise'. ${ }^{20}$

The high proportion of drownings among New Zealand's children and youths between 1935 and 1960 can partly be seen as relative to the size of the population of each age group; children constituted a high percentage of drowning

20 'This Swimming', The New Zealand Railways Magazine, Vol. 9, no. 11, February 1935, p. 42. 
Figure 8

Age at Drowning for Māori and Pākehā, 1935-60

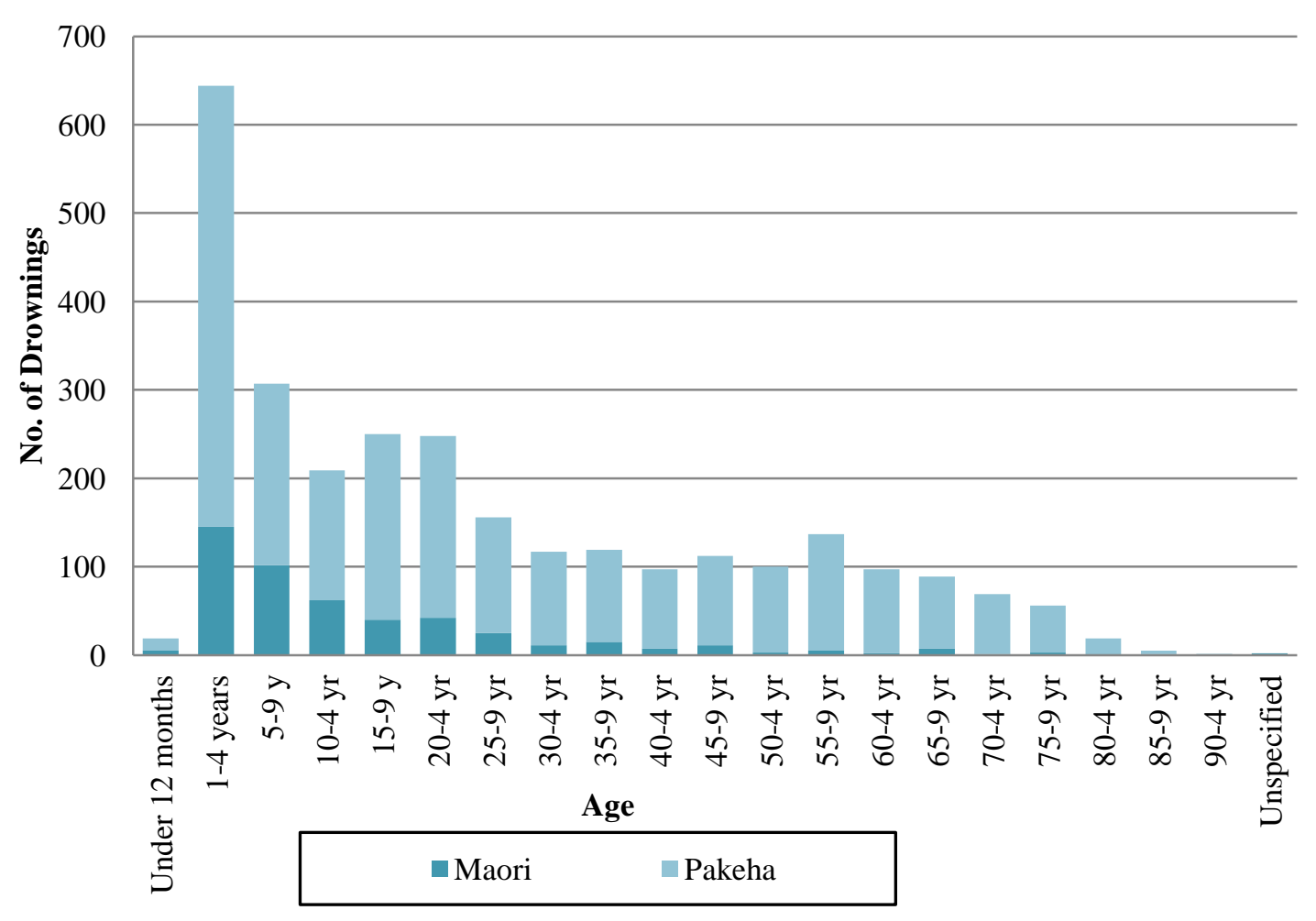

Statistics of New Zealand, 1935-1960.

Figure 9

Pākehā Child and Youth Accidental Drownings, 1935-1960

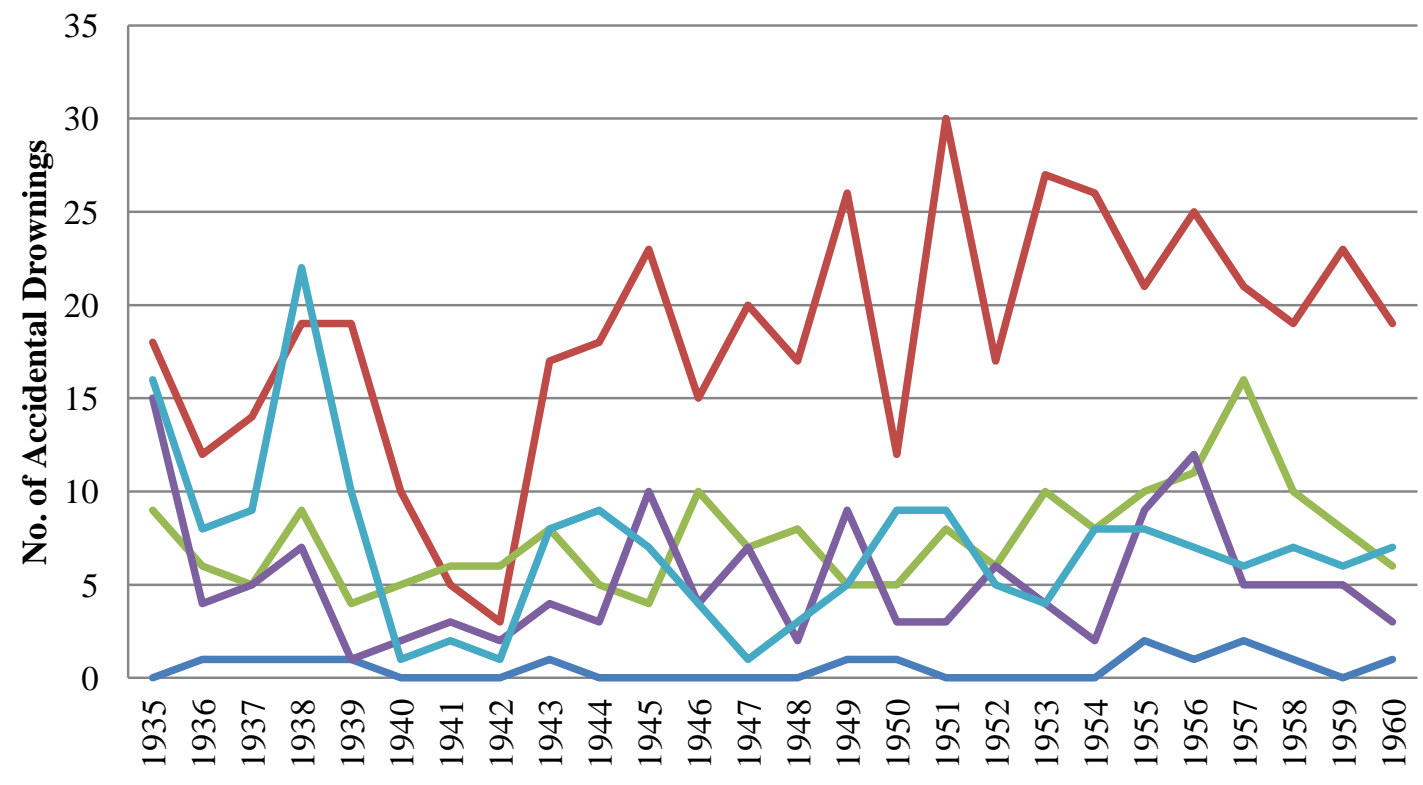

Year

\begin{tabular}{|ll|}
\hline Under 12 months & 1-4 years \\
10-14 years & 15-19 years
\end{tabular}

Statistics of New Zealand, 1935-1960. 
Figure 10

Māori Child and Youth Accidental Drownings

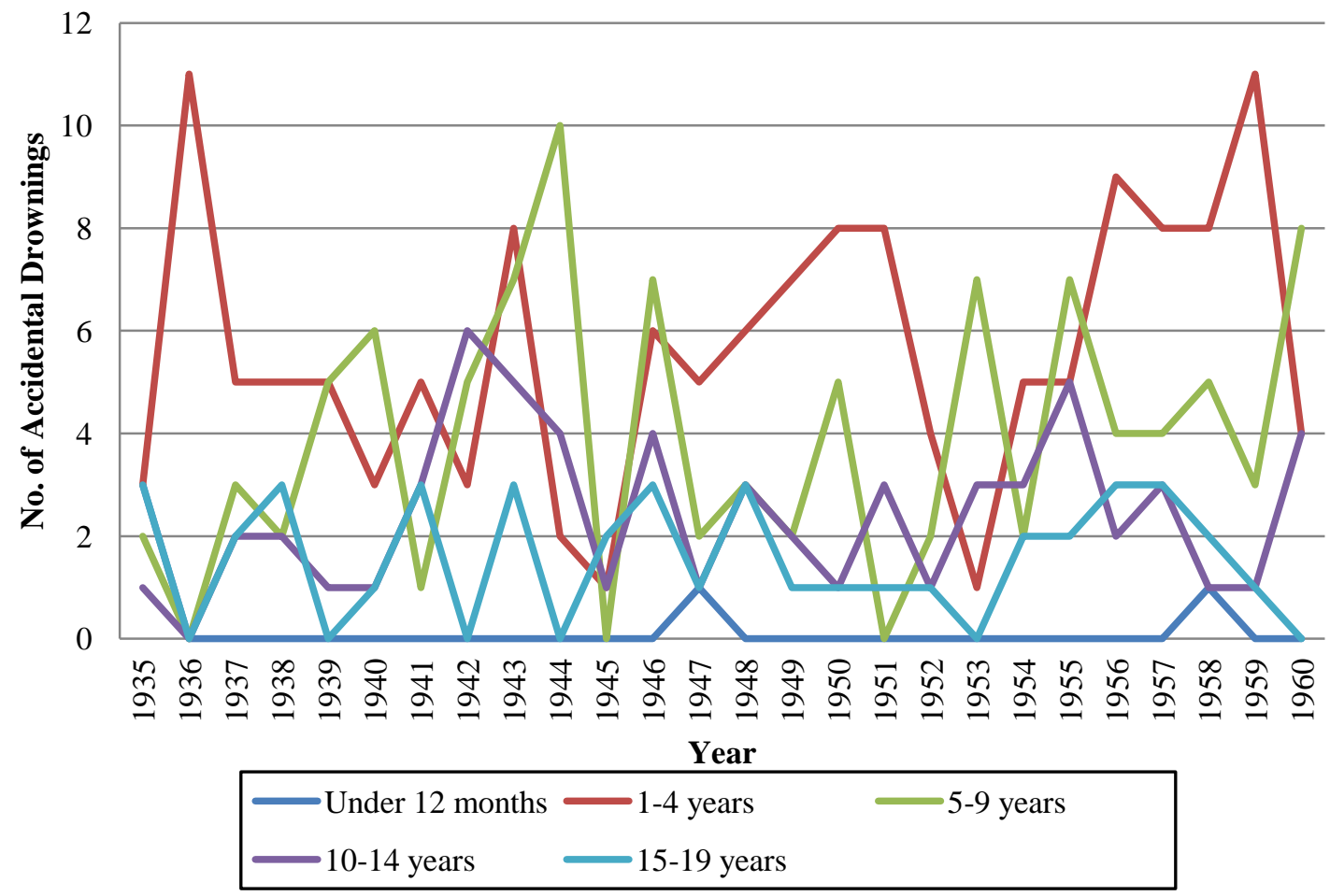

Statistics of New Zealand, 1935-1960.

victims but they also constituted a large proportion of New Zealand's population, especially after the baby boom began. ${ }^{21}$ The percentage of drowning deaths that Māori children and youths represented from 1935-1960 was tragically and stunningly high. But it is important to see this in the context of the Māori birth rate. Before, during, and after the baby boom, the Māori birth rate was significantly higher than the Pākehā rate. ${ }^{22}$ This led to Māori having a massive child and youth population. In 1956 'approximately one-half of the Maori population was under 16 years of age ... and only about 8 per cent were 50 years of age and over' ${ }^{23}$ In that same year, children younger than fifteen accounted for thirty-seven per cent of Māori drowning victims, but made up almost half of the population. Thus, Māori children were "underrepresented" in the drowning statistics.

During the 1935-1960 period though, drowning deaths became proportionally more prevalent among New Zealand's child and youth populations

\footnotetext{
${ }^{21}$ John Wilson, 'New Zealand's Aging Population', Te Ara - Encyclopedia of New Zealand; http://www.teara.govt.nz/en/society/1/2 [accessed 12 September 2011].

${ }^{22}$ Statistics New Zealand, Baby Boomers (Wellington: Statistics New Zealand, 1995), p. 13.

${ }^{23}$ Ministry of Works, Town and Country Planning Branch, A Survey of New Zealand Population: An Analysis of Past Trends and an Estimate of Future Growth (Wellington: Town and Country Planning Branch - Ministry of Works, 1960), p. 32.
} 
in wider society. In 1936, twenty-six per cent of the total population were aged fifteen or younger, and twenty-five per cent of drowning victims were aged less than fifteen years. By 1956, thirty-one per cent of the population were younger than sixteen, but fifty per cent of drowning victims were aged fourteen or under. ${ }^{24}$ Thus, over the 1935-1960 period, as New Zealand's child population increased, so too did the proportion of young drowning victims. However, child drownings increased at a faster rate than did the population. This overrepresentation may have been a result of New Zealand's large and youthful population having more hours and opportunities to be around water, which became increasingly the case during this period, and thus exposed to water hazards.

Another aspect which possibly contributed to the fact that zero- to nineteen-year-olds accounted for almost half of New Zealand's drowning deaths (while twenty to eighty-nine-year-olds all up comprised fifty-two per cent of drowning victims) is the differing skill sets between adults and children. That is, children did not have the same level of swimming competence or rational thinking/safety knowledge that (some) adults had and practised in order to avoid getting into dangerous situations or to get out of those situations. Such a deficiency in knowledge and aptitude would have rendered children more vulnerable to drowning than adults. Unfortunately, this position was not helped by the limited degree of swimming education offered in New Zealand, though it was during this 1936-1956 period that that situation began to change.

In the early twentieth century, swimming/bathing 'was the major summer sport' and recreation for children. ${ }^{25}$ However, swimming ability was, according to official records, far from widespread. ${ }^{26}$ In 1936, the National Committee of Swimming and Life Saving conducted a nation-wide survey of 1,920 primary schools. They found that only twelve per cent of children leaving primary school

\footnotetext{
${ }^{24}$ These calculations were made using population data from census figures presented in Statistics of New Zealand, Population Census, 1936, 1956.

${ }^{25}$ Brian Sutton-Smith, A History of Children's Play, New Zealand 1840-1950 (Wellington: New Zealand Council for Educational Research, 1981), p. 129.

${ }^{26}$ Aporo Joyce, who grew up in Hokianga in the 1940s and 1950s, maintains that actually '[a]ll the kids in those days knew how to swim', despite a lack of a public pool or formal swimming instruction (Aporo Joyce, interviewed by Jessica Maynard, 7 October 2011, in Tawa, Wellington). Everyone who contributed their stories as part of the research for this thesis was similarly adamant that every child knew how to swim in the mid-twentieth century. Such claims are thus, out of sync with contemporary records and may simply be a nostalgic remembrance of the past. However, it was more likely that these different accounts of swimming ability are a consequence of the different definitions and understandings of swimming that existed during the period.
} 
were certified as proficient swimmers (i.e. able to swim 220 yards), and only twenty-seven per cent were able to swim twenty-five yards, while forty-five per cent of students claimed to be able to swim but were not certified. ${ }^{27}$ In another survey conducted in the summer of 1938/9, it was discovered that forty-three per cent of children in Standard 4 and above in 195 schools were unable to swim. ${ }^{28}$ Similar claims also pervaded New Zealand's newspapers. Though on a positive note, the Evening Post reported in 1939 that at Wellington's Karori School, before their school pool was built in 1936, 'only 14 per cent of the children attending the school stated that they could swim ... Now a total of 284 pupils out of a school roll of 406 can swim 25 yards or over'. ${ }^{29}$ No records exist regarding adult swimming ability during the mid-twentieth century, but contemporary reports about children's swimming capabilities suggest that a substantial number of children were defenceless against the drowning risk. ${ }^{30}$ Thus, such reports fit with the drowning figures in revealing that drowning posed a serious threat to children.

It was the deaths of children that were of greatest concern to New Zealanders with regard to the occurrence of drowning in the mid-twentieth century; the fact that drownings were more common among males than females and among Māori than Pākehā was of little relevance to the perceived drowning problem. The Gisborne Times told it readers in 1937 that

This position [the frequency of drowning deaths] is a serious one in a country like New Zealand, with its long coastlines, and the 'Learn To Swim' week is an important step in the prevention of what, after all, is the needless loss of life of the pick of the country; for bathers as a rule are either children or young men and women. ${ }^{31}$

\footnotetext{
${ }^{27}$ R. N. Akel, 'Public Health Survey of Baths of Wellington City and Environs and the Learn-toSwim Campaign', Preventive Medicine Dissertation, University of Otago, 1939, pp. 168-9. Those 'uncertified' swimmers, who were the majority in New Zealand, were children who, rather than learn at the hands of professional instructors or teachers, were taught how to swim by parents, older siblings, or friends. Or they taught themselves, like Whangarei-resident Marie Terry, who learnt to swim 'by being part of a group (osmosis)' at Oherai beach in the late 1930s (Marie Terry to Jessica Maynard, 19 October 2011).

${ }^{28}$ National Committee of Swimming and Life Saving, 'Report on Drowning Fatalities, 1939-40, Wellington, 1941', IA 1, 2934, 139/7/15, part 8, ANZW.

29 'Effect of Baths', EP, 14 April 1939, p. 17.

${ }^{30}$ Although no comprehensive evidence exists to suggest that learning to swim actually lessens the chance of drowning, swimming ability is generally considered to be a means of preventing drowning deaths.

31 'Learn to Swim Week', Times, 30 November 1937, IA 1, 2932, 139/7, part 1, ANZW.
} 
Although children became more conspicuous among the country's drowning victims between 1936 and 1956, drowning did not become a more prominent cause of death, and nor were children overrepresented in the drowning figures when the Learn-to-Swim campaign began.

Alarm over child and youth deaths by drowning was a manifestation of New Zealanders' perceptions of mortality, accident, and prevention. Since the late nineteenth century, child wellbeing and welfare had become increasingly important matters and were seen as vital to New Zealand's growth. Prior to the 1880s, married Pākehā women had, on average, nine births. ${ }^{32}$ However, '[b]etween 1881 and 1926, the rate of child-bearing among women aged fifteen to forty-five years more than halved'. ${ }^{33}$ This decline was in part a consequence of improvements in infant mortality. In 1901, for instance, the death rate per 1,000 population for children under one year was seventy-nine for males and sixty-four for females. By 1937, this rate had fallen to thirty-seven for males and twenty-seven for females. ${ }^{34}$ In addition, life expectancy increased, thanks to better sanitation and disease control. At the end of the nineteenth century, twenty per cent of the population died by the age of thirty, but by 1930 , that percentage had halved. ${ }^{35}$ As a consequence of these developments, New Zealanders increasingly expected their children to live into adulthood, and this removed the necessity of having large families to compensate for the deaths of some children. ${ }^{36}$ Although the declining birth rate suggested that the quality of life was improving, eugenicists feared that the fall indicated that 'the Anglo-Saxon race was decaying'. ${ }^{37}$ In response, doctors, social reformers, and politicians began to take more of an interest in the lives of New Zealand's children and urged mothers to have more children and take better care of them to ensure the survival of the white race. The establishment of Plunket Society by Truby King in 1907 was one measure introduced as a means to improve 'the

\footnotetext{
${ }^{32}$ Jane Tolerton. 'Contraception and sterilisation - 19th-century contraception', Te Ara - the Encyclopedia of New Zealand; http://www.TeAra.govt.nz/en/contraception-and-sterilisation/1 [accessed 11 June 2011].

${ }^{33}$ James Belich, Paradise Reforged: A History of New Zealanders from the 1880s to the Year 2000 (Auckland: Allan Lane; Penguin, 2001), p. 181.

34 Statistics of New Zealand, The New Zealand Official Year Book, 1939; http://www3.stats.govt.nz/New_Zealand_Official_Yearbooks/1939/NZOYB_1939.html\#idsect1_1_ $\underline{36979}$ [accessed 20 June 2011]

35 Borrie, p. 180.

36 Ibid.

${ }^{37}$ Sue Kedgley, Mum's the Word: the Untold Story of Motherhood in New Zealand (Auckland: Random House, 1996), p. 40.
} 
quality, as well as the quantity, of the populace' by promoting 'women's maternal role' and informing mothers on how to feed and nurture their children based on scientific doctrines. ${ }^{38}$

Life expectancy and infant mortality continued to improve into the twentieth century, particularly in the post-World War II era, when, for instance, the manufacture of penicillin and streptomycin drugs offered effective treatment for diseases like tuberculosis which had plagued New Zealand in the nineteenth and early twentieth century. ${ }^{39}$ Such developments reinforced notions of the ability to stave off death. And the war itself, providing widespread experience of the heartbreak associated with a life cut short, further strengthened the resolve to prevent deaths, especially with regard to children.

As death was progressively seen as an event confined to old age, deaths by drowning, particularly among children, were increasingly seen as premature and thus fell outside the bounds of what was considered to be an acceptable death. ${ }^{40}$ The unexpected death of a child, whose life had been cut short, was ever more 'heart-breaking'; as death and drowning became less anticipated, their occurrence appeared more shocking. ${ }^{41}$ Thus, throughout the late nineteenth and early twentieth centuries, New Zealanders became firmer in the belief that drowning was a death that could and should better be prevented. ${ }^{42}$ In the mid-twentieth century, New Zealanders became even stauncher in this view, to the point where by the late 1950 s the 'incorrigible disregard of some [parents] for the safety of their youngsters during the swimming and boating season' was considered to be 'comparable with criminal neglect'. ${ }^{43}$ Child drownings, as unexpected, untimely, and tragic deaths, thus provided a prominent rationale for instituting the Learn-toSwim and Prevent Drowning campaigns.

\footnotetext{
${ }^{38}$ Bronwyn Dalley, Family Matters: Child Welfare in Twentieth Century New Zealand (Auckland: Auckland University Press, 1998), p. 14; Kedgley, p. 40.

${ }^{39}$ Catherine Coleborne, 'Health and Illness, 1840s-1990s', in Giselle Byrnes (ed.), The New Oxford History of New Zealand (Melbourne: Oxford University Press, 2009), pp. 501, 505.

${ }^{40}$ Philip Cleaver, 'Dealing with Death: The Pakeha Treatment of Death, 1850-1910', MA thesis, Victoria University of Wellington, 1996, p. 7.

41 'Water Wisdom is Common Sense', Bay of Plenty Times, 22 December 1956, IA 70, 4, 12, ANZW.

${ }^{42}$ Although partly established in response to changing leisure habits and perceptions of sport, it is interesting to note that the Amateur Swimming Association, the Royal Life Saving Society, and surf lifesaving clubs were all formed in New Zealand in the late nineteenth and early twentieth centuries, as concern about the quality and quantity of the Pākehā population was escalating.

43 'The Risks Our Children Take', Free Lance, 8 March 1957, IA 70, 4, 12, ANZW.
} 
Between the nineteenth and mid-twentieth century, New Zealand experienced massive change in the patterns and characteristics of drowning fatalities. Drowning went from being the most common cause of accidental death in the nineteenth century, to being the cause of one per cent of Māori deaths and less than one per cent of Pākehā deaths by 1960. From 1935-1960, drownings were more common among Māori than Pākehā and were also more frequent occurrences among the male than the female population. But there were no shifts in these patterns to suggest that drowning was becoming more of a problem for Pākehā or Māori, males or females. Children and youths accounted for a high proportion of drowning deaths between 1935 and 1960, and during this period they were increasingly overrepresented among New Zealand's drowning victims. But as the drowning rate was declining, drowning was less of a hazard for children in 1960 than it had been prior to the mid-1930s. Thus, the Learn-to-Swim and Prevent Drowning campaigns were not a response to a new or increasing problem, but to a perception that drowning deaths were too common. ${ }^{44}$ Essentially, death by drowning was seen as an ever more 'unacceptable' cause of death and was an increasing cause for concern, while the frequency of drownings declined. Therefore, drowning statistics in themselves do not explain why the Learn-to-Swim and Prevent Drowning campaigns were introduced when they were; something else was going on to warrant the existence of these campaigns.

This chapter has sought to explore New Zealanders' underlying unease about drowning deaths and drowning prevention. It argues that reactions to drowning fatalities are a socio-cultural issue, shaped by 'anxiety-inducing tensions' which are subject to change when 'the fears affecting our lives' become 'much stronger or much weaker ... The degree of anxiety, like the whole pleasure economy, is different in every society, in every class and historical phase'. ${ }^{45}$ If the campaigns were not technically a response to worsening drowning figures, what were they responding to? Why did drowning prevention and swimming ability become matters of national importance in the mid-twentieth century? The following chapter considers these questions.

44 'Drowning Still New Zealand Death', The Northland Times, 31 January 1959, IA 70, 4, 13, ANZW

${ }^{45}$ Norbert Elias, Eric Dunning, Johan Goudsblom, and Stephen Mennell, The Civilizing Process: Sociogenetic and Psychogenetic Investigations, 2d ed. (Oxford: John Wiley Professio, 2000), p. 326. 


\section{Chapter Two}

'We have accepted a great responsibility and pledged our organisation to the Government to do the work': a new approach to swimming education and drowning prevention ${ }^{1}$

In the late 1930s, New Zealand's drowning rate became the subject of prominent political concern. '[T]o my mind', Mark Fagan, a Labour Minister without portfolio, told his colleagues during a parliamentary debate on the Physical Welfare and Recreation Bill on 23 November 1937:

[T] here is [no sport] more useful, either during school life or in after years, than the sport of swimming ... it is not generally known that the deaths by drowning in the Dominion far exceeded the number of deaths due to accidents upon our roads ... In a country which is richly endowed with water this is a matter requiring urgent attention. ${ }^{2}$

And 'urgent attention' it did receive. This chapter examines the social and political factors that prompted sharper responses to drowning deaths and the lack of swimming inability in the mid-twentieth century. It investigates why and how the Learn-to-Swim and Prevent Drowning campaigns came into being, were managed, and progressed from the time of their launch in 1936 and 1949 respectively, to their demise in 1956. These campaigns, run and funded by the Physical Welfare Branch of the Department of Internal Affairs and New Zealand's swimming and lifesaving associations, were part of the 1935-1949 Labour Government's wider physical welfare agenda which sought 'to make bodies modern', that is, to reform and improve them. ${ }^{3}$ This chapter considers to what extent the state acted as a modernising agent within the domain of amateur swimming, why swimming was a priority in this period, and how the campaigns fit in with the Government's wider agenda. Ostensibly, the Learn-to-Swim and Prevent Drowning campaigns were a response to and represented the perception that drownings were too common and that swimming and being able to swim was a good thing. However, these notions existed long before and long after the campaigns were instigated. Therefore, the

\footnotetext{
${ }^{1}$ N. A. Ingram, National "Learn to Swim Campaign" circular, 19 November 1938, IA 1, 2933, 139/7/1, Archives New Zealand Wellington (ANZW).

${ }^{2}$ Mark Fagan, New Zealand Parliamentary Debates (NZPD), 23 November 1937, Vol. 249, pp. 610-1.

${ }^{3}$ Charlotte Macdonald, Strong, Beautiful, and Modern: National Fitness in Britain, New Zealand, Australia, and Canada, 1935-1960 (Wellington: Bridget Williams Books, 2011), p. 17.
} 
chapter asks why these campaigns were carried out from 1936 to 1956 . Why were swimming and drowning prevention seen as more important, and important enough to warrant greater funding and support? The following discussion examines the event which first signalled a shift in thinking about swimming and explores how that change came to light. The chapter then looks at how the Physical Welfare and Recreation Act came into being and its role in expanding recreational swimming culture.

The goal of promoting swimming as a recreation, and as a means to prevent drowning deaths, was not new in the 1930s. In the nineteenth century, attempts to prevent drownings primarily took the form of warnings (i.e. parents warning children against the dangers of the water) and 'making the environment safer': local authorities erected warning signs near danger spots, placed lamp posts and protective ropes along wharves, and provided life reels on riverbanks and beaches. ${ }^{4}$ In the $1890 \mathrm{~s}$, safety efforts became more defined. Concern about the declining birth rate, the increasing popularity of bathing, and more structured leisure in mechanised, urban society lay behind these changes. In 1890, the New Zealand Amateur Swimming Association was founded to promote swimming as 'a useful recreative exercise' and 'a means of saving life'. ${ }^{5}$ As the country's first national swimming body, its role was to teach swimming to club members and in some schools, and coach swimming as a sport. It also held swimming competitions and carnivals, and superintended, regulated, and standardised swimming practices. The Royal Life Saving Society of New Zealand was also established in the 1890s with the purpose of teaching rescue and resuscitation methods. On New Zealand's beaches, the work of the Royal Life Saving Society was supported by the establishment of surf clubs from 1910, a development which grew alongside the increasing popularity of sea bathing. By 1932, the surf clubs efforts in protecting lives were so extensive that they decided to break away from the Royal Life Saving Society and co-ordinate their work under a national body that could represent their distinctive aims. That organisation was the New Zealand Surf Life Saving

\footnotetext{
${ }^{4}$ Kevin Moran, The Shaping of Swimming and Water Safety Education in New Zealand (Auckland: Tradewinds, 2010), p. 26.

${ }^{5}$ New Zealand Amateur Swimming Association, Instruction of Public School Children in Swimming for Recreative Purposes and as a Means of Saving Life (Wellington: Government Printer, 1901), pp. 5-6.
} 
Association. ${ }^{6}$ Thus, by the 1930s, New Zealand had a well-established set of swimming, surf and lifesaving associations supporting New Zealanders' bathing habits.

These voluntary associations were a 'private' interest, as was the rest of the recreational domain. That is, it was an area of life that 'lay outside the purview of government'. ${ }^{7}$ Central government showed some interest in and support for the voluntary associations (with the exception of the Surf Life Saving Association), by providing subsidies that were erratic and discretionary in amount and consistency from the beginning of the twentieth century. ${ }^{8}$ This, however, was simply a sign of the state's acknowledgement of the value of the organisations' educational work, 'whose efforts are deemed to be in the public interest'. ${ }^{9}$ What was new about the approaches to swimming and drowning prevention formulated in the late 1930s was the intentions and level of government involvement.

In 1936, the National Committee of Swimming and Life Saving was established, on the suggestion of the Government, as a means to extend the scope of aquatic recreation in New Zealand and with the specific purpose of fostering a more formal link between central government and voluntary associations. In April of that year, W. E. (Bill) Parry, Minister of Internal Affairs, 1935-1949, set up a meeting with representatives from the Amateur Swimming Association, Royal Life Saving Society, and Surf Life Saving Association. The aim of the meeting was to discuss the possibility of forming a body, composed of representatives from each individual association, capable of overseeing the task of teaching recreational swimming and preventing drownings. Parry hoped that such a collaboration would reduce any duplication in the work of the associations and render the approach to

\footnotetext{
${ }^{6}$ Douglas Booth has noted that in New Zealand it was 'the rescue and safety component of the movement' that the clubs and association promoted, rather than the sporting side which dominated in Australia. He attributes this to the New Zealand clubs longer affiliation with the Royal Life Saving Society. Douglas Booth, 'Healthy, Economic, Disciplined Bodies: Surfbathing and Surf Lifesaving in Australia and New Zealand, 1890-1950', New Zealand Journal of History, Vol. 31, no. 1,1998 , p. 58.

${ }^{7}$ Macdonald, p. 26.

${ }^{8}$ It was not until the Labour Government was elected and introduced a new policy towards sport and recreation that the Surf Life Saving Association began to receive some government funding. Under-Secretary of Internal Affairs to Secretary to the Treasury, 1 October 1937, IA 1, 2128, 86/15, part 2, ANZW. New Zealand Surf Life Saving Association, Fourth Annual Report and Statement of Accounts, Season 1935-1936, Wellington, 1936, p. 11.

${ }^{9}$ Michael Bassett, The Mother of All Departments: The History of the Department of Internal Affairs (Auckland: Auckland University Press, 1997), p. 92.
} 
drowning prevention and swimming instruction more efficient. ${ }^{10}$ The Minister was also eager to initiate a federation of swimming and lifesaving organisations to act as a 'co-ordinating link between the Government and the three constituent bodies'. ${ }^{11}$ In other words, the group would operate as an advisory body to the Minister of Internal Affairs, alerting them to the areas in which more attention could be directed and more progress made.

In October 1936, despite some initial hesitancy from the associations, uncertain about the feasibility of directing the efforts of three divergent organisations under one body, the swimming and lifesaving bodies agreed to form the National Committee of Swimming and Life Saving. ${ }^{12}$ They hoped that through this partnership they would receive greater funding and support from the government, thereby enabling them to extend their work and status in New Zealand society. Within a month, thanks to suggestions from the Amateur Swimming Association, the committee decided that its overarching objective would be to educate 'the people as a whole to understand that swimming and bathing is most desirable', and 'to encourage the greatest use of swimming and bathing activities' and facilities, by managing a Learn-to-Swim campaign. ${ }^{13}$ In the summer of 1936/1937, the first campaign was organised by the National Committee of Swimming and Life Saving, carried out by the swimming association, and funded by the swimming and lifesaving associations. ${ }^{14}$ The 1936 meeting, the new committee that was formed, and the campaign that was launched rendered swimming and drowning prevention matters of national importance; they signalled the beginning of a distinct period of central government involvement in and commitment to New Zealanders' leisure and recreation.

\footnotetext{
${ }^{10}$ New Zealand Surf Life Saving Association, 'Notes of a Deputation which waited upon the Minister of Internal Affairs at Wellington on 27 th $^{\text {th }}$ April, 1936', IA 1, 2129, 86/15/2, part 1, ANZW.

${ }^{11}$ National Committee of Swimming and Life Saving, 'A Deputation from the above Committee waited on the Minister of Internal Affairs, the Hon. W. E. Parry, at Wellington, on November 13, 1941', IA 1, 2932, 139/7, part 2, ANZW.

${ }^{12}$ National Committee of Swimming and Life Saving, 'Report of National "Learn to Swim Week", December $5^{\text {th }}$ to $11^{\text {th }} 1937^{\prime}$, IA $1,2932,139 / 7$, part 1 , ANZW.

${ }^{13}$ N. A. Ingram to J. W. Heenan, 5 February 1939, IA 1, 2932, 139/7, part 1, ANZW; National Committee of Swimming and Life Saving, Report on Drowning Fatalities, November $1^{\text {st }}, 1948-$ April $30^{\text {th }} 1949$, J 1, 1601, 21/2/13, ANZW; National Committee of Swimming and Life Saving, New Zealand Report of Drowning Fatalities, November 1, 1949 to April 30, 1950, IA 70, 3, 7, ANZW.

${ }^{14}$ Each of the swimming and lifesaving associations gave $£ 20$ to the National Committee for the purpose of teaching swimming. New Zealand Surf Life-Saving Association, Sixth Annual Report and Statement of Accounts, 1937-1938 Season (Wellington: New Zealand Surf Life-Saving Association, 1938), p. 19.
} 
Parry's illustrious enthusiasm for the outdoors, exercise, and health was a major inspiration for his idea to foster a better relationship with New Zealand's swimming and lifesaving associations. However, the establishment of the National Committee of Swimming and Life Saving was more than a spontaneous decision on Parry's part to generate more opportunities for swimming and drowning prevention work. There was powerful public and political impetus behind it, tied up with the first Labour Government's wider political manifesto.

The election of the Labour Government in 1935 marked a shift in the nation's political direction, which had important and far-reaching consequences throughout New Zealand society, consequences which extended into recreational swimming culture. The Labour Government envisaged a very different role for the state to its conservative predecessors. A socialist party in its origins, Labour espoused 'a vision of a decent society which provided for the needs of its citizens' ${ }^{15}$ In order for such a society to be realised, Labour maintained that the state needed to accept responsibility as protector, promoter, and provider of 'every type of social and humane welfare'. ${ }^{16}$ Essentially, the Labour Government sought to ensure equality in opportunity.

Underlying Labour's redefinition of government duties was the belief that national advancement was 'based on human welfare', rather than simply and most importantly founded on the nation's economic health; if its citizens were not thriving, neither was the nation. ${ }^{17}$ As F. G. Dunn of the National Committee of Swimming and Life Saving remarked during Fitness Week in February 1939, the Labour Government's policies marked 'the beginning of a new age, and one where the ideal that wealth meant $£$ s. $d$. was changing to one where it meant the health of the people'. 18 'Every healthy citizen' was considered to be 'an asset to the nation', and as such, the state had a duty to invest in people's welfare - to make sure that its citizens always had access to medical care and decent housing, and never had to go

\footnotetext{
${ }^{15}$ Bronwyn Dalley, Family Matters: Child Welfare in Twentieth Century New Zealand (Auckland: Auckland University Press, 1998), p. 94.

${ }^{16}$ Janet Alexander, 'Recreation: An Inappropriate Concept for Legislation? An examination of two attempts at legislating for recreation in New Zealand: The Physical Welfare and Recreation Act 1937; and The Recreation and Sports Act 1973', Research Paper, Victoria University of Wellington, 1981 , p. 17.

${ }^{17}$ Hugh D. Buchanan, 'A Critical Analysis of the 1937 Physical Welfare and Recreation Act and of Government Involvement in Recreation and Sport, 1937-1957', MA thesis, Victoria University of Wellington, 1978, p. 1.

18 'No Room For Apathy', Ellesmere Guardian (EG), 28 February 1939, p. 5.
} 
without food. ${ }^{19}$ As part of the Labour Government's attempts to build up a welfare state, it introduced an array of ground-breaking social policies, including free medical care to all New Zealanders, the milk-in-schools scheme, state housing, universal superannuation, and an unemployment benefit for men and single women. It hoped that the security and stability such policies afforded would not only lead to happiness but would also make citizens productive and thus 'profitable to the nation to which he [sic] belongs' ${ }^{20}$ Thus, New Zealanders demanded a more active state after the failings of the Coalition Government during the Great Depression 'led to new public expectations of' the role of central government, but the state also demanded more of its citizens; Labour instigated a new era of social rights and civic responsibilities. ${ }^{21}$

One of these social rights was (useful) recreation. The Labour Government was a government of workers, and as such, it was also a Government for New Zealand's workers. A primary aim of the 1935-1949 Government was to improve working conditions and the general lives of workers. As part of this aim, the government realised that improving the conditions of non-working hours was also of benefit. The Labour Party consequently set about implementing and guaranteeing 'the "three eights": eight hours of work, eight hours of recreation, eight hours of sleep'. ${ }^{22}$ A unionist, miner, and sporting enthusiast, Parry was one of the most avid supporters of this manifesto. Along with the extension of the state's duties, providing for individual welfare and wellbeing, and democratising resources, New Zealanders' confirmed right to recreation provided the impetus for a new approach to swimming and drowning prevention.

The need for more leisure, and more constructive leisure, was also influenced by concerns about health. In the 1930s, the "healthy body culture" began to emerge in which bodies were seen as malleable, able to be reconstructed, replenished, and improved, and health came to mean not simply an absence of diseases, but the ability to 'enjoy life to the full' ${ }^{23}$ These notions were fundamental

\footnotetext{
${ }^{19}$ Joseph Cotterill, NZPD, 17 November 1937, Vol. 249, p. 527.

${ }^{20}$ William Parry, NZPD, 15 November 1937, Vol. 249, p. 415.

${ }^{21}$ Margaret McClure, A Civilised Community: a History of Social Security in New Zealand, 18981998 (Auckland: Auckland University Press, 1998), p. 48.

${ }^{22}$ Charlotte Macdonald, 'Ways of Belonging: Sporting Spaces in New Zealand History, 1840s to 2007', in Giselle Byrnes (ed.), The New Oxford History of New Zealand (Melbourne: Oxford University Press, 2009), p. 282.

${ }^{23}$ Macdonald, Strong, Beautiful, and Modern, p. 13. Parry, NZPD, 15 November 1937, Vol. 249, p. 418.
} 
to modern, urban society and to the Labour Government who saw maintaining and pursuing health as a duty of the state and of citizenship. ${ }^{24}$ However, it was an area in which the nation was seen to be failing greatly. An expression of 'growing fears about the risks associated with modernity', 'illness, both physical and mental, was [considered to be] the most far-reaching and the largest industry of all' in 1930s New Zealand. ${ }^{25}$ Regular outbreaks of diseases (i.e. influenza, infantile paralysis), the mutilated bodies of World War I soldiers, and apparently increasing rates of sickness, all in spite of the great leaps made in medical science, were seen to be proof that New Zealand was an unhealthy and fragile nation. ${ }^{26}$ This situation was largely attributed to urbanisation and 'the emergence of a supposedly effete urban lifestyle'. ${ }^{27}$ Not only were urban centres polluted, and morally dangerous, the trams and cars, ready supply of consumer goods, and factory and office work also allowed people to live more sedentary lives than ever before. It was this inactivity the use of 'the telephone, the motor-car, and the radio' - which 'lessened the use of our physical faculties' and caused 'a tremendous amount of remedial sickness and disability in the community'. ${ }^{28}$ However, rather than being seen as a sign of racial degeneration as had been the case in the late nineteenth century, medical professionals, social reformers, and politicians maintained that sickness, disease, and 'premature' deaths indicated that New Zealanders were struggling to adapt to and keep up with the new rhythms and demands of modern life. This could be rectified, though, by reconstructing bodies. In Parry's opinion, it was 'by the alliance of sport and social work that the best results' would occur. ${ }^{29}$ 'If machine regimentation is corrected by individual play', he asserted, 'normal conditions will be ours in spite of the increased mechanical tempo of life'; if people were fit and active in their leisure then the detrimental effects of inactivity in other areas of life

\footnotetext{
${ }^{24}$ Macdonald, Strong, Beautiful, and Modern, p. 117.

${ }^{25}$ Caroline Daley, 'Modernity, Consumption and Leisure', in Giselle Byrnes (ed.), The New Oxford History of New Zealand (Melbourne: Oxford University Press, 2009), p. 432. 1944 New Zealand, Physical Welfare and Recreation, statement by the Hon. W. E. Parry, Minister of Internal Affairs, presented to both Houses of the General Assembly by leave, IA 1, 2962, 139/188, ANZW.

${ }^{26}$ Macdonald, p. 13.

${ }^{27}$ Margaret Tennant, 'Children's Health Camps in New Zealand', Social History of Medicine, Vol. 9, no. 1, April 1996, p. 72.

${ }^{28}$ Dr. Michael Watt, 'Report of the Meeting of the National Council of Physical Welfare and Recreation, First Meeting, 24 May, 1938', p. 3, IA 70, 2, 5, ANZW; Sidney Holland, NZPD, 17 November 1937, Vol. 249, p. 520.

29 'Physical Welfare and Recreation Scheme', New Zealand Railways Magazine, Vol. 13, no. 3, June 1938, p. 64.
} 
would dissipate. ${ }^{30}$ Within this frame of thinking, swimming acquired new significance as a social good for the Labour Government because, as Parry later explained, 'whatever is spent on swimming and life-saving goes to building better citizens: persons more physically fit and more valuable to the community'. ${ }^{31}$

The National Committee of Swimming and Life Saving was, however, only the first step in Parry's larger ambitions to create 'a nation whose people were happy, healthy, physically fit and of sound physique'. ${ }^{32}$ His main contribution to the Labour Government's welfare policy was the Physical Welfare and Recreation Act, which facilitated an expansion of the government's influence in New Zealanders' leisure. This Act proved to be of major significance for New Zealand's recreational swimming and drowning prevention culture.

One of the arguments behind the Physical Welfare and Recreation Act was the need for a new leisure culture in a society with more leisure hours. In 1936, the Industrial Conciliation and Arbitration Act introduced the forty-hour week into New Zealand. This brought with it 'a new ideology of socially and economically useful leisure'. ${ }^{33}$ The reduction of working hours was part of an international movement to improve conditions for workers, but was also seen as a partial solution to the circumstances which had contributed to the Great Depression fewer working hours would reduce the potential for overproduction while allowing for increased consumption. This measure was welcomed as a necessity for a modern, capitalist nation such as New Zealand, not only because of the potential for increased consumption, but because it allowed for greater productivity overall. As Colonel James Hargest, MP for Awarua, explained in 1937, a 'factory system that does not provide for a forty-hour week is certainly not conducive to the physical well-being of a nation' as fatigued and thus unhappy workers were inefficient, unproductive, and more likely to fall ill. ${ }^{34}$ Rational recreationists maintained, however, that leisure hours 'might be absolutely useless unless we

\footnotetext{
${ }^{30}$ Proposed National Council: Address by the Minister of Internal Affairs, the Hon. W. E. Parry, and Report of Proceedings of a Meeting of Representatives of New Zealand and Wellington Controlling Bodies of Sport, held at Parliament House, Wellington, 4 March, 1937 (Wellington: Government Printer, 1937), p. 3.

${ }^{31}$ Notes for a speech to be delivered by the Hon. Minister of Internal Affairs, 26 October 1940, IA1, 2933, 139/7/2, ANZW.

${ }^{32}$ Buchanan, p. ii.

${ }^{33}$ Kirstie Ross, 'Signs of Landing: Pakeha Outdoor Recreation and the Cultural Colonisation of New Zealand', MA Thesis, University of Auckland, 1999, p. 29.

${ }^{34}$ Colonel James Hargest, NZPD, 17 November 1937, Vol. 249, p. 517.
} 
have healthy means of using it' because a lack of occupation could to lead to social disorder (i.e. 'idle hands get into mischief'), while inactivity during leisure hours could also bring about further deterioration in New Zealanders' health. ${ }^{35}$ Thus, what was needed, to 'keep our men and women at work' and in good health, was sufficient leisure facilities and organised recreational pursuits which would encourage 'wholesome activities', something which New Zealand was frequently accused of lacking. ${ }^{36}$ In response to the 'problem of leisure', Parry introduced the Physical Welfare and Recreation Bill into Parliament in October 1937, rejecting the traditional belief that 'the way a man [sic] occupied his leisure time was ... immaterial to the affairs of a nation'. ${ }^{37}$ With consequences that effected health and social order, leisure time was too important to 'be left to the arbitrary whim of voluntary or private provisions' ${ }^{38}$

The aim of the Physical Welfare and Recreation Bill was, Parry explained, to provide the 'machinery for the physical welfare and recreation of our people'. ${ }^{39}$ That is, it set out to provide facilities for and encourage New Zealanders to participate in more physically active recreation during their leisure hours so that they would achieve a level of health and fitness conducive to a successful, modern life. The bill was intended to cater specifically to the recreational needs of the adult population. The 'first engagement by central government in adult sport and recreation', Parry's bill was revolutionary. ${ }^{40}$ Parry reasoned that children's wellbeing was the concern of the Education Department, while the Health Department was responsible for those who were already sick, but no government department had yet been assigned the task of ensuring the health and wellbeing of the rest of society, particularly school leavers, workers, and mothers. Although some people were suspicious of the state's intentions in legislating for recreation, seeing the Bill as introducing 'the soft end of conscription', leisure activities were still to be pursued on a voluntary basis. ${ }^{41}$ The Bill was intended to support the

\footnotetext{
${ }^{35}$ Cotterill, NZPD, 27 September 1945, Vol. 270, p. 283.

${ }^{36}$ Garnet Mackley, NZPD, 27 September 1945, p. 294. Dalley, p. 114.

${ }^{37}$ Under-Secretary of Internal Affairs to Hon. Minister of Internal Affairs, 25 September 1944, IA 1, 2962, 139/188, ANZW.

${ }^{38}$ Macdonald, Strong, Beautiful, and Modern, p. 70.

${ }^{39}$ Parry, NZPD, 15 November 1937, pp. 414-5.

${ }^{40}$ Ibid.

${ }^{41}$ Ibid., p. 29.
} 
efforts of sporting and recreational organisations in order to democratise recreation, health, and fitness.

Based on the national fitness legislation introduced in Britain in July 1937 , the Physical Welfare and Recreation Bill presented a plan 'to distribute funds to existing sporting and recreational associations, to encourage local authorities to provide sports grounds and swimming pools, and to foster the professional development of physical education'. ${ }^{42}$ As well as co-ordinating 'fitness programmes throughout the country', the work performed under the Physical Welfare and Recreation Act would be carried out by the Physical Welfare Branch, to be established under the administration of the Department of Internal Affairs. ${ }^{43}$ A National Council of Physical Welfare would also be formed to act as an advisory body to the Minister of Internal Affairs, who was the Chairman of the council, with regard to the allocation of grants and avenues for fitness promotion. The Under Secretary of Internal Affairs, the heads of the Health, Education, and Defence Departments, and ten representatives from various sporting and recreational organisations were to sit on the council. Much like the National Committee of Swimming and Life Saving, the National Council took none of the powers of the constituent bodies but acted 'for them on points of Dominion-wide interest, and in approaching the Government'. ${ }^{44}$

The desirability of building up a healthy nation was a goal that largely transcended party lines. Most politicians were in general agreement with Parry's assertion that the 'prosperity, happiness, health and physique of New Zealanders matter ... [that] a clean, physically fit, healthy, tolerant, moral nation' was key to national success. ${ }^{45}$ Still, the Physical Welfare and Recreation Bill 'implied a radical change' which 'was sufficiently threatening to arouse some opposition'. ${ }^{46}$ One of the greatest dissenting ideas against the Bill came from those who maintained that

\footnotetext{
${ }^{42}$ Ibid., p. 10. Grants were initially given on a basis of $£ 1$ for $£ 2$ with a limit of $£ 500$. Between 1937 and 1946, £10,000 was made available for grants under the Physical Welfare and Recreation Act and 'distributed in small grants mostly to assist promotion of new physical activities, such as volleyball, marching, indoor basketball, etc.' 'Grants - Physical Welfare and Recreation Act, 1937', IA 70, 1, 1, ANZW; Alexander, p. 33.

${ }^{43}$ Caroline Daley, Leisure and Pleasure: Reshaping and Revealing the New Zealand Body 19001960 (Auckland: Auckland University Press, 2003), p. 229.

44 'Learn-to-Swim', J. W. Heenan to W. Parry, 25 November 1938, IA 1, 2932, 139/7, part 1, ANZW.

${ }^{45}$ William Parry, in Report of the Meeting of the National Council of Physical Welfare and Recreation, First Meeting, 24 May, 1938, p. 2, IA 70, 2, 5, ANZW.

${ }^{46}$ Alexander, p. 43.
} 
sport and leisure sat 'outside the bounds of the state, [was] something designated as "private" and [should be] left to the vagaries and highly uneven discretion of independent associations'. ${ }^{47}$ However, swimming was the exception. It was an activity over which there was no debate as to its value and the need for it to become a more common pursuit.

Swimming was widely recognised as one of the healthiest, most beneficial sporting and recreational pursuits. As one member of the swimming association claimed, swimming brought 'into action the entire system, giving every part of the body its proportionate share of work', while developing and producing 'thoroughly and symmetrically ... supple, resilient, well rounded muscles'. ${ }^{48}$ Furthermore, swimming was a corrective tool for physical deformities and in taking up swimming, thereby creating a fit, healthy, attractive body, New Zealanders prevented deaths from 'TB and other avoidable diseases'. ${ }^{49}$ And because it was an activity that was practiced in water, swimming 'accomplishes what all other exercises do without the person being aware of the task' ${ }^{50}$ Its health benefits could be attained 'without putting any undue strain on the heart', joints, or muscles and was thus appropriate for people of all ages. ${ }^{51}$ But perhaps most importantly, Parry explained, swimmers were 'potential protector[s] of life in the community', both in being able to prevent themselves from drowning and by being able to rescue others. ${ }^{52}$ Swimming was touted as an enjoyable and 'invaluable' activity for men and women, 'especially in an island country like New Zealand with long stretches of seabeach and with treacherous mountain rivers in the interior'. '53 '[S] urely there could be no greater objective', the Gisborne Times noted in $1937 .{ }^{54}$ As such a valuable activity, Parry maintained that swimming could not be overlooked by the Government as 'a useful and necessary part of the qualifications of a citizen of

\footnotetext{
${ }^{47}$ Macdonald, p. 168.

48 'Swimming for Health', Ellesmere Guardian, 1 February 1938, p. 2.

49 Information for the Minister for the New Zealand Amateur Swimming Association Championships, New Plymouth, 25 January 1941, IA 1, 2932, 139/7, part 2, AZNW.

50 'Learn to Swim', Hawke's Bay Herald, 30 November 1937, IA 1, 2932, 139/7, part 1, ANZW.

${ }^{51}$ T. Harold Pettit, 1ZB, IA 70, 3, 11, ANZW.

${ }^{52}$ William Parry, New Zealand Amateur Swimming Championships, New Plymouth, January 25, 1941, IA 1, 2932, 139/7, part 2, ANZW.

${ }^{53}$ Baxter O’Neill, New Zealand Amateur Swimming Association: Official Swimming Instructor (Auckland: New Zealand Amateur Swimming Association, [1940]), p. 3. 'Learn to Swim Week', (Gisborne) Times, 6 December 1937, IA 1, 2932, 139/7, part 1, ANZW.

54 'Learn to Swim Week', (Gisborne) Times, 6 December 1937, IA 1, 2932, 139/7, part 1, ANZW.
} 
today'. 55 "A Government so concerned for the welfare of its people as the present Labour Government', a reporter for the Ellesmere Guardian wrote just after the Physical Welfare and Recreation Act was passed,

[S]hould find in the encouragement of swimming and life-saving one avenue for giving assistance, not only in a pleasurable and health-giving form of employing leisure hours in summer, but in training the people in facilities and knowledge which will save lives ... To make the bathing places of New Zealand safe by teaching the people to swim is surely just as much a function of government as making the roads safe for users by enforcing strictly the regulations that all motor vehicles should be driven by people possessing the requisite knowledge and reaching a certain standard of efficiency. ${ }^{56}$

Despite some unresolved reserve, tensions, and disagreements about how to reconcile government involvement in the autonomous domain of voluntary recreation, the Physical Welfare and Recreation Act passed on 23 November 1937. It 'enshrined in statute' the belief that 'New Zealanders needed to get fit ... for the sake of their health and that of the nation'. ${ }^{57}$ It was at this point that the Government fully acknowledged what the Amateur Swimming Association had claimed for years, that ' $[\mathrm{t}]$ he benefit of its [the swimming association's] work is the State's benefit'. 58

With the passage of the Physical Welfare and Recreation Act, the task of extending amateur swimming throughout New Zealand was intensified. The state assumed a direct role in providing New Zealanders with opportunities for recreational swimming. The 1936/1937 and 1937/1938 Learn-to-Swim campaigns were carried out independent of the Department of Internal Affairs as Parry did not have the resources to increase the state assistance beyond providing small grants to the swimming and lifesaving associations. However, from 1937, the Amateur Swimming Association, Royal Life Saving Society, and Surf Life Saving

\footnotetext{
${ }^{55}$ William Parry, New Zealand Amateur Swimming Championships, New Plymouth, January 25, 1941, IA 1, 2932, 139/7, part 2, ANZW.

56 'Teaching of Swimming', EG, 30 November 1937, p. 4.

${ }^{57}$ Daley, Leisure and Pleasure, p. 229.

${ }^{58}$ Baxter O’Neill, Swimming for Efficiency: A Cause that Lacks Assistance (Christchurch: New Zealand Amateur Swimming Association, 1919), p. 9.
} 
Association each received $£ 200$ annually through the Department of Internal Affairs, while the National Committee of Swimming and Life Saving was granted $£ 3,000$ per annum to carry out the Learn-to-Swim campaign. ${ }^{59}$ The first nationwide, state-funded Learn-to-Swim campaign was run in the summer of 1938/1939, with the help of 1,000 volunteers, who were recruited by Parry and trained as Learn-to-Swim swimming instructors. In the following years, once the Physical Welfare Branch was better established, Parry placed the services of its officers 'at the disposal of local swimming centres for the purpose of acting as instructors during "Learn to Swim Campaigns" and in training voluntary instructors in swimming teaching methods'. ${ }^{60}$ Physical Welfare Officers were also given the task of distributing Learn-to-Swim publicity material to the district and sub-committees of the National Committee of Swimming and Life Saving, of which there were eighty by $1939 .{ }^{61}$ Essentially, Physical Welfare Officers became the committee's field workers.

Unfortunately, the outbreak of World War II put a halt to much of the work that the Physical Welfare Branch did in promoting and providing physical recreation as 'the resources of government were quickly turned to supporting New Zealand's fighting troops and wartime production'. ${ }^{62}$ Rather than providing activities for general recreation, Physical Welfare Officers focused their attention on the war effort, running exercise classes for men in military training camps and establishing leadership training programmes for the Home Guard, Emergency Air Training Corps, and the Women's War Service Auxiliary, among others. As part of this wartime work, swimming lessons were also incorporated into Physical Welfare Officers' endeavours.

Prior to 1941 , being able to swim was not a requirement for joining the armed forces, nor was swimming generally included within military training, even in the navy. According to former Wellington resident, William Moore, when he signed up to the navy in 1941 'they asked you "Could you swim? Yes or no?" ... [but] nobody thought that you shouldn't join the navy because you couldn't

\footnotetext{
${ }^{59}$ J. Heenan to W. Parry, 25 November 1938, IA 1, 2932, 139/7, part 1, ANZW.

${ }^{60}$ Physical Welfare Bulletin, August 1947, IA 70, 6, 22, ANZW.

${ }^{61}$ N. A. Ingram to J. W. Heenan, 5 February 1939, IA 1, 2932, 139/7, part 1, ANZW.

${ }^{62}$ Macdonald, Strong, Beautiful, and Modern, p. 81.
} 
swim'. ${ }^{63}$ Drowning was not a common cause of death among New Zealand soldiers overseas during the Second World War but drownings did occur and such deaths sparked considerable public distress and calls for greater attention to be paid to swimming ability, drowning prevention, and resuscitation within the armed forces. ${ }^{64} \mathrm{New}$ Zealand needed all the men it could to defend the nation and its allies, so to lose valuable lives through drowning 'at sea on transports, or from bathing accidents' was seen as not only tragic but wasteful. ${ }^{65}$ In response to such deaths, some regiments serving overseas organised their own surf lifesaving teams. ${ }^{66}$ While the Physical Welfare Branch could not do anything to help those who were fighting overseas, Physical Welfare Officers ran classes on how to perform resuscitation and gave swimming instruction to those in, for instance, the Air Training Corps. ${ }^{67}$ Parry told Parliament in 1944 that in Dunedin, 'a city well known for active interest in swimming, the percentage of [air training] cadets who were not able to swim a stroke when they joined the Corps ranged from 33 to 40, and there was a similar percentage of poor swimmers'. But thanks to the Physical Welfare Officers' efforts, 'a good standard of swimming was achieved'. ${ }^{68}$ Furthermore, 'owing to continued efforts on' Parry's part in appealing to the Minister of Defence, it 'became imperative [in 1941] that before completing training our soldiers must have learnt to swim'. ${ }^{69}$ After the war's end, Physical Welfare Officers helped to provide swimming instruction to recruits at the Trentham army base. The war reinforced the notion that swimming ability was a matter of 'national importance', 'something that everyone must realise for the good of the country' ${ }^{70}$

Despite the focus on the war effort, Learn-to-Swim campaigns continued and Physical Welfare Officers provided some Learn-to-Swim lessons. In Auckland,

\footnotetext{
${ }^{63}$ William Moore, interviewed by Jessica Maynard, 23 September 2011, in Waikanae, Kapiti Coast. Two possible explanations for the disinterest shown in recruits' swimming ability are that it was simply expected that people could already swim, or it was not seen as part of the navy's role to teach swimming/swimming ability was a 'private' matter.

${ }^{64}$ F. H. Jackson, National Committee of Swimming and Life Saving, Report on Drowning Fatalities 1940-1941, IA 1, 2932, 139/7, part 2, ANZW.

${ }^{65}$ T. H. Pettit, 'Report on Resuscitation Instruction', IA 1, W5278, 177, 139/7/4, ANZW.

${ }^{66}$ Ibid.

${ }^{67} 1944$ New Zealand, Physical Welfare and Recreation statement by the Hon. W. E. Parry, Minister of Internal Affairs. Presented to both houses of the General Assembly by leave. H-22B, IA 1, 2962, 139/188, ANZW.

68 Ibid.

${ }^{69}$ Doreen Brown to W. E. Parry, 12 November 1941, IA 1, 2932, 139/7, part 2, ANZW.

${ }^{70}$ Grace ('Hilda') Ross, NZPD, 27 September 1945, Vol. 270, pp. 277-8.
} 
a notable contribution was made to the Learn-to-Swim effort by Physical Welfare Officer, Gladys Gebbie, who ran the Splash Club, a very successful swimming and diving club for women over the age of forty 'to whom the existing sports clubs and public facilities did not necessarily appeal'. ${ }^{71}$ However, the campaigns during wartime were carried out on a much smaller scale than had been the case with the 1938/1939 campaign. The National Committee of Swimming and Life Saving had to rely almost solely on the voluntary swimming and lifesaving associations. The diminished size of the Learn-to-Swim campaign was not, though, simply due to interruptions caused by the war.

Tensions had been mounting within the National Committee of Swimming and Life Saving since the state began funding the Learn-to-Swim campaign. The swimming, lifesaving, and surf lifesaving associations were three distinct organisations and although they agreed to combine forces under the national committee, all three continued to guard 'their interests with a fierce and proud independence'. ${ }^{72}$ The swimming and lifesaving associations persisted in approaching the government as individual bodies, despite the national committee's specific purpose being to form one body with which the Government could deal and thus obtain a better idea of where funding and energy needed to be directed. The associations claimed that they felt that 'they were being neglected if they were not dealt with direct[ly] by the Government'. ${ }^{73}$ This situation partly arose as a result of the fact that the national committee's work was so heavily absorbed by the swimming association, while the Royal Life Saving Society and Surf Life Saving Association were treated as subsidiary. Thus, little co-ordination existed within the National Committee of Swimming and Life Saving. Senior Physical Welfare Officer, C. Ruxton Bach noted in 1941 that '[t]he men who are both public men and members of the associations concerned, do not appear at its [the national committee's] deputations or express its findings'. ${ }^{74}$ Bach even suggested that funding to the Learn-to-Swim campaign be cut because 'grants cannot be justified as in the past', as less attention was given to the campaign within the national

\footnotetext{
${ }^{71}$ Macdonald, Strong, Beautiful, and Modern, p. 83.

${ }^{72}$ Ibid., p. 75.

73 'National Committee of Swimming and Life Saving: A Deputation from the above Committee waited on the Minister of Internal Affairs, the Hon. W. E. Parry, at Wellington, on November 13, 1941', IA 1, 2932, 139/7, part 2, ANZW.

${ }^{74}$ C. Bach to Under-Secretary of Internal Affairs, 21 November 1941, IA 1, 2932, 139/7, part 2, ANZW.
} 
committee. ${ }^{75}$ In response to the escalating problems, Parry decided to hold a meeting in 1941. He told the national committee that he was still in favour of its existence because '[i]t was easier for him to deal with one national body than with a number of units', but he 'left the decision of whether the National Committee should carry on or go out of existence in their own hands'. ${ }^{76}$ Fearing that disbandment would result in a lessening of government support and funding for the swimming and lifesaving associations, the committee decided carry on. However, no changes were made to improve the situation. As such, the National Committee of Swimming and Life Saving was essentially, if not officially, terminated. This put considerable strain on the relationship between the government and the voluntary associations.

For the Physical Welfare Branch, the aim of the Learn-to-Swim campaign was to teach adults how to swim. However, thanks in part to the emphasis the national committee placed on schools, the large majority of participants in Learnto-Swim lessons were children. Consequently, from the 1940s, when the Education Department took 'over the responsibility for seeing that children learn to swim [during the school year], a responsibility in the past, from a Government point of view, [which] was in the hands of the Department of Internal Affairs', the Learn-toSwim campaign lost much of its urgency within the Physical Welfare Branch. ${ }^{77}$ Since the 1880s, swimming had been taught in some schools as a means of health, hygiene, lifesaving, and physical correction. However, taught sporadically and haphazardly, swimming instruction did not occupy a prominent place within the school curriculum, which was not helped by a lack of (suitable) swimming facilities. ${ }^{78}$ Under the direction of politicians Peter Fraser, Walter Nash, and the Director of Education, Clarence Beeby, New Zealand's education system

\footnotetext{
${ }^{75}$ Ibid.

76 'National Committee of Swimming and Life Saving: A Deputation from the above Committee waited on the Minister of Internal Affairs, the Hon. W. E. Parry, at Wellington, on November 13, 1941', IA 1, 2932, 139/7, part 2, ANZW.

${ }^{77}$ C. Ruxton Bach to Under-Secretary of Internal Affairs, 21 November 1941, IA 1, 2932, 139/7, part 2, ANZW.

${ }^{78}$ Swimming was first included in the Syllabus of Physical Instruction in 1920, when New Zealand adopted the 1919 syllabus from Britain. Kevin Moran, 'The Shaping of Aquatics Education in New Zealand Schools: An Historical Study of Curriculum Policy and Practice', M.Ed thesis, Massey University, 1999, p. 107. Still, it was not a compulsory subject. The Evening Post noted in 1936 that there was a general 'rule that in standards 1 and 2 [Year 3 and 4] swimming should be taught if possible; in standard 4 [Year 6], where the facilities exist, there is provision for the instruction of boys and girls; and in forms 1 and 2 (standards 5 and 6) [Year 7 and 8] the syllabus says that swimming and life-saving teaching should be carried out'. 'Swimming Tuition', Evening Post, 24 October 1936, p. 10.
} 
underwent substantial reform from the late 1930s in an attempt to 'extend the existing curriculum, ${ }^{79}$ so that it was not so heavily academic-based, instilling the curriculum 'with the country's democratic ethos'. ${ }^{80}$ As part of this transformation, physical education gained new importance. In 1939, the Physical Education Branch of the Education Department was established. In February 1939, Ken Reid, a Senior Organiser of Physical Education who was also involved in the Learn-toSwim campaigns, met with the Principal of Cornwall Park School in Auckland to discuss 'the desirability of swimming facilities in Primary Schools' ${ }^{81}$ Reid had an idea to build smaller, less expensive swimming pools which would allow swimming instruction to become more widespread in schools. Within two weeks of the initial discussion, New Zealand's first Learners' Pool (30 feet x 12 feet x 3 feet) was constructed at Cornwall Park School. This miniature pool was touted as being infinitely superior to regular-sized swimming pools as it 'required no [extensive] excavation, can be built in a few days, and costs no more than a fairly good school piano'. ${ }^{82}$ A larger, deeper pool, Dudley Wills, Superintendant of Physical Education, would later explain, was not necessary as the aim of school swimming was 'to have every child a competent swimmer when he [sic] enters Junior High school ... We are not concerned at any stage with finding champion swimmers' ${ }^{83}$ The Department of Education expressed great enthusiasm for Reid's Learners' Pool and in 1941, the department introduced a pound-for-pound subsidy up to $£ 200$ for their construction. ${ }^{84}$ Hundreds of schools across New Zealand took the Government up on its offer during the 1940s and 1950s. By 1963, there were 1,136 Learners' Pools in primary schools, twenty-five in intermediate schools, seventy-six in secondary schools, thirty-three in district high schools, and twenty-two in private schools. ${ }^{85}$ A similar subsidy for pool construction had been introduced in 1920 (and

\footnotetext{
${ }^{79}$ Macdonald, Strong, Beautiful, and Modern, p. 79

${ }^{80}$ William Renwick, 'Beeby, Clarence Edward - Biography', Te Ara - the Encyclopedia of New Zealand; http://www.TeAra.govt.nz/en/biographies/5b17/1 [accessed 20 September 2012].

${ }^{81}$ K. C. Reid to J. Marshall, 15 October 1957, BCDQ, A739, 4615a, 28/9/2, Archives New Zealand Auckland, (ANZA).

82 'Miniature Bath', New Zealand Herald, 14 March 1939, IA 1, 2937, 139/19/2, part 3, ANZW.

${ }^{83}$ Superintendent of Physical Education to William A. Gordenstein, 21 April 1952, E 2, 698, 29/19/15, 1952/15b, part 2, ANZW.

${ }^{84}$ K. C. Reid to Miss J. Marshall, 15 October 1957, BCDQ, A739, 4615a, 28/9/2, ANZA.

${ }^{85}$ Dudley Wills to Senior and Area Organisers, 20 March 1963, BCDQ, A739, 4615a, 28/9/2, ANZA. Even with this growth in school pool construction, not all schools had pools and not all schools taught swimming, particularly in poorer and less populated areas where communities could not come up with the funds to build pools. In 1957, for instance, only four 'native schools' out of fifty-one in rural Northland had swimming pools, while at the same time 'the Auckland Education
} 
was terminated in 1932). However, it was not taken advantage of anywhere near to the same extent as the Learners' Pool subsidy. ${ }^{86}$ And although the Education Department began providing teachers with teaching resources concerning how to give swimming instruction from 1940, there were no curriculum changes specific to swimming at this time. Thus, the massive growth in pool construction can undoubtedly be attributed to the greater value placed on swimming within New Zealand society by the 1940s. As a result of the growth of swimming instruction in schools, parents saw less need for their children to take part in the Learn-to-Swim campaigns. ${ }^{87}$ Thus, the location of the urgency for swimming changed but the urgency itself did not dissipate.

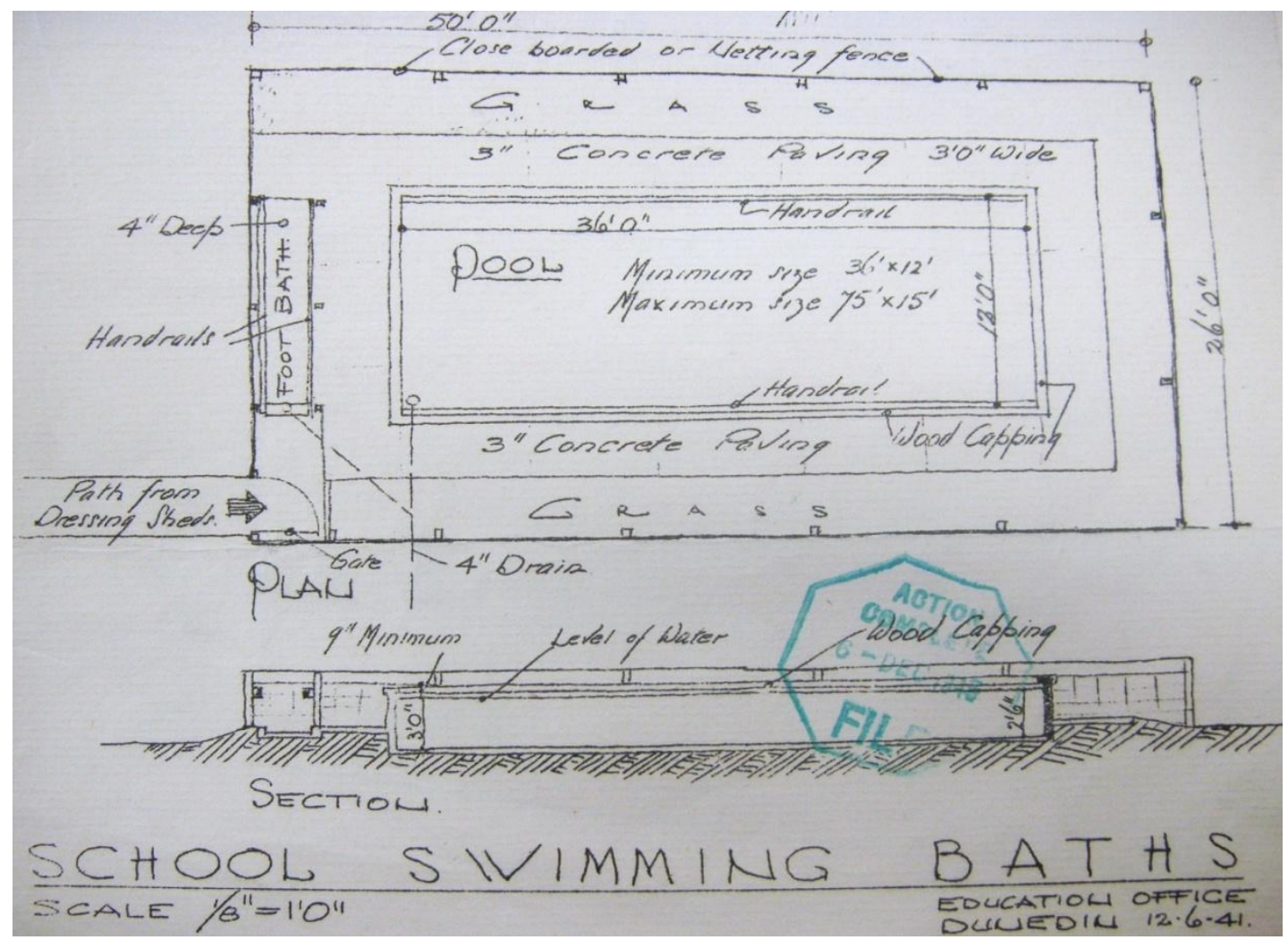

Figure 11 Sketch of a Learners' Pool, or 'miniature' pool.

E, 2, 698, 29/19/15, part 2, 1952/15b, Archives New Zealand, Wellington.

Board reported 185 learners' pools in its area'. Moran, The Shaping of Swimming and Water Safety Education, p. 132.

${ }^{86}$ Moran, 'The Shaping of Aquatics Education in New Zealand Schools', p. 114; Moran, The Shaping of Swimming and Water Safety Education in New Zealand, p. 92.

${ }^{87}$ R. Sheffield to Officer-in-Charge of the Physical Welfare Branch, 21 March 1956, IA 1, 2934, 139/7/15, part 9, ANZW. 
With swimming an increasingly important school subject, the Physical Welfare Branch took a new approach to swimming and drowning prevention in the post-war era. As the war ended and soldiers returned home, the Physical Welfare Branch experienced a new burst of enthusiasm for its work from 1945-1948, and Physical Welfare Officers set about instituting or expanding the provision of holiday facilities for industrial workers, setting up Group Travel in the North Island, building additional mountain tracks, establishing holiday camps, and publishing sports magazines and manuals. ${ }^{88}$ For Parry, '[n] ow more than ever ... New Zealanders deserved a holiday from the stresses of the war years' and with the introduction of the universal forty-hour week in 1945, there was greater need than ever before for the government to support recreational clubs and facilities. ${ }^{89}$ In addition to the work of the Physical Welfare Branch, as part of the Government's post-war recovery programme, Parry instigated a scheme in 1948 for the construction of utilitarian, 'living' memorials to commemorate all those New Zealanders who fought and died during the world wars. ${ }^{90} \mathrm{~A}$ 'vehicle for Parry's vision of a fitter, healthier nation', these government-subsidised memorials took the form of recreational facilities and community centres, which included public pools. ${ }^{91}$ But, the swimming campaigns was one area that experienced decline within the Physical Welfare Branch in the immediate post-war years, so that by 1948, Physical Welfare Officers only helped to conduct Learn-to-Swim classes in Wairarapa, Wellington, Canterbury, and Southland. ${ }^{92}$ Instead, the Physical Welfare Branch turned its attention away from swimming and towards drowning prevention.

Since the inception of the Learn-to-Swim campaign, there had been growing concern within the Physical Welfare Branch and the National Committee of Swimming and Lifesaving, that simply running a Learn-to-Swim campaign was not enough to prevent drowning deaths. As well as realising that swimmers were still not immune from drowning, this anxiety was prompted by the Surf Life Saving

\footnotetext{
${ }^{88}$ Kathryn Harris, 'The Physical Welfare and Recreation Branch of the Department of Internal Affairs', unpublished special study, University of Otago, 1971, p. 38.

${ }^{89}$ Macdonald, Strong, Beautiful, and Modern, p. 89.

${ }^{90}$ Chris Maclean and Jock Phillips, The Sorrow and the Pride: New Zealand War Memorials (Wellington: Historical Branch of the Department of Internal Affairs, 1990), p. 139.

${ }^{91}$ Ibid., p. 142. Pools were built in, for instance, Newmarket (Auckland) and Ashburton, Sheffield, and Rotherham (Canterbury).

${ }^{92}$ Buchanan, p. 85 .
} 
Association and surf lifeguards' dissatisfaction with their level of authority on New Zealand's beaches. Since the National Committee of Swimming and Life Saving was established in 1936, Parry and the Surf Life Saving Association had had discussions about lifeguards being granted

[D]efinite status as the guardians of the beaches with the fullest and widest authorities to not only patrol the beaches but to decide on what area of the beach swimmers and bathers should be permitted to congregate - in their own interests and safety. ${ }^{93}$

Nothing came of those discussions. But the Second World War provided new impetus for the Surf Life Saving Association's request for greater powers and new, more concerted deliberations ensued in the early 1940s. New Zealand's supply of volunteer lifeguards was significantly depleted as men signed up to join the military forces (though women assumed much of the responsibility for surf lifesaving during this period). As a consequence, concern arose that drownings on beaches would skyrocket. Parry made various inquiries, such as with the Australian Surf Life Saving Association, into what could be done to solve the situation. In the end, the association's solution of policing the beaches to deal with unruly swimmers was deemed not only unlawful but also impractical as a result of too few lifeguards. ${ }^{94}$ These discussions about beach control were not, however, a complete failure, for they further exposed the need for something else to be done if New Zealand's drowning rate was to be improved.

The potential for New Zealanders to drown themselves was also thought to have increased thanks to the extension of leisure hours and holidays by legislation passed in 1945. With the introduction of a universal forty-hour week, more New Zealanders had more time to swim, and increasing car ownership meant that they could swim in more places, and more secluded places, away from the watchful eye of pool attendants, lifeguards, or other bathers. As Joseph Cotterill, MP for Wanganui, told Parliament in 1951, '[t] he growth of motor traffic from 1920 to the present day has brought all these facilities close to everybody ... to-day a journey of

\footnotetext{
${ }^{93}$ New Zealand Surf Life Saving Association, Sixth Annual Report and Statement of Accounts, Season 1937-1938, Wellington, 1938, pp. 6-7.

${ }^{94}$ L. B. Campbell to Hon. Minister of Marine, [1944], IA1, 2956, 139/94, ANZW.
} 
fifty miles or more to a beach or a lake for a picnic is just common place'. ${ }^{95} \mathrm{New}$ Zealanders were believed to be at increased risk of drowning because they were more exposed to New Zealand's waters and to waters in which rescue was less likely. And as bathing became more and more popular, the Auckland Star noted in the early 1950s that this problem was going to become greater:

The practice of families spending the mid-summer holidays by the water has grown and is continuing to grow, and overcrowding at the well-known beaches is causing more of them to camps at more remote beaches or lakeside spots, where there is no provision for rescue operations. $^{96}$

Rather than grant surf lifesavers the power to police beaches, which would only solve the problem on beaches rather than at lakes or rivers and only on a few beaches at that, the Physical Welfare Branch launched a drowning prevention campaign.

Just before the National Party was elected to power at the end of 1949, Labour set in motion its final recreation scheme under the Physical Welfare Branch: the Prevent Drowning campaign. Perhaps seeking to capitalise on increasing concern over drowning deaths and retain government funding amidst growing public disdain for government intervention into recreation and the looming election, representatives of the National Committee of Swimming and Life Saving came together and approached Stan Higgins, Physical Welfare Officer and secretary of the committee, with a proposition. ${ }^{97}$ The committee sought to discuss the possibility of 'conducting a publicity campaign designed to mitigate against the incidence of death by drowning, ${ }^{98}$ There was widespread support for the idea of 'mass education of the people in respect of the many and varied dangers presented

\footnotetext{
${ }^{95}$ Cotterill, NZPD, 1 November 1951, Vol. 295, p. 641.

96 'Importance of Swimming', Auckland Star, [1951/1952], IA, 70, 3, 11, ANZW.

${ }^{97}$ Given that the New Zealand Amateur Swimming Association witnessed a significant drop in the number of certificates it issued between 1944 and 1949, and thus in the interest shown towards the club and its activities, it is not implausible that the national committee's approach to Higgins was mainly an attempt to improve its finances. B. O'Neill to Hon. Minister of Internal Affairs, 6 December, 1938, IA 1, 2932, 139/7, part 1, ANZW; National Committee of Swimming and Life Saving, 'Report of Drowning Fatalities, November $1^{\text {st }} 1949$ - April 30 $0^{\text {th }} 1950$ ', J 1, 1601, 21/2/13, ANZW.

${ }^{98}$ N. A. Ingram to Under-Secretary of Internal Affairs, 17 October 1949, IA 1, 2933, 139/7/15, part 1, ANZW
} 
by ignorant and haphazard swimming habits' within the Department of Internal Affairs. Parry called a conference with the national committee to consider how more interest in water safety could be roused. ${ }^{99}$ Out of the conference it was decided that the Department of Internal Affairs would set up a committee to run a Prevent Drowning campaign through the summer months. In October 1949, the National Prevent Drowning Campaign Committee was established, composed of representatives from the Department of Internal Affairs, the National Committee of Swimming and Life Saving, the Education Department, the Department of Health, the Prime Minister's Department, and the Broadcasting Department.

The primary role of the National Prevent Drowning Campaign Committee was to carry out a publicity campaign, inculcating 'into the New Zealander the need for care on beaches and when swimming in unknown rivers and lakes', for which it was given $£ 5,000$ per annum - evidently the Government considered the Prevent Drowning campaign to be more valuable than the Learn-to-Swim campaign. ${ }^{100}$ The drowning prevention committee was also assigned the task of distributing government grants to the Amateur Swimming Association, Royal Life Saving Society, and Surf Life Saving Association. Parry hoped that the National Prevent Drowning Campaign Committee would finally provide the co-ordinating link between the government and the swimming and lifesaving association that he had sought since 1936. However, it was not to be. The voluntary associations played a very small role in the Prevent Drowning campaign because they resented the extent of the involvement of the Physical Welfare Branch; voluntary associations 'felt that they were doing nothing really productive', that they did not have a role to play. ${ }^{101}$ Conversely, the National Prevent Drowning Campaign Committee, or rather the Physical Welfare Branch, ascribed the voluntary associations', and particularly the swimming association's, lack of contribution to indifference in matters which did not directly advance their own specific cause. ${ }^{102}$ This detachment was something which was also encountered with the district

\footnotetext{
${ }^{99}$ Under-Secretary of Internal Affairs to Minister of Internal Affairs, 15 August 1949, IA 1, 2933, 139/7/15, part 1, ANZW.

${ }^{100}$ New Zealand Junior Chamber of Commerce Incorporated Convention Remits, 22 August 1956, IA $1,2934,139 / 7 / 15$, part 10, ANZW.

${ }^{101}$ Prevent Drowning Meeting, Report of Proceedings of the Conference called by the Hon. Mr. S. W. Smith, Minister of Internal Affairs, at Wellington, on 26 July 1956, IA 1, 2934, 139/7/15, part 10, ANZW.

${ }_{102}$ Minutes of the National Prevent Drowning Campaign Committee Meeting, 1 September 1955, IA $1,2934,139 / 7 / 15$, part 8 , ANZW.
} 
branches of the voluntary swimming and lifesaving associations. One of the aims of the drowning prevention committee, under the National Government, was to decentralise the campaign 'so that it can be directed locally'. ${ }^{103}$ That is, district committees would be set up, composed of representatives from the voluntary swimming and lifesaving associations to whom Physical Welfare Officers would distribute Prevent Drowning publicity, which would then be distributed out the community by the district committees. Either due to inability or unwillingness, district committees were never established. As such, physical welfare officers basically assumed sole charge for the conduct of the campaign while the Prevent Drowning committee, not receiving any support from other government departments, was dominated by the Physical Welfare Branch.

The Physical Welfare Branch was under attack from all sides by 1949. Ineffective leadership, administration issues, and a discontented staff created low morale within the branch. And, amidst shifting political sympathies and the advancements made in physical education in the immediate post-war years, public support for the Physical Welfare Branch receded 'with the outgoing tide that washed away the urgency that the Depression and war had brought to government intervention'. ${ }^{104}$ In effect, the ideas, thinking, and context which had led to the establishment of the Physical Welfare and Recreation Act in 1937 were no longer pertinent to New Zealand society by the end of the 1940s. ${ }^{105}$

The election of the National Government in 1949 brought about the final demise of the Physical Welfare Branch. Despite maintaining much of the welfare system that the Labour Government had spent the last fourteen years building up, physical welfare was one area which the 1949-57 Government had no intention of retaining. With 'no particular policy on physical welfare and recreation' of its own, the National Government showed 'an appalling lack of understanding of the intention of the original scheme as introduced by the Labour Government', according to John Stewart, MP for Arch Hill. ${ }^{106}$ This 'lack of understanding' stemmed from the National Government's conservative agenda and, hence, the belief that leisure was a 'private' matter and not the domain of the government. But

${ }^{103}$ National Committee of Swimming and life Saving, Report of Drowning Fatalities, November 1, 1950 to April 30, 1951, H 1, 1715, 34/64, 26709, ANZW

${ }^{104}$ Macdonald, Strong, Beautiful, and Modern, p. 94.

105 Alexander, p. 49.

106 R. A. Stothart, 'The Education of New Zealand Recreation Workers', MA thesis, Victoria University of Wellington, 1977, p. 26. John Stewart, NZPD, 26 August 1953, Vol. 299, p. 710. 
William Bodkin, Parry's successor, also explained that, in a period of post-war prosperity, 'there was a big reservoir of voluntary labour that could be called to its aid in physical welfare and the development of sports'; leisure activities were already sufficiently provided for and thus there was no need for civil servants to do the job of voluntary clubs and associations. ${ }^{107}$ Furthermore, '[w]ith plentiful employment, modest prosperity, and, most of all, security, New Zealanders had at least some time and small means to devote to leisure pursuits'. ${ }^{108}$ Thus, this was not an area with which the state needed to concern itself. National maintained that '[i]t was better to allow people to run their own show and look after their own physical welfare', than have the government intervene. ${ }^{109}$ Beginning the process of disbanding the Physical Welfare Branch, the money available for grants under the Physical Welfare and Recreation Act was gradually and continually axed and was to be provided through lottery funds, illustrating 'the Government's reluctance to put Vote money towards an area they considered a low priority'. ${ }^{110}$ However, the Prevent Drowning campaign continued to have priority within the work of the Physical Welfare Branch, evident in the fact that, for instance, in 1952, the Physical Welfare Branch received an allowance of $£ 10,000$, half of which was to go towards the Prevent Drowning campaign. ${ }^{111}$

The Learn-to-Swim and Prevent Drowning campaigns, being part of the first Labour Government's welfare state, did not escape criticism under the National Government. From the outset of National's first term in power, National politicians questioned the necessity of the campaigns. In November 1950, Bodkin explained that he did not consider it

$[\mathrm{N}]$ ecessary that grants be made available to swimming and lifesaving clubs in connection with the "Learn to Swim" campaign. The only avenue for expending monies would be for extensive publicity for which there is no real need as sufficient coverage is given free of charge per media of the press and radio as news items. ${ }^{112}$

\footnotetext{
${ }^{107}$ William Bodkin, NZPD, 23 September 1952, Vol. 294, p. 1568.

108 Macdonald, 'Ways of Belonging', pp. 284-5.

${ }^{109}$ Sidney Smith, NZPD, 23 September 1952, Vol. 298, p. 1568.

110 Alexander, p. 36.

${ }^{111}$ Reverend Clyde Carr, NZPD, 25 September 1953, Vol. 300, p. 2028.

112 Order Paper, House of Representatives, 10 November, 1950, IA 70, 1, 1, ANZW.
} 
Similarly, Sidney Smith, who took up the position of Minister of Internal Affairs after Bodkin retired, maintained that as swimming was increasingly taught in schools, there was little need for the Internal Affairs Department to run Learn-toSwim and Prevent Drowning campaigns. ${ }^{113}$ However, despite the National Government's disdain for the Physical Welfare Branch and its work, it continued to fund and run the Learn-to-Swim and Prevent Drowning campaigns.

The decision to continue on with the campaigns, primarily the Prevent Drowning campaign, was possibly due to the fact that the perceived need for New Zealanders to be able to swim and for resolute efforts to be made to preventing drowning deaths was stronger than ever, both in public and political circles. ${ }^{114}$ The prevention of death by drowning was so highly valued, particularly by the $1950 \mathrm{~s}$ when aquatic recreation was such a popular pastime, that New Zealanders believed that a national effort was still needed. Not until New Zealand reached 'the irreducible minimum number of deaths from drowning' would there be less need for the campaign, but even then, to remain at the 'irreducible minimum', efforts would need to continue. ${ }^{115}$

But also, the Prevent Drowning campaign was compatible with the National Party's philosophy of individual responsibility, self-reliance, self-care, and 'private solutions'. ${ }^{116}$ The Prevent Drowning campaign urged people to take responsibility for their own safety and sought to provide swimmers, and nonswimmers, with sufficient knowledge about the dangers of the water 'so that they can look after themselves', so that they did not need constant supervision from lifeguards on every beach all the time or warning signs at every dangerous rapid. ${ }^{117}$ Nor did the National Prevent Drowning Campaign Committee encourage New Zealanders to go out and take to the waters, to participate in active recreation, as the Learn-to-Swim campaign had - that was something they were doing without the government's intervention. The campaign simply prompted swimmers that they

\footnotetext{
${ }^{113}$ Secretary of Internal Affairs to Minister of Internal Affairs, 30 April 1958, IA 1, 1850, 139/7/15/18, part 1, ANZW.

${ }^{114}$ Minutes of Special Meeting, 10 April 1954, IA 1, 2934, 139/7/15, part 11, ANZW.

${ }^{115}$ National Prevent Drowning Campaign Committee, Official Drowning Survey for the Period November 1, 1953 - April 30, 1954, IA 1, 2934, 139/7/15, part 7, ANZW.

${ }^{116}$ McClure, p. 130.

${ }^{117}$ Cotterill, NZPD, 1 November 1951, p. 642.
} 
could 'have all the fun' they wanted 'in or near water without tempting fate by taking foolish risks'. 118

Furthermore, the Prevent Drowning campaign was not that dissimilar in terms of structure, purpose, and government support, from the road safety campaign. For several decades, the New Zealand Government had been funding an extensive publicity campaign, directed by the Transport Department, which implored drivers to drive safely and responsibly on the roads in an attempt to lower the growing road toll. ${ }^{119}$ There was very little difference between the Road Safety campaign and the Prevent Drowning campaign except that the drowning campaign was organised by the, increasingly out of favour, Physical Welfare Branch. Thus, it would have been difficult for the government to justify running one campaign and not the other. The National Government could not reject the claim that legislators 'have a duty to see that in the enjoyment of recreation such as this [i.e. swimming] ... it does not involve unnecessary loss of valuable lives'. ${ }^{120}$ As such, it was not the message and purpose of the Prevent Drowning campaign to which the National Government objected, rather what was contested was whose responsibility it was to provide New Zealanders with water safety advice. In 1956, that question was resolved.

The final demise of the Physical Welfare Branch came in 1956/1957. Seeking to implement a 'restricted service to national undertakings' and place more responsibility on voluntary organisations, in September 1953, Cabinet directed that the branch reduce its numbers to eight by March the following year. ${ }^{121}$ In 1956, the remaining officers in Hamilton, Gisborne, Wellington and Lower Hutt were transferred to other government departments, marking 'the cessation of the [Internal Affairs] Department's role in providing direct assistance to sporting and recreational bodies in the field'. ${ }^{122}$ Two permanent officers remained in Head

\footnotetext{
${ }^{118}$ Sidney Smith, Press Statement 23/12/54, 'Holidaymakers should heed recent heavy drowning toll', IA 1, 2934, 139/7/15, part 7, ANZW.

119 The Transport Department's campaign received significantly more funding than the swimming and drowning prevention campaigns combined. For instance, in 1955, the Government provided $£ 500,000$ for the Road Safety campaign, 100 times the amount that was given to the Prevent Drowning campaign, and yet the rate of deaths cause by traffic accidents was only about twice as high as it was for drowning deaths. Evidently, car accidents were seen as a far more serious problem than drownings. [Colin Jones to Secretary of the Prevent Drowning Campaign Committee, 7 June 1955, IA 1, 2934, 139/7/15, part 8, ANZW].

${ }^{120}$ Cotterill, NZPD, 1 November 1951, p. 641.

${ }^{121}$ William Bodkin, NZPD, 26 August 1953, Vol. 299, p. 700. Stothart, p. 42.

${ }^{122}$ 'Physical Welfare', H22-16, IA 1, 2997, 158/9/20, part 1, ANZW.
} 
Office, however, providing administrative support for the Mountain Safety campaign (launched by the Department of Internal Affairs in 1954) and the Water Safety campaign. ${ }^{123}$

The disbandment of the Physical Welfare Branch had significant consequence for the Prevent Drowning campaign. With its demise looming, questions began to arise within the National Prevent Drowning Campaign Committee over the future of the committee and its campaign. In 1954 and 1955, Smith, now Minister of Internal Affairs, held a series of meetings with the National Prevent Drowning Campaign Committee to take stock of what had been done to reduce the high loss of life through drowning in this country' and assess the value of the campaign. ${ }^{124}$ Smith 'said that he had grave doubts about the point as to whether the Physical Welfare Officers could do the job better than anybody else'; he did not think that the structure of the prevention drowning committee, with the voluntary associations and the government (technically) working together, was particularly appropriate or effective. ${ }^{125}$ There was some truth to Smith's assertions. The tensions that existed between the swimming and lifesaving associations, and between those associations and the government, came to the surface during the discussions to reveal that the system of 'co-operation' between the government and the voluntary associations was not working. The National Committee of Swimming and Life Saving had crumbled long ago and the National Prevent Drowning Campaign Committee was experiencing much of the same problems as the swimming and lifesaving committee had. For example, the Amateur Swimming Association continued to push for more backing to be given its own efforts over the other associations' work, arguing 'that the only way to prevent drownings was to teach people to swim'. ${ }^{126}$ While, at a meeting in 1955, 'it was pointed out that the [National Prevent Drowning Campaign] Committee had no official advice about

\footnotetext{
${ }^{123}$ Macdonald, Strong, Beautiful, and Modern, p. 95. The Mountain Safety campaign embraced the same general shape and values as the Prevent Drowning campaign. Thus, it is not surprising that it also continued after the Physical Welfare Branch was closed. It could be argued that the Mountain Safety Council provided a framework on which the National Water Safety Council was later based in that it was composed of representatives from voluntary associations concerned with the various elements of tramping and mountaineering, but had Higgins as its secretary.

${ }^{124}$ Colin Jones to Secretary of the National Prevent Drowning Campaign Committee, 7 June 1955, IA $1,2934,139 / 7 / 15$, part 8 , ANZW.

${ }^{125}$ Prevent Drowning Committee, Notes of a Deputation which waited on the Hon. Mr. S. W. Smith, Wellington, 14 February 1955, IA 1, 2934, 139/7/15, part 7, ANZW. Minutes of the Prevent Drowning Committee Meeting, 9 June 1955, IA 1, 2934, 139/7/15, part 8, ANZW.

126 “"Learn to Swim" Campaign Causes a Controversy', Otago Daily Mail, 8 November 1955, IA 70, 4,12, ANZW.
} 
the two delegates appointed to the committee [by the surf lifesaving association] and thought it had been about two years since a surf delegate had attended the meeting'. ${ }^{127}$ The apparent inability of the voluntary swimming and lifesaving associations, and the state, to work in partnership therefore justified the break-up of the National Prevent Drowning Campaign Committee, but there remained a rationale for a national effort to prevent drownings.

By the late 1950s, despite all the efforts that had been made over the last twenty years to increase swimming ability and prevent drowning deaths, drownings still occurred and New Zealanders still maintained that these deaths were too common - they had 'become such a grim feature of New Zealand summers'. ${ }^{28}$ Attributed to continuing apathy about safety, it was seen to be 'continually important to warn the public of the dangers, especially as, year after year, so many infants are drowned in such places as troughs and sheep-dips, and there are so many bathing and boating fatalities'. ${ }^{129}$ Knowledge of swimming and 'water wisdom' was now expected to 'be included in the aquatic education of every New Zealander'. ${ }^{130}$ A more systematic approach to drowning prevention had been established by the National Prevent Drowning Campaign Committee, an approach that New Zealanders saw as valuable and necessary. Thus, even with Smith's reservations, he suggested that 'there should be some tie-up between this committee [National Prevent Drowning Campaign Committee] and the Learn to Swim campaign'. ${ }^{131}$ In other words, Smith suggested that the voluntary associations assume all responsibility for running a nation-wide drowning prevention campaign, for which the state would provide grant monies. Disapproval was voiced by the National Prevent Drowning Campaign Committee who maintained that the "voluntary organisations would have to undertake a large amount of work that had previously been done by full-time Physical Welfare Officers', which would lead to a less comprehensive campaign. ${ }^{132}$ However, with

${ }^{127}$ Minutes of Prevent Drowning Committee Meeting, 9 June 1955, IA 1, 2934, 139/7/15, part 8, ANZW.

128 'Sharp Lesson in Summer Drownings', Gisborne Herald, 4 February 1956, IA 70, 4, 12, ANZW.

${ }^{129}$ W. O. Stockley to Hon. Minister of Internal Affairs, 7 September 1955, IA 1, 2934, 139/7/15, part 8, ANZW

130 “"Water Wisdom": A Must for New Zealanders', Marlborough Express, 12 December 1956, IA 70, 4, 12, ANZW.

131 'Conference of Prevent Drownings Committee and Natatorial Bodies, 1954', IA 1, 2934, 139/7/15, part 7, ANZW.

132 Ibid. 
the Physical Welfare Branch being shut down, the matter was settled and the National Water Safety Council was established in late 1955 as a reconstituted form of the National Committee of Swimming and Life Saving. ${ }^{133}$ The line was drawn between the responsibility of government and the role of civic society. ${ }^{134}$

The National Water Safety Council was composed of representatives from the Amateur Swimming Association, Royal Life Saving Society, and Surf Life Saving Association, along with representatives from the Junior Chamber of Commerce, Education Department, Physical Education Specialists, and the Department of Internal Affairs. ${ }^{135}$ Furthermore, the drowning prevention committee became the National Water Safety Committee, the working committee of the National Water Safety Council, which worked on behalf of Internal Affairs with Higgins as its secretary. ${ }^{136}$ To compensate for the absence of civil servants to carry out the council's work, local water safety committees were set up to act as field agents for the council, and consisted of 'representatives of Swimming Centres, the Royal Life Saving Society Branches, the Surf Life Saving Clubs, Junior Chamber of Commerce, Education Department Physical Education specialists, and other local organisations' interested in water safety. ${ }^{137}$

There was little difference between the efforts of the National Water Safety Council and the drowning prevention committee. The aim of the council was to 'inculcate water wisdom' in New Zealand by co-ordinating the 'publicity of the Prevent Drowning Committee' and integrating the work of the Amateur Swimming Association, Royal Life Saving Society, and the New Zealand Surf Life Saving Association, into a 'National Scheme'. ${ }^{138}$ It was the task of the council to 'remind us of dangers. Their task should also remind us to co-operate in this national effort

\footnotetext{
${ }^{133}$ The Learn-to-Swim campaign continued but as a function of the Amateur Swimming Association, completely independent of any government involvement.

${ }^{134}$ Macdonald, Strong, Beautiful, and Modern, p. 30.

${ }^{135}$ Secretary of Internal Affairs to Deputy Director of Inland Revenue, 8 March 1957, IA 1, 2934, $139 / 7 / 15$ part 11 , ANZW.

${ }^{136}$ Royal Life Saving Society of New Zealand, 'Forty-Seventh Annual Report and Financial Statement of the Royal Life Saving Society, New Zealand. Council for the year ended $31^{\text {st }}$ August 1960', IA 1, 2128, 86/15, part 4, ANZW.

${ }^{137}$ Secretary for Internal Affairs to Deputy Director of Inland Revenue, 8 March 1957, IA 1, 2934, 139/7/15, part 11, ANZW; 'Prevent Drowning Meeting, Report of Proceeding of a Conference called by the Hon. Mr. S. W. Smith, Minister of Internal Affairs at Wellington, on 26 July, 1956', IA $1,2934,139 / 7 / 15$, part 10, ANZW.

${ }^{138}$ National Water Safety Council, Circular to all Local Committees, IA 1, 2934, 139/7/15, ANZW; Royal Life Saving Society of New Zealand, 'Forty-Third Annual Report and Financial Statement of the Royal Life Saving Society, New Zealand. Council for the year ended $31^{\text {st }}$ August 1956', IA 1, 2934, 139/7/15, part 10, ANZW.
} 
of preserving life'. ${ }^{139}$ For their Water Safety campaign, the National Water Safety Council received a government grant of $£ 5,000$. The Government also gave $£ 2,000$ to the Royal Life Saving Society, $£ 3,500$ to the Amateur Swimming Association, $£ 5,000$ to the Surf Life Saving Association. ${ }^{140}$ This money, though, came from lottery profits, rather than vote money. Thus, while the Government continued to recognise the value of the work of the swimming and lifesaving associations, it was not considered to be an appropriate way to spend public money. The main transformation that occurred as the National Water Safety Council replaced the National Prevent Drowning Campaign Committee was that the Department of Internal Affairs no longer shouldered the principal duty of fostering a 'water wise' culture in New Zealand; the work of the council was entirely in the hands of the voluntary associations. In essence, with regard to the swimming and lifesaving associations, New Zealand's swimming culture returned to its pre-1936 state. However, as the following chapter will reveal, recreational swimming was anything but unchanged.

This chapter has examined the relationship that existed between New Zealand's swimming and lifesaving organisations and the state from 1936-1956, and explored how this alliance facilitated an expansion of swimming culture. Within the framework of the Labour Government's building of a welfare state, swimming acquired new significance as a means to achieve a higher level of individual and national health. As such, New Zealand's first Labour Government could not ignore the potential for swimming within its welfare state and the activity subsequently came to occupy a prominent place within Parry's efforts to recast recreation "as the "life-blood of democracy". ${ }^{141}$ When the Physical Welfare and Recreation Act was passed in 1937, the Government further extended its influence into the realm of recreational swimming culture, however, its influence was in a constant state of flux as political and social conditions shifted throughout the 1930s, 1940s, and 1950s. Thus, this chapter argues that the Learn-to-Swim and Prevent Drowning campaigns were a response to and shaped by modern conditions in the mid-twentieth century. Learn-to-Swim and Prevent Drowning campaigns,

${ }^{139}$ Radio Announcement by Hon. S. W. Smith, 2YA, 3.45pm, 29 November 1956, IA 1, 2934, 139/7/15, part 11, ANZW.

${ }^{140}$ Secretary of Internal Affairs to Minister of Internal Affairs, 30 April 1958, IA 1, 1850, 139/7/15/18, part 1, ANZW; Buchanan, p. 85.

${ }^{141}$ Daley, Leisure and Pleasure, pp. 230-1. 
individually and collectively, were manifestations of the social and political context in which the Physical Welfare and Recreation Act was implemented. Although the Learn-to-Swim and Prevent Drowning campaigns were part of the wider efforts of the Physical Welfare Branch, this chapter has paid little attention to the Branch as the focus of this chapter has the Branch's work in swimming as part of the Labour Government's attempts to introduce and facilitate a new leisure culture consistent with its 'social citizenship' agenda. This period saw a massive extension of New Zealanders' opportunities to learn to swim and can largely be attributed to the fact that, during this time, the government assumed a new role in New Zealanders' 'private' lives, rendering swimming ability a public issue. For two decades the government and New Zealand's voluntary natatorial bodies attempted to 'expand and shift the terms of New Zealand's leisure culture and, in particular, to invest leisure with constructive possibility and to democratise the enjoyment and opportunity for leisure more evenly through the population'. ${ }^{142}$ Theirs was an ambitious goal, seeking to amalgamate the aims and directions of three voluntary associations and two government departments (including the Education Department). These swimming and drowning prevention campaigns were shaped by administrative and political mechanisms in the mid-twentieth century. They reveal the extent to which the state became an active agent in New Zealanders' leisure and provide an example of the complexities and conflicts that existed in attempts to create modern bodies. ${ }^{143}$ How the Learn-to-Swim and Prevent Drowning campaigns attempted to create those bodies and encourage a new culture of recreation is the subject of the next chapter.

\footnotetext{
${ }^{142}$ Macdonald, Strong, Beautiful, and Modern, p. 98.

${ }^{143}$ Ibid., p. 16.
} 


\section{Chapter Three}

The Learn-to-Swim and Prevent Drowning campaigns at work, 1936-1956

Swimming and water safety were two of the most enduring avenues through which the Physical Welfare Branch of the Department of Internal Affairs pursued its work in improving New Zealanders' leisure. This chapter examines the specific programmes that the Branch, alongside voluntary swimming and lifesaving associations, instigated in order to raise 'the general standard of swimming competence' and build 'a nation of real swimmers'. ${ }^{1}$ It considers the nature and content of the Learn-to-Swim and Prevent Drowning campaigns and the means employed to achieve their goals. Following a broad chronological order, this chapter explores the approaches, audience, and aims of the Learn-to-Swim campaign, followed by an investigation of those same elements in the Prevent Drowning campaign.

In the summer of 1936/37, amateur swimming was promoted to the general public with the launch of New Zealand's first Learn-to-Swim campaign. The concept of the Learn-to-Swim campaign initially grew out of the efforts and activities of the New Zealand Amateur Swimming Association, the principal organisation that ran swimming classes prior to the late 1930s. Although bathing was a well-established pastime by the outbreak of World War I, swimming, associated with sport and competition, remained a niche pastime. ${ }^{2}$ Since its establishment in 1890, the swimming association had worked tirelessly to encourage more New Zealanders to join its clubs. But as a voluntary organisation, it did not have the resources to make any substantial endeavours towards increasing the appeal of swimming and club membership. However, the establishment of the National Committee of Swimming and Life Saving in April 1936 and the support that Bill Parry, Minister of Internal Affairs, 1935-1949, expressed towards swimming, greatly improved the position of the swimming association. Although the swimming and lifesaving associations were hesitant at first about working more closely with the Government, they were eager to receive greater government support and the national committee also promised to provide its constituent bodies

\footnotetext{
${ }^{1}$ H. G. R. Mason, in Department of Education, The Teaching of Swimming: Special Report on Education Subjects No. 18 (Wellington: Department of Education, 1940), p. 1.

${ }^{2}$ Caroline Daley, Leisure and Pleasure: Reshaping and Revealing the New Zealand Body 19001960 (Auckland: Auckland University Press, 2003), p. 126.
} 
with new avenues and support bases through which to better pursue their individual and, in Parry's view, collective goals. Soon after the committee was formed, the swimming association approached its members with the idea of running a Learn-toSwim campaign, an extended version of a programme some of its swimming clubs had been running for several years. By mid-November 1936, the committee had set out a general outline for a Learn-to-Swim week. This was to be an intensive swimming course, to be held from 22-27 February 1937.

Organised and funded by the National Committee of Swimming and Life Saving, a Learn-to-Swim campaign was launched in December 1936. The intention of the campaign, as its name suggests, was to teach people how to swim (i.e. nonswimming club members who had not had the opportunity to learn before), with the supplementary objective of encouraging them to become members of swimming clubs. Learn-to-Swim lessons were provided by swimming coaches from the swimming association in towns and cities, in which swimming clubs and municipal pools were more common. The campaign was thus largely an urban one. Nearly 13,000 children and adults participated in this campaign - a remarkable figure given that it was organised in such a short space of time, received little media exposure, and was cut short as a result of an outbreak of infantile paralysis. ${ }^{3}$ Public pools were closed and the Learn-to-Swim campaign had to be terminated in many districts in mid-January 1937. The Learn-to-Swim week that was planned for February 1937 was cancelled altogether. The epidemic continued throughout 1937 and consequently, plans for a 1937/1938 campaign had to be abandoned. Despite the unfortunate curtailment of their efforts, the national committee had laid a foundation on which the Labour Government could then build to provide greater support for active recreation on a national basis.

The passage of the Physical Welfare and Recreation Act in November 1937 provided the Government with greater means to assist sporting and recreational organisations through funding and offering the support of Physical Welfare Officers. With this Act, the Learn-to-Swim campaign received a massive boost and as a consequence, the scope of the campaign grew substantially. From 1 November 1938 to 31 March 1939, the first countrywide, State-funded Learn-toSwim campaign was carried out by the National Committee of Swimming and Life

3 'Learn-to-Swim', J. W. Heenan to W. E. Parry, 25 November 1938, IA 1, 2932, 139/7, part 1, ANZW. 
Saving. There was a particular emphasis on the month of February when an intensive Learn-to-Swim Week was held. ${ }^{4}$ First and foremost, the Learn-to-Swim campaign offered swimming lessons, free of charge, to non-swimmers who wished to learn the skill. The lessons not only taught them 'to keep themselves afloat in the water, but to swim correctly and in such a way as to derive the best physical benefit from the sport'. 5 These introductory swimming lessons were given in school pools, municipal baths, and, when no other facilities existed, at beaches, rivers, creeks, and waterholes. In the Waikato during the 1938/1939 campaign:

[A] portion of the Waikato River was cut off and planked [so] as to give good facilities for instruction [in Ngaruawahia, Taupiri, and Huntly]; at Kawhia, Raglan, and Tauranga the beach was used; while at Whakatane and Opotiki, creeks were dammed and used as much as possible. At Herriesville, Gordonton, and Wharepoa creeks were made use of, and in one case A SHEEP-DIP WAS THOROUGHLY CLEANSED AND USED QUITE SUCCESSFULLY [capitals in original]. ${ }^{6}$

The national committee maintained that it was precisely those communities in which there were no 'appropriate' swimming facilities that the greatest need for swimming instruction existed as without such facilities, efficient instruction was least possible. ${ }^{7}$ Thus, rather than neglect those communities in which pools were still seen as, according to one member of the public, a 'luxury' rather than 'a real necessity', Learn-to-Swim instructors improvised as best they could. ${ }^{8}$

Learn-to-Swim classes, wherever they were held, were primarily the responsibility of swimming instructors from the Amateur Swimming Association. During the first campaign, 'no fewer than 1700 honorary coaches' volunteered to

\footnotetext{
${ }^{4}$ Although the campaign was nation-wide in that it was spread out all across New Zealand, it did not penetrate the more isolated, rural areas of New Zealand. However, the involvement of volunteers in the first campaign and Physical Welfare Officers in the later campaigns extended the reach of the campaign further than had been possible during the 1936/1937 campaign.

5 'Learn-to-Swim Campaign', Auckland Star (AS), 16 January, 1939, IA 1, W2578, 183, 139/19/2, ANZW.

${ }^{6}$ National Committee of Swimming and Life Saving, "Learn-to-Swim" Campaign, 1939: National Survey of Campaign, Embracing Reports of District Committees, and Recommendations, etc., (Wellington: National Committee of Swimming and Life Saving, 1939), p. 17.

7 'Learn-to-Swim Campaign 1939', 8 June 1939, IA 1, 2933, 139/7/1, ANZW.

8 'Correspondence', Evening Post (EP), 12 February 1940, p. 6
} 
give Learn-to-Swim lessons as well. ${ }^{9}$ Many of these volunteers were public servants and general members of the public, recruited by Parry. In subsequent years, when the Physical Welfare Branch was better established, paid Physical Welfare Officers took over from the 'honorary coaches' to provide swimming instruction. Between 1938 and 1956, this Learn-to-Swim programme featured as an annual summer event in New Zealand.

Publicity work was another component of the campaign. In an attempt to encourage greater appreciation of the sport and thus get people to take part in the Learn-to-Swim campaign, New Zealand's champion swimmers toured the country to give swimming demonstrations and instruction. The 1938/1939 campaign included a tour of 'the finest team of women swimmers' in New Zealand, all of whom were record holders and/or had represented New Zealand in the Empire Games. ${ }^{10}$ Chaperoned by diving coach E. Isaacs, Mona Leydon, Gwen Rix, Joyce Macdonald, Winnie Dunn, and Kathleen Grey began a tour of the North Island in Kaikohe on 21 December 1938. After travelling around the North Island, Grey, along with E. Tinsley and Jean Finlayson, completed a swimming tour of the South Island, which lasted until the end of March 1939. ${ }^{11}$ Taking advantage of the excitement generated by the Empire Games held in Sydney in February 1938, this was certainly an attempt to encourage greater interest in swimming among New Zealand's female population, whose recreational practices were of particular concern for Parry. ${ }^{12}$

The profile-raising side of the campaign also provided an opportunity for the voluntary lifesaving associations to contribute to Learn-to-Swim efforts and thus benefit from their involvement in the national committee. As part of the Learnto-Swim campaign, predominantly during Learn-to-Swim week, the Royal Life Saving Society gave resuscitation demonstrations and lessons in town halls and at schools. Similarly, surf lifeguards held promotional days on New Zealand's beaches, exhibiting rescue breathing and performing impressive mock rescues which attracted large crowds of spectators. All three voluntary swimming and

\footnotetext{
9 'Learn to Swim Campaign', The Times (TT), 17 November 1939, IA 1, 2937, 139/19/2, part 3, ANZW.

10 “"Finest Ever"”, AS, 2 December 1938, p. 11.

11 'Girl Swimmers', EP, 17 December 1938, p. 11; 'Swimming', AS, 26 February 1938, p. 20.

${ }^{12}$ Notes for a Speech to be delivered by the Hon. Minister of Internal Affairs at a combined meeting of Swimming and Life Saving Bodies, to be held in the Wellington Education Board's Offices, at 2pm on Saturday, $26^{\text {th }}$ October, 1940, IA 1, 2933, 139/7/2, ANZW.
} 
lifesaving associations focused on their area of expertise in public demonstrations. But they did so under a national banner of creating a more extensive and capable swimming culture.

Newspaper, print, and radio also provided the national committee with an avenue through which to promote its work. Weekly radio talks and radio advertisements about the benefits of swimming were a familiar feature of the Learn-to-Swim campaign. Physical Welfare Officers also held information and discussion evenings in town halls throughout New Zealand, during which an instructional film entitled Learn to Swim was often shown. This silent film was made by Ken Reid in the early 1940s as a teaching resource for the Education Department but was also employed by the Physical Welfare Branch as a means to demonstrate swimming techniques to larger audiences. ${ }^{13}$ Printed material was, however, the more common form of publicity. Physical Welfare Officers were given the task of distributing the mountains of posters, cartoons, and instructional pamphlets (of which 400,000 were printed for the 1938/1939 campaign) the national committee and Physical Welfare Branch produced. ${ }^{14}$ They also arranged window displays (figure 12). The Royal Life Saving Society also contributed pamphlets and articles on how to perform the Holger Nielsen method of resuscitation (figure 13). But it was newspaper articles which were the most prominent form of publicity, providing information about how to master swimming techniques (figure 14), advertising when and where Learn-to-Swim lessons would be held, updating New Zealanders about how many drowning deaths had recently occurred, and endorsing the advantages of swimming. Never before had the general public been provided with so much information on swimming, but that was precisely the point - how could New Zealanders be expected to swim if they did not know anything about it?

\footnotetext{
${ }^{13}$ Kevin Moran, The Shaping of Swimming and Water Safety Education in New Zealand (Auckland: Tradewinds, 2010), p. 107.

14 'Learn-to-Swim', Bulletin No. 1, IA 1, 2932, 139/7, part 1, ANZW.
} 


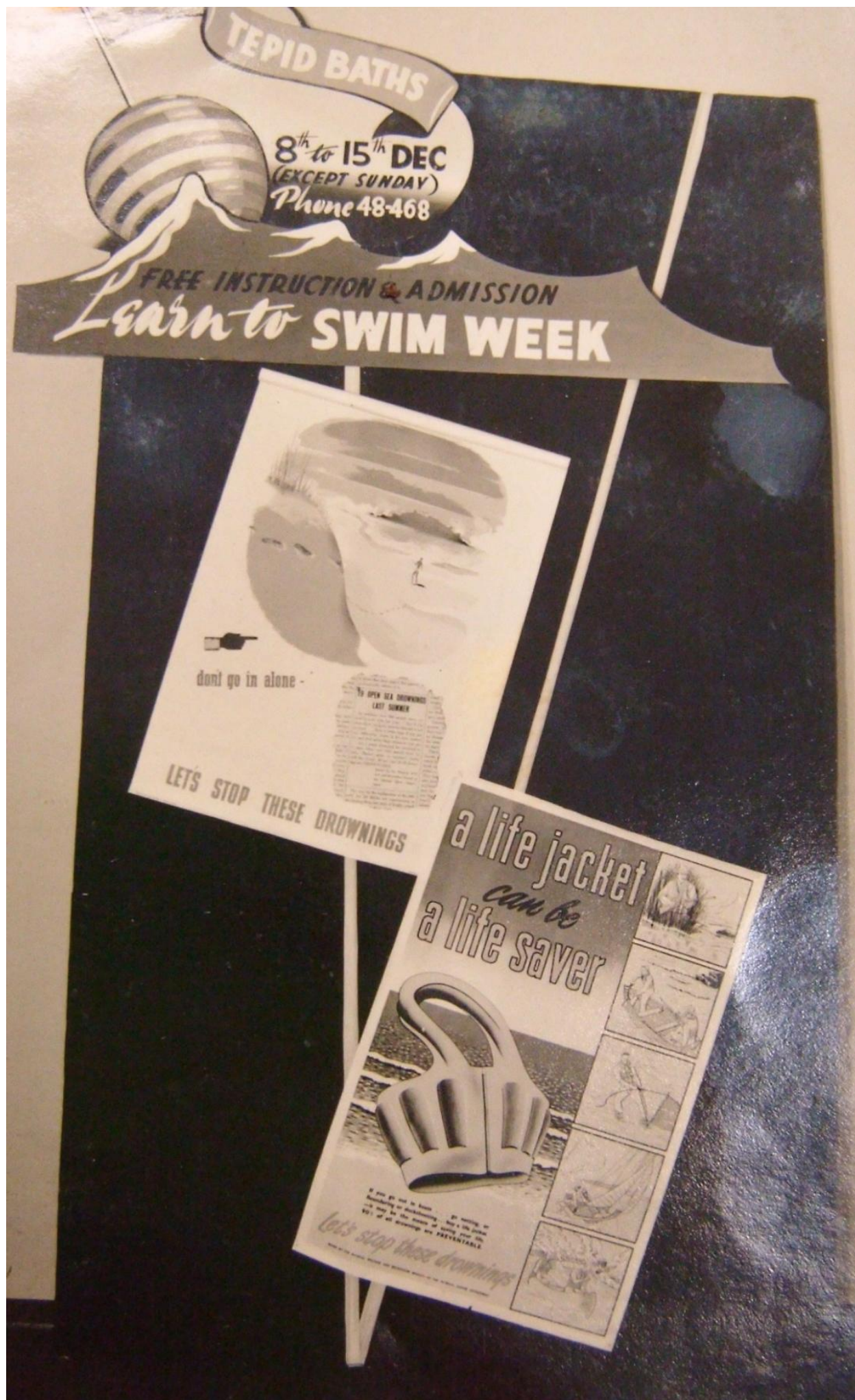

Figure 12 Placed in the windows of shops whose owners were sympathetic to the aims of the Learn-to-Swim campaign, window displays were one form of Learn-to-Swim publicity. The lifejacket featured in this display caused some problems for the Physical Welfare Branch as several members of the public inquired as to where they could purchase such a lifejacket. They had been unable to find any stores. As it turned out, that particular lifejacket did not exist, but was simply an artistic rendition. Nonetheless, New Zealanders were evidently paying attention to Learn-to-Swim publicity.

IA, 70, 3, 11, Archives New Zealand, Wellington (ANZW). 
MR ALBERT VEART, president of the Auckland Surf Life-Saving Association, demonstrates the Holger Neilsen method of artificial respiration as used on adults in the three pictures on the right.

This method has proved much more effective than the old Schaeffer method taught to most of today's adults during their school years.

The resuscitator kneels gt the patient's head, again facing down the body, and places his palms flat on the shoulder blades.

He rocks forward until his arms are perpendicular, applying about $30 \mathrm{lb}$ of pressure.

He then slides his hands under the patient's arm pits and down to the elbows, gently pulling them up and out from the body forcing air into the lungs. He then begins the movement again by placing his hands on the patient's shoulder blades.

There should be 9 to 12 such movements every minute.

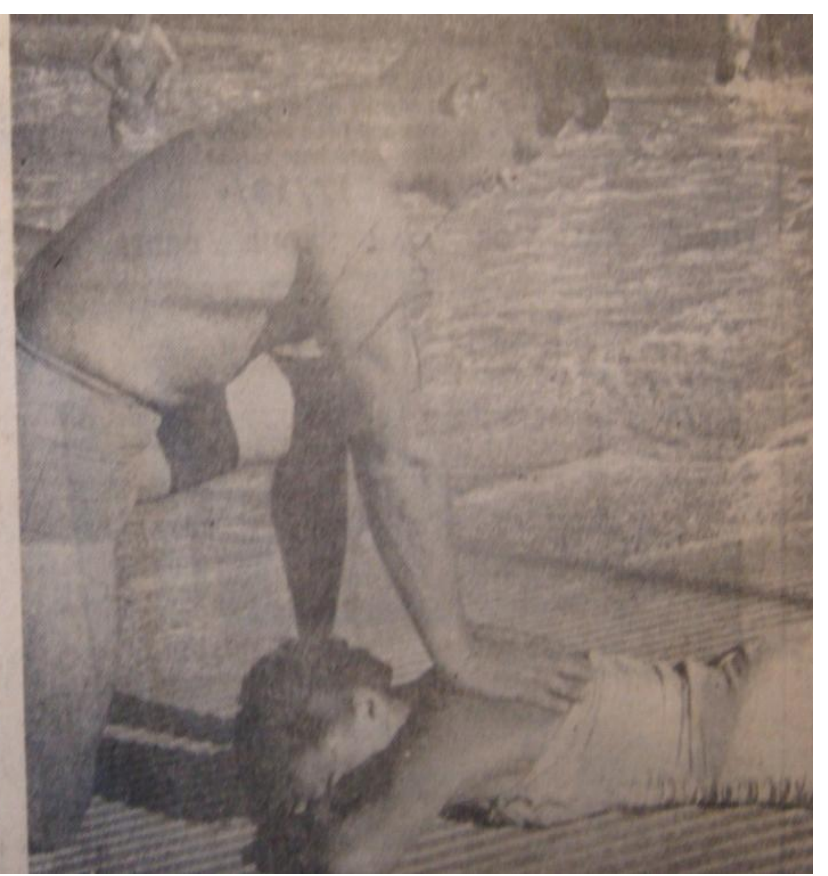

Figure 13 Holger Neilsen was the official/standard method of rescue breathing performed in New Zealand from the 1930s until late 1950s when mouth-to-mouth resuscitation was recognised as a more effective method. Being able to perform resuscitation, and thus prevent drowning deaths, was an important part of a swimmers' education.

'Lifesaving is Something We Need to Know', Auckland Star, IA 70 4, 12, ANZW.

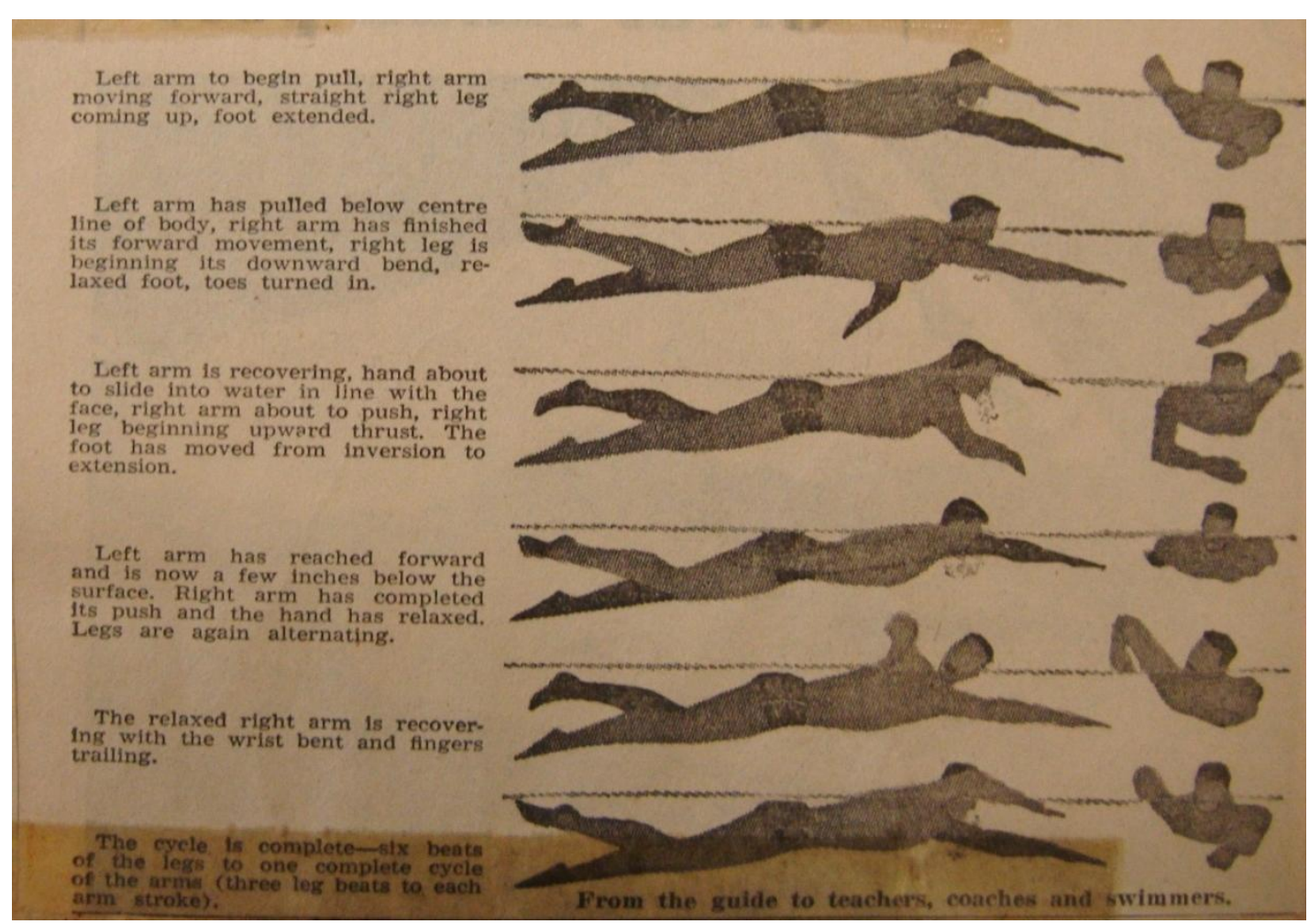

Figure 14 Part of the publicity for the Learn-to-Swim campaigns included printing swimming instructions in newspapers. If non-swimmers could not attend, they could still receive information on how to swim properly.

Valerie Bloomfield, 'New Zealand is the Leading Swimming Nation - Not Australia', BCDQ, A739, 4614b, 28/9/2, Archives New Zealand, Auckland (ANZA). 
As with other programmes introduced by the Physical Welfare Branch, the Learn-to-Swim campaign was intended to target adult and youth non-swimmers as it was the responsibility of the Department of Education to see that children were taught to swim. Prior to the launch of the Learn-to-Swim campaign, if New Zealanders were not taught how to swim 'properly' when they were children, through schools or clubs and institutions like the Wellington Boy's Institute, there were no formal opportunities to learn later in life without first having to join a swimming club. And because swimming clubs 'concentrate[d] on the competitive aspect of the sport', the Physical Welfare Branch reasoned that 'about $90 \%$ of potential swimmers are lost to the sport', those who 'would have been interested in the "fun" side rather than the competitive side'. ${ }^{15}$ This was a situation the Physical Welfare Branch sought to rectify, particularly with regards to enticing more adults to participate in active recreation. However, in terms of the number of adult swimmers taught, the Learn-to-Swim campaign was not particularly successful.

The very ambitious goal of the 1938/1939 campaign was to teach 75,000 people to swim. ${ }^{16}$ In the end, 28,478 New Zealanders were actually taught to swim during the November-March period - less than half the number of swimmers aimed for, but still an impressive result. Moreover, only 2,119 of these participants were youths (i.e. 14-19 years) and adults, a pattern that was repeated year after year. ${ }^{17}$ This was a source of bitter disappointment for the Physical Welfare Branch as it seemed to contravene a founding premise of the Physical Welfare and Recreation Act that if greater facilities and opportunities for active recreation were provided, New Zealanders would take full advantage of them. Still, the Auckland Star reported, rather impressively, that during the 1938/1939 campaign in Auckland, the 'ages of the pupils [who were taught to swim] ranged from $7 \frac{1 / 2}{2}$ years to $67,{ }^{18}$

Obviously, swimming was recognised, by some people at least, as an activity suitable for all ages and was pursued by people of all ages. The National Committee of Swimming and Life Saving commonly attributed adults' limited

\footnotetext{
${ }^{15}$ L. H. Joblin to William Parry, 16 October 1941, IA 1, 2128, 86/15/1, part 1, ANZW; C. Ruxton Bach to B. O'Neill, 15 August 1941, IA 1, 2932, 139/7, part 2, ANZW.

${ }^{16}$ Given that the National Committee of Swimming and Life Saving spent $£ 2,000$ of the $£ 3,000$ it was allocated for the campaigns teaching just over a third of the intended number of non-swimmers, the committee seriously overestimated the capacity of the campaign. 'Learn to Swim Campaign', TT, 17 November 1939, IA 1, 2937, 139/19/2, part 3, ANZW.

${ }^{17}$ National Committee of Swimming and Life Saving, p. 6.

18 'Good Results', AS, 1 March 1939, IA 1, 2937, 139/19/2, part 3, ANZW.
} 
participation in Learn-to-Swim lessons to unwillingness 'in admitting inability to swim', that is, adults were embarrassed by their swimming inability. ${ }^{19}$ But perhaps their apparent disinterest was more a result of time restraint. Although the fortyhour week was introduced into New Zealand in 1936, and became universal in the mid-1940s, did adults actually have the time to devote a significant portion of their week to learning to swim? Were they too busy taking their children to Learn-toSwim classes to participate themselves? Did adults just want to relax and recharge during their leisure hours rather than expending more energy in rigorous exercise? These were factors that neither the national committee nor the Physical Welfare Branch appear to have considered.

The lack of youth and adult non-swimmers who received lessons as part of the Learn-to-Swim campaign was not helped by the fact that the national committee directed so much of its attention towards primary schools. Having worked with many schools to provide their pupils with swimming instruction for decades prior to the launch of the Learn-to-Swim campaign, the Amateur Swimming Association had ready-made connections with schools. The National Committee of Swimming and Life Saving approached 'the Principals of all schools and colleges in the Dominion' and appealed to them to become involved in the campaign and employ the services of Learn-to-Swim instructors. ${ }^{20}$ The campaign was reported to have been 'warmly supported [at first] throughout the country by the Education Department and boards, school teachers, coaches and volunteer helpers'. ${ }^{21}$ Participating schools generally ran their own Learn-to-Swim week, during which time swimming instruction became a major focus of the school curriculum. $^{22}$ This, however, was probably not an entirely new experience for schools that already taught swimming as it was in February, when there was a more relaxed school timetable and when swimming was the most enjoyable, that

\footnotetext{
${ }^{19}$ NCSLS, Learn-to-Swim Campaign, 1939, p. 6.

${ }^{20}$ National Committee of Swimming and Life Saving, Report of Meeting held 27 November 1938, IA 1, 2932, 139/7, part 1, ANZW.

21 'Learn to Swim Campaign', TT, 17 November 1939, IA 1, 2937, 139/19/2, part 3, ANZW. The campaigns were not, however, evident in 'native schools'. This may have been a consequence of the absence of swimming clubs and facilities in isolated, rural areas where Māori still largely lived in the mid-twentieth century. But also, swimming was even less common in 'native schools' than nonnative schools, and where school swimming facilities existed, their intention was not generally to teach swimming. Rather, pools, or plunge baths, were 'used not only for cases of uncleanliness, but chiefly for the remedial treatment of children suffering from hakihaki [eczema] and similar skin diseases' (Inspector of Native Schools to Director of Education, 22 December 1936, BAAA 1001, 218/b, 44/4/21, ANZA).

${ }^{22}$ Appendix to the Journal of the House of Representatives (AJHR), 1938, E-2, p. 6, in Moran, p. 98.
} 
significant attention was given to swimming. What was new was the level of support the national committee offered school teachers and in later campaigns, volunteer instructors and Physical Welfare Officers often completely relieved teachers of the task of providing swimming instruction. During the 1951/1952 campaign, Stan Higgins, a District Supervisor for the Physical Welfare Branch, reported that one entire school in Palmerston North was 'handed over to our [physical welfare] officers ... These [Learn-to-Swim] classes went on all day and the numbers averaged 35 [pupils] every half hour'. ${ }^{23}$ With such demands on Learnto-Swim instructors, it is not surprising that they had little time to deal with adult swimmers. However, the Learn-to-Swim publicity, over which the Physical Welfare Branch had more influence, tended to target adults.

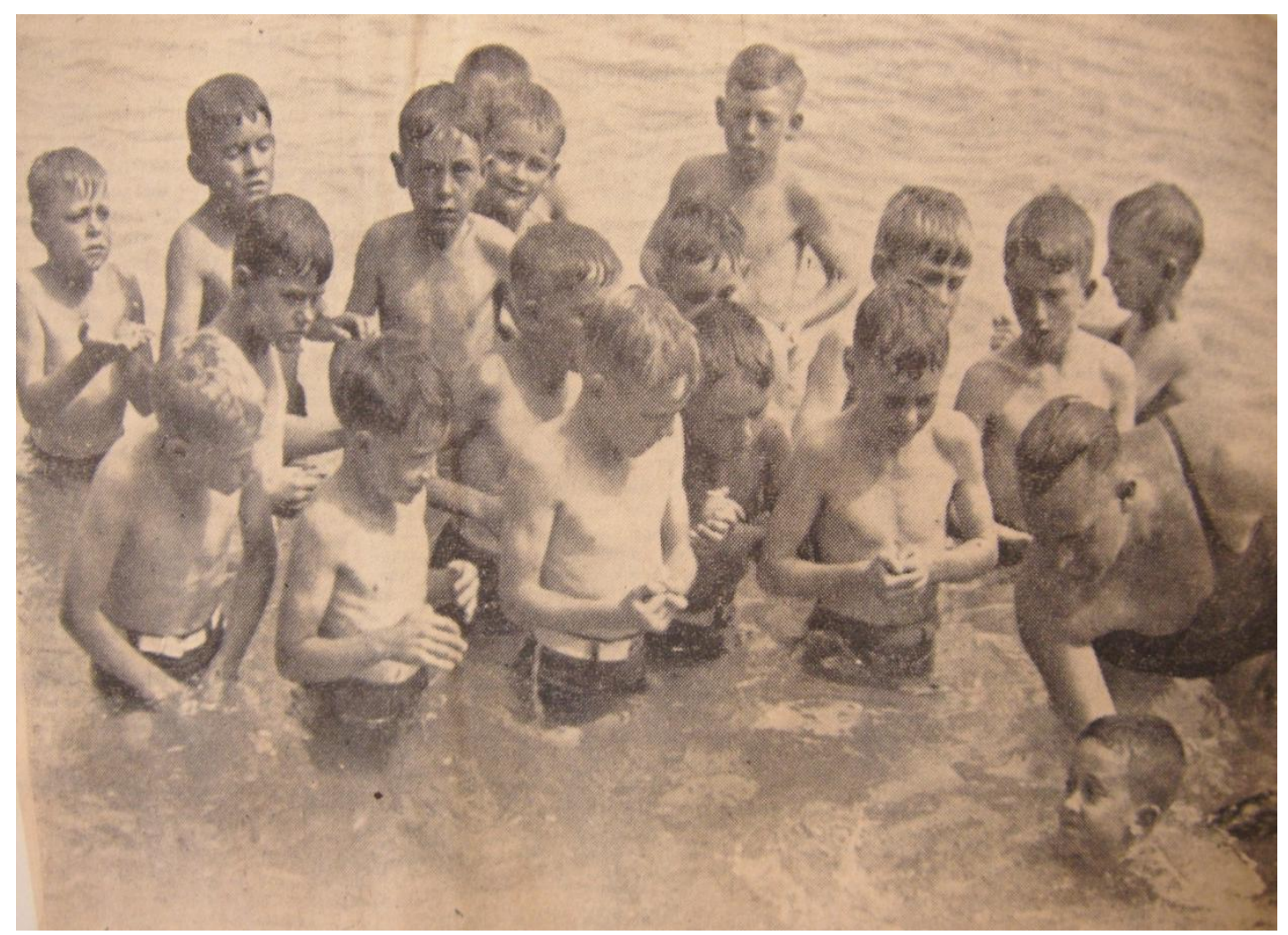

Figure 15 These boys from Remuera School represent just a handful of the children who received Learn-to-Swim lessons in schools. Despite the apparent chilliness of the water, these boys show a keen interest in their lesson one January morning at the Parnell Baths, in 1939.

'Learning to Swim', New Zealand Herald, 17 January 1939, IA 1, 2937, 139/19/2, part 3, ANZW.

\footnotetext{
${ }^{23}$ S. V. Higgins to Secretary of Internal Affairs, 1 May 1952, IA 70, 1, 1, ANZW.
} 
Presumably, children did not get much of a say as to whether or not they participated in their schools' Learn-to-Swim week, or even in Learn-to-Swim lessons outside of the school environment. Adults, though, did have a choice. If swimming did not appeal to them, then that was the end of the matter. Thus, if more adults were going to take up swimming in their leisure hours, they needed to be awoken to the allure of swimming. As L. Joblin from the surf lifesaving association stated, what the Physical Welfare Branch and the National Committee of Swimming and Life Saving needed to do to encourage more interest in swimming was to create a 'new outlook on swimming'. ${ }^{24}$ This was the aim of the Learn-to-Swim publicity.

The principal messages conveyed through the Learn-to-Swim campaign were that swimming was a healthful form of physical exercise and a way to prevent drowning deaths. The Times told its readers in 1937 that:

Swimming is the only sport in which a knowledge leads not only to the saving of one's own life but also the lives of others. From the health point of view, swimming gives harmonious play to the whole muscular system of the body, and brings the lungs into action to the fullest extent. $^{25}$

The health and lifesaving advantages that swimming afforded were not new messages. Some doctors like William Chapple, who was also a politician, had been promoting swimming as the 'ideal exercise for young and old, male and female' for decades. ${ }^{26}$ But the Learn-to-Swim campaign also sought to convince New Zealanders of the benefits of being able to swim and of swimming for recreation, for health, for enjoyment, for fitness, and for lifesaving. An important part of the work of the National Committee of Swimming and Life Saving was the collection and publication of drowning statistics, which drew attention to the severity of New Zealand's drowning problem and justified the need for greater swimming ability. For instance, in 1937, the Evening Post noted that between 1927 and 1937, 1580 people drowned, while there were 2154 deaths on the roads. Despite the extent of

\footnotetext{
${ }^{24}$ L. H. Joblin to William Parry, 16 October 1941, IA 1, 2128, 86/15/1, part 1, ANZW.

25 'Learn to Swim Week', Times, 6 December 1937, IA 1, 2932, 139/7, part 1, ANZW.

${ }^{26}$ W. A. Chapple, First Principles in the Art of Physical Development (London: Cassell and Co., 1910), p. 33.
} 
public attention given to motor vehicle accidents, the article continued, 'the number of drownings in summer and autumn months actually exceeds the number of road fatalities' in that same period, meaning that if swimming was a year-round activity, deaths by drowning would surpass the total annual number of those caused by car accidents. ${ }^{27}$ Furthermore, no one knew if or when the ability to swim would mean that a life could be saved, either one's own life or that of someone else. ${ }^{28}$ Thus, even if people did not like to swim or bathe, in order for them to make sure that they or somebody else did not drown, that they were prepared for any eventuality, swimming ability was a must.

Additionally, because swimming was a healthy leisure pursuit, and 'the most pleasurable of all pastimes', it also created the happy, modern bodies that enabled New Zealanders to "efficiently carry out their obligations to the community in which they live and to the state, of which they form apart [sic]'. ${ }^{29}$ Drawing on the Labour Government's linking of individual and national health, Physical Welfare Officers announced across the airwaves, through New Zealand's newspapers, and at public lectures and meetings that 'it was everyone's duty to learn to swim'. ${ }^{30}$ Learning to swim was a civic responsibility, something that New Zealanders owed to themselves and their fellow citizens because it would lead to a better life and would mean they were able to contribute to society as lifesavers and as workers. To what extent people learnt to swim because they felt compelled to do so is hard to say. Though the fact that swimming was 'enjoyable, and may be the means of saving life at any time' were probably more important factors, especially for children, who were often noted to take part in swimming lessons during the school week but were accused of simply wanting to miss school as they 'were conspicuous by their absence on the Saturday'. 31

In order for New Zealanders to achieve the healthful leisure that the Physical Welfare Branch promoted, Physical Welfare Officers aimed to teach nonswimmers how to swim along 'the most modern lines', replacing the conventional

\footnotetext{
27 'Appalling Total', EP, 10 November 1938, p. 20

28 'No Room for Apathy', Ellesmere Guardian (EG), 28 February 1939, p. 5.

29 'Learn to Swim Week', Times, 6 December 1937, IA 1, 2932, 139/7, part 1, ANZW; 'Physical and Mental Welfare', EG, 24 February 1939, p. 4.

30 'No Room for Apathy', EG, 28 February 1939, p. 5.

31 'Learn to Swim Week', Times, 6 December 1937, IA 1 2932, 139/7, part 1, ANZW; National Committee of Swimming and Life Saving, "Learn-to-Swim" Campaign, 1939, p. 28.
} 
'scrambling stage' of swimming (i.e. bathing or '[f]ree swimming'). ${ }^{32}$ That is, New Zealanders had to learn to swim 'properly and efficiently' as bathing was not considered to be a vigorous enough activity to produce healthy, well-formed bodies, nor did it involve enough skill to make potential lifesavers. ${ }^{33}$ 'It was of little use', The Star claimed in 1939:

[T] he younger swimmer having the ability to get himself [sic] from the land if he did not know how to use his energy to the best advantage. Such a practice was only giving the would-be swimmer the knowledge that would probably lead him into danger. ${ }^{34}$

The more informal and familiar methods of learning to swim (i.e. teaching oneself or being taught by a parent) were, consequently, publicised by the National Committee of Swimming and Life Saving as unsafe and inadequate. With the intention of establishing modern swimming as part of New Zealanders' leisure, the national committee developed and implemented a standard, universal method of swimming instruction. In December 1938, a group of five prominent swimming coaches, J. Perrine, K. C. Reid, P. Mathieson, H. Smith, and D. Anderson, produced the official Learn-to-Swim syllabus which was to be followed in every Learn-to-Swim class around New Zealand. To ensure that the Learn-to-Swim method of instruction was followed and swimming taught correctly, the authors of the instruction guide toured the country to demonstrate the programme to all Learnto-Swim instructors.

The aim of the Learn-to-Swim method was to teach skill, style, and technique, as modern swimming was defined as 'the ability to move through the water with the maximum degree of efficiency and the minimum degree of effort' ${ }^{35}$ Instructors taught a progressive approach to swimming in which would-be swimmers were 'up-skilled' in a series of detailed stages. 'Confidence' was the first step to becoming a good swimmer, the initial stage of which involved holding

\footnotetext{
${ }^{32}$ National Committee of Swimming and Life Saving, "Learn-to-Swim" Campaign, 1939, p. 38; B. C. Thomson and T. R. Pryde, 'A Survey of Learners' Swimming Pools in Dunedin', Preventive Medicine Dissertation, University of Otago, 1959, p. 24.

${ }^{33}$ William Parry, New Zealand Amateur Swimming Championships, New Plymouth, January 25, 1941, IA 1, 2932, 139/7, part 2, ANZW.

34 'Swimming Centre Blamed', The Star, 14 January 1939, IA 1, W2578, 183, 139/19/2, ANZW.

${ }^{35}$ Brian Jillings, 'Teaching Swimming for Safety and Recreation', New Zealand Journal of Physical Education, no. 28, November, 1962, p. 17.
} 
'the nose, shut the eyes, breathe in and shut the mouth, and, with all these closed in this manner, submerge the head for the count of five'. ${ }^{36}$ Learning how to breathe correctly in the water was also an important first step (figure 16). Next, swimmers were taught flotation, balance and foot propulsion, arm movements, breaststroke, and backstroke, and in order to make sure non-swimmers had a thorough understanding of the techniques, land drill was usually given before learners tested out their skills in the water (figure 17). The codified and systematised swimming taught through the Learn-to-Swim campaign was essentially the same type of swimming that competitive swimmers were taught and practiced. However, by placing the emphasis on health and drowning prevention, the Learn-to-Swim programme attempted to emphasise the non-sporting aspects of swimming; for the Physical Welfare Branch, New Zealanders were not necessarily learning to swim so that they could compete in competitions, but they learnt amateur swimming which provided them with healthy bodies.

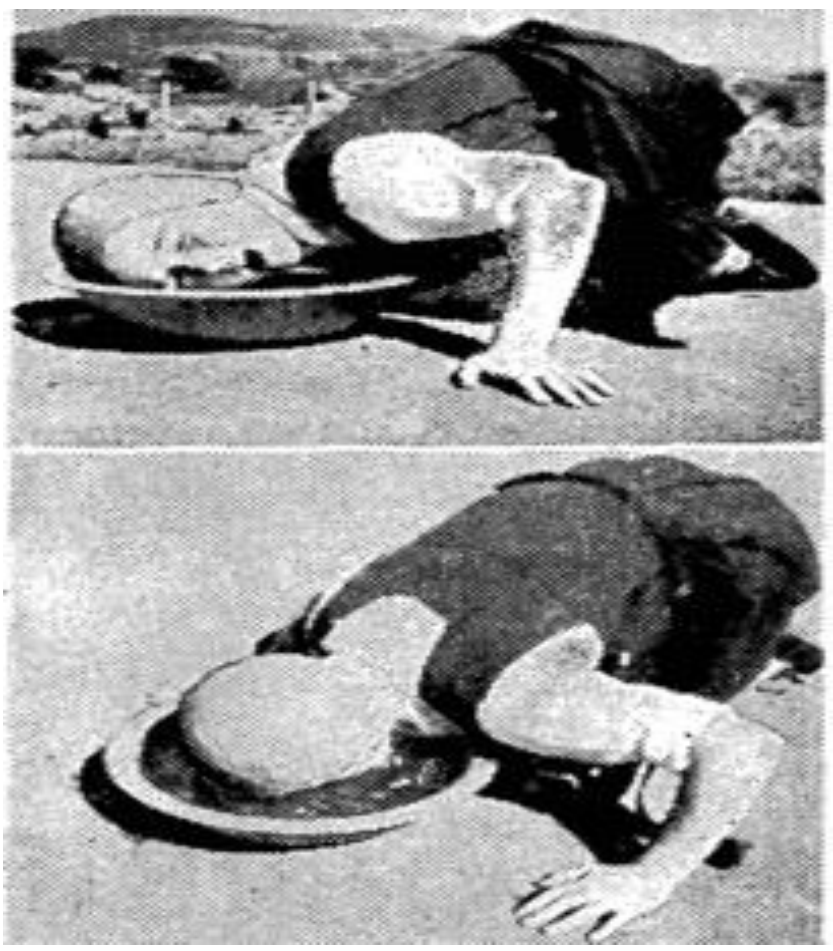

Figure 16 Learning how to breathe properly while swimming was an important lesson in the Learn-to-Swim programme. So important was it that school children were urged to practice whenever and wherever they could, like in the relative safety of a bowl of water.

\footnotetext{
36 'Learning to Swim', Bay of Islands Luminary, 14 February 1939, IA 1, 2937, 139/19/2, part 3, ANZW.
} 


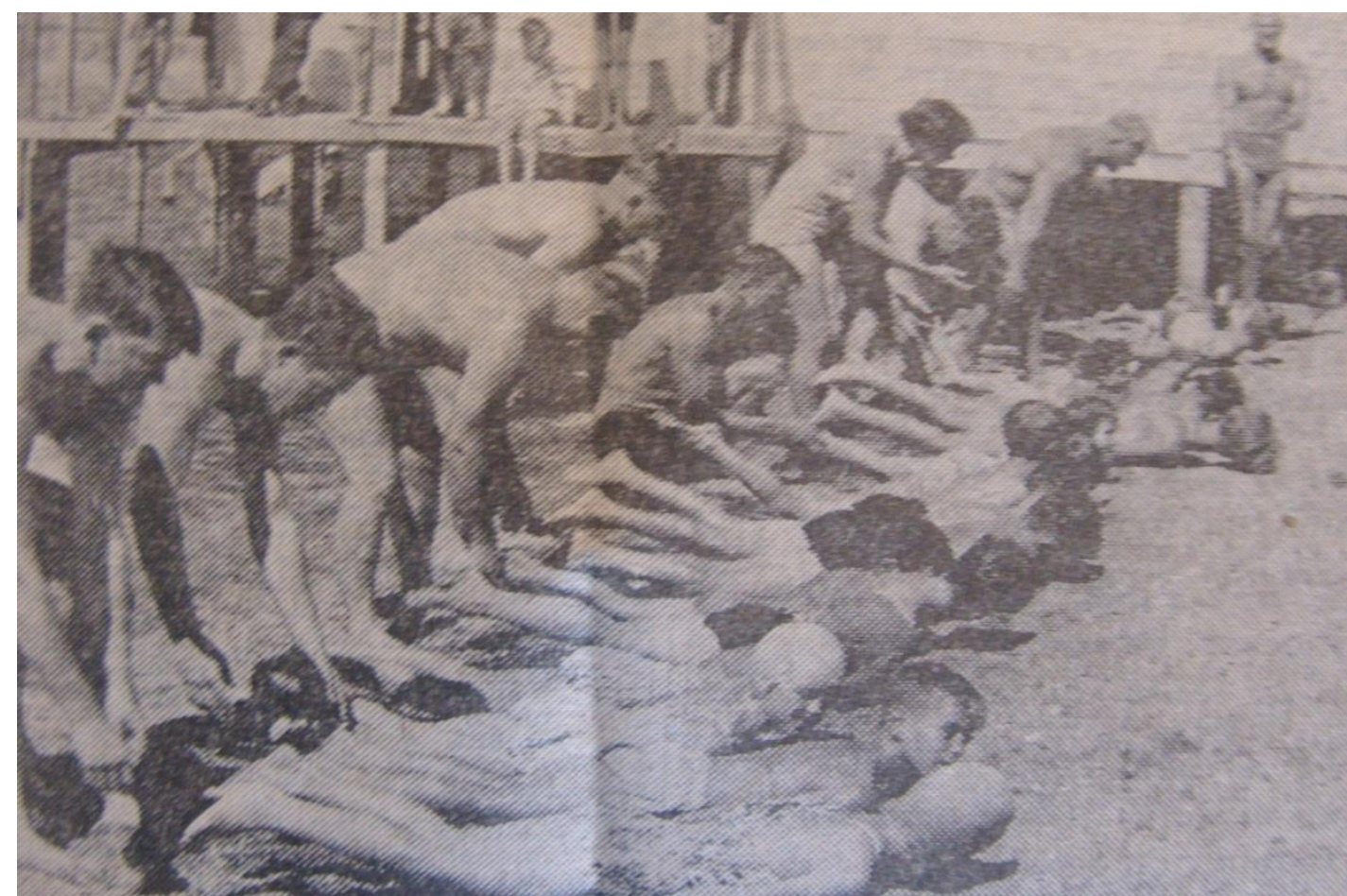

Figure 17 As part of Learn-to-Swim instruction, children were frequently given land drill lessons before getting in the water, like these children at Evans Bay, Wellington, in 1957. Land drill was a means of teaching swimming techniques (i.e. how to kick correctly) before learners entered the water

'Learning to Crawl First', EP, 11 February 1957, IA, 70, 4, 12, ANZW.

The way in which swimming was taught proved to be a source of contention between the Amateur Swimming Association and the Physical Welfare Branch. Style and technique were meant to be the principal focus of Learn-to-Swim classes, according to the Physical Welfare Branch, because it was these aspects which provided the best health and lifesaving benefits. However, for the Amateur Swimming Association, which was fundamentally a sporting body, the swimming it promoted was one based more on distance and speed. Under the direction of the swimming association, the National Committee of Swimming and Life Saving determined that those who successfully completed the Learn-to-Swim course would be able to swim any one swimming stroke, such as the crawl stroke (i.e. freestyle) or breaststroke, a distance of twenty-five yards. ${ }^{37}$ If this standard was achieved, then an individual could be classed as a swimmer and would be issued a

\footnotetext{
${ }^{37}$ This distance of twenty-five yards was half that required by the Amateur Swimming Association for swimmers to qualify for a pass. Undoubtedly, the National Committee of Swimming and Life Saving set this shorter distance to increase success rate of the Learn-to-Swim campaign, as well as to entice those people to learn who had perhaps been put off by the longer distance required. 'Meeting with Minister of Internal Affairs, New Zealand Amateur Swimming Association, New Zealand Surf Life Saving Society, Royal Life Saving Society’, IA 1, 2933, 139/7/1, ANZW.
} 
certificate to mark their (and the swimming association's) 'progress in the art of swimming' (figure 18). ${ }^{38}$ However, the Physical Welfare Branch, and increasingly the Education Department, was wary about the swimming association's objectives and was not pleased with the idea of issuing certificates because they were perceived to encourage the wrong type of swimming and for the wrong reasons, that is, to get a reward. The 'principal purpose [of the association was] ... sporting', Senior Physical Welfare Officer, C. Ruxton Bach explained, and as such it was less concerned with whether a person could successfully swim to save themselves if they, for example, fell out of a boat, than it was with swimming for competition. ${ }^{39}$ According to Phillip Smithells, Superintendent of Physical Education, the 'going for your life' swimming that the swimming association taught 'often destroys style in attempting to get it' ${ }^{40}$ The granting of 'swimming certificates because they [learners] can struggle twenty-five yards in a swimming bath', C. L. Cross from the Surf Life Saving Association noted, not only produced incompetent swimmers but also 'lull[ed] parents and "swimmers" into a sense of false security', thereby increasing the possibility of drowning. ${ }^{41}$ Equally, the Amateur Swimming Association asserted that in focusing on skill and technique, or in taking 'a person to the "feet to the bottom" stage and then leave him [sic] (which is what the average Learn-to-Swim campaign does)' was 'to invite trouble'. ${ }^{42}$ Despite these accusations, the swimming association was not simply concerned with swimming as a sport, and it did genuinely believe in the value of swimming. Neither did the association neglect the technical side of swimming, which was central to modern, competitive swimming. These clashes were a manifestation of the different views of swimming that existed, and also of different notions about whose role it was to teach swimming.

\footnotetext{
38 'Swimming in Schools', Policy Statement by the Wellington Primary Schools Amateur Swimming and Life Saving Association, 1941, IA 1, 2128, 86/15, part 3, ANZW.

${ }^{39}$ C. Bach to Under-Secretary of Internal Affairs, 21 November 1941, IA 1, 2932, 139/7, part 2, ANZW.

${ }^{40}$ Conference of Hon. Education Officers of the New Zealand Surf Life Saving Association, held in the Board Room of the Commercial Travellers Club, Wellington, on Friday, August 29, 1941, at 10.30 am', IA 1, 2932, 139/7, part 2, ANZW.

${ }^{41}$ C. L. Cross to Secretary of Internal Affairs, 24 October 1950, IA 1, 2933, 139/7/15, part 2, ANZW.

${ }^{42}$ Hon. Secretary of the New Zealand Amateur Swimming Association to Secretary of the Prevent Drowning Campaign Committee, 6 August 1955, IA 1, 2934, 139/7/15, part 8, ANZW.
} 


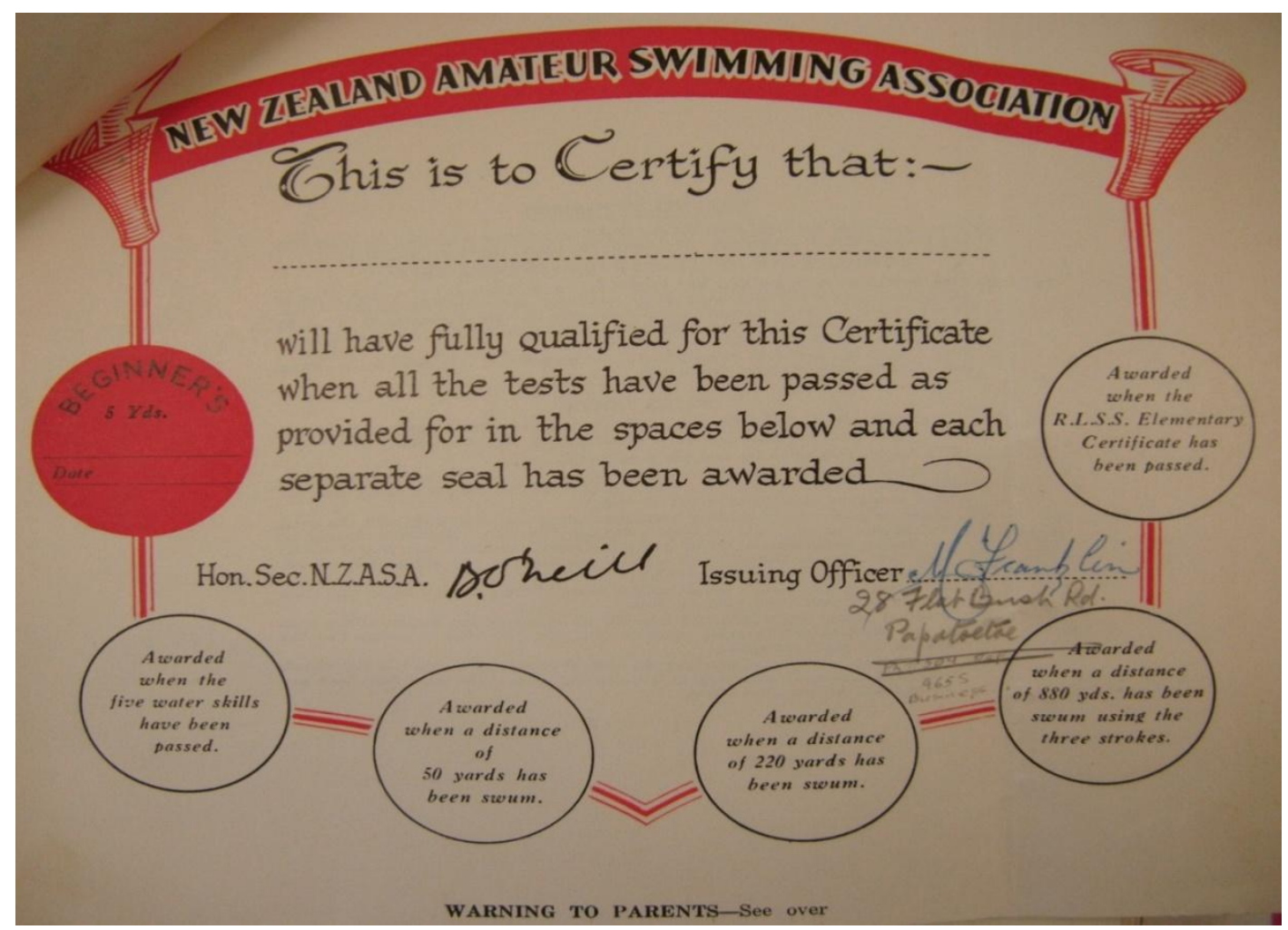

Figure 18 New Zealanders who had Learn-to-Swim lessons and passed would be given a certificate similar to the one shown above. Certificates were issued by the Amateur Swimming Association when people could swim five yards (Beginner), had achieved some general water skills, could swim fifty yards (Learner), swim 220 yards (Proficiency), swim 880 yards (Merit), and could perform a rescue. The overleaf of the certificates warned parents that they needed to remain cautious of their children's swimming abilities despite their apparent swimming achievements.

BCDQ, A739, 4614b, 28/9/2, ANZA.

These tensions similarly emerged in discussions about how far the 'Learnto-Swim' campaign should go. The Amateur Swimming Association continually asserted that a five-month campaign was insufficient to teach someone to swim, and because drownings occurred throughout the year, the Learn-to-Swim campaign needed to be a year round programme. Furthermore, annoyed by the state's involvement, volunteer instructors argued that the Government was demanding too much of them. During the 1938/1939 campaign, D. J. Fyffe of the Royal Life Saving Society explained that '[i]f they [the Physical Welfare Branch] think it is going to be an annual affair, of one month's hard work taking up all their [the volunteers'] time, with no return at all [because swimmers did not get any other opportunities to continue learning], the instructors will not help again'. 43

${ }^{43}$ 'Learn-to-Swim Campaign', Press (Christchurch), 1 March 1939, IA 1, 2937, 139/19/2, part 3, ANZW. 
Essentially, the voluntary associations were seeking additional support and funding so that they could continue to expand their efforts. However, the Physical Welfare Branch insisted that there was no need for the campaign to be a year-long event because the immediate intention was to create opportunities for people to get a taste for swimming so they would pursue the activity in their leisure time. It was not intended to create professional/competitive swimmers - that was the job of the Amateur Swimming Association. The enthusiasm and optimism with which the National Committee of Swimming and Life Saving had started out with began to decline as the Government became more involved. It became evident that it was a hugely difficult task to try to reconcile the distinct and firm aims of three voluntary swimming and lifesaving associations with a government department.

As World War II broke out, the Learn-to-Swim campaign was considerably curtailed on account of the Physical Welfare Branch redirecting much of its attention towards the war effort. In the post-war period, tensions between and within the National Committee of Swimming and Life Saving and the Government caused a breakdown in co-ordination between the associations. Although Physical Welfare Officers continued to provide Learn-to-Swim lessons and distribute publicity material, the Learn-to-Swim campaigns' importance within the Physical Welfare Branch subsequently declined. As the Physical Welfare Branch became more involved in the Prevent Drowning campaign in the 1950s, support for the Learn-to-Swim campaigns shrank further. In the wider society, the Learn-to-Swim campaign also lost much of its relevance as the Education Department expressed new enthusiasm for teaching children to swim. Dwindling interest in the Learn-toSwim campaign was not, however, indicative of the diminishing importance of swimming. In fact, Government support for the activity remained strong, as is evident in its funding for the construction of Auckland's Newmarket memorial pool, built for the 1950 Empire Games. Conflict between the Government and the voluntary swimming and lifesaving associations may have contributed to the diminishing significance of the Learn-to-Swim campaign, but its final demise came in 1956, when the government withdrew all support. Swimming clubs continued to run Learn-to-Swim weeks, but they were not part of a national effort and nor was the state involved on any level.

It would be unfair to suggest that the Learn-to-Swim campaign was a failure simply because it came to an end in 1956 and the administrative difficulties 
that it experienced. The campaign was run for twenty years and did teach some New Zealanders how to swim. However, it is difficult to assess the exact extent to which the Learn-to-Swim campaign was successful. The success of the campaigns in creating greater interest in swimming between 1936 and 1956 can most directly be determined by the total number of people taught to swim under the Learn-toSwim programme. However, no comprehensive, nation-wide results were compiled (with the exception of during the first campaign in 1938/1939). However, the information that does exist reveals that interest in the campaign was significant and widespread. Auckland frequently laid claim to the largest number of participants in Learn-to-Swim lessons with 'no fewer than 6,901 non-swimmers mastering the simple secret of swimming' during the first campaign. ${ }^{44}$ The achievements of the campaign depended greatly on the efforts of the district committees of the National Committee of Swimming and Life Saving and the Physical Welfare Officers, who distributed publicity material, promoted the campaigns, organised pool usage, and took the swimming lessons. As such, responses and enthusiasm tended to vary between regions, but generally, the feedback was encouraging. In 1940, for instance, E. Salisbury, the Southland Educational Officer for the Amateur Swimming Association, reported that in Invercargill

[T]he campaign had been a "howling" success. On the first night the doors had to be shut at the bath, for they could not handle the number of people applying for instruction. They had had an average attendance per night of 176 in the first three weeks. ${ }^{45}$

With an estimated total population of 22,600 in 1940, a significant proportion of Invercargill inhabitants thus took part in the campaign. ${ }^{46}$ But importantly, despite the diminishing importance of the Learn-to-Swim campaign within the work of the Physical Welfare Branch, the number of people who participated in the swimming lessons (in centres where the campaign was still held) did not appear to subside, suggesting that the campaign succeeded in convincing at least some New

\footnotetext{
44 'Learn to Swim Campaign', New Zealand Railways Magazine, Vol. 14, No. 10, January 1940, p. 53.

${ }^{45}$ 'Varying Results of Learn to Swim Drive among Adults', Star-Sun, 8 May 1940, IA, 1, 2932, 139/7, part 2, ANZW.

46 'The New Zealand Official Year Book, 1940', Statistics New Zealand; http://www3.stats.govt.nz/New_Zealand_Official_Yearbooks/1940/NZOYB_\%201940.html [accessed 20 June 2011].
} 
Zealanders of the need for swimming education. The Learn-to-Swim campaign held in Wellington in 1950/1951 was noted to have 'been a qualified success in every way ... with a grand total of 720 adults and 534 children' receiving lessons, which 'constituted a record for the Wellington district'. ${ }^{47}$ In the 1951/1952 season, 3020 Wellingtonians enrolled for Learn-to-Swim classes. ${ }^{48}$ However, not everyone who received Learn-to-Swim lessons passed the course, and in some towns, the pass rates were very low. ${ }^{49}$ Nevertheless, the National Committee of Swimming and Life Saving and the Physical Welfare Branch provided opportunities for New Zealanders to fulfil existing and new found aspirations to learn to swim and thousands of New Zealanders jumped at the chance.

Levels of swimming ability by the late 1950s provide another possible means to judge the effectiveness of the Learn-to-Swim campaign, though the accounts that exist are partial and sometimes conflicting. In 1939, the Auckland Star claimed that, '[o]n average only one child in five attending school in Auckland can swim', and even then, that was apparently a generous approximation. ${ }^{50}$ However, by 1951, the Herald asserted that 'about half of the 1240 pupils at Avondale College, New Zealand's largest school, can swim'. The article, however, stated that, although there was no public pool in Avondale, the 'fact that so many adolescents enter secondary school unable to swim is surprising, for many primary schools in and around Auckland have learners' pools'. ${ }^{51}$ Clearly, a new expectation had developed by the 1950 s that swimming ability should be the rule rather than the exception and anything less was a great disappointment.

Even so, an evident improvement had occurred in the swimming ability of young New Zealanders, in Auckland at least. By 1958, only fifteen per cent of pupils in Auckland primary schools were described as non-swimmers. ${ }^{52}$ Swimming ability among Māori children, on the other hand, was noted as being 'below that of

\footnotetext{
${ }^{47}$ F. J. Eggleton to Under-Secretary of Internal Affairs, 17 April 1950, IA 1, 2933, 139/7/15, part 1, ANZW.

${ }^{48}$ S. V. Higgins to Secretary of Internal Affairs, 6 May 1952, IA 70, 1, 1, ANZW.

${ }^{49}$ In Ohope, 2,800 children and 100 adults received swimming instruction as part of the 1954/1955 campaign, but only ninety-five children were recorded as having qualified as swimmers by the end. This may have been influenced, however, by the fact that lessons were provided in the sea as there was no public pool in Ohope. R. Sheffield to Secretary of Internal Affairs, 23 January 1955, IA 1, 2934, 139/7/15, part 8, ANZW.

50 'Learn-to-Swim Campaign', Auckland Star, 16 January 1939, IA 1, W2578, 183, 139/19/2, ANZW.

51 'Many Pupils Unable to Swim', Herald, 16 November 1951, IA 70, 3, 11, ANZW.

${ }^{52}$ Correspondence to Head-teachers from Physical Education department, Department of Education, Auckland, May 9, 1958, in Moran, p. 132.
} 
comparable pakeha [sic] children'. ${ }^{53}$ In Kaitaia in 1958, there were twenty-two state schools, ten of which had bathing facilities, none of which were pools. Out of sixteen schools, 100 per cent of pupils were non-swimmers in three schools. In eight other schools, eighty to ninety per cent of pupils were non-swimmers, while in one school, non-swimmers accounted for twenty-five per cent of pupils - this was the lowest proportion of non-swimmers seen in any of the schools. ${ }^{54}$ In the wider society, the Bay of Plenty Times noted in 1957 that '[o]nly five per cent, or one in 20 New Zealanders could swim well enough to protect themselves or be of some assistance to people in difficulties'. ${ }^{55}$ How this calculation was made is not clear. However, given that such an account was probably intended as a means to validate continuing public efforts to teach New Zealanders to swim, it was likely to have been an overestimation of swimming inability. Nonetheless, there were evident gaps where significant improvements could still be made. The Education Department certainly played a part in increasing the number of swimmers in New Zealand during this period. However, swimming was only just becoming more common in schools and school swimming lessons were often taught by Physical Welfare Officers. Thus, the role of the Learn-to-Swim campaign in democratising recreational swimming culture and swimming ability from 1936-1956 cannot be dismissed.

The incidence of drowning deaths in New Zealand may also be an indication as to the success of the Learn-to-Swim campaign. During the midtwentieth century, swimming/bathing became a much more popular recreation than it had ever been before and there was a considerable expansion in opportunities to swim, not just in terms of the construction of swimming facilities, but also with regard to access to water, thanks to increased leisure hours and car ownership. In spite of these developments, the drowning rate did not increase, and neither did it level out, but continued to decline. Thus, New Zealanders were evidently becoming ever more capable in the water. In addition, deaths from drowning continued to be predominantly the result of accidental submersion (i.e. slipping off rocks, falling

\footnotetext{
${ }^{53}$ P. MacPherson to Department of Education, 6 November 1958, BCDQ, A739/4615a, 28/9/2, part 1, ANZA.

54 'Kaitaia, Maori School List', BCDQ, A739, 4615a, 28/9/2, ANZA. The incredibly high number of recorded non-swimmers may have simply been determined by the number of certificate holders, rather than by children's actual ability to swim.

55 'Every New Zealand Child Should Be Taught to Swim', Bay of Plenty Times, 18 December 1957, IA $70,4,13$, ANZW.
} 
out of a boat), rather than as a consequence of swimming, even though swimming had become more common. ${ }^{56}$ As such, it would be difficult to argue that the swimming education provided by the Physical Welfare Branch was having anything but a positive effect on New Zealand's drowning rate.

The success of the Learn-to-Swim campaign in encouraging the uptake of swimming can possibly be most readily determined by the number of people who joined swimming clubs and received certificates. In the first decade of the twentieth century, the annual number of certificates awarded by the Amateur Swimming Association was in the mere hundreds. By the 1920s, the association was claiming to issue several thousand certificates per annum, mainly to school children, with the highest recorded number of certificates issued prior to the Learn-to-Swim campaigns being 15,836 in 1929. During the Great Depression, New Zealanders showed less interest in the work of the Amateur Swimming Association, perhaps not surprisingly given the economic difficulties. But in 1938, the first year in which the Learn-to-Swim campaign was run on a nationwide basis, 32,002 New Zealanders were presented with swimming certificates. This was an increase of approximately 28,000 from the number of certificates awarded in 1933, some of which were issued through the Learn-to-Swim campaign. ${ }^{57}$ The outbreak of World War II appeared to have little effect on New Zealanders' enthusiasm for swimming as the swimming association continued to experience growth in the number of certificates it issued. There was a drop in the number of swimming certificates awarded in the immediate post-war period, but the 1950s saw the numbers increase again. In the 1952/1953 swimming season, the Amateur Swimming Association conferred 44,980 swimming qualifications. ${ }^{58}$ During the $1954 / 1955$ season, 89,000 certificates and seals were issued for swimming progress and efficiency to school children alone. ${ }^{59}$

\footnotetext{
${ }^{56}$ See for instance National Committee of Swimming and Life Saving, 'Report of Drowning Fatalities, November 1, 1950 - April 30, 1951, with summaries of the years 1946 to 1950 inclusive', H 1, 1715, 34/64, 26709, ANZW; National Prevent Drowning Campaign, 'Official Drowning Survey for period November 1, 1953 - April 30, 1954', ABQU 632, W4452, 2, 1-7, 0253, ANZW.

${ }^{57}$ No complete records exist as to the number of certificates issued in 1934, 1935, and 1936, and no certificates were issued in 1937 as a consequence of the infantile paralysis epidemic; B. O'Neill to Hon. Minister of Internal Affairs, 6 December, 1938, IA 1, 2932, 139/7, part 1, ANZW.

58 'New Record Set', The Dominion, 18 August 1941, IA 1, 2932, 139/7, part 2, ANZW; Hon. Sec. New Zealand Surf Life Saving Association to Sec. of Prevent Drowning Committee, 24 August 1954, IA 1, 2934, 139/7/15, part 7, ANZW.

${ }^{59}$ Rex Moore to S. W. Smith, 22 August 1955, IA 1, 2934, 139/7/15, part 8, ANZW.
} 
By the 1950s, there was little need 'to stress the value of swimming' as it was an activity that people now enthusiastically pursued. ${ }^{60}$ The Learn-to-Swim campaign had done its job. It may not have created a nation of swimmers, but it certainly went a long way to extending New Zealanders' opportunities to learn to swim. With the growing popularity of swimming, however, a new recreational need arose.

Despite the extensive efforts made by Physical Welfare Officers and the swimming and lifesaving association throughout the 1940s, New Zealanders still commonly believed that the country had a 'very high drowning rate'. ${ }^{61}$ Drowning was an aspect of aquatic recreation that had the potential to cause extensive harm and distress, served as a deterrent to swimming for some people, and became a greater risk factor as swimming became more common. In the 1950s, drowning prevention occupied a prominent place within the work of the Physical Welfare Branch. The formation of the National Prevent Drowning Campaign Committee and the inauguration of the Prevent Drowning campaign in 1949 gave New Zealanders their first taste of modern 'water wisdom'. Water safety messages, such as '[d]on't play in troughs or sheep dips', were occasionally integrated into Learn-to-Swim publicity. ${ }^{62}$ However, the Prevent Drowning campaign was the nation's first 'attempt at mass education of the people in respect of the many and varied dangers presented by ignorant and haphazard swimming habits'. ${ }^{63}$

The Prevent Drowning campaign was run annually between 1949 and 1956 from November to March, coinciding with the Learn-to-Swim campaign. Instituting a defensive rather than an offensive approach to drowning prevention

\footnotetext{
${ }^{60}$ Hon. Secretary of the New Zealand Amateur Swimming Association to Minister of Education, 16 September 1950, E 2, 698, 29/19/15, 1952/15b, part 2, ANZW.

${ }^{61}$ Hon. Secretary of the New Zealand Amateur Swimming Association to Minister of Education, 16 September 1950, E 2, 698, 29/19/15, 1952/15b, part 2, ANZW.

${ }^{62}$ Publicity Branch of the National Committee of Swimming and Life Saving, National Learn to Swim Campaign. Press and Radio Bulletin, No. 2, January 3, 1939, IA 1, 2932, 139/7, part 1, ANZW. The Royal Life Saving Society and Surf Life Saving Association already provided New Zealanders with some safety recommendations but this information was quite narrow in scope and was presented to a limited audience. The Surf Life Saving Association produced little safety material. Their means of informing New Zealanders about the dangers of the water was principally through direct instruction when people were swimming at the beach. The Royal Life Saving Society, on the other hand, primarily distributed their safety information through institutions like schools. Neither of these efforts attempted to teach people how to spot and avoid dangers, but emphasised how to cope with a situation once it had arisen.

${ }^{63}$ Under-Secretary of Internal Affairs to Minister of Internal Affairs, 15 August 1949, IA 1, 2933, 139/7/15, part 1, ANZW.
} 
such as that taken by the Surf Life Saving Association, the Prevent Drowning campaign sought to advise New Zealanders to take care during their leisure hours in and around water and informed them on how to recognise and avoid water hazards. Learning to swim was still considered essential for all New Zealanders. However, the National Prevent Drowning Campaign Committee emphasised the point that swimming ability, or lack thereof, was only part of the drowning problem; learning to swim was 'not enough: if it were, there would be very few drowning fatalities'. ${ }^{64}$ Instead, the campaign committee contended that drownings arose 'from circumstances which should not have existed in the first place', and thus what was needed in order to really effect change was for those 'circumstances', that is, unsafe behaviour and ignorance about risks, to be managed and transformed. ${ }^{65}$ In the last few years of its existence, the Physical Welfare Branch set out to educate New Zealanders on 'water wisdom' and create water conscious, autonomous citizens in the hope that this would lessen the incidence of drowning in New Zealand. How they attempted to achieve this was through intensive and widespread publicity.

The publicity that the National Prevent Drowning Campaign Committee commissioned was largely of the same variety as was produced for the Learn-toSwim campaign. But with a $£ 5,000$ government grant for the sole purpose of promoting 'water safety', Prevent Drowning publicity was much more extensive. Radio talks and advertisements, posters, pamphlets, and newspaper and magazine articles made up a large majority of the publicity material, which spoke of using 'common sense' when around bodies of water, of being "Water Wise" ... [realising] the dangers and tak[ing] care to avoid them' ${ }^{66}$ The film, How to Drown, made in 1951, was a popular and well-received form of Prevent Drowning publicity. Shown in schools and town halls across the country, it provided a comical look into how easily drownings could occur or, as Joseph Cotterill, MP for Wanganui, explained, the film 'stress[ed] the absurdity of a situation [in which drownings occurred] in order to demonstrate the need for taking some care' ${ }^{67}$ The publicity was disseminated through a variety of channels, from the New Zealand

\footnotetext{
${ }^{64}$ Dudley Wills, 'Swimming with Safety', New Zealand School Journal, no. 4, Summer, 1954, p. 62

${ }^{65}$ I. A. G. Abernethy and J. E. Horton, 'Drowning and Near Drowning in New Zealand', Preventive Medicine Dissertation, University of Otago, 1956, p. 2.

${ }^{66}$ P. Veart, Radio Broadcast, IA 70, 3, 11, ANZW.

67 'How to Drown', ARNZ, 18828, R. V. 23, ANZW; Joseph Cotterill, New Zealand Parliamentary Debates, Vol. 295, 1 November 1951, p. 641.
} 
School Journal to the Transport Workers' Magazine, from radio sports' hours or women's hours to the Girls' Life Brigade Bulletin, seeking to reach all corners and sectors of New Zealand society. The task of organising and distributing the masses of publicity material and arranging 'film screenings, speeches, newspaper publicity and demonstrations' fell to Physical Welfare Officers. ${ }^{68}$ Unlike the Learn-to-Swim campaign which provided direct swimming instruction and urged New Zealanders to make their way to pools, beaches, rivers, and lakes (i.e. to use their leisure to pursue active recreation), the Prevent Drowning campaign offered no instruction and did not provide any demonstrations, it simply afforded material on safety.

The message portrayed through the publicity was more intricate than a simple 'reminder' telling swimmers and bathers to be vigilant around water and not to drown. According to the National Prevent Drowning Campaign Committee, the drowning rate seemed to indicate that New Zealanders did not know how to avoid drowning and the dangers the water posed, thus they needed some direction. The Prevent Drowning campaign, in opposition to the Amateur Swimming Association's philosophy, conveyed the idea that the key to 'safe swimming' lay in 'teaching people not to overestimate their ability ... [and] not to regard ability to swim a certain distance as the "be all and end all" of the art of swimming and water safety'. ${ }^{69}$ In order for people to practice 'safe swimming', the drowning prevention committee drew up a set of safety rules for swimmers and bathers to follow and educated them on how to identify risks (figure 19 and 20). Publicity material warned New Zealanders not to

[T]ake risks when swimming or bathing ... There is safety in numbers, go along with the crowd, don't swim alone ... Don't bathe too soon after a meal. Wait at least an hour ... Don't go beyond your depth ... Don't stay in the water when feeling tired, cold, numb ... Don't over-estimate your ability, even the strongest swimmer may suffer cramp ... Don't try to swim across rivers, streams or currents ... Don't bathe outside the marked safety zones ... If you tire easily, stay in shallow water ... Don't

\footnotetext{
68 'Physical Welfare Branch, Annual Report, 1952', IA 70, 1, 1, ANZW.

69 'Honourable Minister of Internal Affairs. The Inter-Departmental Committee Set up to Conduct a Campaign to Prevent Drownings in the 1949-50 Summer', IA 1, 2933, 139/7/15, part 2, ANZW.
} 
rush blindly into the water ... If you go on long swims, have two people along with you in a boat, one to row, one to watch you. ${ }^{70}$

Such knowledge, the committee hoped, would minimise the chance of accidents. New Zealanders, of course, had had varied measures attempting to prevent drownings prior to the National Prevent Drowning Campaign Committee's fashioning of 'Water Wisdom', and most of its water safety canons had been promoted by swimming instructors since around the beginning of the twentieth century. But this systematic, nationwide, government-funded, government-lead approach, and its urgency, were new, both in its structure and in its objective to change New Zealanders behaviour around, and attitudes towards, water.

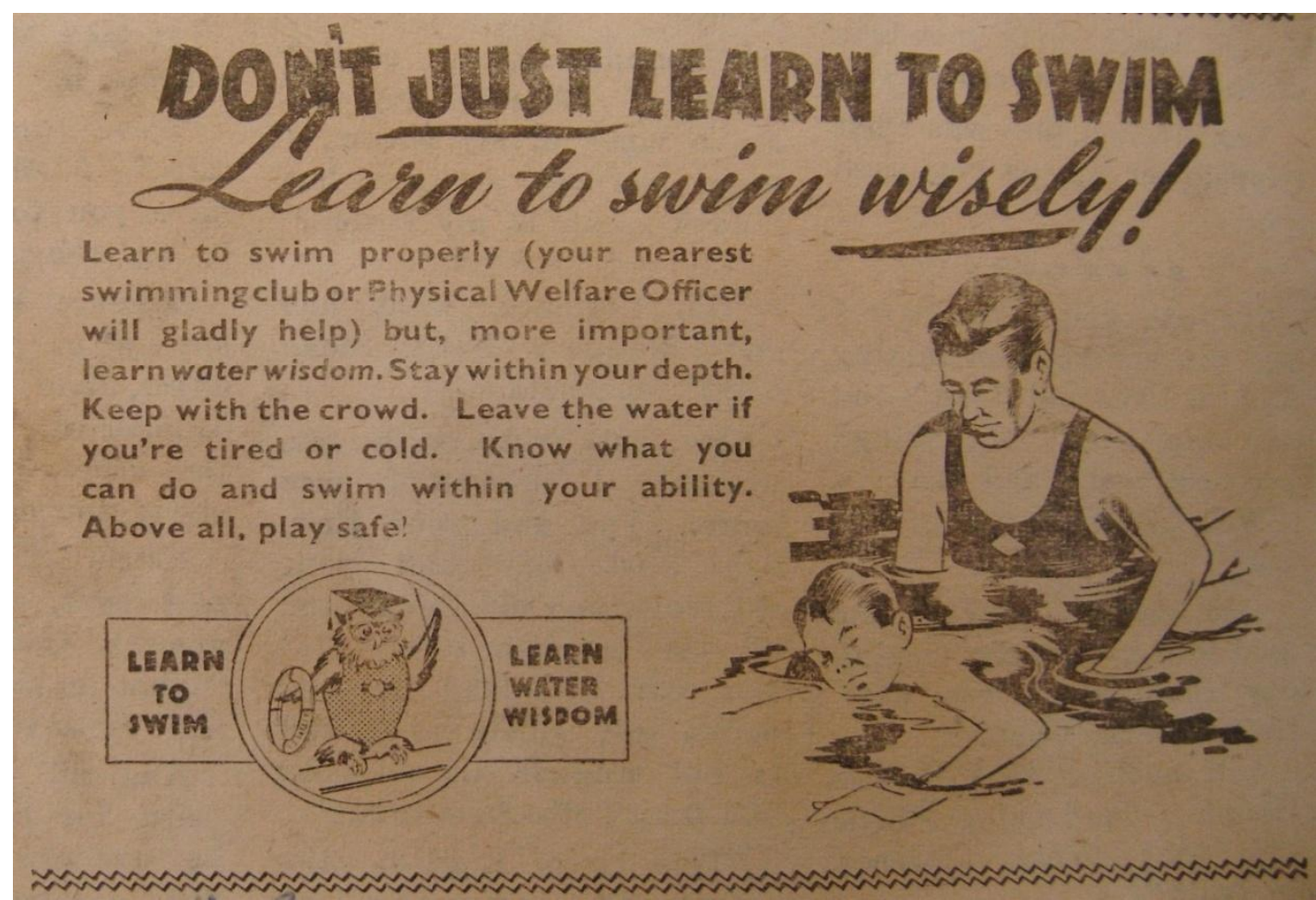

Figure 19 Learning to swim was not just about being able to keep afloat in the water or swimming distances. Swimmers also had to have safety knowledge and skills.

'Don't Just Learn to Swim, Learn to Swim Wisely', Challenge: Transport Workers' Magazine, 1 February, 1952, IA, 70, 3, 11, ANZW.

\footnotetext{
70 'Points in Publicity Aimed at Preventing Drownings', IA, 70, 3, ANZW.
} 


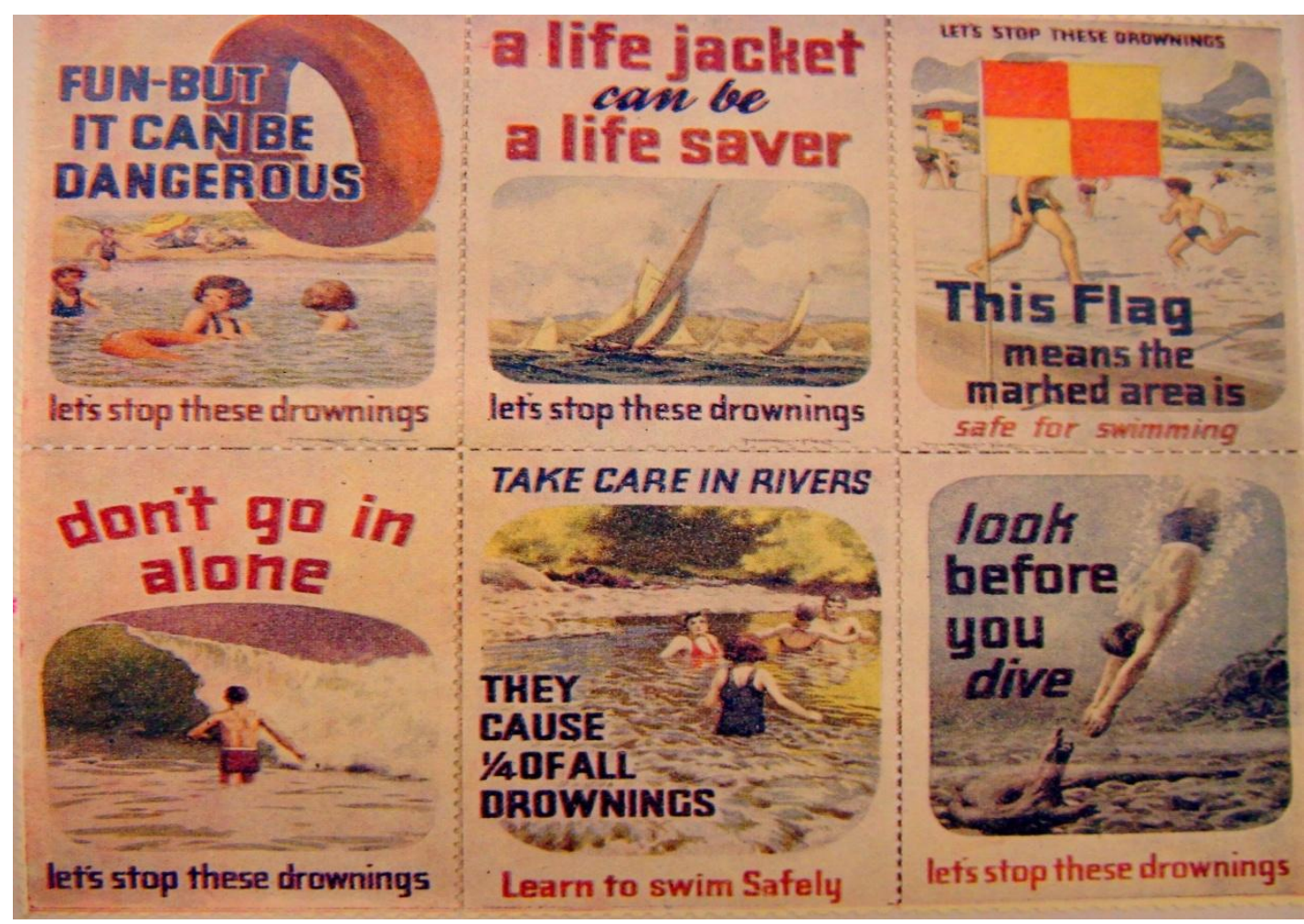

Figure 20 Stickers, thousands of which were printed, were a popular way of teaching children 'water wisdom'.

ABDU, W3570, 240, 7/16, ANZA.

The Learn-to-Swim campaign, by the late 1940s, was basically a campaign aimed at children. The Prevent Drowning campaign, on the other hand, resumed Parry's initial aim of targeting adults and saw drowning as an adult problem, or rather as a problem that could be solved by adults (figure 21). With increasing social and political importance placed on the family and motherhood from the late 1930s, there was a greater awareness of and emphasis on the role that parents, and particularly mothers, played in their children's lives. ${ }^{71}$ Consequently, more was expected of mothers in nurturing and caring for their children. While child drownings were largely seen to have simply been unfortunate accidents in the nineteenth century, such deaths were increasingly blamed on parents. 'In this fair land of ours', S. Childs, Mayor of Franklin, told the Franklin Times in 1952,

[W]ith its beaches, rivers, lakes, and streams and long hot summer days, it is well-nigh impossible to keep children out of the water and the obvious thing to do is to teach them to swim ... If on the other hand,

\footnotetext{
${ }^{71}$ Bronwyn Labrum, 'The Changing Meanings and Practices of Welfare, 1840s-1990s', in Giselle Brynes (ed.), The New Oxford History of New Zealand (Melbourne: Oxford University Press, 2009), p. 409.
} 
through inertia or laziness or disinterest or irresponsibility they fail to co-operate with the swimming club and a child loses its life through not being able to swim, then it might be fairly said that the parents have been accessory to the drowning and that the guilt lies at their door. ${ }^{72}$

Thus, if child drownings were going to be prevented, they were going to be prevented by parents. Not only did parents need to make sure that their children could swim, they themselves needed to be attentive to the dangers of the water because of the potential for children of all ages to drown (figure 22). Prevent Drowning publicity told parents that when their children were too young to be taught how to swim or learn water wisdom, constant supervision around water was essential. But so too was parental supervision, control, and caution needed for older children who now, having some knowledge of swimming, were at risk of getting into difficulties while playing in the water. The National Prevent Drowning Campaign Committee was deeply concerned that a 'lack of enthusiasm for swimming' and water safety rules shown by parents may not only have prevented some children from receiving adequate aquatic education, but also had the potential to foster indifference to safe swimming in their own children, thereby continuing the cycle of detrimental attitude towards risk. ${ }^{73}$ If children were going to be spared a possible drowning fate, then, Physical Welfare Officer R. Sheffield argued, 'parents themselves need educating regarding their children's interests'. ${ }^{74}$

\footnotetext{
72 'Learn to Swim', Franklin Times, 25 January 1952, IA 70, 3, 11, ANZW.

${ }^{73}$ M. Strawbridge to Chairman of the Taranaki Education Board, 12 December 1950, ABDU, W3570, 240, 7/16, ANZA.

${ }^{74}$ R. Sheffield to Officer-in-Charge of the Physical Welfare Branch, 21 March 1956, IA 1, 2934, 139/7/15, part 9, ANZW.
} 




Figure 21 The Prevent Drowning campaigns commonly appealed to mothers to take greater responsibility for their children's safety, by monitoring their behaviour and the environment.

The New Zealand Herald, 12 March 1953, p. 5, IA, 1, 2934, 139/7/15, part 6, ANZW. 


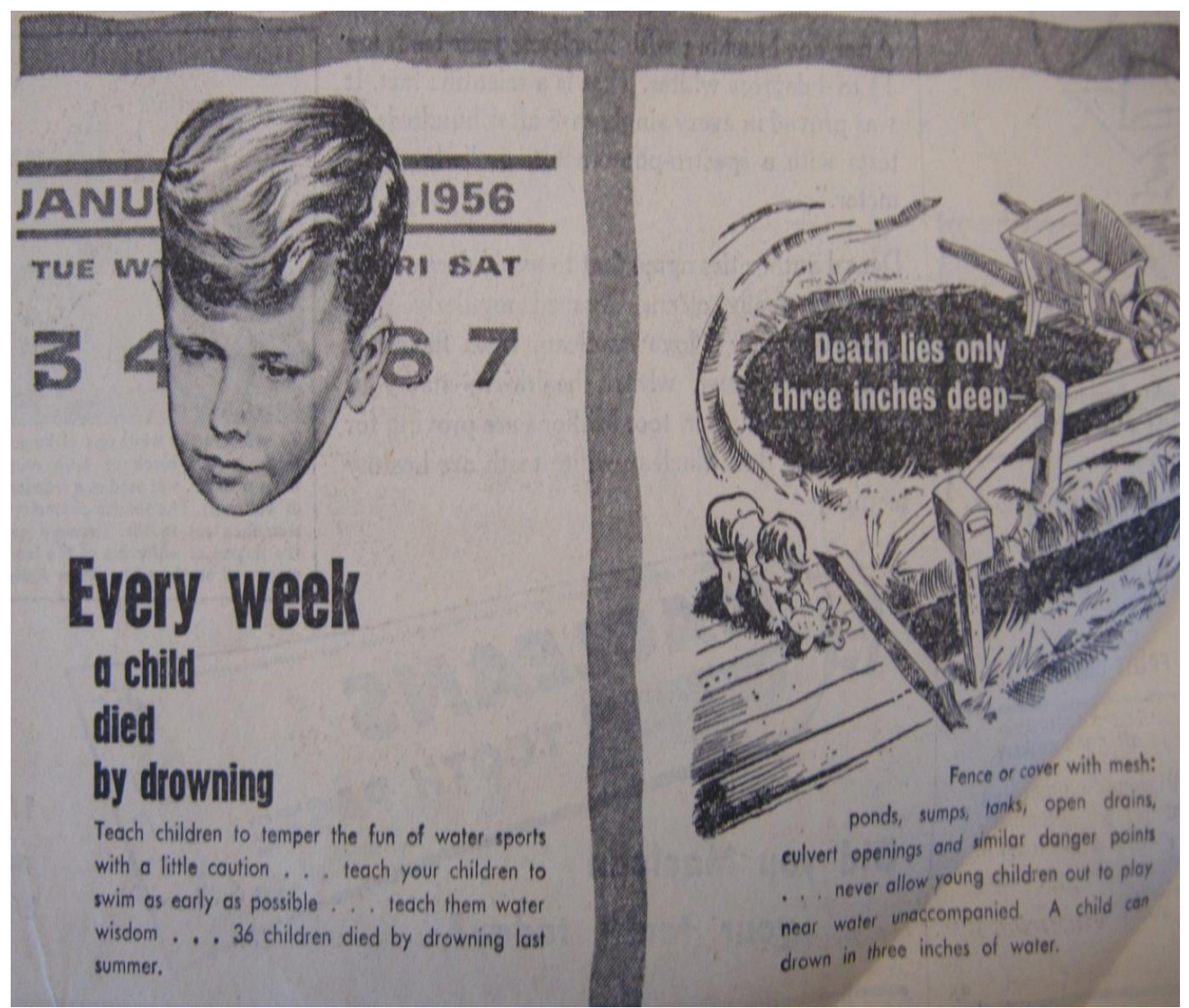

Figure 22 Prevent Drowning publicity pushed the idea of the different risks for children of different ages and thus of the need for parents to always be alert to the dangers regardless of whether their children could swim or not.

IA $70,4,12$, ANZW.

The main focus of the drowning prevention publicity was on adults and the necessity for them to become more responsible for their children's safety. However, the Physical Welfare Officers also spent a considerable proportion of their time distributing water safety information in schools because child drownings were so tragic that there could never be too many safeguards against these deaths. This was also a practical way to reinforce water safety messages in the homes of New Zealand's children. Unlike the material aimed at adults, the pamphlets, posters, cartoons, and stickers that Physical Welfare Officers supplied to children intended to encouraged them to acquire swimming and water skills, rather than simply bombarding them with rules. In 1954, the National Prevent Drowning Campaign Committee formulated the Fish Club Scheme, 'designed to foster water wisdom amongst children and to set a standard of competency that would assure a 
reasonable degree of safety to bathers' ${ }^{75}$ This programme established five levels of swimming and water safety competence and awarded badges ('minnow', 'sprat', 'fish', 'porpoise', and 'shark') to children according to their achievements. In order to be awarded the 'minnow' badge, children had to be able to tread water, turn from their face to their back and vice versa in the water, scull on their back using only their arms, stand in water and dive under, swim five yards, and stop and turn without touching the bottom or sides of a pool. By the time children reached the final 'shark' stage, they were expected to be able to swim 880 yards, bob and float in the water, swim twenty-five yards breaststroke, perform resuscitation, swim fully clothed, dive, and carry out rescues. ${ }^{76}$ Any notions of swimming for sport/competition were long gone. Instead, the skills taught in this programme were those which would help to ensure the ability to cope with and survive in the water. These badges proved to be a popular learning tool and were reported to have given 'considerable impetus to the swimming programmes'. ${ }^{77}$ The campaign committee also introduced wall charts and progress cards into schools in 1955 for teachers to monitor their pupils' progress. ${ }^{78}$ According to Higgins, these 'were printed purely for school use to pin point the ability of the individual' ${ }^{79}$ However, an expression of the deeper hostility that existed between the Physical Welfare Branch and the Physical Education Branch, the Education Department asserted that the charts were intended as 'an incentive to the child to do as well as his neighbour' and thus fostered competition in swimming. ${ }^{80}$ This was not at all how the Physical Welfare Branch viewed its efforts which were, first and foremost, about preventing drowning deaths.

Furthermore, the National Prevent Drowning Campaign Committee made a special appeal to Māori in the mid-1950s. From 1948, Physical Welfare Officers had been working with Maori Welfare Officers to see "what they could do to make sport and recreation part of the general "welfare" work' of the Maori Affairs

\footnotetext{
${ }^{75}$ W. A. Bodkin to Mr. Bowden, 18 April 1954, IA 1, 2934, 139/7/15, part 6, ANZW.

76 'Anti-Drowning Committee, Clubs', BCDQ, A739/4610c, 28/6/6B, ANZA

${ }^{77}$ J. W. Marshall to Superintendent of Physical Education, 18 February 1957, IA 1, 2934, 139/7/15, part 11, ANZW.

${ }^{78}$ D. Wills to Secretary of National Prevent Drowning Campaign Committee, 22 March 1956, IA 1, 2934, 139/7/15, part 9, ANZW.

${ }^{79}$ S. V. Higgins to Mr. W. M. Taylor (Endale School), 1 April 1957, IA, Series 1, Box 2934, Record no. 139/7/15, Part 11, ANZW.

${ }^{80}$ K. C. Reid to Superintendent of Physical Education, 7 July 1950, BCDQ, A739, 4610c, 28/6/6B, ANZA.
} 
Department. This was an attempt to instil leisure 'habits [in urban Māori] that would fit with the modernist demands of a waged workforce', while also "forestalling "problems" in the "adjustment" of young Māori newly arrived in provincial towns and main cities'. ${ }^{81}$ Part of the growing awareness of Māori among the Pākehā population that came with increasing Māori urbanisation, the Physical Welfare Branch initiated a Māori Prevent Drowning campaign with assistance from the Māori Affairs Department. Also a specific response to the disproportionately high drowning rate for Māori children, this campaign was carried out from around 1955 and mainly involved printing Prevent Drowning advertisements and information in Te Ao Hou, a magazine published by the Māori Affairs Department, and broadcasting messages on the radio, many in te reo. Like other Prevent Drowning material, the focus of the Māori publicity was on getting parents to assume a larger role in ensuring their children were water conscious (figure 23). One radio advertisement told listeners that

Last year 24 Maoris [sic] were accidentally drowned, among them were 10 children under 10 years of age. We must stop this loss of Maori life ... Remember heroes in olden times. Yes, they were wise in the dangers of water. They learnt to swim and swim well. Teach your young ones how to be good swimmers. Swim well Maori people. Have your children taught. Swimming clubs want to teach them. Make them wise to water. Save young Maori lives. ${ }^{82}$

Prevent Drowning publicity often asserted that in learning to swim safely, Māori were maintaining their traditional customs and thus their identity. However, the Prevent Drowning campaign disregarded traditional Māori methods of swimming and drowning prevention, such as telling children how taniwha 'had the power to change their appearance to any water related creature and cause harm or wellbeing to humans', making children 'wary, careful and respectful of the rivers and the sea'. ${ }^{83}$ Thus, the Prevent Drowning campaign sought to impose new swimming practices upon Māori, admitting them into a 'national' system and pattern of leisure,

\footnotetext{
${ }^{81}$ Charlotte Macdonald, Strong, Beautiful, and Modern: National Fitness in Britain, New Zealand, Australia, and Canada, 1935-1960 (Wellington: Bridget Williams Books, 2011), p. 91.

${ }^{82}$ Maori Water Safety Radio Campaign Recorded Script 1957, IA 1, 2934, 139/7/15, part 11, ANZW.

${ }^{83}$ John Mokomoko to Jessica Maynard, 30 October 2011.
} 
thinking, and code of conduct that would stamp out, as the author of one 1956 study of drowning deaths noted, the supposed "irrepressible and "happy-go-lucky" nature of these people [Māori]' that caused so many drowning deaths. ${ }^{84}$

Needless to say, New Zealanders were not simply going to change their bathing habits because the Government told them they should. And, while the number of motor vehicle accidents could 'be kept down by methods of official control and supervision' on the roads, there were no laws that could be applied 'to bathing disasters, which in the main are due to carelessness or recklessness on the part of the individual bather' ${ }^{85}$ The Prevent Drowning campaign had to try to persuade New Zealanders of the benefits and necessity of swimming wisely and following water safety rules. That drowning was an accident that should be prevented was not a matter on which New Zealanders needed to be sold. What they needed to come to realise, the Prevent Drowning campaign maintained, was how easily drownings could occur, how frequently they did occur, and how little effort was required to ensure that a day at the beach did not end in tragedy.

Fostering a sense of fear and fright was a method of drawing attention to the Prevent Drowning message and awakening the nation to the dangers of the water. During the 1954/1955 campaign, for instance, 'a solemn warning' was aired on the radio, exposing why adults needed to learn to swim and learn what to do in an emergency:

You go to the beach. Your child, or your friend's child gets into difficulty in the surf. You rush to the rescue. You cannot swim. You and the child are swept away. This happened to holiday makers last month. It happened this month. It will happen again and again until parents and every member of the family learns to be a good swimmer ... [This is a] grim reminder to be water wise - all the time. ${ }^{86}$

Such dramatic, emotive, and alarming declarations were far from uncommon. During the 1955/1956 campaign, an article was printed in the Girls' Life Brigade Bulletin stating that '[e]very summer since 1953 nearly 100 New Zealanders lost

${ }^{84}$ I. A. G. Abernethy and J. E. Horton, 'Drowning and Near Drowning in New Zealand', Preventive Medicine Dissertation, University of Otago, 1956, p. 38.

85 'Bathing Tragedies', Evening Star, 17 January 1941, IA 1, 2932, 139/7, part 2, ANZW.

${ }^{86}$ Department of Internal Affairs, Prevent Drowning Campaign 1954-5, Stations 1ZB, 2ZB, 3ZB, 4ZB, IA 1, 2934, 139/7/15, part 7, ANZW. 


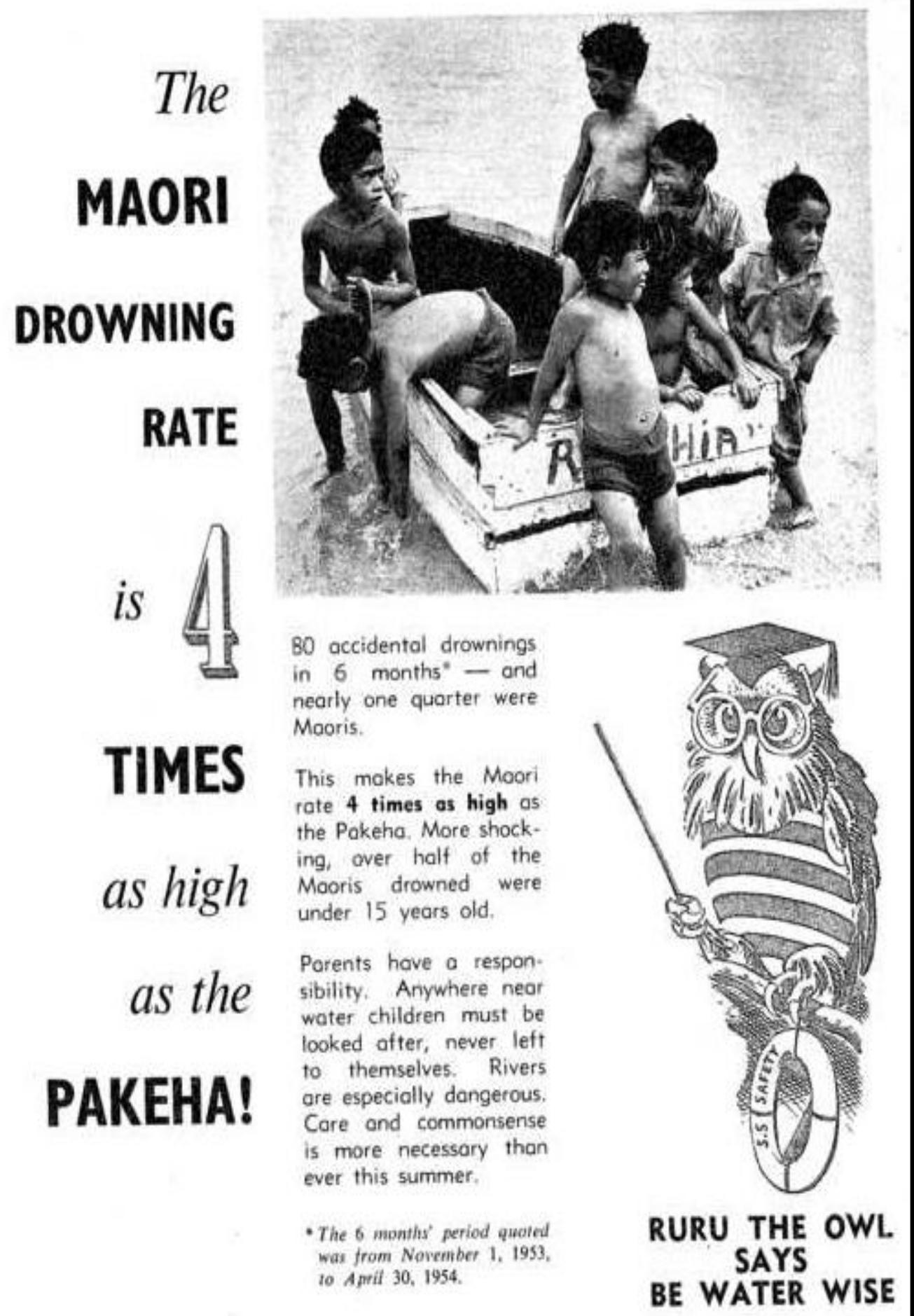

Issued by the National Prevent Drowning Commitee on behalf of the Internal Affairs Department,

Figure 23 From the mid-1950s, the National Prevent Drowning Campaign Committee launched a campaign specifically targeting Māori. Advertisements such as this were a common form of relaying the importance of taking care around water and in particular, of urging Māori parents to assume a greater role in ensuring their children's safety. 


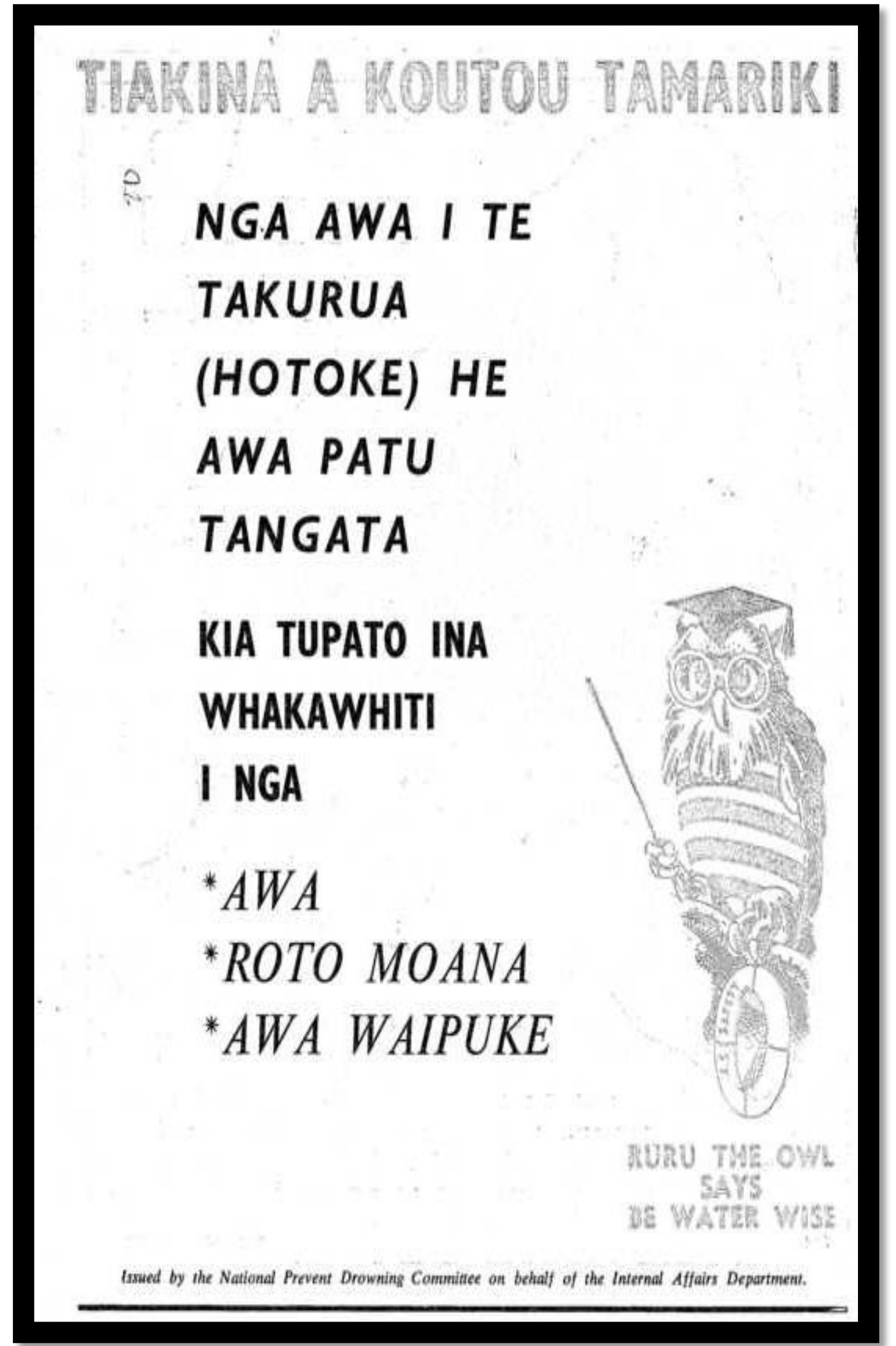

Figure 24 In attempt to reach New Zealand's Māori population, the National Prevent Drowning Campaign Committee often printed publicity material in te reo.

Te Ao Hou, no. 12, September, 1955, p. 66. 

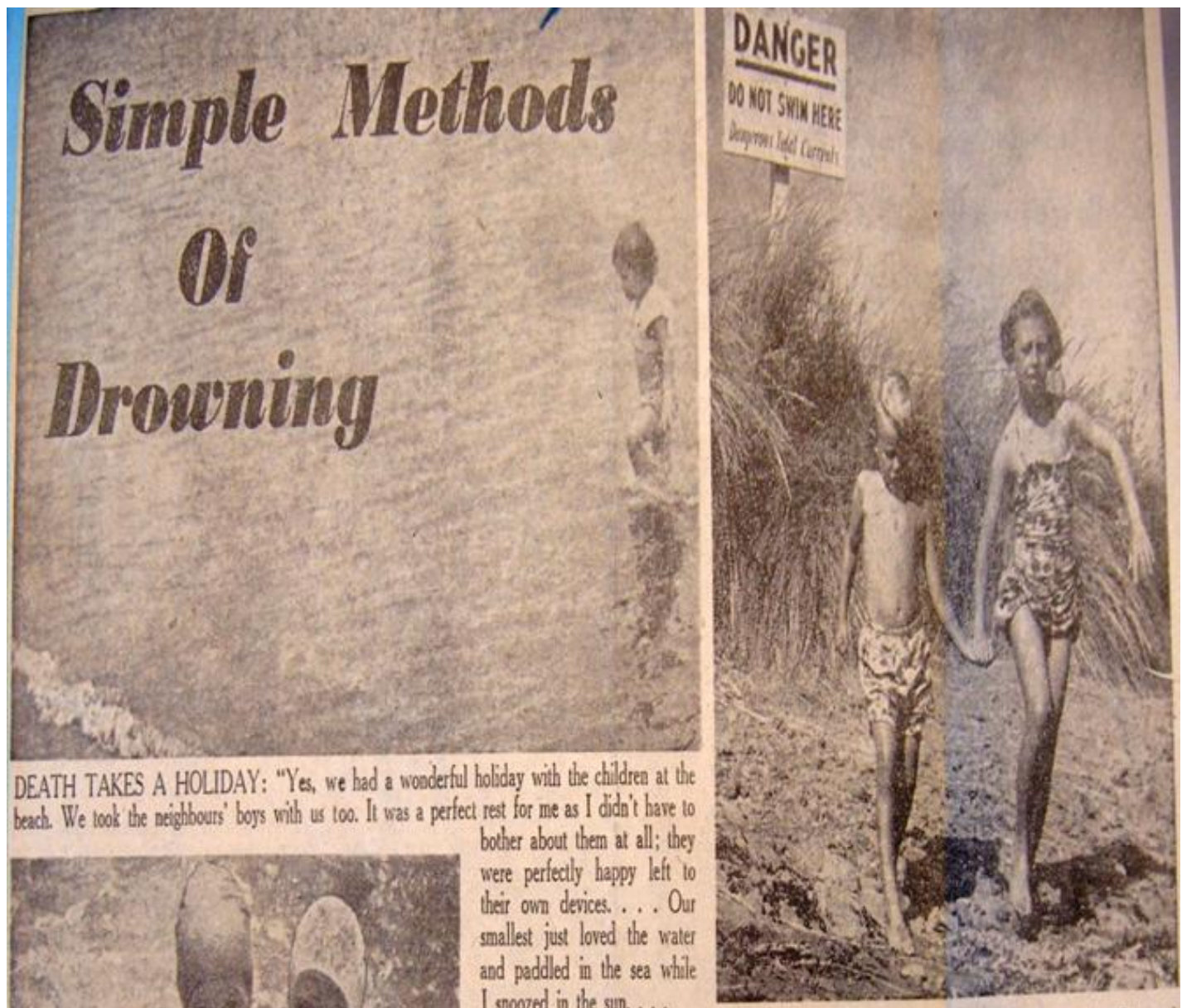

DEATH TAKES A HOLIDAY: "Yes, we had a wooderful holiday with the childree at the heach. We look the neichbouss' boys with us too. It was a perfect rest for me as I didn't have to

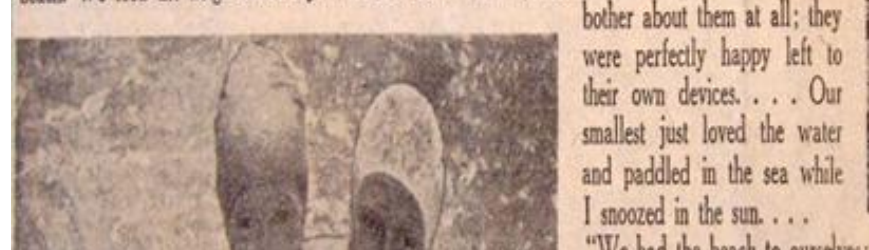
bother about them at all; they were perfectly happy left to smallest just loved the water and paddled in the sea whine I snoozed in the sun. ...

"We had the beach to ourselves; there were signs stuck about saying it was dangerous, but Tim and Jo are old enough to have the sense not to go too far out....

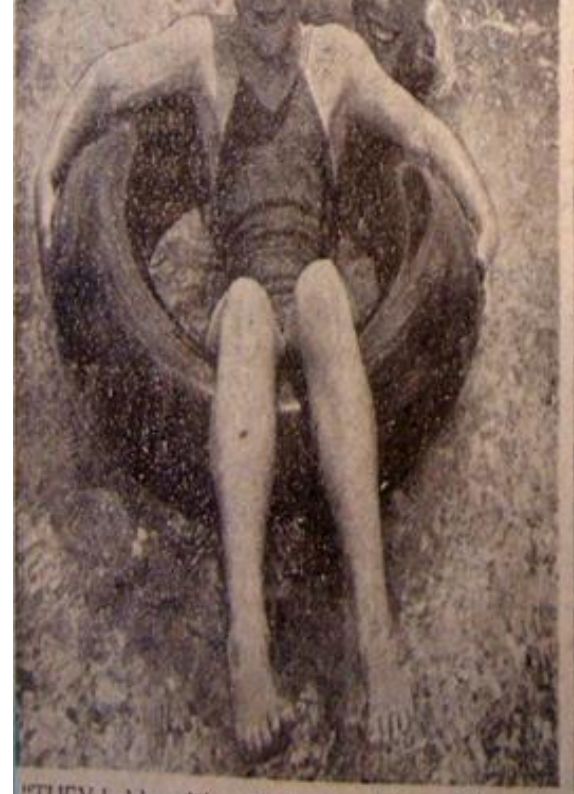

"THEY had lots of fun with the tyre and it does help 10 give then confidence in the wales. No parics when they dritied a bit

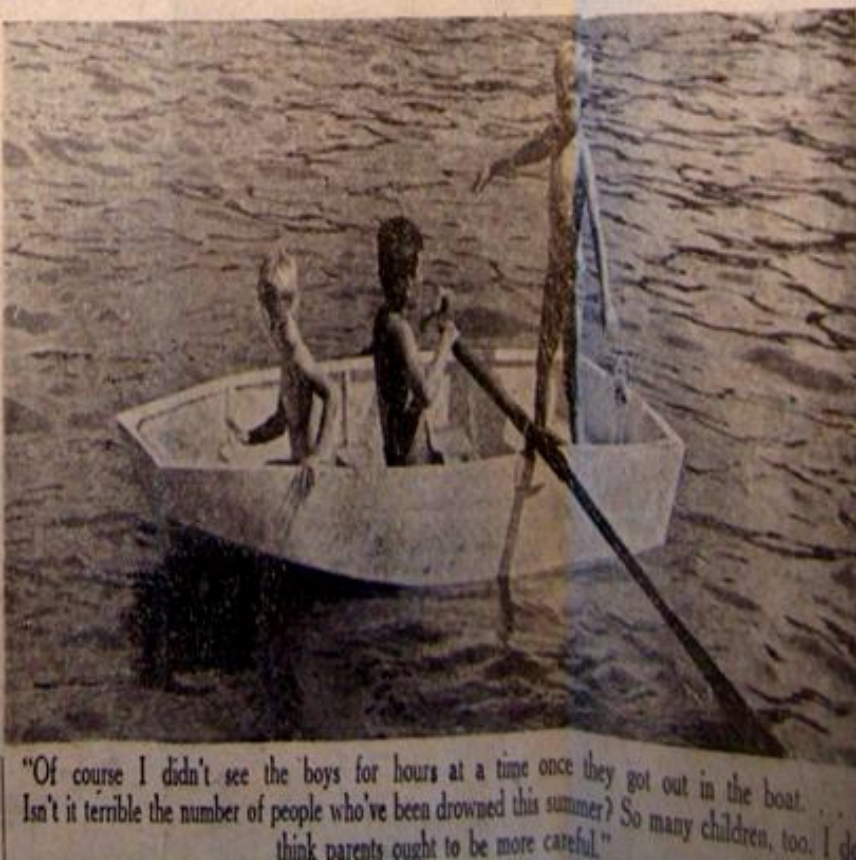

Figure 25 Newspaper articles were a common method of promoting the 'Prevent Drownings' message. This 1957 advertisement depicts situations that often lead to drownings among children and presents a very similar sentiment to the one expressed in the How to Drown film. 
their lives through drowning. Statistically the same number of fatalities may be expected this summer. Who will be the victims? Will you be one? ${ }^{87}$ The Prevent Drowning campaign suggested that anyone could get into difficulties in the water, that drowning could strike at any time, and could happen in the blink of an eye. Who would want to risk those odds? The emphasis on the near inevitability of drowning was not, the campaign committee claimed, an attempt to create a fear complex, it was simply a way to get New Zealanders to understand the need for constant care around water. ${ }^{88}$

Additionally, the Prevent Drowning campaign attempted to expose, to paraphrase Cotterill, the absurdity of drowning deaths, that is, to reveal how illogical it was not to learn how to swim and not to behave in a manner that could prevent oneself and one's family from dying (figure 25). 'Why normally sensible people', the Northland Times declared:

[W] ho obey all the rules of the road in motor vehicles, who live orderly, peaceful and law-abiding lives as citizens, should throw discretion and safety to the winds when they go bathing or boating in capricious waters is something that is difficult to understand. All these deaths suggest a failure to realise the threat to human life that is always present. ${ }^{89}$

Drownings were a terrible tragedy because they resulted in the "needless loss of young life at a time of the year when leisure and enjoyment should be the main consideration'. But they were even more 'heart-breaking' because they were apparently so easily avoided. ${ }^{90}$ All that it took to prevent drowning deaths was for people to be rational, responsible and use their 'common sense, or shall we say be "Water Wise", like the drowning prevention committee's mascot, the water wise owl. ${ }^{91}$

Another point emphasised by the Prevent Drowning campaign was that, while 'water safety' was something that benefitted the community, it was not a

${ }^{87}$ 'Will You Accidentally Drown This Year?', Girls' Life Brigade Bulletin, November [1955], IA 1, 2935, 139/7/15, part 12, ANZW.

${ }^{88}$ National Committee of Swimming and Life Saving, 'Survey of Drowning Fatalities November 1, 1949 to April 30, 1950', H 1, 1715, 34/64, 26709, ANZW.

89 'Appalling Toll of Drowning', Northland Times, 4 February 1957, IA 70, 4, 12, ANZW.

90 'Water Wisdom is Common Sense', Bay of Plenty Times, 22 December 1956, IA 70, 4, 12, ANZW.

${ }^{91}$ Mr. Veart, Broadcast, 1951-1952 IA 70, 3, 11, ANZW. 
duty of citizenship as swimming ability had been regarded under the 1935-1949 Labour Government. As the Hokitika Guardian noted in 1956, '[s]wimming is a national summer pastime, and it rests largely with the individual to make it a less tragic one than it is'. ${ }^{92}$ A reflection of the National Government's viewpoint, drowning prevention was a 'private' matter (but one which was important enough to receive some public support). Anyone could meet their death by drowning, and thus the Prevent Drowning campaign declared that everyone had a responsibility to be 'water wise'. But, this was a duty that people owed solely to themselves and their immediate family and friends. 'Water safety is a personal and public responsibility', a circular written by the Tauranga Amateur Swimming and Life Saving Club claimed:

We owe it to ourselves to take care. To teach our children to take care. To teach our children of water hazards and see that they learn to swim well. To our neighbours we have an obligation to become familiar with methods of artificial respiration so that in an emergency we can assist in reviving the victim of a water accident. ${ }^{93}$

Swimming competence and 'water wisdom' was no longer equated with being a responsible, social citizen. Rather it showed awareness of personal responsibility and self-reliance. But this also meant that the pressure was solely on the individual. The more serious side of drowning prevention, the National Prevent Drowning Campaign Committee asserted, did not, however, diminish the enjoyment of swimming. No New Zealander denied that reducing the drowning rate to the 'irreducible minimum' was a good thing, but if swimming between the flags, swimming with other people, not swimming too far out from the shore, watching for rips, checking for obstructions in the water, etc., were seen to limit 'how much pleasure, pure and simple, New Zealanders could enjoy', the drowning prevention committee feared that their safety messages would be ignored. ${ }^{94}$ Thus, to lessen any objections towards the suggested application of some restraints to leisure activity,

\footnotetext{
92 'Too Many Drownings', Hokitika Guardian, 6 February 1956, IA 70, 4, 12, ANZW.

93 'We must stop these drownings', Eileen Barry to Secretary of the National Prevent Drowning Campaign Committee, 4 September 1956, IA 1, 2934, 139/7/15, part 10, ANZW.

${ }^{94}$ National Prevent Drowning Campaign Committee, 'Official Drowning Survey for the Period Nov. $1^{\text {st }} 1953$ - April 30 ${ }^{\text {th }} 1954$ ', IA, 1, 2934, 139/7/15, Part 7, ANZW; Caroline Daley, Leisure and Pleasure: Reshaping and Revealing the New Zealand Body 1900-1960 (Auckland: Auckland University Press, 2003), p. 255.
} 
the Prevent Drowning campaign insisted that 'the prevention of drowning does not mean the prevention of swimming', and nor did water safety 'spoil anyone's fun'. 95 In fact, caution was described as a way to make swimming more enjoyable because it took (some of) the risk out of swimming and thus it meant that people did not need to worry so much about the dangers, which impeded complete and carefree enjoyment. The National Committee of Swimming and Life Saving explained in one of its drowning reports that:

You need not be an excellent swimmer to be Water-Wise ... but if he [sic] is water wise ... then he will be a sensible swimmer ... and that can help towards many long hours in the water ... [the drowning prevention campaign strives] to still further educate the people young and old in New Zealand to realise that they can swim in great comfort and with great enjoyment if they will learn to swim with caution and commonsense. $^{96}$

'Water wisdom' was thus anything but a barrier to New Zealanders' fun, freedom, and pleasure in their leisure; the more people followed water safety rules 'the longer they will live to enjoy the pleasures of reasonable bathing, ${ }^{97}$ In attempting to strike a balance between fun and risk, between the rational and irrational elements of swimming, the Prevent Drowning campaign advocated that there was every reason to swim and be 'water wise', and no reason at all not to.

Even more so than for the Learn-to-Swim campaign, it is hard to ascertain the extent to which New Zealanders in the 1950s engaged with the Prevent Drowning campaign and its water safety messages, as the practice of 'water wisdom' is much more difficult to measure than swimming ability. There was no significant change in drowning patterns, either in rate or nature, between 1949 and 1956 to indicate to what extent New Zealanders had become 'water wise'. There was a slight increase in the number of drowning deaths that occurred during that period (figure 3) but that could have resulted for any number of reasons including

\footnotetext{
95 "Swim Safely" Campaign, Facts and Figures, Notes for Speakers, IA 1, W2578, 178, 139/7/15, part 5, ANZW; National Water Safety Committee, 'Annual Survey of Accidental Drownings, May 1, 1962 - April 30, 1963’, BCDQ, A739, 4616a, 28/9/5, ANZA.

${ }^{96}$ National Committee of Swimming and Live Saving, 'Survey of Drowning Fatalities, November 1, 1952 - April 30, 1953', ABQU 632, W4452, 2, 1-7, 0253, ANZW.

97 Ibid.
} 
that there may have been more people bathing or perhaps the summer months were warmer for longer. But, the drowning rate did not increase, despite a surge in interest in swimming. At the time, the campaign was often given credit for the decline in the drowning rate. The National Prevent Drowning Campaign Committee stated in 1956 that

It would appear from the [drowning] figures that the Campaign is having a very great effect on the Water Wisdom of the community ... Since the campaign has been running the figures compare very favourably with those of 20 years ago. ${ }^{98}$

Comments from the Surf Life-saving Association also suggested that New Zealanders were in fact becoming more alive to the need for water safety. 'Five years ago [in 1951] they [surf lifeguards] had extreme difficulty in getting people to bathe in the sea that was safe; today $95 \%$ of the public bathed in patrolled areas', which was attributed to a growing understanding of water safety, thanks to the efforts of the Prevent Drowning campaign. ${ }^{99}$ Although there are no substantiated figures to back up their claims, the overall impression from those who were involved in the campaign was that 'there definitely appears to have been an [elevated] awareness in ... the necessity for taking precautions. People seem to have become swimming conscious in the sense that they are more aware of the hazards'. 100

\footnotetext{
${ }^{98}$ National Prevent Drowning Campaign, Minutes of Meeting, 5 March 1956, IA 1, 2934, 139/7/15, part 9.

${ }^{99}$ Prevent Drowning Meeting, Report of Proceedings of the Conference called by the Hon. S. W. Smith, Minister of Internal Affairs, at Wellington, on 26 July 1956, IA 1, 2934, 139/7/15, part 10, ANZW.

${ }^{100}$ P. J. Cusack, Prevent Drowning and Learn to Swim Campaigns, Auckland Area, 1951-2, IA 70, 3,11 , ANZW.
} 


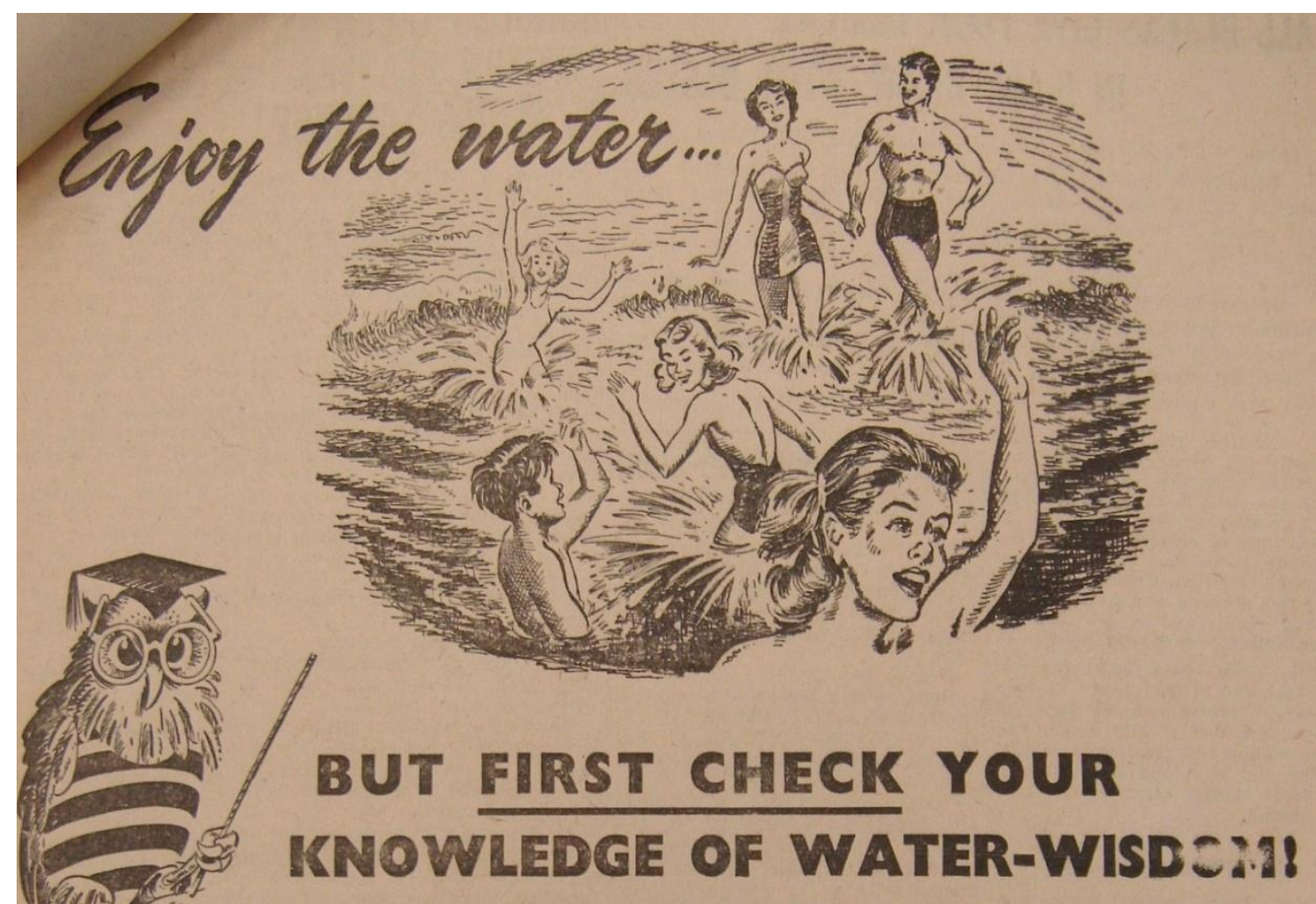

We New Zealanders are a water-loving people.... and there's no finer, healthier sport. But the tragic fact is that each year too many people (last year 65) are drowned through carelessness and ignorance. If you're going anywhere near the water this summer, check these precautions ... your own life or that of one of your loved ones may well depend upon it.

\title{
ON BEACHES:
}

Swim between the checkered flags. The local authorities know which areas are safo and patrol them... to go outside is to risk your life needlessly. If you bave cbildren, keep an eye on them ... more than balf of all drownings last season were "under fifteens." Be on your guard, too, against artificial swimming aids such as inflated tubes, life rafts, etc. They can quickly carry an unvary child out of bis depth.

\section{ON RIVERS:}

One out of every three drownings takes place in a river, creek or stream. The size of a river is no guide to its safety... some of the smallest, especially those with strong currents which can quickly sweep you off your feet, are the most treacherous. Never try to swim across a strange river. Diving in rivers is dangerous ... stbmerged stonos or logs can kill.

\section{ANYWHERE :}

\begin{abstract}
Don't svim alone .... there's safety in numbers.
Avoid "borseplay" , . . it's stupid and dangerous.

Set the example, don't "show off"; you can enjoy yourself as much in 3 feet of water as 30. Teach your children to swim and see that they (as well as you) have an all-round knowledgo of water skills, including life saving and artificial respiration.

If you bave children, remember that a beginner's certificate doesn't qualify them to cope with wiexpected emergencies. Don't weaken their confidence, but see that their sport is properly supervised at all times.
\end{abstract}

IBSU $0^{\circ}$ BY THE PREVENT DROWMING OOMMITTEE ON BEHALF OF THE INTERNAL AFFAIRA DEPARTMENT

Figure 26 Part of the Prevent Drowning Campaign involved informing New Zealanders of the risks that water-based recreation posed and advising them on how to avoid getting into dangerous situations. 


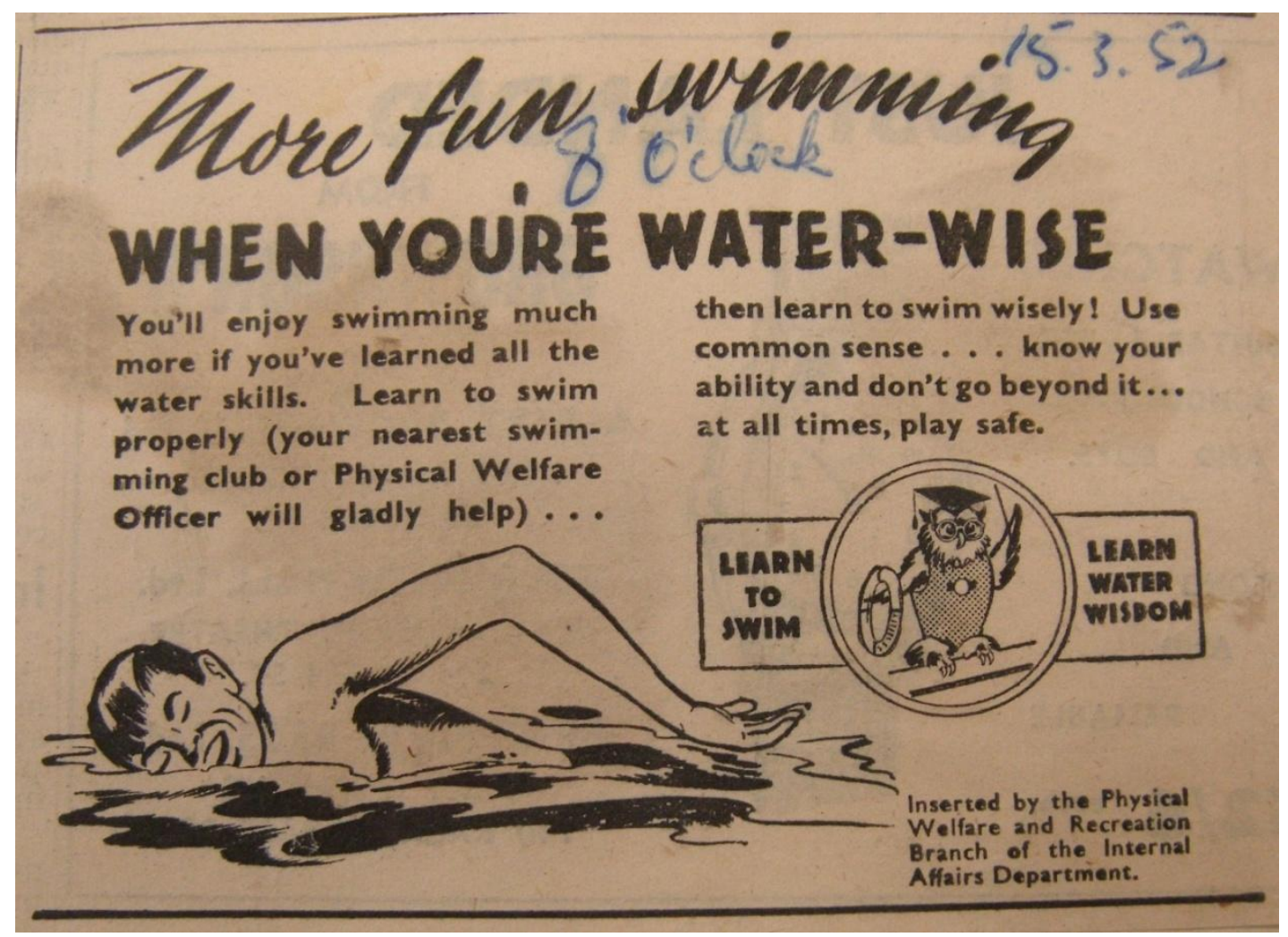

Figure 27 The National Prevent Drowning Campaign Committee assured New Zealanders that by being water wise they could enjoy the water ever more because there was less chance of them getting into difficulty.

8 o'clock Sports Edition and Star, 15 March 1952, IA, Series 70, Box 3, Item 11, ANZW.

In 1956, when the National Government was in the last stages of shutting down the Physical Welfare Branch, the Prevent Drowning campaign was similarly brought to an end. Without any Physical Welfare Officers, such a campaign was impossible. However, New Zealand society still saw immense value in drowning prevention and drowning was seen, even now, after decades of intensive growth in swimming, to be a major issue. Thus, demand remained for a national body to work towards preventing drowning deaths. This cause was taken up by voluntary swimming and lifesaving associations, who formed the National Water Safety Council. This council and its Water Safety campaign were almost identical to the Prevention Drowning campaign and the drowning prevention committee, except that it was privately rather than publicly run.

The Learn-to-Swim and Prevent Drowning campaigns represent the change in policy and attitudes towards swimming and drowning that New Zealand saw from 1936-1956. These campaigns mark a distinct period in the nation's recreational history not simply because of the extensive role that central 
government played in expanding opportunities for swimming, but also because they introduced New Zealanders to a new type of leisure, one that was at once more structured, and yet also offered greater freedom and enjoyment. The Learn-toSwim campaign was aimed at making New Zealanders' leisure time more constructive by presenting them with a chance to learn how to swim outside of the sporting and educational domains. Promoted as a healthful, enjoyable recreation, a means to prevent drowning deaths, and a duty of citizenship, recreational swimming became systematic, regulated, and prescriptive. But administrative tensions meant that the method of teaching and what was taught were disputed. Physical Welfare Officers assumed a less direct and involved role in New Zealanders' recreation through the Prevent Drowning campaign, with their main responsibility being to organise and distribute water safety information. This material advised swimmers, and non-swimmers, how to take care of themselves in and around water, as well as how to recognise and avoid risks so that the country's drowning rate would be reduced to the 'irreducible minimum'. With publicity as its sole means of achieving its aim, the National Prevent Drowning Campaign Committee had to present New Zealanders with intensely convincing reasons as to why they should be 'water wise'. Although the Learn-to-Swim and Prevent Drowning campaigns were short lived, their end was a consequence, not of the campaigns' failure to influence leisure, but of the view in the post-World War II era that leisure was a 'private' concern. The campaigns taught thousands of New Zealanders how to swim, created and facilitated widespread interest in swimming, and fostered a 'water wise' culture, all of which potentially saved many lives. The state was thus a key contributor to the modernisation of New Zealand's swimming culture in the mid-twentieth century. 


\section{Conclusion}

Between 1936 and 1956, swimming inability and drowning deaths became matters of major public and political importance in New Zealand. Interest in recreational swimming swelled and the pastime was transformed from a largely sporadic, informal, and variable leisure activity to one which was also specialised, standardised, and prescribed. This process of popularisation and modernisation was largely instigated by the efforts of the Physical Welfare Branch of the Department of Internal Affairs and its inauguration of the Learn-to-Swim and Prevent Drowning campaigns. The aim of this thesis has been to investigate and explain how recreational amateur swimming and water safety became widely valued leisure skills and pursuits from 1936-1956. Seeking to explore the social origins of the emergence of swimming and 'water wisdom' in New Zealand, this study reveals that changing attitudes towards death and health, leisure, and the role of the state were central elements in the expansion of amateur swimming in the mid-twentieth century.

In an attempt to account for why distress over swimming inability and drowning deaths grew in the mid-twentieth century, this thesis traced the trends and characteristics of drowning deaths in New Zealand. In the nineteenth century, drowning posed a major threat to settlers. However, as New Zealand became increasingly urbanised, the risk of drowning declined, to the point where the 1901 drowning rate was almost five times lower than the 1858 rate. By 1935, the Pākehā drowning rate was half its 1901 rate, and by 1960, it was one-third of the 1935 rate. Between 1935 and 1960, males, Māori, and children featured heavily among New Zealand's drowning victims. There were no notable changes to the ratio of male-tofemale or Māori-to-Pākehā drowning deaths during this period, though the proportion of drowning deaths for which children accounted increased. Nevertheless, the nation's drowning rate declined significantly from 1935-1960. As such, although Kevin Moran suggests that ' $[\mathrm{h}]$ istorically, demands for greater emphasis on swimming and water safety education have been consonant with rising fatalities from drowning accidents', in fact, between 1936 and 1956, alarm over levels of swimming inability and the incidence of drowning deaths escalated whilst 
the drowning rate fell. ${ }^{1}$ In other words, more concerted, proactive, and systematic approaches to drowning prevention, the Learn-to-Swim and Prevent Drowning campaigns were introduced in an effort to combat an already declining and uncommon cause of death. Therefore, drowning statistics alone do not explain why central government and voluntary swimming and lifesaving associations joined forces to democratise swimming ability in the mid-twentieth century.

Rather than being a direct response to drowning deaths, the Learn-toSwim and Prevent Drowning campaigns were the product of a convergence of various social and political circumstances which saw New Zealanders regard swimming inability and deaths by drowning as more avoidable and less excusable than ever before. Elected to power in 1935, the primary goal of New Zealand's first Labour Government was to establish a more stable and equal society in which every citizen, particularly workers, were guaranteed a decent standard of living. For Labour, the nation's health was equated with the health of its citizens and thus the Government reasoned that it had a duty to invest in New Zealanders' wellbeing. Bill Parry, Minister of Internal Affairs, believed that having a healthier nation, greater fitness and more active recreation was one of New Zealand's 'vital needs', and consequently, was an area in which the state needed to extend its influence. ${ }^{2}$ Swimming, well-known for its health benefits and as a safeguard against drowning, was an activity in which Parry was deeply interested. In 1936 he met with New Zealand's voluntary swimming and lifesaving associations to discuss the potential for more vigorous efforts to be made in expanding New Zealanders' opportunities to swim. This meeting led to the formation of the National Committee of Swimming and Life Saving and in the summer of 1936/1937. With Parry's help, the committee ran the first Learn-to-Swim campaign. Following the passage of the Physical Welfare and Recreation Act in November 1937, which sought to foster a new recreational culture, Government support and assistance for expanding amateur swimming as a popular recreation became more comprehensive. The Learn-to-Swim campaign became an annual event, fully funded by the government, and run with the support of Physical Welfare Officers. During World War II,

\footnotetext{
${ }^{1}$ Kevin Moran, The Shaping of Swimming and Water Safety Education in New Zealand (Auckland: Tradewinds, 2010), p. 2.

${ }^{2}$ William Parry, Notes for Minister's Speech. YMCA Sports Dinner, Auckland, p. 6, IA 1, 2929, 139/1, Archives New Zealand, Wellington (ANZW).
} 
Learn-to-Swim efforts were reduced but the importance of swimming ability for adults was realised within the wider reaches of New Zealand society.

In the late 1940s, patterns of leisure and political allegiances began to shift. This saw a new need for, and concept of, drowning prevention. In 1949 the National Prevent Drowning Campaign Committee was established by the Physical Welfare Branch. From this point on, the Physical Welfare Branch turned its attention towards carrying out Prevent Drowning campaigns, aimed at teaching and encouraging 'water wisdom', while its involvement in the Learn-to-Swim campaign diminished. Despite assuming primary responsibility for executing the Prevent Drowning campaign, the conservative National Government (1949-1957) sought to withdraw state influence from many of the 'private' areas into which the 1935-1949 Labour Government had intervened. From the early 1950s, National set about closing the Physical Welfare Branch and in 1956, just before the branch was completely disbanded, the Government relinquished its role in encouraging recreational swimming and water safety education, the task returning to the hands of the voluntary swimming and lifesaving associations. However, support for the existence of a national body to promote 'water wisdom' remained and the swimming and lifesaving associations established the National Water Safety Council to carry out a Water Safety campaign, for which the government provided some funding. This study reveals that the Learn-to-Swim and Prevent Drowning campaigns represent a period in New Zealand's leisure history during which the government assumed a prominent role in New Zealanders' aquatic recreation and amateur swimming was incorporated into the wider leisure economy, propelled by modern discourses of health, leisure, and government duty.

In spite of the priority given to the Learn-to-Swim and Prevent Drowning campaigns within the efforts of the Physical Welfare Branch, the campaigns have only been mentioned briefly in histories of the Physical Welfare and Recreation Act. This thesis, however, places the campaigns at the centre of the historical discussion. The Learn-to-Swim and Prevent Drowning campaigns were two very distinctive approaches to shaping New Zealanders' leisure practices, one aimed at improving the quality of leisure time so as to produce healthier citizens and the other principally concerned with promoting safety and preventing the "needless loss 
of young life'. ${ }^{3}$ Run by the Amateur Swimming Association and Physical Welfare Officers, the Learn-to-Swim campaign was a novel means of dealing with widespread swimming inability and presented New Zealand's non-swimmers with an opportunity to learn to swim outside of the educational and competitive domains.

Learn-to-Swim publicity claimed that swimming was one of the most healthful exercises people could participate in and not only that, it prevented drownings by harnessing the skills necessary to be a lifesaver. An expression of the Labour Government's belief in the link between national and individual health, Learn-to-Swim instructors asserted that it was the duty of every non-swimmer to learn how to swim. Still, swimming was proclaimed to be as enjoyable as it was important, with its health benefits being realised with relative ease. According to Learn-to-Swim promoters, the full extent of swimming's potential could only be achieved by learning how to swim along 'the most modern lines'; that is, it was not simply enough to have a paddle and a play, New Zealanders had to become proficient swimmers, capable of performing precise techniques and adhering to a standard method of practice. ${ }^{4}$ Improving health and preventing drownings were key objectives in the Learn-to-Swim campaign, but the underlying intention was to democratise amateur swimming, to reach out to those prospective avid swimmers who had not yet had the opportunity to learn to swim.

The Prevent Drowning campaign was less concerned with promoting and providing leisure than it was with making sure that leisure was executed safely, carefully, and sensibly. The National Prevent Drowning Campaign Committee maintained that learning to swim was only part of the solution to reducing New Zealand's drowning rate. Instead the answer lay in changing New Zealanders' attitudes towards the water and providing them with the knowledge to recognise and avoid its dangers. A more defensive approach to water safety than had been seen in New Zealand before, the Prevent Drowning campaign developed and disseminated water safety rules and information which, if respected, would prevent life threatening situations from arising and thus prevent drowning deaths. A significant part of the work of the Prevent Drowning campaign was convincing

\footnotetext{
3 'Water Wisdom is Common Sense', Bay of Plenty Times, 22 December 1956, IA 70, 4, 12, ANZW.

${ }^{4}$ National Committee of Swimming and Life Saving, "Learn-to-Swim" Campaign, 1939: National Survey of Campaign, Embracing Reports of District Committees, and Recommendations, etc. (Wellington: National Committee of Swimming and Life Saving, 1939), p. 38
} 
New Zealanders of the great need for 'water wisdom'. Posters, stickers, and pamphlets warned that drowning deaths were alarmingly common in New Zealand and could strike exceptionally quickly. They revealed that drowning deaths were completely incongruous because they were so easily prevented and they declared that being 'water wise' served to enhance rather than impede enjoyment. And unlike the Learn-to-Swim campaign which appealed to notions of responsible citizenship, the Prevent Drowning campaign presented an individualistic concept of water safety. 'Water wisdom' was not something to practice as a duty to the nation but was a responsibility that one owed to oneself and one's family; it was solely up to the individual to make sure they and their family were safe in the water.

To what extent these swimming and drowning prevention campaigns were a success in terms of reducing drowning numbers and improving swimming ability is difficult to accurately assess. Still, there is evidence to suggest that the campaigns had a positive impact on New Zealanders' swimming ability, enthusiasm for swimming, and drowning rates. Reports of the campaigns recorded large numbers of participants in Learn-to-Swim classes, even in the later years when political support for the campaign was slipping. Additionally, considerable improvement was made in levels of swimming ability; the drowning rate did not increase despite greater opportunities to swim, and the swimming association experienced greater demand for its swimming coaching and lessons. There seemed 'to be little doubt', Baxter O'Neill, secretary of the Amateur Swimming Association, claimed in 1945, that the community was 'becoming more alive to the value of swimming', just as New Zealanders were described as becoming increasingly aware of the need for caution around water, something which was reflected in the country's continually declining drowning rate. ${ }^{5}$

The Learn-to-Swim and Prevent Drowning campaigns were a reaction to modern conditions in the mid-twentieth century, but they were also a reflection of New Zealand's modernity, a reflection of the delicate balance that existed between the rational and irrational, fun and fear, freedom and restriction, and life and death. They were an attempt to modernise New Zealand's swimming culture and thereby modernise New Zealanders.

\footnotetext{
${ }^{5}$ Baxter O’Neill to William Parry, 10 October 1945, IA 1, 2128, 86/15/1, part 1, ANZW.
} 
This thesis has not explicitly drawn attention to change over time during the 1936-1956 period as its main aim has been to draw attention to the fact that this period was a distinct phase in the history of swimming. However, there were evident shifts within New Zealand's social and political climate between 1936 and 1956 which influenced attitudes towards and attempts to improve swimming and drowning rates. By the outbreak of World War I, the beach was firmly established as a pleasurable site of bathing. ${ }^{6}$ However, swimming (i.e. a systematic, regulated, prescribed activity) was largely an educational subject or sporting pursuit, and as such it was an interest of the few. In the post-Great Depression era, however, the urgency of restoring New Zealand's vitality saw recreation assume an important role within the Labour Government's nation-building agenda. 'Proper' swimming, taught in pools, by a swimming coach using a standardised method of instruction, became a prominent part of this effort, embracing the rational recreationist ethos of productive, efficient leisure. In the early 1940s, war disrupted all aspects of life but it proved to be advantageous with regard to establishing interest in swimming as the deaths of New Zealand's troops overseas by drowning created considerable distress. As a response, the Ministry of Defence began to take greater steps towards protecting the welfare of the defence force; swimming ability was seen as vital to New Zealand's success. The 1940s also saw swimming become more prominent within the education system as the school curriculum was expanded to better suit the nation's democratic code. Subsidies were provided for the construction of school pools, which hundreds of schools took advantage of, and the emphasis of swimming lessons was directed away from swimming for sport to swimming for safety.

The post-war years saw continued growth in New Zealanders' awareness of the benefits and delights of swimming, but post-war prosperity saw New Zealanders' leisure become increasingly privatised and this created new impetus for drowning prevention. Car ownership and increasing leisure time meant that New Zealanders had greater access to the country's more secluded, unguarded beaches, expanding their potential to drown. Thus, water safety - teaching people how to be their own lifesavers and making them more responsible for their own safety - became vital. In the 1950s, with schools largely responsible for teaching

\footnotetext{
${ }^{6}$ Caroline Daley, Leisure and Pleasure: Reshaping and Revealing the New Zealand Body 1900-
} 1960 (Auckland: Auckland University Press, 2003), p. 159. 
children to swim and the importance of swimming ability widely appreciated, there was less need for a Learn-to-Swim campaign to continue. But it was precisely because of the high regard in which New Zealanders held swimming that 'water wisdom' education retained public and national prominence.

By the time former Wellington-resident William Moore's children were learning to swim in the 1950s and 1960s, an obvious and significant shift had occurred in recreational swimming practices from when Moore himself had learnt to swim as a toddler. While most children prior to, and indeed well past, the 1930s received an informal (i.e. self-taught, taught by parents, siblings, or friends) or nonexistent swimming education, Moore's four children participated in a specialised and institutionalised swimming culture that would dominate into the twenty-first century. That is, they received lessons at the Freyberg pool in Wellington as part of their school's physical education programme and further advanced their swimming ability by taking lessons from a professional swimmer and coach at the Naenae pools. ${ }^{7}$ The period 1936-1956 was one of massive growth and change for recreational swimming culture. '[T] he older, more passive, pre-World War I notion [and practice] of "bathing", was replaced with the skilled and trained 'active recreation' of swimming, there was a boom in swimming public and school pool construction, public money was more readily accessible for swimming related schemes, swimming tuition became more widely available, and 'water wisdom' became a notable feature in New Zealanders' repertoire of recreational knowledge and skills. ${ }^{8}$ By the 1960 s, swimming bore little resemblance to the activity that was pursued in the early twentieth century. It was this period which saw the rise of New Zealand's modern recreational swimming culture, and was a development in which the Learn-to-Swim and Prevent Drowning campaigns played a significant role.

The history of swimming and water safety affords a striking and remarkable view of New Zealand society. Within a matter of decades, swimming went from being a limited, sporting activity to a necessary skill that, along with 'water wisdom', all New Zealanders were expected to learn and practice. A possible avenue for future historical investigations could be to consider whether the New Zealand experience of swimming during the mid-twentieth century was

\footnotetext{
${ }^{7}$ William Moore, interviewed by Jessica Maynard, 23 September 2011, in Waikanae, Kapiti Coast.

${ }^{8}$ Charlotte Macdonald, Strong, Beautiful, and Modern: National Fitness in Britain, New Zealand, Australia, and Canada, 1935-1960 (Wellington: Bridget Williams Books, 2011), p. 57.
} 
evident elsewhere. It would be interesting to see if swimming had such priority within the recreational domains of other nations. This study can only tenuously surmise that similar patterns of change occurred overseas within the domain of swimming, specifically in Britain, Australia, and Canada, as national fitness programmes were also run in these states around the same time as the Physical Welfare Branch was active in New Zealand.

There are numerous angles to and features of swimming, which historians could consider in future studies. One area which could be examined with particular reference to the topic of this thesis is road safety. A seemingly mismatched subject at first, there are notable connections between swimming and water safety and driving and road safety, particularly during the period on which this study has focused; a road safety campaign, managed by the Transport Department, was in existence at the same time as the Learn-to-Swim and Prevent Drowning campaigns. Aside from being part of the broad realm of transport, freight, sports, and travel, driving and road safety also sit within the domain of leisure, and the road safety and drowning prevention campaigns present an opportunity for an interesting comparative history. These campaigns were characterised by government involvement, increasing (or the perception of increasing) accidental deaths, and employed similar methods to achieve their aims. But there were also significant differences in terms of implementation, funding, levels of government involvement, and who was responsible for reducing risks. Such a study could provide a distinctive perspective of swimming, as well as of driving, and offer insight into the growth of risk society and risk management.

While the perceptions of and reactions to drowning and swimming inability may have changed since the Learn-to-Swim and Prevent Drowning campaigns were first instigated, it is safe to say that the belief in 'the value of swimming and the necessity of having every child taught to swim' remains strong in twenty-first century New Zealand. ${ }^{9}$ In the last half of the twentieth century, swimming and 'water wisdom' continued to gain ground as essential skill. By the end of the twentieth century, approximately ninety-five per cent of New Zealanders

\footnotetext{
${ }^{9}$ Baxter O’Neill to William Parry, 10 October 1945, IA 1, 2128, 86/15/1, part 1, ANZW.
} 
could swim. ${ }^{10}$ With this continued expansion of swimming, the activity came to be regarded as part of our national identity. The then-Minister of Internal Affairs, Nathan Guy, noted at the 2011 Water Safety Conference that

New Zealand is an island nation, and a big part of our culture is based around the water. Swimming in the ocean or at the local river, lake or swimming pool is a part of the Kiwi way of life. But there's still too many New Zealanders who can't swim well enough. ${ }^{11}$

In recent years, swimming and water safety have once again received considerable public attention in New Zealand and the issue of whose responsibility it is to provide swimming education has resurfaced amid concerns over the closure of school pools and the apparent rising drowning rate. Journalist Nikki Macdonald wrote in a newspaper article in December 2011, for instance, that New Zealanders

[O]ught to be fish on legs. The moment the sun stirs over a watery horizon, Kiwis pack towels, pull on jandals and head to the nearest beach or river ... [but] we're growing a generation of Kiwis who can't save themselves. Around the country, derelict swimming pools gather slime ... Already, twice as many Kiwis as Brits and Australians drown'. ${ }^{12}$

New Zealanders' notion of swimming as being 'part of the Kiwi way of life' implies that swimming competency has always been good, that swimming has always been taught in schools, and that it has always been widely recognised as a necessary survival skill in this island nation. Thus, recent media accounts have incited distress because reports of swimming inability and drownings seem to suggest that something is going wrong. However, this thesis has challenged how longstanding and how robust New Zealand's swimming culture and competency has been.

\footnotetext{
${ }^{10}$ Jock Phillips, 'Sports and Leisure - Informal Sports', Te Ara - the Encyclopedia of New Zealand; http://www.TeAra.govt.nz/en/sports-and-leisure/3 [accessed 20 September 2011].

11 Nathan Guy, 'Speech to the Water Safety New Zealand Conference', beehive.govt.nz; http://www.beehive.govt.nz/speech/speech-water-safety-new-zealand-conference [accessed 12 January 2011].

${ }^{12}$ Nikki Macdonald, 'Deep Water', Your Weekend: The Dominion Post, 17 December 2011, pp. 810 .
} 
This thesis has examined the rise of one of contemporary society's most popular leisure activities over the period 1936-1956. During this time, New Zealand society began to value swimming as a social and individual good but also as a recreation which could be enjoyed. The establishment of the National Water Safety Council in 1956 signalled the end of a period of extensive government intervention into New Zealanders' swimming. However, interest in swimming and respect for 'water wisdom' remained intact and swimming continued to grow as a popular recreation. This thesis has studied the shifting values and concerns that characterised modern society in the mid-twentieth century and shaped how New Zealanders understood health, leisure, and government duty. But the topic also has the potential to inform and elucidate current concerns, which are based around a desire to strengthen the (perceived) social norm of swimming that the midtwentieth century gave rise to. The Learn-to-Swim and Prevent Drowning campaigns were a distinct response to the social and political settings in New Zealand in the mid-twentieth century. This was not a period when recreational swimming was regarded as characteristic of 'Kiwiness', but when swimming was seen as a means to become 'happy, healthy, and useful'. 
Appendices 


\section{Appendix A - Pākehā Drownings, 1858-1901}

Year Population

Total Violent

Total

1858

1859

1860

1861

1862

1863

$1864 \quad 171,009$

1865

1866

1867

1868

1869

1870

$1871 \quad 254,928$

1872

1873

1874

1875

1876

1877

$1878 \quad 412,465$

1879

1880

1881

1882

1883

1884

1885

\section{Drownings Deaths Deaths}

$53 \quad 70 \quad 582$

$\begin{array}{lll}45 & 74 & 704\end{array}$

$\begin{array}{lll}52 & 98 & 1092\end{array}$

$\begin{array}{lll}63 & 133 \quad 1109\end{array}$

$51 \quad 145 \quad 1231$

$106 \quad 241 \quad 1983$

$80 \quad 218 \quad 2921$

$\begin{array}{lll}151 & 291 \quad 2757\end{array}$

$141 \quad 303 \quad 2540$

$125 \quad 278 \quad 2702$

$153 \quad 322 \quad 2662$

$136 \quad 322$

$117 \quad 259$

$107 \quad 307$

$116 \quad 300$

$114 \quad 320$

$103 \quad 328$

$164 \quad 392$

$189 \quad 462$

172

15

15

17

140

161

170

148

147
499

468

511

503

459

505

494

548

517
2721

2703

2642

3112

3647

4161

5712

4909

4685

4645

5583

5437

5491

5701

6061

5740

6081
Rate of

Drowning Drowning drownings

$\%$ Violent

Deaths 76

61

53

47

35

44

37

52

47

45

48

42

45

35

39

36

31

42

41

35

33

30

34

31

32

34

27

28
100,000

population

9.1

89

6.4

4.8

5.7

64

4.1

5.3

2.7

5.5

5.6

4.6

57

5.7

5.0

4.3

4.0

42

3.7

3.1

2.5

35

2.9

3.9

3.7

3.3

38

2.8

3.1

2.5

29

2.8

2.8

2.6

2.4 
Rate of

Total Violent Total Drownings \%

drownings

\begin{tabular}{|c|c|c|c|c|c|c|c|}
\hline Year & Population & $\begin{array}{r}\text { Total } \\
\text { Drownings }\end{array}$ & $\begin{array}{l}\text { Violent } \\
\text { Deaths }\end{array}$ & $\begin{array}{r}\text { Total } \\
\text { Deaths }\end{array}$ & $\begin{array}{r}\text { Drownings \% } \\
\text { Violent } \\
\text { Deaths }\end{array}$ & $\begin{array}{r}\text { Drowning \% } \\
\text { all Deaths }\end{array}$ & $\begin{array}{r}\text { per } \\
100,000 \\
\text { population }\end{array}$ \\
\hline 1886 & 576,524 & 161 & 571 & 6135 & 28 & 2.6 & 28 \\
\hline 1887 & & 181 & 555 & 6137 & 33 & 2.9 & \\
\hline 1888 & & 168 & 513 & 5708 & 32 & 2.9 & \\
\hline 1889 & & 174 & 508 & 5772 & 34 & 3.0 & \\
\hline 1890 & & 160 & 521 & 5994 & 31 & 2.7 & \\
\hline 1891 & 624,455 & 145 & 506 & 6518 & 29 & 2.2 & 23 \\
\hline 1892 & & 177 & 529 & 6459 & 34 & 2.7 & \\
\hline 1893 & & 155 & 545 & 6767 & 28 & 2.3 & \\
\hline 1894 & & 301 & 697 & 6918 & 43 & 4.4 & \\
\hline 1895 & & 179 & 597 & 6863 & 30 & 2.6 & \\
\hline 1896 & 407,094 & 165 & 588 & 6432 & 28 & 2.6 & 41 \\
\hline 1897 & & 184 & 545 & 6595 & 34 & 2.8 & \\
\hline 1898 & & 123 & 547 & 7244 & 23 & 1.7 & \\
\hline 1899 & & 149 & 542 & 7680 & 28 & 1.9 & \\
\hline 1900 & & 148 & 575 & 7200 & 26 & 2.1 & \\
\hline 1901 & 770,304 & 149 & 582 & 7634 & 26 & 2.0 & 19 \\
\hline
\end{tabular}

Total

$6,204 \quad 18,228 \quad 205,370$

34

3 


\section{Notes for statistics 1858-1901:}

Population is based on the census as stated in Ministry of Works, Town and Country Planning Branch, A Survey of New Zealand Population: An Analysis of Past Trends and an Estimate of Future Growth (Wellington: Ministry of Works, 1960), p. 2.

From 1858-71, the statistics record all unnatural deaths (i.e. not caused by disease or illness) as having occurred as a consequence of 'external causes' (although I refer to them as violent deaths here). From 1872-1901, unnatural deaths were referred to as accidental and/or violent deaths.

Drownings include suicides because there was no differentiation between drowning by suicide and accidental drowning in the earliest figures.

The percentages of deaths caused by drownings are rounded to one decimal point because later figures were so small that they had to be rounded to a decimal point. All other percentages and rates were rounded to the nearest whole number.

No official statistics were recorded for Māori deaths during this period.

Source: Statistics of New Zealand, 1858-1901. 


\begin{tabular}{|c|c|c|c|c|c|c|}
\hline Year & Population & $\begin{array}{l}\text { Total } \\
\text { Deaths }\end{array}$ & $\begin{array}{l}\text { Violent } \\
\text { Deaths }\end{array}$ & $\begin{array}{l}\text { Accidental } \\
\text { Drownings }\end{array}$ & $\begin{array}{l}\text { Drowning\% } \\
\text { of Violent } \\
\text { Deaths }\end{array}$ & $\begin{array}{l}\text { Drowning \% of } \\
\text { All Deaths }\end{array}$ \\
\hline 1935 & $1,485,814$ & 12,217 & 779 & 134 & 17 & 1 \\
\hline 1936 & $1,492,344$ & 13,056 & 864 & 115 & 13 & 0.9 \\
\hline 1937 & $1,504,826$ & 13,658 & 903 & 107 & 12 & 0.8 \\
\hline 1938 & $1,519,606$ & 14,754 & 999 & 149 & 15 & 1 \\
\hline 1939 & $1,539,420$ & 14,158 & 853 & 92 & 11 & 0.7 \\
\hline 1940 & $1,546,312$ & 14,282 & 879 & 113 & 13 & 0.8 \\
\hline 1941 & $1,538,620$ & 15,146 & 867 & 96 & 11 & 0.6 \\
\hline 1942 & $1,545,112$ & 16,385 & 886 & 66 & 7 & 0.4 \\
\hline 1943 & $1,538,651$ & 15,447 & 933 & 61 & 7 & 0.4 \\
\hline 1944 & $1,556,318$ & 15,363 & 837 & 66 & 8 & 0.4 \\
\hline 1945 & $1,593,947$ & 16,051 & 787 & 79 & 10 & 0.5 \\
\hline 1946 & $1,659,145$ & 16,093 & 871 & 72 & 9 & 0.5 \\
\hline 1947 & $1,696,188$ & 15,904 & 849 & 75 & 9 & 0.5 \\
\hline 1948 & $1,731,583$ & 15,812 & 999 & 77 & 8 & 0.5 \\
\hline 1949 & $1,767,674$ & 16,012 & 933 & 80 & 9 & 0.5 \\
\hline 1950 & $1,795,830$ & 16,715 & 898 & 64 & 7 & 0.4 \\
\hline 1951 & $1,831,058$ & 17,512 & 1014 & 90 & 9 & 0.5 \\
\hline 1952 & $1,875,940$ & 17,413 & 1010 & 81 & 8 & 0.5 \\
\hline 1953 & $1,924,680$ & 17,009 & 1039 & 78 & 8 & 0.5 \\
\hline 1954 & $1,966,454$ & 17,667 & 1,198 & 87 & 7 & 0.5 \\
\hline 1955 & $2,005,871$ & 17,953 & 1169 & 95 & 8 & 0.5 \\
\hline 1956 & $2,044,752$ & 18,403 & 1023 & 102 & 10 & 0.6 \\
\hline 1957 & $2,089,307$ & 19,411 & 1220 & 107 & 9 & 0.6 \\
\hline 1958 & $2,137,483$ & 19,014 & 1188 & 81 & 7 & 0.4 \\
\hline 1959 & $2,180,543$ & 19,814 & 1135 & 83 & 7 & 0.4 \\
\hline 1960 & $2,217,242$ & 19,524 & 1195 & 76 & 6 & 0.4 \\
\hline Total & & 424,773 & 25,328 & 2,326 & 9 & 0.5 \\
\hline
\end{tabular}


Appendix C - Māori Drownings, 1935-1960

\begin{tabular}{|c|c|c|c|c|c|c|}
\hline Year & Population & $\begin{array}{l}\text { Total } \\
\text { Deaths }\end{array}$ & $\begin{array}{l}\text { Violent } \\
\text { Deaths }\end{array}$ & $\begin{array}{l}\text { Accidental } \\
\text { Drownings }\end{array}$ & $\begin{array}{l}\text { Drowning \% } \\
\text { of Violent } \\
\text { Deaths }\end{array}$ & $\begin{array}{l}\text { Drowning \% } \\
\text { all Deaths }\end{array}$ \\
\hline 1935 & 80,559 & 1447 & 83 & 19 & 23 & 1.3 \\
\hline 1936 & 82,887 & 1602 & 94 & 19 & 20 & 1.2 \\
\hline 1937 & 85,146 & 1557 & 83 & 22 & 27 & 1.4 \\
\hline 1938 & 87,157 & 2120 & 76 & 16 & 21 & 0.8 \\
\hline 1939 & 89,092 & 1775 & 100 & 18 & 18 & 1.0 \\
\hline 1940 & 90,993 & 1593 & 97 & 16 & 16 & 1.0 \\
\hline 1941 & 92,328 & 1901 & 92 & 20 & 22 & 1.1 \\
\hline 1942 & 94,460 & 1732 & 91 & 22 & 24 & 1.3 \\
\hline 1943 & 96,984 & 1675 & 80 & 27 & 34 & 1.6 \\
\hline 1944 & 99,477 & 1686 & 74 & 20 & 27 & 1.2 \\
\hline 1945 & 100,743 & 1635 & 74 & 6 & 8 & 0.4 \\
\hline 1946 & 101,675 & 1627 & 93 & 24 & 26 & 1.5 \\
\hline 1947 & 105,094 & 1538 & 101 & 16 & 16 & 1.0 \\
\hline 1948 & 107,816 & 1473 & 96 & 16 & 17 & 1.1 \\
\hline 1949 & 110,544 & 1566 & 107 & 16 & 15 & 1.0 \\
\hline 1950 & 113,262 & 1369 & 119 & 20 & 17 & 1.5 \\
\hline 1951 & 116,471 & 1324 & 105 & 17 & 16 & 1.3 \\
\hline 1952 & 120,209 & 1483 & 123 & 11 & 9 & 0.7 \\
\hline 1953 & 124,126 & 1345 & 133 & 11 & 8 & 0.8 \\
\hline 1954 & 128,456 & 1209 & 145 & 21 & 14 & 1.7 \\
\hline 1955 & 133,075 & 1272 & 145 & 29 & 20 & 2.3 \\
\hline 1956 & 138,081 & 1293 & 131 & 25 & 19 & 1.9 \\
\hline 1957 & 143,284 & 1451 & 148 & 20 & 14 & 1.4 \\
\hline 1958 & 148,369 & 1287 & 146 & 21 & 14 & 1.6 \\
\hline 1959 & 154,074 & 1314 & 139 & 21 & 15 & 1.6 \\
\hline 1960 & 159,768 & 1368 & 152 & 21 & 14 & 1.5 \\
\hline Total & & 39,642 & 2,827 & 494 & 17 & 1.2 \\
\hline
\end{tabular}


Appendix D -Pākehā Drowning Rate, 1935-1960

\begin{tabular}{|c|c|c|c|}
\hline Year & $\begin{array}{l}\text { Accidental } \\
\text { Drownings }\end{array}$ & Pākehā Population & $\begin{array}{l}\text { Rate of Drownings } \\
\text { per } 100,000 \\
\text { Population }\end{array}$ \\
\hline 1935 & 134 & $1,485,814$ & 9 \\
\hline 1936 & 115 & $1,492,344$ & 8 \\
\hline 1937 & 107 & $1,504,826$ & 7 \\
\hline 1938 & 149 & $1,519,606$ & 10 \\
\hline 1939 & 92 & $1,539,420$ & 6 \\
\hline 1940 & 113 & $1,546,312$ & 7 \\
\hline 1941 & 96 & $1,538,620$ & 6 \\
\hline 1942 & 66 & $1,545,112$ & 4 \\
\hline 1943 & 61 & $1,538,651$ & 4 \\
\hline 1944 & 66 & $1,556,318$ & 4 \\
\hline 1945 & 79 & $1,593,947$ & 5 \\
\hline 1946 & 72 & $1,659,145$ & 5 \\
\hline 1947 & 75 & $1,696,188$ & 5 \\
\hline 1948 & 77 & $1,731,583$ & 4 \\
\hline 1949 & 80 & $1,767,674$ & 5 \\
\hline 1950 & 64 & $1,795,830$ & 4 \\
\hline 1951 & 90 & $1,831,058$ & 5 \\
\hline 1952 & 81 & $1,875,940$ & 4 \\
\hline 1953 & 78 & $1,924,680$ & 4 \\
\hline 1954 & 87 & $1,966,454$ & 4 \\
\hline 1955 & 95 & $2,005,871$ & 5 \\
\hline 1956 & 102 & $2,044,752$ & 5 \\
\hline 1957 & 107 & $2,089,307$ & 5 \\
\hline 1958 & 81 & $2,137,483$ & 4 \\
\hline 1959 & 83 & $2,180,543$ & 4 \\
\hline 1960 & 76 & $2,217,242$ & 3 \\
\hline
\end{tabular}

Total 2,326 
Appendix E -Māori Drowning Rate, 1935-1960

\begin{tabular}{|c|c|c|c|}
\hline Year & $\begin{array}{l}\text { Accidental } \\
\text { Drownings }\end{array}$ & $\begin{array}{l}\text { Māori } \\
\text { Population }\end{array}$ & $\begin{array}{l}\text { Rate of Drownings per } \\
100,000 \text { Population }\end{array}$ \\
\hline 1935 & 19 & 80,559 & 24 \\
\hline 1936 & 19 & 82,887 & 23 \\
\hline 1937 & 22 & 85,146 & 26 \\
\hline 1938 & 16 & 87,157 & 16 \\
\hline 1939 & 18 & 89,092 & 20 \\
\hline 1940 & 16 & 90,993 & 18 \\
\hline 1941 & 20 & 92,328 & 22 \\
\hline 1942 & 22 & 94,460 & 23 \\
\hline 1943 & 27 & 96,984 & 28 \\
\hline 1944 & 20 & 99,477 & 20 \\
\hline 1945 & 6 & 100,743 & 6 \\
\hline 1946 & 24 & 101,675 & 24 \\
\hline 1947 & 16 & 105,094 & 18 \\
\hline 1948 & 16 & 107,816 & 15 \\
\hline 1949 & 16 & 110,544 & 14 \\
\hline 1950 & 20 & 113,262 & 18 \\
\hline 1951 & 17 & 116,471 & 15 \\
\hline 1952 & 11 & 120,209 & 9 \\
\hline 1953 & 11 & 124,126 & 9 \\
\hline 1954 & 21 & 128,456 & 16 \\
\hline 1955 & 29 & 133,075 & 22 \\
\hline 1956 & 25 & 138,081 & 18 \\
\hline 1957 & 20 & 143,284 & 14 \\
\hline 1958 & 21 & 148,369 & 13 \\
\hline 1959 & 21 & 154,074 & 14 \\
\hline 1960 & 21 & 159,768 & 13 \\
\hline
\end{tabular}

Total

494 


\section{$\underline{\text { Appendix F - Drowning Rate (Māori and Pākehā), 1935-1960 }}$}

\begin{tabular}{|c|c|c|c|c|c|}
\hline $\begin{array}{c}\text { Year } \\
1935\end{array}$ & $\begin{array}{l}\text { Pākehā } \\
\text { Drownings } \\
134\end{array}$ & $\begin{array}{l}\text { Māori } \\
\text { Drownings } \\
\end{array}$ & $\begin{array}{l}\text { Total } \\
\text { Drownings } \\
\qquad 153\end{array}$ & $\begin{array}{l}\text { Total } \\
\text { Population } \\
1,566,373\end{array}$ & $\begin{array}{l}\text { Rate of } \\
\text { Drownings } \\
\text { per100,000 } \\
\text { Population } \\
10\end{array}$ \\
\hline 1936 & 115 & 19 & 134 & $1,575,231$ & 9 \\
\hline 1937 & 107 & 22 & 129 & $1,589,972$ & 8 \\
\hline 1938 & 149 & 16 & 163 & $1,606,763$ & 1 \\
\hline 1939 & 92 & 18 & 110 & $1,628,512$ & 7 \\
\hline 1940 & 113 & 16 & 129 & $1,637,305$ & 8 \\
\hline 1941 & 96 & 20 & 116 & $1,630,948$ & 7 \\
\hline 1942 & 66 & 22 & 88 & $1,639,572$ & 5 \\
\hline 1943 & 61 & 27 & 88 & $1,635,635$ & 5 \\
\hline 1944 & 66 & 20 & 86 & $1,655,795$ & 5 \\
\hline 1945 & 79 & 6 & 85 & $1,694,690$ & 5 \\
\hline 1946 & 72 & 24 & 96 & $1,760,820$ & 5 \\
\hline 1947 & 75 & 16 & 91 & $1,801,282$ & 5 \\
\hline 1948 & 77 & 16 & 93 & $1,839,399$ & 5 \\
\hline 1949 & 80 & 16 & 96 & $1,878,218$ & 5 \\
\hline 1950 & 64 & 20 & 84 & $1,909,092$ & 4 \\
\hline 1951 & 90 & 17 & 107 & $1,947,529$ & 6 \\
\hline 1952 & 81 & 11 & 92 & $1,996,149$ & 5 \\
\hline 1953 & 78 & 11 & 89 & $2,048,806$ & 4 \\
\hline 1954 & 87 & 21 & 108 & $2,094,910$ & 5 \\
\hline 1955 & 95 & 29 & 124 & $2,138,946$ & 6 \\
\hline 1956 & 102 & 25 & 127 & $2,182,833$ & 6 \\
\hline 1957 & 107 & 20 & 127 & $2,232,591$ & 6 \\
\hline 1958 & 81 & 21 & 102 & $2,285,852$ & 4 \\
\hline 1959 & 83 & 21 & 104 & $2,334,617$ & 4 \\
\hline 1960 & 76 & 21 & 97 & $2,377,010$ & 4 \\
\hline
\end{tabular}

Total 
$\underline{\text { Appendix G - Pākehā Drownings by Sex, 1935-1960 }}$

\begin{tabular}{|c|c|c|c|c|}
\hline Year & Males & Females & $\begin{array}{l}\text { Total Pākehā Accidental } \\
\text { Drownings }\end{array}$ & $\%$ of Females Drowned \\
\hline 1935 & 117 & 17 & 134 & 13 \\
\hline 1936 & 100 & 15 & 115 & 13 \\
\hline 1937 & 91 & 16 & 107 & 15 \\
\hline 1938 & 129 & 20 & 149 & 13 \\
\hline 1939 & 69 & 23 & 92 & 25 \\
\hline 1940 & 89 & 24 & 113 & 21 \\
\hline 1941 & 72 & 24 & 96 & 35 \\
\hline 1942 & 51 & 15 & 66 & 22 \\
\hline 1943 & 46 & 15 & 61 & 25 \\
\hline 1944 & 54 & 12 & 66 & 18 \\
\hline 1945 & 66 & 13 & 79 & 16 \\
\hline 1946 & 58 & 14 & 72 & 19 \\
\hline 1947 & 57 & 18 & 75 & 24 \\
\hline 1948 & 56 & 21 & 77 & 27 \\
\hline 1949 & 56 & 24 & 80 & 30 \\
\hline 1950 & 52 & 12 & 64 & 19 \\
\hline 1951 & 76 & 14 & 90 & 16 \\
\hline 1952 & 62 & 19 & 81 & 23 \\
\hline 1953 & 58 & 20 & 78 & 26 \\
\hline 1954 & 71 & 16 & 87 & 18 \\
\hline 1955 & 69 & 26 & 95 & 27 \\
\hline 1956 & 81 & 21 & 102 & 21 \\
\hline 1957 & 82 & 25 & 107 & 23 \\
\hline 1958 & 65 & 16 & 81 & 20 \\
\hline 1959 & 63 & 20 & 83 & 24 \\
\hline 1960 & 62 & 14 & 76 & 18 \\
\hline Total & 1,852 & 474 & 2,326 & 20 \\
\hline
\end{tabular}


$\underline{\text { Appendix H - Māori Drownings by Sex, 1935-1960 }}$

\begin{tabular}{|c|c|c|c|c|}
\hline Year & $\begin{array}{l}\text { No. Males } \\
\text { Drowned }\end{array}$ & $\begin{array}{l}\text { No. Females } \\
\text { Drowned }\end{array}$ & $\begin{array}{l}\text { Total Māori } \\
\text { Accidental } \\
\text { Drownings }\end{array}$ & $\begin{array}{l}\% \text { of Female } \\
\text { Drowning Victims }\end{array}$ \\
\hline 1935 & 12 & 7 & 8 & 37 \\
\hline 1936 & 13 & 6 & 19 & 32 \\
\hline 1937 & 18 & 4 & 22 & 18 \\
\hline 1938 & 12 & 4 & 16 & 22 \\
\hline 1939 & 14 & 4 & 18 & 22 \\
\hline 1940 & 12 & 4 & 16 & 25 \\
\hline 1941 & 15 & 5 & 20 & 25 \\
\hline 1942 & 17 & 5 & 22 & 23 \\
\hline 1943 & 19 & 8 & 27 & 30 \\
\hline 1944 & 15 & 5 & 20 & 25 \\
\hline 1945 & 6 & 0 & 6 & 0 \\
\hline 1946 & 21 & 3 & 24 & 13 \\
\hline 1947 & 13 & 3 & 16 & 16 \\
\hline 1948 & 11 & 5 & 16 & 31 \\
\hline 1949 & 12 & 4 & 16 & 25 \\
\hline 1950 & 15 & 5 & 20 & 25 \\
\hline 1951 & 13 & 4 & 17 & 24 \\
\hline 1952 & 9 & 2 & 11 & 18 \\
\hline 1953 & 8 & 3 & 11 & 27 \\
\hline 1954 & 14 & 4 & 18 & 19 \\
\hline 1955 & 22 & 7 & 29 & 24 \\
\hline 1956 & 19 & 6 & 25 & 24 \\
\hline 1957 & 17 & 3 & 20 & 15 \\
\hline 1958 & 16 & 5 & 21 & 25 \\
\hline 1959 & 14 & 7 & 21 & 33 \\
\hline 1960 & 13 & 8 & 21 & 38 \\
\hline Total & 373 & 121 & 494 & 24 \\
\hline
\end{tabular}




\section{$\underline{\text { Appendix I - Pākehā Drownings by Age, 1935-1960 }}$}

$\begin{array}{lrrrrrrrrrr}\text { Age/Year } & \mathbf{1 9 3 5} & \mathbf{1 9 3 6} & \mathbf{1 9 3 7} & \mathbf{1 9 3 8} & \mathbf{1 9 3 9} & \mathbf{1 9 4 0} & \mathbf{1 9 4 1} & \mathbf{1 9 4 2} & \mathbf{1 9 4 3} & \mathbf{1 9 4 4} \\ \text { Under } 12 & & & & & & & & & & \\ \text { months } & 0 & 1 & 1 & 1 & 1 & 0 & 0 & 0 & 1 & 0 \\ \text { 1-4 years } & 18 & 12 & 14 & 19 & 19 & 10 & 5 & 3 & 17 & 18 \\ \text { 5-9 years } & 9 & 6 & 5 & 9 & 4 & 5 & 6 & 6 & 8 & 5 \\ \text { 10-14 years } & 15 & 4 & 5 & 7 & 1 & 2 & 3 & 2 & 4 & 3 \\ \text { 15-19 years } & 16 & 8 & 9 & 22 & 10 & 1 & 2 & 1 & 8 & 9 \\ \text { 20-24 years } & 8 & 19 & 13 & 16 & 5 & 7 & 8 & 9 & 1 & 3 \\ \text { 25-29 years } & 11 & 7 & 8 & 10 & 3 & 9 & 3 & 4 & 3 & 3 \\ \text { 30-34 years } & 5 & 3 & 7 & 13 & 5 & 15 & 6 & 8 & 1 & 4 \\ \text { 35-39 years } & 8 & 6 & 5 & 6 & 4 & 12 & 10 & 5 & 0 & 0 \\ \text { 40-44 years } & 6 & 5 & 3 & 7 & 7 & 9 & 8 & 5 & 5 & 4 \\ \text { 45-49 years } & 6 & 6 & 9 & 5 & 4 & 6 & 5 & 2 & 0 & 3 \\ \text { 50-54 years } & 8 & 12 & 3 & 8 & 7 & 4 & 4 & 2 & 1 & 1 \\ \text { 55-59 years } & 8 & 10 & 9 & 7 & 11 & 3 & 3 & 1 & 0 & 3 \\ \text { 60-64 years } & 9 & 9 & 5 & 7 & 2 & 3 & 7 & 4 & 6 & 5 \\ \text { 65-69 years } & 3 & 2 & 4 & 4 & 3 & 6 & 5 & 3 & 5 & 1 \\ 70-74 \text { years } & 1 & 1 & 2 & 5 & 2 & 7 & 5 & 3 & 0 & 3 \\ \text { 75-79 years } & 1 & 3 & 4 & 1 & 4 & 5 & 3 & 2 & 1 & 1 \\ \text { 80-84 years } & 2 & 0 & 1 & 2 & 0 & 3 & 5 & 0 & 0 & 0 \\ \text { 85-89 years } & 0 & 1 & 0 & 0 & 0 & 3 & 2 & 2 & 0 & 0 \\ \text { 90-94 years } & 0 & 0 & 0 & 0 & 0 & 2 & 2 & 3 & 0 & 0 \\ \text { Unspecified } & 0 & 0 & 0 & 0 & 0 & 1 & 4 & 1 & 0 & 0 \\ \text { Total } & 134 & 115 & 107 & 149 & 92 & 113 & 96 & 66 & 61 & 66\end{array}$


Age/Year

$\begin{array}{llllllllll}1945 & 1946 & 1947 & 1948 & 1949 & 1950 & 1951 & 1952 & 1953 & 1954\end{array}$

Under 12

$\begin{array}{lrrrrrrrrrr}\text { months } & 0 & 0 & 0 & 0 & 1 & 1 & 0 & 0 & 0 & 0 \\ \text { 1-4 years } & 42 & 23 & 25 & 36 & 25 & 17 & 14 & 11 & 30 & 26 \\ \text { 5-9 years } & 4 & 10 & 7 & 8 & 5 & 5 & 8 & 6 & 10 & 8 \\ \text { 10-14 years } & 10 & 4 & 7 & 2 & 9 & 3 & 3 & 6 & 4 & 2 \\ \text { 15-19 years } & 7 & 4 & 1 & 3 & 5 & 9 & 9 & 5 & 4 & 8 \\ \text { 20-24 years } & 3 & 5 & 7 & 12 & 4 & 8 & 1 & 9 & 5 & 3 \\ \text { 25-29 years } & 3 & 3 & 4 & 5 & 1 & 1 & 6 & 4 & 3 & 6 \\ \text { 30-34 years } & 1 & 5 & 5 & 2 & 5 & 1 & 3 & 3 & 3 & 3 \\ \text { 35-39 years } & 4 & 1 & 0 & 6 & 4 & 3 & 10 & 3 & 1 & 3 \\ \text { 40-44 years } & 4 & 0 & 1 & 2 & 1 & 2 & 4 & 3 & 3 & 6 \\ \text { 45-49 years } & 2 & 7 & 1 & 8 & 4 & 3 & 1 & 3 & 5 & 4 \\ \text { 50-54 years } & 4 & 2 & 4 & 3 & 1 & 1 & 2 & 2 & 0 & 3 \\ \text { 55-59 years } & 4 & 1 & 6 & 0 & 3 & 1 & 3 & 0 & 3 & 0 \\ \text { 60-64 years } & 4 & 1 & 4 & 3 & 3 & 3 & 0 & 7 & 3 & 3 \\ \text { 65-69 years } & 5 & 3 & 1 & 1 & 4 & 3 & 3 & 4 & 2 & 4 \\ \text { 70-74 years } & 1 & 7 & 3 & 2 & 3 & 4 & 5 & 5 & 1 & 2 \\ \text { 75-79 years } & 0 & 3 & 3 & 3 & 1 & 3 & 1 & 2 & 3 & 1 \\ \text { 80-84 years } & 0 & 1 & 1 & 0 & 0 & 1 & 1 & 0 & 0 & 5 \\ \text { 85-89 years } & 0 & 0 & 0 & 0 & 0 & 0 & 0 & 2 & 1 & 0 \\ \text { 90-94 years } & 0 & 0 & 0 & 0 & 0 & 0 & 0 & 0 & 0 & 0 \\ \text { Unspecified } & 0 & 0 & 0 & 0 & 0 & 0 & 0 & 0 & 0 & 0\end{array}$

$\begin{array}{lllllllllll}\text { Total } & 98 & 80 & 80 & 96 & 79 & 69 & 74 & 75 & 81 & 87\end{array}$ 
$\%$ of All

\begin{tabular}{|c|c|c|c|c|c|c|c|c|}
\hline Age/Year & 1955 & 1956 & 1957 & 1958 & 1959 & 1960 & Total & Drownings \\
\hline \multicolumn{9}{|l|}{ Under 12} \\
\hline months & 2 & 1 & 2 & 1 & 0 & 1 & 14 & 0.6 \\
\hline $1-4$ years & 2 & 1 & 2 & 1 & 0 & 1 & 355 & 15 \\
\hline 5-9 years & 30 & 25 & 10 & 8 & 31 & 24 & 262 & 11 \\
\hline 10-14 years & 10 & 11 & 16 & 10 & 8 & 6 & 157 & 7 \\
\hline $15-19$ years & 9 & 12 & 5 & 5 & 5 & 3 & 180 & 8 \\
\hline 20-24 years & 8 & 7 & 6 & 7 & 6 & 7 & 187 & 8 \\
\hline 25-29 years & 11 & 8 & 15 & 7 & 5 & 8 & 151 & 6 \\
\hline $30-34$ years & 4 & 4 & 7 & 7 & 7 & 1 & 128 & 6 \\
\hline 35-39 years & 1 & 1 & 8 & 4 & 5 & 6 & 116 & 5 \\
\hline 40-44 years & 7 & 4 & 8 & 4 & 3 & 2 & 113 & 5 \\
\hline 45-49 years & 1 & 2 & 2 & 3 & 3 & 2 & 97 & 4 \\
\hline 50-54 years & 1 & 5 & 5 & 1 & 3 & 3 & 90 & 4 \\
\hline 55-59 years & 5 & 4 & 4 & 1 & 3 & 4 & 97 & 4 \\
\hline 60-64 years & 3 & 2 & 2 & 4 & 3 & 4 & 106 & 4 \\
\hline 65-69 years & 0 & 4 & 1 & 3 & 0 & 1 & 75 & 3 \\
\hline $70-74$ years & 6 & 6 & 2 & 3 & 4 & 4 & 87 & 4 \\
\hline $75-79$ years & 5 & 2 & 1 & 2 & 2 & 3 & 60 & 3 \\
\hline $80-84$ years & 1 & 3 & 1 & 0 & 2 & 2 & 31 & 1 \\
\hline 85-89 years & 0 & 1 & 1 & 0 & 1 & 0 & 14 & 0.6 \\
\hline 90-94 years & 0 & 0 & 0 & 0 & 0 & 0 & 7 & 0.3 \\
\hline Unspecified & 0 & 0 & 0 & 0 & 0 & 0 & 6 & 0.3 \\
\hline Total & 104 & 102 & 96 & 70 & 91 & 81 & 2326 & \\
\hline
\end{tabular}




\section{$\underline{\text { Appendix J - Māori Drownings by Age, 1935-1960 }}$}

$\begin{array}{lllllllllll}\text { Age/ Year } & 1935 & 1936 & 1937 & 1938 & 1939 & 1940 & 1941 & 1942 & 1943 & 1944\end{array}$

Under 12

months

$1-4$ years

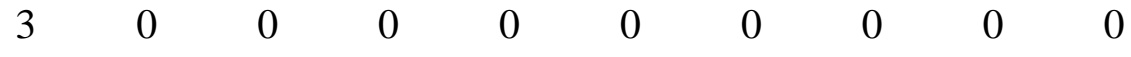

5-9 years

31

$10-14$ years

20

$15-19$ years

1

20-24 years

25-29 years

30-34 years

3

35-39 years

$2 \quad 2 \quad 2$

$\begin{array}{lll}0 & 1 & 2 \\ 2 & 0 & 0\end{array}$

40-44 years

45-49 years

50-54 years

55-59 years

60-64 years

65-69 years

70-74 years

5

$0-3$

$\begin{array}{lll}0 & 3 & 0\end{array}$

$0 \quad 0$

$0 \quad 0$

$0 \quad 1$

75-79 years

80-84 years

85-89 years

90-94 years

Unspecified

Total

$\begin{array}{llll}19 & 19 & 22 & 16\end{array}$ 
$\begin{array}{lllllllllll}\text { Age/Year } & 1945 & 1946 & 1947 & 1948 & 1949 & 1950 & 1951 & 1952 & 1953 & 1954\end{array}$

Under 12

$\begin{array}{lllllllllll}\text { months } & 0 & 0 & 1 & 0 & 0 & 0 & 0 & 0 & 0 & 0 \\ \text { 1-4 years } & 1 & 6 & 5 & 6 & 7 & 8 & 8 & 4 & 1 & 5 \\ \text { 5-9 years } & 0 & 7 & 2 & 3 & 2 & 5 & 0 & 2 & 7 & 2 \\ \text { 10-14 years } & 1 & 4 & 1 & 3 & 2 & 1 & 3 & 1 & 3 & 3 \\ \text { 15-19 years } & 2 & 3 & 1 & 3 & 1 & 1 & 1 & 1 & 0 & 2 \\ \text { 20-24 years } & 0 & 3 & 2 & 0 & 2 & 4 & 1 & 0 & 0 & 3 \\ \text { 25-29 years } & 0 & 0 & 1 & 1 & 1 & 0 & 1 & 2 & 0 & 3 \\ \text { 30-34 years } & 0 & 0 & 0 & 0 & 0 & 0 & 0 & 0 & 0 & 0 \\ \text { 35-39 years } & 1 & 0 & 1 & 0 & 0 & 0 & 0 & 0 & 0 & 0 \\ \text { 40-44 years } & 0 & 0 & 1 & 0 & 0 & 0 & 1 & 0 & 0 & 1 \\ \text { 45-49 years } & 0 & 0 & 1 & 0 & 0 & 0 & 1 & 0 & 0 & 1 \\ \text { 50-54 years } & 0 & 0 & 0 & 0 & 0 & 0 & 0 & 0 & 0 & 0 \\ \text { 55-59 years } & 0 & 0 & 0 & 0 & 0 & 0 & 0 & 0 & 0 & 1 \\ \text { 60-64 years } & 0 & 0 & 0 & 0 & 0 & 0 & 0 & 1 & 0 & 0 \\ \text { 65-69 years } & 0 & 0 & 0 & 0 & 1 & 0 & 1 & 0 & 0 & 0 \\ \text { 70-74 years } & 0 & 0 & 0 & 0 & 0 & 1 & 0 & 0 & 0 & 0 \\ \text { 75-79 years } & 0 & 0 & 0 & 0 & 0 & 0 & 0 & 0 & 0 & 0 \\ \text { 80-84 years } & 0 & 0 & 0 & 0 & 0 & 0 & 0 & 0 & 0 & 0 \\ \text { 85-89 years } & 1 & 0 & 0 & 0 & 0 & 0 & 0 & 0 & 0 & 0 \\ \text { 90-94 years } & 0 & 1 & 0 & 0 & 0 & 0 & 0 & 0 & 0 & 0 \\ \text { Unspecified } & 0 & 0 & 0 & 0 & 0 & 0 & 0 & 0 & 0 & 0\end{array}$

$\begin{array}{lllllllllll}\text { Total } & 6 & 24 & 16 & 16 & 16 & 20 & 17 & 11 & 11 & 21\end{array}$ 
$\%$ of All

$\begin{array}{lllllll}\text { Age/Year } & 1955 & 1956 & 1957 & 1958 & 1959 & 1960\end{array}$

Total Drownings

Under 12

\begin{tabular}{|c|c|c|c|c|c|c|c|}
\hline months & 0 & 0 & 0 & 1 & 0 & 0 & 5 \\
\hline $1-4$ years & 5 & 9 & 8 & 8 & 11 & 4 & 146 \\
\hline $5-9$ years & 7 & 4 & 4 & 5 & 3 & 8 & 102 \\
\hline $10-14$ years & 5 & 2 & 3 & 1 & 1 & 4 & 63 \\
\hline $15-19$ years & 2 & 3 & 3 & 2 & 1 & 0 & 41 \\
\hline 20-24 years & 1 & 2 & 2 & 1 & 0 & 1 & 42 \\
\hline $25-29$ years & 4 & 0 & 0 & 1 & 0 & 1 & 26 \\
\hline 30-34 years & 1 & 2 & 0 & 2 & 1 & 1 & 11 \\
\hline 35-39 years & 3 & 1 & 0 & 0 & 2 & 0 & 15 \\
\hline 40-44 years & 0 & 1 & 0 & 0 & 1 & 0 & 7 \\
\hline $45-49$ years & 1 & 1 & 0 & 0 & 1 & 0 & 11 \\
\hline $50-54$ years & 0 & 0 & 0 & 0 & 0 & 0 & 3 \\
\hline 55-59 years & 0 & 0 & 0 & 0 & 0 & 1 & 5 \\
\hline 60-64 years & 0 & 0 & 0 & 0 & 0 & 0 & 2 \\
\hline 65-69 years & 0 & 0 & 0 & 0 & 0 & 0 & 7 \\
\hline 70-74 years & 0 & 0 & 0 & 0 & 0 & 0 & 1 \\
\hline $75-79$ years & 0 & 0 & 0 & 0 & 0 & 1 & 3 \\
\hline $80-84$ years & 0 & 0 & 0 & 0 & 0 & 0 & 0 \\
\hline $85-89$ years & 0 & 0 & 0 & 0 & 0 & 0 & 1 \\
\hline 90-94 years & 0 & 0 & 0 & 0 & 0 & 0 & 1 \\
\hline Unspecified & 0 & 0 & 0 & 0 & 0 & 0 & 2 \\
\hline Total & 29 & 25 & 20 & 21 & 21 & 21 & 494 \\
\hline
\end{tabular}


Note for statistics 1935-60:

Accidental drownings do not include suicides or drownings due to motor vehicle accidents. Violent deaths refer to all externally caused deaths, that is, deaths not caused by illness or disease, or natural causes.

Deaths do not include those of soldiers who died overseas during World War II. All percentages and rates of drowning are rounded to the nearest whole number, except for the percentage of deaths caused by accidental drownings. The percentage values of the age of drowning victims equalling less than one per cent have also been rounded to one decimal place.

Source: Statistics of New Zealand, 1935-1960. 


\section{Bibliography}

\section{Primary Sources}

\section{Archives New Zealand, Auckland}

Hamilton Education Board Residual Management Unit - Te Paroa Totara Maori School - Bath Building and Drainage, 1939 - YCAU, A889, 10521, 404 e 346

Maori Schools - Building and Site Files - Bathing Facilities, 1936-1940 - BAAA, 1001,218 b, 44/4/21

Physical Education - Maori Schools 1961 - 63, BCDQ, A739, 4610c, 28/6/6B

Physical Education - Miscellaneous Schemes - Teach Swimming 1948 - 62, BCDQ, A739, 4614b, 28/9/2

Physical Education - Swimming Policy 1950 - 79, BCDQ, A739, 4614a, 28/9/1 A

Physical Education - Swimming Pools 1950 - 63, Part 1, BCDQ, A739, 4615a, $28 / 9 / 2$

Physical Education - Swimming Pools 1963 - 64, Part 2, BCDQ, A739, 4615b, $28 / 9 / 2$

Physical Education - Water Safety 1941 - 65, BCDQ, A739, 4616a, 28/9/5

\section{Archives New Zealand, Wellington}

Accidents - Drowning, 1916-1946 - ABQU, 632, W4452, 2, 1-7, 0003

Accidents - New Zealand Road Safety Council Education and Propaganda Secretary's File, 1936-1937 - TD 1, 86, 16/29

Accidents - Statistics on Accidental Drowning and Submersion (E929), 1948-1971 - ABQU, 632, W4452, 2, 1-7, 0253

Anti-Drowning Publicity Campaign, 1949-1957 - H 1, 1715, 34/64, 26709 
Buildings and Sites - Secondary Schools Swimming Baths - Miscellaneous Correspondence, 1938-1966 - ABEP, 7749, W4262, 344, 7/20/2, part 1

Buildings and Sites -Primary Schools - Miscellaneous Correspondence, 1956-1960 - ABEP, 7749, W4262, 365, 7/22/2, part 1

Circulars and other instructions - IA 70, 1, 1

Education - School Buildings and Grounds - Swimming Pools, 1950-1957 - AAFD 811, W2347, 85, c, CAB 62/11/3, part 1

Folder of Papers, Reports, Correspondence, and Talks on the "Prevent Drowning" Campaign, 1951-1952 - IA 70, 3, 11

Health Education - New Zealand Water Safety Council, 1958-1976 - AAFB, W4914 632, 191, 34/64, Alternative Record 48314

How to Drown - ARNZ, 18828, R. V. 23

Itineraries and Miscellaneous Matters, Programmes - IA 70, 2, 2

Miscellaneous - Annual Reports - Internal Affairs, 1955-56 - IA 1, W2578, 220, $158 / 9 / 19$

Miscellaneous - Report - Annual - Department of Internal Affairs, 1938 - IA 1, $2995,158 / 9$

Miscellaneous - Report - Annual - Department of Internal Affairs, 1957 - IA 1, 2997, 158/9/20, part 1

Miscellaneous - Swimming and Life Saving Swimming Baths - General, 1937-1945 - E 2, 485, 39/19/15, part 1, 1945/11c

National Committee of Swimming and Life Saving - Water Safety, 1948-1965 - J 1, $1601,21 / 2 / 13$

National Council of Physical Welfare and Recreation, 1939-1949 - E 1, W773, 6, 29/82/4 
Newspaper Clippings Relating to the 'Prevent Drowning' Campaign, 1954-1957 IA $70,4,12$

Newspaper Clippings Relating to the 'Prevent Drowning' Campaign, 1957-1959 IA $70,4,13$

Physical Education - General - National Fitness Council of Australia, 1963-1982 ABEP, 7749, W4262, 1865, 28/1/8, part 2

Physical Education - General - Physical Welfare Branch, 1947 - ABEP, W4262 $7749,1865,28 / 1 / 5$, part 1

Physical Education - General - Physical Welfare Branch, 1947-1985 - ABEP, 7749, W4262, 1865, 28/1/5, part 1

Physical Welfare Bulletin Volume 1 No. 45, August 1947 ... Recreation Information Service Bulletin No. 3, 1947-1953 - IA 70, 6, 22

Physical Welfare - Drowning - Publicity Campaign, 1918-1953 - IA 1, W2578, 178, $139 / 7 / 15$, part 5

Physical Welfare - General File - Learn to Swim Campaign, 1940-56 - IA 1, W2578, 177, 139/7/4

Physical Welfare - National Council - Suggested Summer School Refresher, 19431944 - IA 1, W2578, 183, 139/25, part 2

Physical Welfare - Newspaper Clippings - Learn to Swim, 1938-1939 - IA 1, W2578, 183, 139/19/2

Physical Welfare - Physical Culture, 1938-1940 - IA 1, W2578, 183, 139/33

Physical Welfare - Physical Culture, 1939 - IA 1, W2578, 185, 139/70

Physical Welfare - Physical Culture Classes, 1938-1940 - IA 1, W2578, 183, $139 / 33$

Physical Welfare - Physical Culture Classes, 1938-1946 - IA 1, W2578, 183, 139/31 
Physical Welfare - Physical Welfare Officers, 1950-1955 - IA 1, W2578, 185, $139 / 87 / 4$

Physical Welfare - Sport - National Water Safety Council - Formation - Activities etc. of, 1956-1959 - IA 1, 1850, 139/7/15/18, part 1

Physical Welfare - Swimming General File - Learn to Swim Campaign, 1940-1956 - IA 1, W2578, 177, 139/7/4

Piha Beach - Control - Legal Position; proposed swimming pool, Piha ratepayers' Association, 1936-1940, 1948-1951 - M 1, 616, 4/2885

Report of the Meeting of the National Council of Physical Welfare and Recreation First Meeting - 24 May, 1938 - IA 70, 2, 5

Report of the Meeting of the National Council of Physical Welfare and Recreation Second Meeting - 14 July, 1938 - IA 70, 2, 6

Report of the Meeting of the National Council of Physical Welfare and Recreation Third Meeting - 14 September, 1938 - IA 70, 3, 7

Report of the Meeting of the National Council of Physical Welfare and Recreation Fourth Meeting - 29 March, 1939 - IA 70, 3, 8

Safety in the Water, 1957 - AAPG, W3435, 17, 3/2/104

School Swimming Baths, 1941-1966- H 1, 469, 35/3/1, 32456

Sport - International 'Learn to Swim' Week - General File - IA 1, 2932, 139/7, part $1-2$

Sport - Investigation - Boys and Girls Leisure Time Activities - IA 1, 2942, 139/30

Sport - Newspaper Clippings - Learn to Swim Campaign - IA 1, 2937, 139/19/2, part 3

Sport - Physical Fitness Week - General File Re - IA 1, 2942, 139/32 
Sport - Physical Training and Recreation - National Council of Sport Establishment etc. of - Legislation re - Physical Welfare and Recreation Act, 19371941 - IA 1, 2929, 139/1

Sport - Physical Welfare and Recreation Branch - Control of Office, etc. - IA 1, $2951,139 / 71$

Sport - Physical Welfare Branch - Future activities - Policy re - IA 1, 2963, 139/251

Sport - Physical Welfare Branch - Future Activity of Policy, 1937-1961 - IA, W1917, 4, 139/251, part 2

Sport - Physical Welfare and Recreation - Australia - Report - Mr. Harper - IA 1, $2957,139 / 107 / 1$

Sport - Physical Welfare and Recreation - Report by Minister - Internal Affairs IA $1,2962,139 / 188$

Sport - Physical Welfare - Swimming - General File - Learn to Swim Campaign, 1940-1956 - IA 1, W2578, 177, 139/7/4

Sport - Scheme for Maori Recreation - General File - IA 1, 2931, 139/2/3

Sport - Swimming Conference - Minister and Swimming Organisations - IA 1, $2933,139 / 7 / 1$

Sport - Swimming etc. Control of Beaches - IA 1, 2956, 139/94

Sport - Swimming - Drowning etc. - Suggested Publicity Campaign - IA 1, 2933, $139 / 7 / 15$, part 1-4

Sport - Swimming - Drowning etc. - Suggested Publicity Campaign - IA 1, 2934, $139 / 7 / 15$, part $6-11$

Sport - Swimming - Drowning etc. - Suggested Publicity Campaign - IA 1, 2935, 139/7/15, Part 12

Sport - Swimming -Instruction in Military Camps - IA 1, 2933, 139/7/8 
Sport - Swimming and Life Saving Conference 1940 - IA 1, 2933, 139/7/2

Sport - Swimming Tour of Dominion by Allan Gardiner - IA 1, 9933, 139/7/5

Sport - Wellington - Instructors - Learn to Swim - Wairarapa - IA 1, 2952, $139 / 73 / 15$

State Literary Fund - Grant - New Zealand Amateur Swimming Association - IA 1, $2128,86 / 15 / 1$, part 1

State Literary Fund - Grant - New Zealand Surf Life Saving Association - IA 1, $2129,86 / 15 / 2$, part $1-3$

State Literary Fund - Grant - Royal Life Saving Society - IA 1, 2127, 86/15, part 1

State Literary Fund - Grant - Royal Life Saving Society - IA 1, 2128, 86/15, part 24

Surf Life Saving Clubs - Control of Bathing, 1934-1940 - M 1, 612, 4/2799

Teacher Recruitment, Training and Welfare, School Inspection and Instruction Swimming and Water Safety, 1926-1986 - ABDU, W3570, 240, 7/16

Training - Swimming and Life Saving, 1943-1967 - AALJ, 7291, 3508, 75, $210 / 17 / 2$, part 2

Weekly Review No. 399, ARNZ, 18828, R.V. 765

\section{Wellington City Archives}

Appliances for the Safety of Bathers on Days Bay Beach - Royal Life Saving Society, 00233:350:1919/1272

Average Weekly Attendance, Thorndon Baths - Baths Committee, 00233:367:1920/369 
Beaches and Baths: Licence Fee, Swimming Sports, Te Aro Baths, 00009:19:4/10

Construction of Tepid Baths - Town Clerk, Wellington, 00233:239:1913/991

Mixed Bathing at Thorndon Baths - The Thorndon Amateur Swimming Club, 00233:231:1913/37

Re. Pupils Admission to Te Aro Baths - St Patrick's College, 00233:95:1903/2008

Swimming Boom at Thorndon Baths - W. Lewis, 00233:510:1926/249

\section{Newspapers and Periodicals}

Appendices to the Journal of the House of Representatives, 1870, 1935-1957

Ellesmere Guardian, 1891-1945

Evening Post, 1865-1945

New Zealand Journal of Physical Education, 1954-1960

New Zealand Parliamentary Debates, 1937-1957

New Zealand Railways Magazine, 1926-1940

New Zealand School Journal, 1935-1960

New Zealand Surf Life Saving Association, Annual Report and Statement of Accounts, 1935-1960

Statistics of New Zealand, 1858-1901, 1935-1960

Statistics of New Zealand, Population Census, 1936, 1956

Te Ao Hou, 1955-1960 


\section{Oral History Interviews}

Joyce, Aporo and Brenda, interviewed by Jessica Maynard, 7 October 2011, in Tawa, Wellington

Moore, William, interviewed by Jessica Maynard, 23 September 2011, in Waikanae, Kapiti Coast

\section{Correspondence}

Mokomoko, John to Jessica Maynard, 30 October 2011

Terry, Marie to Jessica Maynard, 19 October 2011

\section{Articles}

Bright, John, “'Bill” Parry - Humanist. The Career of a Redoubtable Politician', New Zealand Life, 1 January/February, 1948, pp. 12-4

Lockhart, Leonard P., 'The Physical Welfare of Youth', The British Medical Journal, Vol. 2, no. 3963, December 1936, pp. 1254-6

'Physical Training And Recreation: The Government Memorandum', The British Medical Journal, Vol. 1, no. 3971, February 1937, pp. 342-3

\section{Official Published Material}

Department of Education, Swimming: A Guide Book for Teachers, Coaches and Swimmers (Wellington: Department of Education, 1957)

Education, 1953) , The Teaching of Swimming (Wellington: Department of 
Parry, W. E., For Women and Youth of New Zealand: Aims and Principles Guiding the Work of the Hon. W. E. Parry (Wellington: Standard Press, 1939)

Proposed National Council: Address by the Minister of Internal Affairs, the Hon. W. E. Parry, and Report of Proceedings of a Meeting of Representatives of New Zealand and Wellington Controlling Bodies of Sport, held at Parliament House, Wellington, 4 March, 1937 (Wellington: Government Printer, 1937)

\section{Books}

Bedggood, L. R., Health and Physical Education in New Zealand (Hamilton: L. R. Bedggood, 1954)

Chapple, W. A., First Principles in the Art of Physical Development (London: Cassell and Co., 1910)

Gillespie, O. N., 50 Years of Swimming: History of the Wellington Amateur Swimming Club, 1894-5 to 1944-5 (Wellington: Wellington Amateur Swimming Club, 1947)

Ingram, N. A, A Factual History of Surf Life Saving in New Zealand, 1910-1952 (Lower Hutt: Hutt Printing and Publishing, 1952)

National Committee of Swimming and Life Saving, "Learn-to-Swim" Campaign, 1939: National Survey of Campaign, Embracing reports of District Committees, and Recommendations, etc. (Wellington: National Committee of Swimming and Life Saving, 1939)

New Zealand Amateur Swimming Association, Instruction in Public School Children in Swimming for Recreative Purposes and as Means of Saving Life (Wellington: Government Printer, 1901)

O’Neill, Baxter, Official Handbook: Comprising Constitutional and General Rules, Swimming Laws, Diving Rules, Championship Results, Records, etc. (Christchurch: New Zealand Amateur Swimming Association, 1956) , New Zealand Amateur Swimming Association: Official Swimming

Instructor (Auckland: New Zealand Amateur Swimming Association, [1940]) 
, Swimming for Efficiency: A Cause that Lacks Assistance

(Christchurch: New Zealand Amateur Swimming Association, 1919)

Royal Life Saving Society of New Zealand, Special Souvenir Number, $21^{\text {st }}$ Annual Report for the Year Ended July 31, 1931 (Christchurch: Royal Life Saving Society of New Zealand, 1931)

Thomson, A. S., The Story of New Zealand: Past and Present - Savage and Civilised, Vol. 2 (London: John Murray, 1859), 2 volumes

Preventive Medicine Dissertations, University of Otago Medical School Library, Dunedin

Abernethy, I. A. G., and Horton, J. E., 'Drowning and Near Drowning in New Zealand', Preventive Medicine Dissertation, University of Otago, 1956

Akel, R. N., 'Public Health Survey of Baths of Wellington City and Environs and the Learn-to-Swim Campaign', Preventive Medicine Dissertation, University of Otago, 1939

Mark, T. E. G., 'Christchurch Municipal (Tepid) Bath: Present and Future', Preventive Medicine Dissertations, University of Otago, 1948

Thomson, B. C., and Pryde, T. R., 'A Survey of Learners' Swimming Pools in Dunedin', Preventive Medicine Dissertation, University of Otago, 1959

\section{Secondary Sources}

\section{Articles}

Bailey, Peter, "'A Mingled Mass of Perfectly Legitimate Pleasures": the Victorian Middle Class and the Problem of Leisure', Victorian Studies, Vol. 21, no. 1, Autumn 1977, pp. 7-28

Bassett, G., 'A Survey in Physical Education in 144 New Zealand Secondary Schools', New Zealand Journal of Physical Education, Vol. 35, 1965, pp. 21-9 
Booth, Douglas, 'Healthy, Economic, Disciplined Bodies: Surfbathing and Surf Lifesaving in Australia and New Zealand, 1890-1950', New Zealand Journal of History, Vol. 31, no. 1, 1998, pp. 43-58

Boyes, Mike, 'Taking Risks is a Social Phenomenon', New Zealand Physical Educator, Vol. 41, no. 1, February 2008, p. 4

Callister, Paul, and Didham, Robert, 'Workforce Composition - Men's Work, Women's Work', Te Ara - Encyclopedia of New Zealand; http://www.teara.govt.nz/en/workforce-composition/4 [accessed 11 May 2011]

Crawford, Scott A. G. M., 'Recreation in Pioneering New Zealand: Some Early Newspaper Sources in Otago Province, 1848-61', Victorian Periodicals Review, Vol. 23, no. 3, Fall 1990, pp. 97-103

Daley, Caroline, 'Women Endurance Swimmers: Dissolving Grease Suits and Decentring New Zealand History', Sporting Traditions, Vol. 21, no. 2, May 2005, pp. 29-55

Gardiner, Rosemary, and Crawford, Scott A. G. M., 'Time to Play: The Impact of Industrialisation on New Zealand Recreation and Sport, 1840-1900', New Zealand Legacy, Vol. 1, no. 2, 1989, pp. 20-3

Gustafson, Barry, 'Parry, William Edward - Biography', Te Ara - Encyclopedia of New Zealand; http://www.TeAra.govt.nz/en/biographies/3p12/1 [accessed 20 September 2011]

Haimona, Mark, and Takurua, Nātana, 'Kia Maanu, Kia Ora: Stay Afloat, Stay Alive - Acknowledging the Significance of Tikanga Māori in Formulating and Communicating Water Safety Policies and Practices', Journal of Maori and Pacific Development, Vol. 8, no. 2, September 2007, pp. 83-90

Hess, Rob, and Parker, Claire, 'Against the Tide: New Work on Australasian Aquatic Cultures', International Journal of the History of Sport, Vol. 26, no. 14, pp. 2060-8

Hokowhitu, Brendan, "Physical Beings": Stereotypes, Sport and the "Physical Education" of New Zealand Maori', Culture, Sport, Society, Vol. 6, no. 2-3, 2003, pp. $192-218$ 
Gerard Hutching. 'Shipwrecks - 20th-century shipwrecks', Te Ara - the Encyclopedia of New Zealand; http://www.TeAra.govt.nz/en/shipwrecks/5 [accessed 20 June 2012].

Jaggard, E. K. G., 'Saviours and Sportsmen: Surf Life Saving in Western Australia, 1909-1930', Sporting Traditions, Vol. 2, no. 2, May 1986, pp. 2-22

Kossuth, Robert S., 'Dangerous Waters: Victorian Decorum, Swimmer Safety, and the Establishment of Public Bathing Facilities in London (Canada)', The International Journal of the History of Sport, Vol. 22, no. 5, September 2005, pp. 796-815

Light, Richard, and Rockwell, Tracy, 'The Cultural Origins of Competitive Swimming in Australia', Sporting Traditions, Vol. 22, no. 1, November 2005, pp. 21-38

Love, C., 'State Schools, Swimming and Physical Training', International Journal of the History of Sport, Vol. 24, no. 5, May 2007, pp. 654-66

, 'Taking a Refreshing Dip: Health, Cleanliness and the Empire', International Journal of the History of Sport, Vol. 24, no. 5, May 2007, pp. 693-706

, "Whomsoever You See in Distress": Swimming, Saving Life and the Rise of the Royal Life Saving Society', The International Journal of the History of Sport, Vol. 24, no. 5, May 2007, pp. 667-81

Lynch, Pip, 'The Origins of Outdoor Education in New Zealand: Progressive Liberalism and post-War Rejuvenation, 1935-1965', New Zealand Physical Educator, Vol. 36, no. 1, May 2003, pp. 63-81

Macdonald, Nikki, 'Deep Water', Your Weekend: The Dominion Post, 17 December 2011, pp. 8-10

McDermott, Marie-Louise, 'Changing visions of Baths and Bathers: Desegregating Ocean Baths in Wollongong, Kiama and Gerringong', Sporting Traditions, Vol. 22, no. 1, November 2005, pp. 1-20

McShane, Ian, 'The Past and Future of Local Swimming Pools', Journal of Australian Studies, Vol. 33, no. 2, 2009, pp. 195-208

Meredith, Paul 'Urban Māori - Urbanisation', Te Ara - Encyclopedia of New Zealand; http://www.teara.govt.nz/en/urban-maori/1 [accessed 20 July 2011] 
Osmond, Gary, 'Forgetting Charlie and Tums Cavill: Social Memory and Australian Swimming History', Journal of Australian Studies, Vol. 33, no. 1, 2009, pp. 93-107

Parker, Claire, 'The North/South Divide and the Development of Swimming in Nineteenth-Century England', Sporting Traditions, Vol. 25, no. 2, November 2008, pp. $55-70$

Pascoe, John, 'The New Zealand Death', New Zealand's Heritage: the Making of a Nation, Vol. 20, no. 2, 1971, pp. 556-60

Philips, Jock, 'Sport and Leisure - Informal Sports', Te Ara - Encyclopedia of New Zealand; http://www.teara.govt.nz/en/sports-and-leisure/3 [accessed 14 April 2011]

Pool, Ian, 'Death Rates and Life Expectancy', Te Ara - the Encyclopedia of New Zealand; http://www.TeAra.govt.nz/en/death-rates-and-life-expectancy [accessed 20 June 2011]

Pool, Ian, and Du Plessis, Rosemary, 'Families: A History - Late $19^{\text {th }}$ and Early $20^{\text {th }}$ Century Families', Te Ara - Encyclopedia of New Zealand; http://www.teara.govt.nz/en/families-a-history/3 [accessed 20 June 2011]

, 'Families: A History - Baby Boom Begins

1945-1959', Te Ara - Encyclopedia of New Zealand;
http://www.teara.govt.nz/en/families-a-history/5 [accessed 20 June 2011]

Renwick, William, 'Beeby, Clarence Edward - Biography', Te Ara - the Encyclopedia of New Zealand; http://www.TeAra.govt.nz/en/biographies/5b17/1 [accessed 20 September 2012].

Saunders, Kay, 'Specimens of Superb Manhood: the Lifesaver as a National Icon', Journal of Australian Studies, Vol. 56, 1998, pp. 96-105

'Swimming in Schools', from An Encyclopaedia of New Zealand, edited by A. H. McLintock, originally published in 1966 Te Ara - Encyclopedia of New Zealand; http://www.teara.govt.nz/en/1966/swimming/3 [accessed 29 March 2011]

Stothart, Bob, 'Pegs in the Ground: Landmarks in the History of New Zealand Physical Education', Journal of Physical Education New Zealand, Vol. 33, no. 2, September 2000, pp. 5-15 
Tennant, Margaret, 'Children's Health Camps in New Zealand', Social History of Medicine, Vol. 9, no. 1, April 1996, pp. 69-87

Tolerton, Jane 'Contraception and Sterilisation - 19th-Century Contraception', Te Ara - the Encyclopedia of New Zealand; http://www.TeAra.govt.nz/en/contraception-and-sterilisation/1 [accessed 11 June 2011]

Trubuhovich, R. V., 'Some Prehistory of New Zealand Intensive Care Medicine', Anaesth Intensive Care, Vol. 37, No. 1, July 2009, pp. 16-29

'Wairarapa', from An Encyclopaedia of New Zealand, edited by A. H. McLintock, originally published in 1966, Te Ara - the Encyclopedia of New Zealand; http://www.TeAra.govt.nz/en/1966/disasters-and-mishaps-shipwrecks/5 [accessed 20 June 2012]).

Wilson, John, 'New Zealand's Aging Population', Te Ara - Encyclopedia of New Zealand; http://www.teara.govt.nz/en/society/1/2 [accessed 12 September 2011]

Winterton, Rachel, and Parker, Claire, "A Utilitarian Pursuit": Swimming Education in Nineteenth-Century Australia and England', International Journal of the History of Sport, Vol. 26, no. 14, November 2009, pp. 2106-25

Zweiniger-Bargielowska, Ina, 'Building a British Superman: Physical Culture in Interwar Britain', Journal of Contemporary History, Vol. 41, no. 4, October 2006, pp. $595-610$

\section{Books and Chapters}

Alcorn, Noeline, To the Fullest Extent of His Powers: C. E. Beeby's Life in Education (Wellington: Victoria University Press, 1999)

Anderson, Susan C., and Tabb, Bruce H. (eds.), Water Leisure and Culture: European Historical Perspectives (Oxford and New York: Berg, 2002)

Ariès, Philip, Western Attitudes towards Death from the Middle Ages to the Present (Baltimore: Johns Hopkins University Press, 1974)

Bailey, Peter, Leisure and Class in Victorian England: Rational Recreation and the Contest for Control, 1830-1885 (London: Routledge and Kegan Paul, 1978) 
Barnett, Stephen, and Wolfe, Richard, At the Beach: The Great New Zealand Holiday (Auckland: Hodder \& Stoughton, 1993)

Bassett, Michael, and King, Michael, Tomorrow Comes the Song: A Life of Peter Fraser (Auckland, Penguin, 2000)

, The State in New Zealand, 1840-1984, Socialism without Doctrines (Auckland: Auckland University Press, 1998) , The Mother of All Departments: The History of the Department of Internal Affairs (Auckland: Auckland University Press, 1997)

Beattie, James Herries, Traditional Lifeways of the Southern Maori: The Otago University Museum Ethnological Project, 1920 (Dunedin: Otago University Press, 1994)

Beck, Ulrich, Risk Society: Towards a New Modernity, trans. Mark Ritter (London: Sage Publications, 1992)

Beeby, C. E., The Biography of an Idea: Beeby on Education (Wellington: New Zealand Council for Educational Research, 1992)

Belich, James, Making Peoples: A History of the New Zealanders from Polynesian Settlement to the End of the Nineteenth Century (North Shore: Penguin, 2007)

, Paradise Reforged: A History of New Zealanders from the 1880s to the Year 2000 (Auckland: Allan Lane; Penguin, 2001)

Best, Elsdon, Games and Pastimes of the Maori: an Account of Various Exercises, Games, and Pastimes of the Natives of New Zealand, as Practised in Former Times, Including Some Information Concerning Their Vocal and Instrumental Music, $2 \mathrm{~d}$ ed. (Wellington: Government Printer, 1976)

Booth, Douglas, Australian Beach Cultures: The History of Sun, Sand and Surf (London and Portland: Frank Cass, 2001)

, 'Surf Lifesaving: The Development of an Australian "Sport", in Mangan, J. A., and Nauright, John (eds.), Sport in Australasian Society: Past and Present (New York and Abingdon: Frank Cass, 2000), pp. 167-87 
, 'Swimming, Surfing and Surf-lifesaving', in Vamplew, Wray, and Stoddart, Brian (eds.), Sport in Australia: A Social History (New York: Cambridge University Press, 1994), pp. 231-254

Borrie, W. D., The European Peopling of Australasia: A Demographic History, 1788-1988 (Canberra: ANU Printing Services, 1994)

Borsay, Peter, A History of Leisure: The British Experience Since 1500 (New York: Palgrave MacMillan, 2006)

Brown, Doreen, and Williams, Evan H., New Zealand Amateur Swimming Association Inc., 75 ${ }^{\text {th }}$ Anniversary: A Short History, 1890-1965 (Christchurch: New Zealand Amateur Swimming Association, 1965)

Byrnes, Giselle (ed.), The New Oxford History of New Zealand (Melbourne: Oxford University Press, 2009)

Cleaver, Phillip, The Pakeha Treatment of Death in Nineteenth- and Early Twentieth-Century Wellington (Wellington: Wellington Historical \& Early Settlers' Association, 1996)

Collins, Chris, and Jackson, Steve (eds.), Sport in Aotearoa/New Zealand Society, 2d ed., (Melbourne and Auckland: Thomson, 2007)

, and Downey, John, 'Politics, Government, and Sport', in Collins, Chris (ed.), Sport in New Zealand Society (Palmerston North: Dunmore Press, 2000), pp. 201-26

Coney, Sandra, Standing in the Sunshine: A History of New Zealand Women Since they Won the Vote (Auckland: Penguin, 1993)

Daley, Caroline, 'On the Beach: Or the "Unbearable Scandal" of Shrinking Swimwear', in Labrum, Bronwyn, McKergow, Fiona, and Gibson, Stephanie (eds.), Looking Flash: Clothing in Aotearoa New Zealand (Auckland: Auckland University Press, 2007), pp. 154-68

Leisure and Pleasure: Reshaping and Revealing the New Zealand Body 1900-1960 (Auckland: Auckland University Press, 2003)

Dalley, Bronwyn, and Tennant, Margaret (eds.), Past Judgement: Social Policy in New Zealand History (Dunedin: University of Otago Press, 2004) 
Family Matters: Child Welfare in Twentieth Century New

Zealand (Auckland: Auckland University Press, 1998)

Douglas, Edwards M. K., Waiora, Waimaori, Waikino, Waimate, Waitai: Maori Perceptions of Water and the Enivronment (Hamilton: Centre for Māori Studies and Research, University of Waikato, 1984)

Dutton, Geoffrey, Sun, Sea, Surf and Sand - The Myth of the Beach (London and Portland: Frank Cass, 1985)

Dutton, Kenneth R., The Perfectible Body: The Western Ideal of Physical Development (London: Continuum, 1995)

Elias, Norbert, Dunning, Eric, Goudsblom, Johan, and Mennell, Stephen, The Civilizing Process: Sociogenetic and Psychogenetic Investigations, 2d ed. (Oxford: John Wiley Professio, 2000)

Gluckman, Laurie, Touching on Deaths: a Medical History of Early Auckland Based on the First 384 Inquests (Auckland: Doppelganger, 2000)

Grant, Mariel, 'The National Health Campaigns of 1937-1938', in Fraser, Derek (ed.), Cities, Class and Communication: Essays in Honour of Asa Briggs (Hertfordshire: Harvester Wheatsheaf, 1990), pp. 216-34

Gustafson, Barry, From the Cradle to the Grave: A Biography of Michael Joseph Savage (Auckland: Penguin, 1988)

Harvey, Bob, Between the Flags: 100 Years of Surf Life Saving in New Zealand (Wellington: Surf Life Saving New Zealand, 2010)

Huntsman, Leone, Sand in Our Souls: The Beach in Australian History (Carlton: Melbourne University Publishing, 2001)

Jackson, Ivan, Sand between My Toes: The Story of Surf Lifesaving in New Zealand (North Shore: Penguin Books, 2006)

Jarvie, Grant, Sport, Culture and Society: An Introduction (London and New York: Routledge, 2006) 
Kedgley, Sue, Mum's the Word: the Untold Story of Motherhood in New Zealand (Auckland: Random House, 1996)

King, Michael (ed.), Te Ao Hurihuri: The World Moves On: Aspects of Māoritanga (Wellington: Hicks Smith, 1975) , The Penguin History of New Zealand (Auckland, Penguin, 2003)

Lenček, Lena, and Bosker, Gideon, The Beach: The History of Paradise on Earth (Auckland: Viking, 1999)

Love, C., A Social History of Swimming in England, 1800-1918: Splashing in the Serpentine (New York: Routledge, 2008)

Macdonald, Charlotte, Strong, Beautiful, and Modern: National Fitness in Britain, New Zealand, Australia, and Canada, 1935-1960 (Wellington: Bridget Williams Books, 2011)

MacDonald, Tui, 'Katerina Nehua, 1903-48', in Macdonald, Charlotte, Penfold, Merimeri, and Williams, Bridget (eds.), The Book of New Zealand Women (Wellington: Bridget Williams Books, 1991), pp. 465-7

Maclean, Chris, and Phillips, Jock, The Sorrow and the Pride: New Zealand War Memorials (Wellington: Historical Branch of the Department of Internal Affairs, 1990)

McClure, Margaret, A Civilised Community: a History of Social Security in New Zealand, 1898-1998 (Auckland: Auckland University Press, 1998)

McLean, Gavin, Blue, White and Dynamite: 100 Years of the Lyall Bay Surf Life Saving Clubs (Wellington: Lyall Bay Surf Life Saving Club, 2011)

Mein Smith, Philippa, A Concise History of New Zealand (Cambridge: Cambridge University Press, 2005)

Ministry of Works, Town and Country Planning Branch, A Survey of New Zealand Population: An Analysis of Past Trends and an Estimate of Future Growth (Wellington: Town and Country Planning Branch - Ministry of Works, 1960) 
Moore, Mike, Recreation and Government in New Zealand: Change in Relationships (Wellington: Ministry of Recreation and Sport, 1985)

Moran, Kevin, The Shaping of Swimming and Water Safety Education in New Zealand (Auckland: Tradewinds, 2010)

National Water Safety Council, Water Safety is Your Business (Wellington: National Water Safety Council, 1966)

New Zealand Amateur Swimming Association, For the Record: New Zealand Amateur Swimming Association (Inc.) 1890-1976. New Zealand Title Holders Representatives, Record Holders and a Concise History (Christchurch: New Zealand Amateur Swimming Association, 1976)

Pearsall, Donald, Lifesaving: The Story of the Royal Life Saving Society: The First 100 Years (Devon: David \& Charles, 1991)

Perkins, Harvey, and Cushman, Grant (eds.), Time Out? Leisure, Recreation and Tourism in New Zealand and Australia (Auckland: Longman, 1998)

Pointon, David, A Dip in the Clear, Blue Water (Auckland: Auckland City Council, 1984)

Queen's High School, St Clair Salt Water Pool, 1884-1984 (Dunedin: Queen's High School, 1984)

Rail, Genevieve (ed.), Sport and Postmodern Times (Albany: University of New York Press, 1998)

Rice, Geoffrey (ed.), The Oxford History of New Zealand (Auckland: Oxford University Press, 1992)

Segel, Harold B., Body Ascendant: Modernism and the Physical Imperative (London: Johns Hopkins University Press, 1998)

Sinclair, Keith, A Destiny Apart: New Zealand's Search for National Identity (Wellington: Allen and Unwin, 1986) 
Smith, Janet, Liquid Assets: The Lidos and Open Air Swimming Pools of Britain (London: English Heritage, 2005)

Statistics New Zealand, Baby Boomers (Wellington: Statistics New Zealand, 1995)

Stead, C. K., South-West of Eden: A Memoir, 1932-1956 (Auckland: Auckland University Press, 2010)

Stothart, R. A., The Development of Physical Education in New Zealand (Auckland: Heinemann Educational Books, 1974)

A Chronology of New Zealand Physical Education, 1850-1990 (Wellington: New Zealand Association of Health, Physical Education and Recreation, 1991)

Sutton-Smith, Brian, A History of Children's Play, New Zealand 1840-1950 (Wellington: New Zealand Council for Educational Research, 1981)

Tennant, Margaret, The Fabric of Welfare: Voluntary Organisations, Government and Welfare in New Zealand, 1840-2005 (Wellington: Bridget Williams Books, 2007)

Urbain, Jean-Didier, At the Beach, trans. Catherine Porter (Minneapolis: University of Minnesota Press, 2003)

Walvin, James, Beside the Seaside: A Social History of the Popular Seaside Holiday (London: Allen Lane, 1978)

Leisure and Society, 1830-1950 (New York: Longman, 1978)

Water Safety New Zealand, Annual Report 2010 (Wellington: Water Safety New Zealand 2011)

Zealand, 2011)

Drowning Report 2010 (Wellington: Water Safety New

Wilk, Christopher (ed.), Modernism: Designing a New World, 1914 - 1939 (London: V \& A Publications, 2006) 
Williams, Clifford R. A., An Investigation and Study of Swimming in all Aspects with Special Emphasis on the Learn-to-Swim Methods and Swimming Administration, in United States of America, Canada, Great Britain, Holland, West Germany, Hong Kong, Japan, Winston Churchhill Memorial Trust Fellowship, May 30 to August 13, 1979 (Wellington: C. R. A Williams, 1979)

Willis, John D., Zealandia's Brave: The Royal Humane Society in New Zealand, 1850-1998 (Christchurch: Royal Humane Society of New Zealand, 2001)

Wiltse, Jeff, Contested Waters: A Social History of Swimming Pools in America (North Carolina: University of North Carolina Press, 2007)

\section{Theses}

Alexander, Janet, 'Recreation: An Inappropriate Concept for Legislation? An examination of two attempts at legislating for recreation in New Zealand: The Physical Welfare and Recreation Act 1937; and The Recreation and Sports Act 1973', Research Paper, Victoria University of Wellington, 1981

Anderson, M. R., 'Education 648: Research Report: Outdoor Education: A Critical Analysis of the Main Themes', M.Ed thesis, University of Otago, 1988

Buchanan, Hugh D., 'A Critical Analysis of the 1937 Physical Welfare and Recreation Act and of Government Involvement in Recreation and Sport, 19371957', MA thesis, Victoria University of Wellington, 1978

Carryer, Basil, 'The Duty of the State', M.Ed thesis, Waikato University, 1990

Cleaver, Philip, 'Dealing with Death: The Pakeha Treatment of Death, 1850-1910', MA thesis, Victoria University of Wellington, 1996

Harris, Kathryn, 'The Physical Welfare and Recreation Branch of the Department of Internal Affairs', unpublished special study, University of Otago, 1971

Joyce, Emma, 'The Pursuit of Sun, Sand, and Surf: Beach-going in New Zealand, 1910-1970', MA thesis, University of Auckland, 2006 
Madle, David Victor, 'Patterns of Death by Accident, Suicide and Homicide in New Zealand, 1860-1960: Interpretation and Comparisons', $\mathrm{PhD}$ thesis, Victoria University of Wellington, 1996

Maynard, Jessica, 'From the New Zealand Death to Beach Culture: The Pakeha Relationship with the Sea in Auckland and Wellington, 1840-1910', BA (hons) dissertation, Victoria University of Wellington, 2010

Moran, Kevin, 'The Shaping of Aquatics Education in New Zealand Schools: An Historical Study of Curriculum Policy and Practice', M.Ed thesis, Massey University, 1999

Parker, Alison Claire, 'An Urban Historical Perspective: Swimming a Recreational and Competitive Pursuit 1840 to 1914', PhD thesis, University of Sterling, 2003

Powell, Debra, "It was Hard to Die Frae Hame": Death, Grief and Mourning Among Scottish Migrants to New Zealand, 1840-1890', MA thesis, Waikato University, 2007

Ross, Kirstie, 'Signs of Landing: Pakeha Outdoor Recreation and the Cultural Colonisation of New Zealand', MA thesis, University of Auckland, 1999

Stothart, R. A., 'The Education of New Zealand Recreation Workers', MA thesis, Victoria University of Wellington, 1977

Voyković, Anthony A., 'Nga Roimata o Hine-nui-te-Po: Death in Maori Life', MA thesis, University of Otago, 1981

\section{Internet Sources}

Guy, Nathan, 'Speech to the Water Safety New Zealand Conference', beehive.govt.nz; $\quad$ http://www.beehive.govt.nz/speech/speech-water-safety-newzealand-conference [accessed 12 January 2011]

'Hampstead Memorial Baths, Ashburton', New Zealand History Online; www.nzhistory.net.nz/media/photo/hampstead-memorial-baths-ashburton, [accessed 19 September 2011] 
Khawaja, Mansoor, and Thomson, Nicholas, 'Population Aging in New ZealandArticle', Statistics New Zealand; http://www.stats.govt.nz/browse_for_stats/people_and_communities/older_people/p op-ageing-in-nz.aspx [accessed 12 September 2011]

'Manutahi Memorial Baths', Kete New Plymouth: War Memorials WWI and WWII in Taranaki; http://ketenewplymouth.peoplesnetworknz.info/war_memorials_wwi_and_wwii_in taranaki/topics/show/44-manutahi-memorial-baths [accessed 19 September 2011]

Statistics of New Zealand, 'The New Zealand Official Year Book, 1939'; http://www3.stats.govt.nz/New_Zealand_Official_Yearbooks/1939/NZOYB_1939.h tml\#idsect1_1_36979 [accessed 20 June 2011]

' The New Zealand Official Year Book, 1940';

http://www3.stats.govt.nz/New_Zealand_Official_Yearbooks/1940/NZOYB_\%2019 40.html [accessed 20 June 2011].

Szymanski, Stefan, 'A Theory of the Evolution of Modern Sport', International Association of Sports Economists, Working Paper, Paper no. 06-30, November, 2006; http://college.holycross.edu/RePEc/spe/Szymanski_Evolution.pdf [accessed 20 July 2011] 